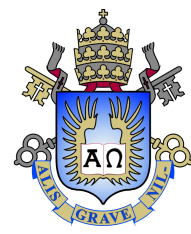

Lucas Mesz

\title{
Portfólio em Exploração de Petróleo sob Incertezas: Condições para a Guerra de Atrito e a Barganha Cooperativa
}

Dissertação de Mestrado

Dissertação apresentada como requisito parcial para obtenção do grau de Mestre pelo Programa de Pós-graduação em Administração de Empresas do Departamento de Administração da PUC-Rio.

Orientador : Prof. Luiz Eduardo Teixeira Brandão Co-orientador: Prof. Marco Antonio Guimarães Dias 


\title{
Portfólio em Exploração de Petróleo sob Incertezas: Condições para a Guerra de Atrito e a Barganha Cooperativa
}

Dissertação apresentada como requisito parcial para obtenção do grau de Mestre pelo Programa de Pós-graduação em Administração de Empresas do Departamento de Administração da PUC-Rio. Aprovada pela Comissão Examinadora abaixo:

\author{
Prof. Luiz Eduardo Teixeira Brandão \\ Orientador \\ Departamento de Administração - PUC-Rio
}

Prof. Marco Antonio Guimarães Dias

Co-orientador

Departamento de Engenharia Elétrica - PUC-Rio

Prof. Carlos de Lamare Bastian Pinto

Departamento de Administração - PUC-Rio

Prof. ${ }^{a}$ Glaudiane Lilian de Almeida Universidade Federal Fluminense - UFF 
Todos os direitos reservados. É proibida a reprodução total ou parcial do trabalho sem autorização da universidade, do autor e do orientador.

\section{Lucas Mesz}

Graduado em geologia pela Universidade de São Paulo (2008) e graduado em ciências econômicas pela Universidade Estadual do Rio de Janeiro (2016). Possui especialização em geofísica pela Petrobras, carreira que atua desde 2009. Trabalha em exploração de petróleo e gás nas bacias da costa brasileira.

Ficha Catalográfica

Mesz, Lucas

Portfólio em Exploração de Petróleo sob Incertezas: Condições para a Guerra de Atrito e a Barganha Cooperativa / Lucas Mesz; orientador: Luiz Eduardo Teixeira Brandão; coorientador: Marco Antonio Guimarães Dias. - Rio de Janeiro: PUC-Rio, Departamento de Administração , 2021.

v., 182 f: il. color. ; $30 \mathrm{~cm}$

Dissertação (mestrado) - Pontifícia Universidade Católica do Rio de Janeiro, Departamento de Administração .

Inclui bibliografia

1. Administração de Empresas - Teses. 2. Finanças Corporativas - Teses. 3. Opções Reais. 4. Opção de Espera. 5. Opção de Aprendizado. 6. Guerra de Atrito. 7. Barganha Cooperativa. 8. Portfólio Exploratório. I. Brandão, Luiz Eduardo. II. Dias, Marco Antonio Guimarães. III. Pontifícia Universidade Católica do Rio de Janeiro. Departamento de Administração. IV. Título. 
Aos meus pais, Ivete e Edmir Mesz, pelo amor, suporte e incentivo. 


\section{Agradecimentos}

Gostaria de agradecer à tríade: Fernando Antonio Lucena Aiube, Marco Antonio Guimarães Dias e Luiz Eduardo Teixeira Brandão. Tudo o que sei sobre a Teoria das Opções Reais é proveniente desses grandes condutores do ensino.

O presente trabalho foi realizado com apoio da Coordenação de Aperfeiçoamento de Pessoal de Nível Superior - Brasil (CAPES) - Código de Financiamento 001.

Agradeço à Petrobras e aos profissionais que incentivaram e permitiram esta pesquisa.

Em especial, agradeço à Camila dos Anjos Barros, pela atenção, o carinho e a compreensão presentes o tempo todo. 


\section{Resumo}

Mesz, Lucas; Brandão, Luiz Eduardo; Dias, Marco Antonio Guimarães. Portfólio em Exploração de Petróleo sob Incertezas: Condições para a Guerra de Atrito e a Barganha Cooperativa. Rio de Janeiro, 2021. 182p. Dissertação de Mestrado Departamento de Administração , Pontifícia Universidade Católica do Rio de Janeiro.

Esta pesquisa modela a estratégia exploratória sequencial de prospectos de óleo e gás em diferentes níveis de incerteza. Considera a consolidação da carteira pelo conceito de revelação da informação e as vantagens do uso da teoria do Valor da Informação para a sequência ótima de perfuração. Inclui a incerteza de preços com o Movimento Geométrico Browniano para o preço spot do barril de petróleo. Dado o tempo do contrato de concessão de exploração de petróleo, são analisados os valores das opções de investir nos ativos e no portfólio exploratório. Além dessas incertezas, o modelo considera o efeito competitivo de outra empresa em um jogo conhecido como Guerra de Atrito, examinado com uso de diversos estudos de caso. Esse jogo ocorre quando os ativos têm correlações e as empresas aguardam informação pública e gratuita de ocorrência de hidrocarboneto da perfuração do ativo pela operadora vizinha.

Os resultados apontam que é melhor para a empresa analisar suas oportunidades exploratórias com a teoria das opções reais, sendo melhor a análise por portfólio exploratório, que combina o valor da espera com o valor da informação. Os efeitos da interação estratégica são relevantes, essencialmente quando os portfólios das duas empresas têm os gatilhos exploratórios similares. Em jogos assimétricos, o que define a degeneração para ação de perfurar de uma das operadoras é a relação entre os gatilhos exploratórios e os gatilhos de perfuração simultânea, efeito que também pode ser analisado na comparação do benefício da espera por informações das empresas em conflito. Caso haja perpetuação na guerra de atrito, é proposto uma mudança para o jogo de barganha cooperativa. Nessa mudança, deve haver troca de informações entre as empresas em negociação, sendo a informação privada de melhor qualidade que a informação pública, elevando a medida de aprendizado dos ativos da carteira. No caso de pequena melhora na medida de aprendizado, a mudança para a barganha cooperativa já se torna vantajosa para ambos os jogadores.

\section{Palavras-chave}

Opções Reais; Opção de Espera; Opção de Aprendizado; Guerra de Atrito; Barganha Cooperativa; Portfólio Exploratório. 


\section{Abstract}

Mesz, Lucas; Brandão, Luiz Eduardo (Advisor); Dias, Marco Antonio Guimarães (Co-Advisor). Portfolio in oil exploration under uncertainty: conditions for war of attrition and cooperative bargaining. Rio de Janeiro, 2021. 182p. Dissertação de mestrado Departamento de Administração, Pontifícia Universidade Católica do Rio de Janeiro.

This research models the sequential exploratory strategy of oil and gas prospects at different levels of uncertainty. To do so, it considers portfolio consolidation by the concept of information disclosure and the advantages of using Information Value theory for the optimal drilling sequence. The price uncertainty of the spot price of a barrel of oil is modeled as a Geometric Brownian Motion. Given the length of the oil exploration concession contract, the option values of investing in the assets and exploration portfolio are analyzed. In addition to these uncertainties, the model considers the competitive effect of another company in a game known as the War of Attrition, examined using several case studies. This game occurs when assets are correlated, and companies wait as free-riders for information of hydrocarbon occurrence from the drilling of the asset by the neighboring operator.

The results point out that the firm should analyze its exploratory opportunities under the real options approach, and improves with exploratory portfolio analysis, which combines the value of waiting with the value of information. The impact of strategic interactions is relevant, especially when the two firms' portfolios have similar exploratory triggers. In asymmetric games, the ratio between the exploratory triggers and the simultaneous drilling triggers defines the degeneration to drilling action of one of the operators. This effect can also be analyzed when comparing the benefit of waiting for information from the conflicting companies. If there is perpetuation in the war of attrition, agents can change to a cooperative bargaining game. In this case, there should be an information exchange between the trading firms, with private information being more relevant than public information. In the case of a marginal improvement in the learning measure, the change to cooperative bargaining already becomes advantageous for both players.

\section{Keywords}

Real Options; Defer Option; Learning Option; War of Attrition; Cooperative Bargain; Exploration Portfolio. 


\section{Sumário}

1 Introdução $\quad 15$

$\begin{array}{lll}1.1 & \text { Contextualização } & 15\end{array}$

$\begin{array}{lll}1.2 & \text { Problema de Pesquisa } & 17\end{array}$

1.3 Objetivos 19

$\begin{array}{lll}1.3 .1 \text { Geral } & 19\end{array}$

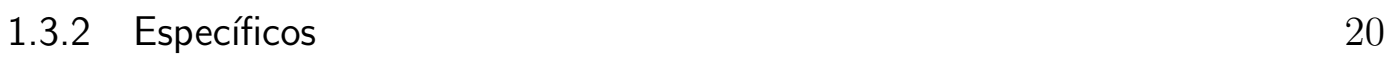

$\begin{array}{lll}1.4 & \text { Justificativa } & 22\end{array}$

1.5 Contribuições 23

1.5.1 Gerencial 23

1.5.2 Teórica 24

2 Referencial Teórico $\quad 25$

2.1 Opções Reais 25

2.1.1 Incerteza de Preços $\quad 27$

2.1.2 Opções Reais: Recursos Minerais e Indústria de Óleo e Gás 31

2.2 Portfólio de Opções Reais 33

2.2.1 Valor da Informação - Incerteza Técnica 36

2.3 Teoria dos Jogos: Guerra de Atrito e Barganha Cooperativa 40

2.4 Teoria dos Jogos com Opções 42

3 Modelagem Matemática $\quad 45$

3.1 Apresentação das variáveis $\quad 45$

3.2 Modelo Paramétrico - VPL e VME 46

3.3 Incerteza de Preços 48

3.4 Incerteza técnica - Fator de Chance $\quad 55$

3.4.1 Dependência - Função Bernoulli Bivariada 60

3.5 Incerteza estratégica $\quad 66$

$\begin{array}{lll}3.6 & \text { Portfólio } & 81\end{array}$

3.7 Modelos $\quad 86$

3.7.1 Um, Dois e Três prospectos: Um bloco $\quad 86$

3.7.2 Dois prospectos: Um em cada bloco 88

3.7.3 Três prospectos: Carteira com 2 e um prospecto vizinho 89

$4 \quad$ Estudo de Caso e Resultados $\quad 92$

4.1 Dados de Entrada $\quad 92$

4.1.1 Hiperparâmetros do Preço do Petróleo: MGB 92

4.1.2 Investimento em Desenvolvimento - Volume Recuperável 100

$\begin{array}{ll}\text { 4.1.3 Taxa livre de risco } & 101\end{array}$

$\begin{array}{lll}\text { 4.1.4 Parâmetros Exógenos } & 102\end{array}$

4.1.5 Parâmetros Endógenos 103

4.2 Modelos 104

4.2.1 Um, Dois e Três prospectos: Um bloco 105

4.2.2 Dois prospectos: Um em cada bloco 121

4.2.2.1 Jogo Simétrico: do Atrito à Barganha 121 
4.2.2.2 Jogo Assimétrico: do Atrito à Barganha?

4.2.3 Jogo com três prospectos: Carteira com 2 e um prospecto vizinho

5 Conclusão

161

$\begin{array}{lll}\text { A Portfólio Sem Risco } & 177\end{array}$

$\begin{array}{ll}\text { B Diferenças Finitas } & 179\end{array}$

C Dados e Programas 182 


\section{Lista de figuras}

Figura 3.1 Revelação no sexto investimento - FC e Probabilidades 66

Figura 3.2 Jogo Dinâmico: Guerra de Atrito 67

Figura 3.3 Modelo Básico - Guerra de Atrito - Prob. de Continuar 71

Figura 3.4 Modelo Básico - Guerra de Atrito - Prob. de Fracassar 72

Figura 3.5 Modelo Básico - Guerra de Atrito - Custo Esperado 73

Figura 3.6 Jogo Evolucionário - Guerra de Atrito - Modelo Básico 75

Figura 3.7 J. Evol. - Plano de Fase - Simétrico -Modelo Básico 76

Figura 3.8 J. Evol. - P.de Fase Denso - Simétrico -Modelo Básico 76

Figura 3.9 FC e VME condicionais $\quad 82$

Figura 4.1 Preço Spot- WTI- EIA 93

Figura 4.2 Preços Futuros - WTI 94

Figura 4.3 Estrutura a Termo da Volatilidade $\quad 95$

Figura 4.4 Taxa livre de Risco - Treasury 3 meses 96

Figura 4.5 Retorno de Conveniência Implícito - $\delta \quad 96$

Figura 4.6 Estrutura a termo do Retorno de Conveniência - Média 97

Figura 4.7 Estrutura a termo do Retorno de Conveniência - $\bar{\delta} \quad 98$

Figura 4.8 Filtro de Kalman - Estimado, Suavizado e Observado 99

Figura 4.9 Investimento em Desenvolvimento - Volume Recuperável 101

Figura 4.10 Título público Americano - 20 anos 102

Figura 4.11 Modelo Geral - Blocos Exploratórios 105

Figura 4.12 Opções em Petróleo - Conceitos em Dias (2015b, Cap .27) 106

Figura 4.13 Curvas de Gatilho - DogFish 108

Figura 4.14 Opção de Explorar - DogFish 109

Figura 4.15 Métricas de Avaliação Exploratória - DogFish - $\tau=3$ anos 109

Figura 4.16 Bloco A- DogFish e Feather 112

Figura 4.17 Valor da Informação $-\pi_{D+F}(P)$ e $\pi_{F+D}(P) \quad 113$

Figura 4.18 Gatilho do Portfólio - DogFish e Feather 114

Figura 4.19 Único Bloco - DogFish e Head 115

Figura 4.20 Gatilho do Portfólio - Head-DogFish 116

Figura 4.21 Único Bloco - DogFish e Head com Volume Maior 116

Figura 4.22 Gatilho -П - DogFish e Head com expansão de 37\% de B 117

Figura 4.23 Modelo - Único Bloco 118

Figura 4.24 Gatilho do Portfólio - DogFish, Feather e Head 119

Figura 4.25 Modelo - DogFish x DogFish 121

Figura 4.26 Jogo Evolucionário de população infinita - \$50/bbl 125

Figura 4.27 Jogo Evol. - P. de Fase - Simétrico -\$ 50/bbl 125

Figura 4.28 Jogo Evolucionário de população infinita - \$72/bbl 126

Figura 4.29 Jogo Evol. - P. de Fase - Simétrico -\$ 72/bbl 127

Figura 4.30 Jogo Evolucionário de população infinita - \$ 80/bbl 127

Figura 4.31 Jogo Evol. - P. de Fase - Simétrico -\$ 80/bbl 128

Figura 4.32 Guerra de Atrito: DogFish x DogFish - $\rho=60 \% \quad 129$

Figura 4.33 Detalhe - G. de Atrito: DogFish x DogFish - $\rho=60 \% \quad 129$

Figura 4.34 Simulação de Monte Carlo e Gatilho 130

Figura 4.35 Histograma - Início da Guerra de Atrito 131 
Figura 4.36 Equilíbrios Mapeados - Jogo Simétrico 132

Figura 4.37 Barganha Cooperativa: DogFish x DogFish - $\rho=60 \% 134$

Figura 4.38 Detalhe - Barganha: DogFish x DogFish - $\rho=60 \% \quad 135$

Figura 4.39 Detalhe - Barganha: DogFish x DogFish - $\rho=80 \% \quad 136$

Figura 4.40 Modelo - 2 Blocos - DogFish e Head 137

Figura 4.41 Jogo Assimétrico: Preço x Valor - DogFish e Head 139

Figura 4.42 Jogo Assimétrico: Benefício da Espera 140

Figura 4.43 Equilíbrios Mapeados - Jogo Assimétrico 142

Figura 4.44 Modelo - 2 Blocos - DogFish e Head Expandido 143

Figura 4.45 Equil. Mapeados - J. Assimétrico - $B_{\text {Head }} 15 \%$ maior 144

Figura 4.46 Equil. Mapeados - J. Assimétrico - $B_{\text {Head }} 37 \%$ maior 145

Figura 4.47 Preço x Valor - DogFish e Head - $B_{\text {Head }} 37 \%$ maior 145

Figura 4.48 Benefício da Espera -D. e H. - $B_{\text {Head }} 37 \%$ maior $\quad 146$

Figura 4.49 J. Evol. - P. de Fase - Assimétrico -\$70/bbl 147

Figura 4.50 Peso na Barganha: DogFish x Head - 37\% maior 148

Figura 4.51 Barganha Cooperativa: DogFish x Head - 37\% maior 149

Figura 4.52 Detalhe - Barganha: DogFish x Head - 37\% maior 149

Figura 4.53 Modelo - 2 Blocos - A - DogFish e Feather - B Head 151

Figura 4.54 Jogo Portfólio: Preço x Valor - $(D+F)$ e Head 153

Figura 4.55 Benefício da Espera: $\Pi(D+F)$ e Head 154

Figura 4.56 Equilíbrios Mapeados - Jogo $\Pi(D+F)$ e Head 156

Figura 4.57 J. Evol. - P. de Fase - Portfólio -\$ 75/bbl 156

Figura 4.58 J. Evol. - P. de Fase Denso - Portfólio -\$75/bbl 157

Figura 4.59 Peso na Barganha: DogFish -Feather- Head 158

Figura 4.60 Barganha Coop.: $\Pi(D+F)$, Head e $\Pi(D+F+H) \quad 158$

Figura 4.61 Detalhe - B. Coop.: $\Pi(D+F)$, Head e $\Pi(D+F+H) 159$

Figura 4.62 Detalhe - B. Coop.: maior $\rho-\Pi(D+F)$, Head e $\Pi(D+F+H)$ 


\section{Lista de tabelas}

Tabela 3.1 FC e Aprendizado: Distribuição Bivariada de Bernoulli 61

Tabela 3.2 FC e Aprendizado: Exemplo de 6 poços sequenciais 64

Tabela 3.3 Subjogo 2 - Guerra de Atrito 68

Tabela 3.4 Subjogo 2 - Guerra de Atrito - Custo afundado 68

Tabela 3.5 Jogo Completo - Guerra de Atrito - $\left\{E_{2}, R_{2}\right\} \quad 69$

Tabela 3.6 Jogo Completo - Guerra de Atrito - $\left\{R_{2}, E_{2}\right\} \quad 69$

Tabela 3.7 Jogo Completo - Guerra de Atrito - Estratégia mista 70

Tabela 3.8 Forma normal: Guerra de Atrito por Informações $\quad 77$

Tabela 3.9 Forma normal: Payoffs- 2 prospectos 88

Tabela 3.10 Forma normal: Payoffs no caso de Portfólio 90

Tabela 4.1 Parâmetros estimados - Filtro de Kalman 99

Tabela 4.2 Parâmetros Exógenos Estimados - (\%) a.a. 102

Tabela 4.3 Parâmetros Endógenos dos Prospectos 103

Tabela 4.4 Correlação dos prospectos da bacia 103

Tabela 4.5 Avaliação de DogFish $-\tau=3$ anos $-P=\$ 50 \quad 107$

Tabela 4.6 Aval. das oport. stand-alone $-\tau=3$ anos- $P=\$ 50 \quad 110$

Tabela 4.7 Aval. dos Portfólios $-\tau=3$ anos $-\mathrm{P}=\$ 50 \quad 120$

Tabela 4.8 Forma normal: Guerra de Atrito 122

$\begin{array}{lll}\text { Tabela } 4.9 \text { Forma normal: Payoffs } & 123\end{array}$

Tabela 4.10 Forma normal: Jogo Simétrico- $P=\$ 50, \rho=60 \%, \tau=3123$

Tabela 4.11 Forma normal: Jogo Simétrico - $P=\$ 72, \rho=60 \%, \tau=3124$

Tabela 4.12 Forma normal: Jogo Simétrico - $P=\$ 80, \rho=60 \%, \tau=3124$

Tabela 4.13 Intervalo da G. de Atrito - Efeito do $\rho$ no $P^{s} \quad 130$

Tabela 4.14 Simbologia do conflito em Quadrantes 132

Tabela $4.15 w_{i} \Pi_{i, j}$ - Divisão da Barganha Cooperativa - M\$ 136

Tabela 4.16 Forma normal: Jogo Assimétrico - $P=\$ 50, \tau=3 \quad 138$

Tabela 4.17 Forma normal: Jogo Assimétrico - $P=\$ 72, \tau=3 \quad 138$

Tabela 4.18 Forma normal: Jogo Assimétrico - $P=\$ 73, \tau=3 \quad 140$

Tabela 4.19 Forma normal: Jogo Assimétrico - $P=\$ 80, \tau=3 \quad 141$

Tabela 4.20 Forma normal: Jogo Assimétrico - $P=\$ 85, \tau=3 \quad 141$

Tabela 4.21 F. normal: J. Assim. - $P=\$ 70, \tau=3$ e $B_{\text {Head }}=37 \%$ maior 146

Tabela 4.22 Forma normal: Payoffs no caso de Portfólio 152

Tabela 4.23 Forma normal: $\Pi(D+F)$ e Head $-P=\$ 50, \tau=3 \quad 154$

Tabela 4.24 Forma normal: $\Pi(D+F)$ e Head $-P=\$ 75, \tau=3 \quad 155$

Tabela 4.25 Forma normal: $\Pi(D+F)$ e Head $-P=\$ 80, \tau=3 \quad 155$

Tabela 4.26 Forma normal: $\Pi(D+F)$ e Head $-P=\$ 85, \tau=3 \quad 155$

Tabela 4.27 Correlação dos prospectos - Informação Privada 159 


\title{
Lista de Abreviaturas
}

\author{
ADF - Augmented Dickey-Fuller test \\ ANP - Agência Nacional do Petróleo \\ EEE - Estratégia Evolucionariamente Estável \\ ENPS - Equilíbrio de Nash Perfeito em Subjogos \\ EPM - Equilíbrio Perfeito Markoviano \\ FC - Fator de Chance/Fator de Sucesso Geológico \\ FPSO - Floating production storage and offloading \\ MGB - Movimento Geométrico Browniano \\ OR - Opções Reais \\ PAD - Plano de Avaliação de Descoberta \\ P\&D - Pesquisa e Desenvolvimento \\ TOR - Teoria das Opções Reais \\ TJ - Teoria dos Jogos \\ TJ+OR - Teoria dos Jogos com Opções \\ VOI - Valor da Informação \\ VME - Valor Monetário Esperado \\ VPL - Valor Presente Líquido
}


[professor de Ottilie] "Contudo, existem frutos fechados em si mesmos, que são de fato os verdadeiros, aqueles que são essenciais e que, cedo ou tarde, produzirão uma bela existência."

Goethe, J. W. v., As afinidades eletivas. Editora Penguin, 2014, tradução de Tercio Redondo. p. 46 . 


\section{Introdução}

\section{1}

\section{Contextualização}

O portfólio exploratório de uma empresa de petróleo é composto por blocos arrematados em leilões organizados pela Agência Nacional do Petróleo (ANP) ou por blocos adquiridos de outras empresas de petróleo. Esses blocos possuem prospectos, que podem se tornar campos de petróleo e que nesta fase inicial possuem diversas incertezas. A principal, estudada pelos geólogos, geofísicos e engenheiros, é a incerteza técnica das oportunidades mapeadas. Em um momento exploratório, as informações sobre as características dos possíveis campos são indiretas e incompletas, feitas por investimentos para obter conhecimento da área e das oportunidades, normalmente por métodos geofísicos regionais, como a gravimetria, a magnetometria e a sísmica de reflexão. Quando há um avanço no conhecimento e uma confiança no potencial exploratório, aumenta-se o valor do investimento e parte-se para os métodos diretos, como a perfuração de poços exploratórios. Assim, somente após a perfuração de um poço exploratório, é possível saber a existência de hidrocarboneto e somente com outros investimentos em informação pode-se conhecer o volume recuperável de hidrocarboneto, suas qualidades físicas e econômicas. Outra incerteza considerada na análise econômica do bloco exploratório é o preço do petróleo. Essa variável é incerta no futuro e determinante na economicidade do projeto. Ademais, é possível considerar a incerteza estratégica, que é em função da ação das empresas concorrentes ao seu portfólio. A depender da similaridade dos projetos exploratórios com os prospectos da empresa vizinha, a perfuração do poço exploratório pode revelar informação para seu portfólio e para os ativos vizinhos, alterando o momento ótimo de investimento no bloco exploratório.

Dessa forma, a revelação da informação pode conduzir os caminhos dos investimentos futuros de um negócio. A informação possui, além do seu custo, o valor do conhecimento para as ações futuras. Essa pode ser obtida por investimentos próprios, ou a depender da legislação e regulamentação do setor, por empresas concorrentes. A segunda situação coloca um dos agentes 
em posição de vantagem, pois este não paga pelo conhecimento. Contudo, a depender do portfólio, a empresa pode observar vantagens em obter os dados o quanto antes e pagar por esse conteúdo, mesmo que a empresa concorrente o tenha sem custo.

Na fase exploratória de um campo de petróleo, devido às características próprias do negócio e à legislação dos órgãos reguladores, esses efeitos devem ser levados em conta no momento da decisão de investimento. A ANP exige, pelo instrumento contratual assinado pela concessionária, a transmissão de todas as informações adquiridas nos investimentos no bloco exploratório. Isso inclui todo os dados obtidos na perfuração dos poços pioneiros, os quais têm o objetivo principal de detectar a ocorrência de hidrocarboneto nas possíveis reservas. Desse modo, o conteúdo se torna de conhecimento público, em especial a existência ou não de petróleo ou gás no poço, transmitido pela ANP ou até mesmo por informe de mercado pela empresa proprietária. Caso a empresa concorrente tenha concessões na vizinhança do bloco explorado, os valores dos seus possíveis ativos se alteram, dado o maior conhecimento geológico. Por consequência, essa informação pode redefinir os momentos de investimentos exploratórios e de desenvolvimento pretendidos, visto que uma empresa pode esperar a outra a perfurar primeiro, jogo conhecido como guerra de atrito. Esse cenário desenha uma disputa por informação, buscando um ótimo entre a receita esperada postergada dos ativos e a informação revelada por investimentos próprios ou de outrem. Decerto, além da incerteza técnica do próprio portfólio e das decisões de outras operadoras, as receitas futuras do portfólio consideram a incerteza do preço de venda do petróleo, sendo esta incerteza a mais corrente nas análises de investimentos.

Por meio de estudos de caso, o objetivo da pesquisa é o apreçamento do portfólio exploratório dadas as incertezas descritas: o preço do petróleo, a incerteza técnica pela revelação da informação e a guerra de atrito com uma empresa concorrente, com a possibilidade de negociação entre as operadoras, alterando o jogo para a barganha cooperativa. Assim, o caso principal considera dois blocos exploratórios com contratos de três anos, operados por empresas distintas e sem obrigação de poço pioneiro, sendo dois prospectos num bloco e uma oportunidade exploratória no bloco vizinho. O arcabouço teórico para este estudo envolve as teorias das opções reais (TOR), o valor da informação (VOI), a teoria dos jogos (TJ), a teoria dos jogos com opções (TJ+OR) e a teoria de análise de portfólio. A exploração de petróleo, por ser o elo inicial da cadeia desse suprimento, carrega consigo todas estas incertezas nos seus projetos. Em virtude disso, o dimensionamento das incertezas no valor dos ativos propicia ao detentor a melhor ação do programa de investimento. 
A principal contribuição da pesquisa é apresentar a diferença de apreçamento do portfólio entre as métricas tradicionais, como o Valor Presente Líquido (VPL) e o Valor Monetário Esperado (VME), e as que consideram incertezas, sejam de preços, técnica-geológica e de outros agentes, agregando a TOR, o VOI, a TJ e a TJ+OR.

O primeiro capítulo trata da introdução ao tema do presente estudo. No capítulo (2), o referencial teórico é apresentado, seguido pela modelagem matemática (capítulo 3). A penúltima parte (capítulo 4) apresenta as análises e os resultados e por fim, a conclusão (capítulo 5).

\section{2}

\section{Problema de Pesquisa}

O sucesso na perfuração exploratória de um prospecto de petróleo pode ter correlação com a informação advinda da perfuração de uma outra oportunidade exploratória. Desprezar a sequência informacional é considerar que as oportunidades do portfólio exploratório são independentes, incompatível com o conhecimento geológico. O vínculo entre os prospectos minerais é devido à mesma gênese, ou seja, a mesma origem na formação das rochas, sejam os reservatórios de hidrocarboneto, ou qualquer elemento do sistema petrolífero. Por vezes, a oportunidade exploratória de valor informacional se encontra na área vizinha proprietária de outra empresa. Assim, o valor da carteira deve alterar em função da ação de perfuração dos prospectos pela concorrente. Ademais, a depender da expectativa de longo prazo do preço do barril de petróleo, a volatilidade e o período do contrato de concessão com a ANP podem alterar o momento do investimento exploratório nos ativos da carteira.

As empresas trabalham com as métricas tradicionais em finanças corporativas, como o VPL, o VME, que é uma derivação do VPL e a taxa interna de retorno. Essas métricas não inserem as incertezas de mercado inerentes ao projeto e trabalham com cenários ou valores médios das variáveis estocásticas. A TOR considera as incertezas de preços futuros, recolocando o ótimo do agente em momentos distintos de investimentos e por consequência, a valores tão maiores quanto o VPL. Já a TJ capta como o ótimo individual é influenciado por outros agentes. Em um ambiente competitivo, como em situações de conquista de fatia de mercado e acesso à informação para investimento, os agentes podem disputar e sair do seu ótimo individual, desenhando um jogo conhecido como guerra de atrito. Na fase exploratória de petróleo, a guerra de atrito ocorre na busca de informação a menor custo, para filtrar os cenários mais improváveis e readequar o investimento planejado para o desenvolvimento da produção. Se não houver cooperação entre as empresas nessa fase, um dos 
agentes pode obter informações sem custo, conhecido como free-rider, caso a relação entre o custo e o benefício da espera for maior que o seu benefício individual de obter a informação. A depender da carteira das companhias, pode acontecer de nenhum dos agentes investir, aguardando a informação gratuita da concorrente. Como medida para evitar esse impasse, é proposto uma mudança de jogo pelos próprios agentes, migrando da guerra de atrito para a barganha cooperativa. Para que essa mudança seja viável, a negociação entre as empresas precisa ser num ambiente mais informativo que o informe público e obrigatório de ocorrência ou não de hidrocarboneto à ANP. Em todos os jogos estudados, para dimensionar o conhecimento pela informação interna do portfólio ou de investimento por outro agente, são aplicados a teoria do VOI em conjunto com análise de portfólio em opções reais.

O portfólio exploratório tem características singulares. Como há dependência genética entre os ativos, há uma cadeia ótima a priori de investimentos sequenciais, a depender da ponderação técnica do fator de sucesso geológico (FC), a correlação entre as oportunidades, as dimensões e os parâmetros estimados das reservas. Ter um portfólio com oportunidades que possuem evolução geológica distintas é relevante na gestão da carteira da empresa e possui análise similar à diversificação de portfólio de Markowitz (1959). Contudo, um portfólio com oportunidades no mesmo play geológico é estratégico, visto que a dependência leva, no caso de insucesso nos poços pioneiros, prontamente ao abandono de uma sequência de oportunidades não testadas. Por outro lado, o sucesso no poço exploratório gera uma abertura de fronteira para novos projetos, similar aos investimentos sequenciais em Pesquisa e Desenvolvimento (P\&D) (SMIT; TRIGEORGIS, 2006), que novos projetos afetam outros na carteira. Esta pesquisa vai se debruçar nessas últimas características do portfólio, as quais o valor da carteira é modulado e amplificado dada a correlação entre os ativos.

Nesta dissertação será calculado o valor da carteira exploratória com todos os vetores de incerteza discutidos. Primeiramente, será introduzido o cálculo de um ativo exploratório (análise stand-alone - VME) e o impacto da análise de dependência nas oportunidades de uma carteira (portfólio -incerteza técnica - VOI). Após, será apresentado o valor da opção de espera para cada ativo exploratório (incerteza de mercado - TOR) e a combinação da análise de portfólio com a espera da opção de explorar (portfólio exploratório - OR com VOI). Por fim, inclui a disputa por informação com outro operador que possui um bloco vizinho e a mudança para a barganha cooperativa (incerteza técnica, mercado e estratégica - VOI, TOR, TJ+OR).

Com o uso do modelo mais complexo que inclui a incerteza técnica, de 
preços e estratégica, se deriva a seguinte questão de pesquisa:

Quais são as condições para a guerra de atrito e a migração para a barganha cooperativa quando uma empresa de petróleo possui um portfólio exploratório?

\section{3 \\ Objetivos}

\subsection{1}

\section{Geral}

De um modelo mais simplificado para um modelo que considera mais planos de incerteza, os valores consolidados da carteira terão diferenças devido aos métodos e às teorias envolvidas, podendo conduzir para decisões distintas de investimento. Porém, o que é relevante na variedade de apreçamentos é saber as limitações e os momentos para considerar cada abordagem.

O modelo simples considera um valor constante de preços, sendo uma média de preços de longo prazo. Os outros modelos consideram os preços com incerteza, nos quais o processo estocástico é o Movimento Geométrico Browniano (MGB), sendo a difusão mais popular em finanças quantitativas. O modelo de incerteza técnica, que considera a revelação da informação e a opção de aprendizado, adapta os conceitos apresentados em Dias (2005b). Esse modelo de incerteza técnica é usado tanto para avaliar um portfólio como para inserir a incerteza estratégica, em que se segue o que foi apresentado em Dias e Teixeira (2009), com os conceitos da guerra de atrito de Hendricks, Weiss e Wilson (1988) e Smith (1974).

Este trabalho tem a proposta de expandir os estudos de Dias e Teixeira (2009), inserindo mais ativos no bloco exploratório em situação de guerra de atrito e barganha cooperativa. Dias e Calvette (2017) também é fonte para esta pesquisa, pois aqui igualmente se analisa um portfólio exploratório com VOI e opções reais (OR), porém usando o método de diferenças finitas para a solução numérica, em vez do método binomial. Para a solução das equações diferenciais por diferenças finitas explícitas teve como referência as formulações expostas em Haug (2007, Cap. 7) e Dias (2015b, Cap.26).

Com a combinação dessas teorias e modelos, é possível investigar quais são as condições para a ocorrência da guerra de atrito e a sua perpetuação até o final do contrato exploratório. Dessa forma, o objetivo é entender quais fatores possibilitam essa disputa de informações, sendo esses os parâmetros internos ao portfólio da empresa e da concorrente, considerando a similaridade entre todos os ativos, além dos efeitos externos dos parâmetros de mercado. 
Assim, o estudo ocorre no início do contrato exploratório, com o mapeamento das estratégias em equilíbrio neste momento e os intervalos de preço do barril do petróleo em que a guerra de atrito pode perdurar. Como se propõe uma mudança para a barganha cooperativa em caso de continuação da guerra de atrito, também se investiga quais são os parâmetros que afetam a troca dos jogos, possibilitando as empresas irem à mesa de negociação.

\subsection{2}

\section{Específicos}

Esta pesquisa envolve algumas teorias, que por vezes são combinadas nas bibliografias estudadas. São comuns os trabalhos com incerteza de preços como variável estocástica. Em especial, o preço do petróleo, que é facilmente agrupado em trabalhos de OR em commodities. Por outro lado, são incomuns os trabalhos em OR aplicados ao ambiente exploratório, contudo, os existentes têm sólida referência nesse campo.

De um modo geral, a frequência de trabalhos com incerteza técnica no desenvolvimento e produção são maiores, não sendo tão comuns sobre a exploração de petróleo. As pesquisas que envolvem a incerteza técnica se definem dentro da teoria do VOI, da revelação da informação e da medida de aprendizado, sendo nesta pesquisa a probabilidade da ocorrência de hidrocarboneto a variável incerta, conhecida como fator de chance (FC). Os trabalhos que consideram os efeitos dos investimentos sequenciais no portfólio são apresentados dentro do campo de pesquisa de portfólio em opções reais. No caso aqui estudado, como se adota o conceito de dependência geológica entre os ativos, o valor do portfólio pode-se distinguir comparado com a simples soma desses ativos exploratórios de forma independente.

A pesquisa que envolve a incerteza estratégia tem um embasamento sólido, com muitas referências em ciências econômicas. A TJ é a base para esta pesquisa, mas em especial os estudos de TJ+OR são as fontes finais para a dissertação. No caso estudado, o agente gera uma externalidade positiva ao outro, revelando a informação sobre a existência de petróleo ao perfurar e esta ação interfere no momento ótimo de perfuração da outra empresa.

$\mathrm{Na}$ apresentação do modelo, o caso é descrito com maior detalhe, assim como as métricas de VPL e VME. O modelo de incerteza de preço é formalizado e suas propriedades estatísticas são exploradas. Sobre a incerteza técnica, são explicados os conceitos de FC geológico e a medida de aprendizado pela dependência entre os ativos exploratórios. Como a perfuração pelo outro agente gera uma informação e condiciona os FCs dos prospectos no bloco vizinho, a incerteza estratégica é apresentada com o conceito de dependência e com 
os modelos clássicos de TJ. Por fim, são apresentadas as combinações desses efeitos num portfólio, incluindo as referentes equações diferenciais e as soluções matemáticas que dão base para esta pesquisa.

Em resultados, antes dos jogos e da análise do portfólio exploratório, os parâmetros de entrada de mercado são estimados. Adotando o MGB para o preço spot do barril de petróleo, os hiperparâmetros de volatilidade e tendência são estimados pela aproximação do primeiro contrato sendo o preço spot e pelos contratos futuros, com o uso do filtro de Kalman. A taxa de conveniência também é estimada por dois métodos: pela discretização do modelo de reversão à média de Ornstein-Uhlenbeck e pela média da taxa de conveniência implícita. Para a taxa livre de risco de longo prazo, considera-se a média de uma janela temporal da série histórica do título público americano de 20 anos. Já para os parâmetros dos casos, denominados de parâmetros endógenos, são propostos em conjunto com a estimativa e a parametrização do Investimento em Desenvolvimento $\left(I_{d}\right)$, sendo este dispêndio dependente do Volume Recuperável esperado $(B)$ da reserva a ser produzida.

Em seguida, analisa-se os modelos de valoração econômica dos prospectos e dos blocos exploratórios, considerando as oportunidades individuais (stantalone) e com as expectativas condicionais nos fatores de chance pelo aprendizado sequencial dos prospectos a serem explorados, com e sem inclusão do valor da espera pela TOR. Além desses apreçamentos, também se compara com a valoração agregada da opção de espera dos ativos, sem considerar a dependência entre os prospectos devido ao aprendizado.

Por fim, são apresentados os diversos jogos em situação de guerra de atrito: no caso de ativos iguais nos dois blocos exploratórios, na situação de prospectos distintos entre si, quando são distintos e com o mesmo momento ótimo de perfuração e na hipótese de dois portfólios em dois blocos. Nesses jogos são analisados os equilíbrios em diversos preços do barril de petróleo no início do contrato exploratório. Com isso, se delimita os intervalos de preços do barril de petróleo em que há a possibilidade do impasse pela informação gratuita, dadas as condições dos próprios ativos exploratórios, assim como os parâmetros externos que afetam a economicidade dos projetos. Em todos os casos é considerada a possibilidade de uma mudança da situação de guerra de atrito para um jogo de barganha cooperativa. Para isso, aceita-se a hipótese da diferença entre a informação pública e a privada, refletindo em uma melhora marginal na medida de aprendizado quando as empresas estão em negociação, afetando positivamente a unitização dos ativos. Aplica-se, na divisão do prêmio da negociação, a solução de maximização do produto de Nash em barganha cooperativa. 


\section{4 \\ Justificativa}

Os modelos teóricos mais simples têm a função de orientar os primeiros caminhos da pesquisa. É o caso da valoração de ativos pelo método do VPL ou VME, este último aplicado em ativo exploratório de recursos minerais. Sobretudo o VPL, a métrica é vastamente ensinada na academia e aceita na indústria como a principal fórmula para a decisão de investimento.

Com a compreensão de como as variáveis afetam o valor do ativo, constroem-se modelos mais complexos e que se aproximam mais da realidade. É o caso da adoção da TOR em valoração de ativos, a qual insere uma incerteza indexada ao tempo no fluxo de caixa, como a incerteza de receita, de investimento ou de quantidade. Essa teoria possibilita ao investidor, além da valoração mais próxima ao valor real do ativo, uma função de momento ótimo para o investimento, algo que o modelo de VPL não fornece ${ }^{1}$.

Contudo, não são todas as incertezas que são indexadas ao tempo. No presente estudo, a revelação da informação geológica é em função da perfuração dos poços exploratórios, ou seja, a indexação deste tipo de processo estocástico é em função do evento investimento, algo endógeno a cada empresa (DIAS, 2002). Para isso, a teoria do valor da informação (VOI) é o suporte para os conceitos de investir para aprender ${ }^{2}$.

Caso aceite todos os modelos supracitados, o investidor adota uma percepção monopolista de mercado. Comumente, quando uma empresa entra num novo mercado, acaba atraindo as outras empresas que oferecem o mesmo produto e afetam negativamente as receitas esperadas (GRENADIER, 2000). Assim, há um efeito de preempção e essa incerteza estratégica deve ser considerada. Por vezes, a externalidade gerada é positiva e um agente freerider pode se estabelecer, como é o caso estudado nesta dissertação. À vista disso, a TJ é a base de estudos para este modelo ${ }^{3}$, assim como a TJ+OR ${ }^{4}$.

Modelos complexos tendem a ser adotados mais rapidamente nas pesquisas acadêmicas quando comparados às aplicações pela indústria. Contudo, quando se trata de decisões de investimento e planejamento estratégico, que envolvem grande quantidade monetária em cada ação, não se encontram grandes barreiras na transmissão desses conhecimentos na prática do mercado. A

${ }^{1}$ Como referência em OR, consultar Dixit e Pindyck (1994) e Trigeorgis (1996). Em português, com mesma profundidade dos anteriores, Dias (2015a,b). Como guia prático, Copeland e Antikarov (2001).

${ }^{2}$ Como referência, consultar Lawrence (1999).

${ }^{3}$ Gibbons (1992) é um livro de fácil compreensão em TJ e Myerson (2009) apresenta um bom resumo sobre a teoria.

${ }^{4}$ Smit e Trigeorgis (2006) e Chevalier-Roignant et al. (2011) são bons resumos sobre a teoria de option-games. 
presente pesquisa, pelo conteúdo teórico, pretende aproximar a medida de valor ao valor real dos ativos. Assim, utiliza a intersecção dessas teorias em exemplos comuns à exploração de petróleo: dois blocos exploratórios operados por empresas distintas, com os prazos definidos para exercer a opção exploratória de perfuração, sendo os prospectos correlacionados entre si e também com os ativos do bloco vizinho.

\section{5}

\section{Contribuições}

\subsection{1}

\section{Gerencial}

A tomada de decisão envolve, além das informações técnicas, também questões comportamentais dos gestores e informação assimétrica detida por eles. Posto que as teorias e soluções apresentadas nesta dissertação tenham caráter hiper-racional (TEECE; PISANO; SHUEN, 1997), é evidente que, se for possível desenhar um modelo que reflita os fatores internos da empresa e os externos do setor de óleo e gás, mesmo que considere somente agentes otimizadores sem elementos comportamentais, ainda assim essa modelagem deve ser levada para a mesa em momentos de decisões.

Esta dissertação tem a contribuir como ferramenta na tomada de decisão em uma carteira exploratória com concorrentes, um quadro consistente com a realidade da indústria. Apresenta como resultado o mais apropriado valor da carteira exploratória, considerando os possíveis estados das variáveis internas e externas à empresa, a sequência de perfuração e o momento ótimo de investimento, além do efeito da ação de outra empresa em seu portfólio.

A perpetuação de um conflito por informação pode gerar uma lacuna de investimento numa bacia exploratória de petróleo. A proposta de mudança para a barganha cooperativa é um incentivo interno das operadoras para que haja investimento, sendo algo tão importante para as empresas como aos órgãos reguladores, que no Brasil é representado pela ANP. Assim, caso haja o impasse, além do desejo das petrolíferas na negociação, o governo também é uma parte interessada, visto que os investimentos elevam a receita tributária e impulsionam outros investimentos regionais. Dessa maneira, este trabalho contribui para uma reflexão na criação de mecanismos contratuais pelas agências que estimulem a formação de joint-venture em situação de guerra de atrito na exploração de petróleo. 


\subsection{2 \\ Teórica}

Esta pesquisa se ocupa em valorar uma carteira exploratória de uma empresa de petróleo, com a interseção das teorias de OR, VOI, TJ, TJ+OR e análise de portfólio. A TJ+OR é relevante para a melhor formulação do comportamento econômico dos agentes em interação, em combinação com as incertezas de mercado (GRENADIER, 2000). Adicionalmente, para essa empresa, é importante saber os efeitos no valor dos seus ativos dados os investimentos em conhecimento, sendo essa lógica captada pela teoria do valor da informação (DIAS, 2004).

Isso posto, a dissertação tem o objetivo de contribuir no conhecimento de apreçamento de ativos na exploração de petróleo. O diferencial é a junção do VOI em portfólio com as opções de espera, com o arcabouço teórico da TJ+OR para a análise do conflito, complementando ainda mais aos estudos feitos nessa área de exploração de óleo e gás (DIAS, 2005b; DIAS; TEIXEIRA, 2009; JAFARIZADEH; BRATVOLD, 2015; GUEDES; SANTOS, 2016). 


\section{2}

\section{Referencial Teórico}

$\mathrm{Na}$ primeira parte do referencial serão apresentados os primeiros e relevantes estudos em OR (seção 2.1), seguidos pelos estudos em incerteza do preço de commodities no apreçamento de ativos (seção 2.1.1). A seção (2.1.2) apresenta os trabalhos em TOR em recursos minerais, com destaque na indústria upstream de óleo e gás. O portfólio em OR é discutido na seção (2.2) e a incerteza técnica na seção (2.2.1). O referencial em TJ, em especial a guerra de atrito e a barganha cooperativa, é apresentado na seção (2.3) e por fim a teoria dos jogos com opções na seção (2.4).

\section{1}

\section{Opções Reais}

O método mais comum de valoração de projetos é o Fluxo de Caixa Descontado. Esse considera o valor futuro esperado do fluxo de caixa livre descontado pela taxa ajustada ao risco. Com esse método, a métrica mais comum de economicidade de projetos é o Valor Presente Líquido (VPL), sendo ótimo quando o valor esperado das receitas líquidas supera o valor do investimento a valor presente. Em projetos com grande incerteza, como em recursos minerais, os eventos extremos são mais prováveis quando comparados aos investimentos com menor incerteza e os métodos que consideram o valor médio podem distorcer a valoração. Essa preocupação motivou pesquisadores a desenvolverem métricas que consideram as incertezas no fluxo de caixa combinada a ação ótima do tomador de decisão.

Nesse contexto, surgiu a pesquisa em Opções Reais (OR). O seu desenvolvimento é derivado das pesquisas em opções financeiras feitas por Black e Scholes (1973) e Merton (1973). O investimento em um ativo real pode ser visto como uma opção sem obrigatoriedade de exercício pelo gestor, dada a incerteza no fluxo de caixa esperado. O paralelo é direto com a opção financeira: o direito e não a obrigação de ter um ativo financeiro, dada a incerteza do ativo base condicionado ao valor do preço do exercício (strike). Com isso, a estruturação lógica da Teoria de Opções para ativos financeiros foi adaptada para os ativos reais, considerando as diferenças entre esses dois objetos.

Dixit e Pindyck (1994) consolidam os conceitos em um dos livros de 
referência no assunto. Esse trata primeiramente de princípios econômicos de valor, dos processos estocásticos de preços, da dinâmica de otimização, do equilíbrio com os demais competidores e de diversos modelos e aplicações. Trigeorgis (1996) e Copeland e Antikarov (2001) também sumarizaram os conceitos de OR, sendo o último livro com características mais práticas de implementação da teoria.

Existem diversas classificações em OR. Trigeorgis (1999, p.22) classifica as opções entre os direitos exclusivos e compartilhados, os adiáveis e com expiração. A classificação de referência nesta dissertação segue Dias (2010). Esse trabalho classifica as OR em tipos operacionais, de aprendizado e de tempo de investimento. As opções operacionais são relacionadas a um ativo base já existente, na possibilidade de expandir, contrair, trocar o insumo, parar temporariamente ou abandonar o projeto. As opções de aprendizado são divididas entre endógenas e exógenas, sendo as exógenas aquelas do tipo de incerteza de mercado ou estratégica, esta última com conceitos teóricos de option-games (TJ+OR). Por outro lado, as endógenas são em função do conhecimento técnico das empresas e aplicação de princípios de learning by doing, conceito abordado na teoria do Valor da Informação (VOI). Já as OR de tempo de investimento, também conhecidas como opção de espera ou opção de investimento, adotam conceitos clássicos de opções de compra financeiras e sua formulação é adequada em projetos de exploração de petróleo. Esta dissertação trabalha com a opção de espera em uma concessão exploratória, em que a empresa de petróleo tem a opção de investir em um poço pioneiro. Essa opção, quando analisada em portfólio, também pode ser classificada como uma opção de aprendizado endógena, pois neste caso, a perfuração sequencial das oportunidades exploratórias possibilita o aprendizado sobre os seus próprios prospectos. As modelagens finais desta dissertação abordam a incerteza da ação de um outro agente, com efeitos exógenos afetando os ativos da carteira, portanto, de acordo com a classificação acima, as opções modeladas também podem ser denominadas de opção de aprendizado exógena.

O primeiro trabalho conhecido em OR foi na área de petróleo. Tourinho (1979) apresenta um modelo em um campo de petróleo, considerando a opção de espera e de abandono. Outro trabalho importante foi de Titman (1985), que analisa a opção de investir em um terreno urbano considerando tamanhos distintos de projetos dada a incerteza de preços, com resultados importantes para o detentor do terreno. Trigeorgis (1993) apresenta um trabalho importante sobre as interações entre diversos tipos de opções e conduz para algumas reflexões sobre a aditividade das flexibilidades gerenciais dos projetos.

Como síntese e sumarizações de trabalhos em OR, Lander e Pinches 
(1998) listam trabalhos com aplicações em diversas áreas e tipos de OR. Schwartz (2013) apresenta um resumo dos conceitos de OR, com modelos em recursos naturais e em pesquisa e desenvolvimento (P\&D). Dias (2010), além de apresentar os tipos de OR, lista os métodos de solução e classifica os principais existentes.

Não é somente a TOR que se conecta com a teoria das opções financeiras, mas também as diversas formas de soluções. Brennan e Schwartz (1978) apresentam soluções por diferenças finitas, sendo a variável estocástica um Movimento Geométrico Browniano (MGB), com transformação logarítmica da variável de estado. Haug (2007, Chap.7, p.337) apresenta uma solução para uma opção de compra financeira americana, similar a solução por diferenças finitas explícitas de uma opção real de investir apresentada em Dias (2015b, Cap.26, p. 408), ambos os trabalhos usados como referencial para esta dissertação (vide Apêndice B). Copeland e Antikarov (2001, Chap. 5) apresentam um modelo para estimar a volatilidade de um projeto por simulação de Monte Carlo. Nesse tipo de abordagem, é possível adicionar diversas variáveis estocásticas que afetam o fluxo operacional do projeto. Brandão, Dyer e Hahn (2005) aprimoraram esse último método para obter a volatilidade do projeto como um todo, com a hipótese que o agregado resultante do fluxo e da interação das variáveis é um MGB. O resultado da volatilidade pode ser inserido em um modelo binomial como de Cox, Ross e Rubinstein (1979), solução também usada em opções financeiras.

Algumas OR podem ter exercício a qualquer momento. Isso torna a solução mais trabalhosa e ganha em complexidade caso tenha mais de uma variável estocástica no fluxo operacional. Longstaff e Schwartz (2001) desenvolveram um método recursivo com mínimos quadrados e simulação de Monte Carlo. Esse método pode ser usado com quaisquer processos estocásticos que possuam equação para simulação. Dessa forma, é possível obter numericamente as soluções de OR de diferentes complexidades com diversas flexibilidades no projeto.

\subsection{1}

\section{Incerteza de Preços}

Os modelos de preço em commodities são amplamente discutidos na literatura. Devido aos mercados internacionais de negociação e à disponibilidade da informação, os modelos são facilmente confrontados com os dados e naturalmente aplicados em valoração de projetos de OR em recursos minerais.

A commodity se define por três elementos - $(b, t, l)$ : bem, tempo e local (SEPPI; RONN, 2002). O bem se refere ao ativo negociado, suas características 
e qualidades. Como se sabe, os recursos minerais são comumente classificados como único, mas cada jazida tem suas características específicas. No caso do petróleo, as correntes mais conhecidas são o WTI e o Brent blend, justamente por serem os tipos negociados em bolsa e os usados pela indústria como referência na venda dos seus produtos. Já o termo tempo da tripla faz referência ao vencimento do contrato futuro, pois como se trata da negociação de um ativo físico, raramente a entrega é imediata e normalmente ocorre em um período de meses a ano. Por último, o local vincula ao espaço de negociação. Os principais mercados para o óleo, o óleo cru e o gás propano são: New York Mercantile Exchange (NYMEX), Hong Kong Futures Exchange (HKEX), Philadelphia Board of Trade (PBOT) e International Petrol Exchange (IPE) (GEMAN, 2005, p.11-12). ${ }^{1}$

De longe, o petróleo é o ativo mais negociado em mercado futuro (GEMAN, 2005, p.19-20). Dentre os metais, o alumínio, o ouro e o cobre ganham destaque, mas estes somados não chegam ao volume negociado de óleo bruto. Ademais, a negociação de petróleo em mercado aberto provoca uma forte influência em toda a cadeia de energia, como de gás natural, de eletricidade, ou de carvão, e se fixa como o maior indicador econômico global (AMIC; GEMAN, 2005, p.203). Por essas diferenças de volume de transação, que refletem em distintas demandas, além dos variados recursos minerais negociados e da cartelização dos mercados, as estruturas de preços para as commodities se diferenciam entres si (GEMAN, 2005, p.28; AMIC; GEMAN, 2005, p.226) e consequentemente os modelos para cada ativo.

O Movimento Geométrico Browniano (MGB) é o modelo de preços basilar em finanças quantitativas. Black e Scholes (1973) e Merton (1973) usaram o MGB para propor a equação analítica do valor de uma opção europeia. O uso é devido à facilidade matemática, à aderência com muitas séries temporais e às propriedades ideais para os preços. Além disso, possui fácil adaptação à modelagem de propagação temporal, como na solução discreta binomial, apresentada por Cox, Ross e Rubinstein (1979). Contudo, as séries históricas dos contratos em petróleo e commodities apresentam feições em que as propriedades estatísticas do MGB não atendem, como a reversão à média, devido às forças de equilíbrio de mercado e os efeitos de saltos, gerados por fricções de mercado e captados, por exemplo, por processo de Poisson (BAKER; MAYFIELD; PARSONS, 1998; PINDYCK, 1999; BENARD et al., 2008; AIUBE; BAIDYA; TITO, 2008). Os modelos que derivam dessas evidências empíricas, apesar de adotarem os fatores de reversão ou as componentes de salto, mantém

\footnotetext{
${ }^{1}$ Aiube (2013) é o livro de referência em português para estudo de modelos em commo-
} dities. 
algum drive de caráter geométrico nas equações diferenciais.

Um modelo alternativo de um fator para as commodities é o modelo 1 de Schwartz (1997). O processo de difusão é o modelo Orstein-Uhlenbeck para o logaritmo dos preços. Nesse trabalho é feito a estimação de ouro, cobre e petróleo, com baixa adesão aos dados comparados aos modelos de mais fatores desse artigo.

Outro modelo de um fator é o processo geométrico de reversão de OrsteinUhlenbeck aplicado ao preço, apresentado em Dixit e Pindyck (1994, Capítulo 3, p.77) e com aplicações em OR (CORTAZAR; SCHWARTZ, 1997; CORTAZAR; CASASSUS, 1998). Esse modelo possui feições de reversão à média e apresenta uma relação quadrática dos preços, diferentemente do modelo 1 de Schwartz (1997), que possui um produto entre o preço e o logaritmo dele. O fato de um processo desenvolver em sua equação diferencial pelo quadrado do preço é de difícil dimensionamento numérico. Essa equação atende às vantagens estatísticas como, por exemplo, não ter os preços negativos, além de reverter à média, mas a justificativa financeira do modelo de propagação é complicada pela grandeza física gerada pelo quadrado dos preços.

Os modelos com mais fatores são importantes para descrever melhor a incerteza de preços. A volatilidade é um dos componentes mais relevantes para a valoração por OR. Adotando dois fatores, há duas estimações de prêmios de risco e de volatilidade. Como os projetos em commodities são de longo prazo (PINDYCK, 2001), os modelos de mais fatores contribuem para a separação dos efeitos imediatos da tendência de longo prazo.

O modelo Schwartz (1997, modelo 2) é um desses, pois possui uma equação diferencial geométrica para os preços e outra equação dependente, com uma difusão de Orstein-Uhlenbeck, representando a taxa de conveniência da commodity. Esse modelo, comparado ao modelo 1, tem significância estatística dos hiperparâmetros para as séries de preços futuros do petróleo no período de tempo estudado no artigo.

A taxa de conveniência e os fatores desse modelo são discutidos em Gibson e Schwartz (1990). A taxa de conveniência é o benefício do proprietário do bem em deter esse ativo, comparado ao detentor da posição comprada no mercado futuro. Essa taxa pode ser vista como um dividendo a receber pelo detentor e se relaciona com o risco de escassez do ativo no mercado. Assim, a taxa de conveniência tem relação com os efeitos de curto prazo do mercado de petróleo, visto que a média de transporte é de 30 dias (AMIC; GEMAN, 2005, p.203-204), sendo o intervalo principal do risco de escassez. Gibson e Schwartz (1990) também analisam a taxa instantânea de conveniência desse mercado, que possui feições estilizadas de forte reversão à média e com o parâmetro de 
incerteza muito volátil.

Schwartz (1998) propõe uma simplificação do modelo 2 de Schwartz (1997) dentro de um modelo de um fator similar ao MGB. A argumentação é devido ao fato dos projetos em commodities serem de longo prazo, em que o modelo de dois fatores representa melhor as feições estilizadas dos preços, por outro lado, o movimento geométrico browniano é um modelo mais prático para modelar OR. Assim, analisa os efeitos de longo prazo do modelo de dois fatores e extrai essas qualidades, inserindo num modelo de um fator. Esse novo modelo de longo prazo difere do modelo tradicional de OR com MGB, pois possui a volatilidade variante no tempo, contudo essa questão é tratável em soluções por diferenças finitas.

O modelo de dois fatores de Schwartz e Smith (2000) é amplamente referenciado na literatura. Esse carrega componentes com características de curto prazo do mercado de commodity relativos às alterações de estocagem, as incertezas econômicas imediatas, sendo modelado por reversão à média de Orstein-Uhlenbeck. Já o fator de longo prazo é modelado por um movimento aritmético em relação ao logaritmo do preço spot, sendo representativo da tendência de consumo de longo prazo ou até mesmo aos ajustes de produção de grande escala da indústria petrolífera. Nesse artigo comparam as variáveis aos parâmetros do modelo 2 de Schwartz (1997), destacando as similaridades e diferenças. Também estimam os hiperparâmetros para o modelo proposto e apresentam um exemplo com OR para dois projetos de produção de petróleo. O projeto de menor dimensão tem receita líquida imediata e menor investimento e o outro possui explotação de longo prazo, com investimentos de maior dimensão. Concluem que as variáveis de curto prazo afetam mais o menor projeto, sendo mais significativas que os parâmetros de longo prazo. Sobre o projeto de maior dimensão, evidenciam a importância da estimação dos parâmetros de longo prazo.

Sobre os de três fatores, Schwartz (1997) propõe um modelo incluindo um processo para a difusão estocástica da taxa de juros. Comparando com o modelo de dois fatores que possui difusão da taxa de conveniência, não há melhoras estatísticas significativas nos parâmetros estimados, por outro lado, há um maior esforço para estimação.

Aiube e Samanez (2014) propuseram um modelo com três fatores derivado de Schwartz e Smith (2000), sendo o drift do termo de longo prazo um processo de reversão à média. Os resultados têm maior aderência aos dados quando comparados com a estimação de dois fatores.

O campo de pesquisa é amplo na tentativa de descrever melhor a incerteza do preço do petróleo. Cortazar e Naranjo (2006) apresentam um modelo de $n$ 
fatores em modelos gaussianos para as séries de preços em petróleo, aplicando até em quatro fatores. Modelos com saltos são não gaussianos e em Aiube, Baidya e Tito (2008) propõem mais um termo com componente de Poisson na extensão do modelo Schwartz e Smith (2000). Outras linhas de pesquisa também estudam as variações do prêmio de risco ao longo do tempo, inclusive nos preços futuros de petróleo (BHAR; LEE, 2011).

Sobre a estimação dos hiperparâmetros das séries, pode-se considerar uma proxy do preço spot como a primeira abordagem em Gibson e Schwartz (1990). Contudo, é importante trabalhar com o maior conjunto de dados, incluindo diferentes vencimentos de contratos futuros. Em modelos gaussianos e com uso das séries de preços futuros, é possível estimar pela montagem do filtro de Kalman os parâmetros do modelo spot (AIUBE, 2013, p. 368). Quando o modelo é não gaussiano, é necessário avançar para outras abordagens, como o filtro de partículas (AIUBE; BAIDYA; TITO, 2008).

\subsection{2}

\section{Opções Reais: Recursos Minerais e Indústria de Óleo e Gás}

Tourinho (1979) foi o primeiro trabalho em campo de petróleo com aplicação de OR. O modelo tem como ativo base o preço do petróleo que segue um MGB e o detentor do campo possui duas opções perpétuas de produzir ou abandonar. Como não considera os dividendos ou a taxa de conveniência, o detentor posterga eternamente a opção de investir. Para resolver esse paradoxo, adiciona um custo de manutenção à solução do portfólio sem risco. Adkins e Paxson (2013) revisitam esse modelo e adicionam a taxa de conveniência à difusão estocástica. Em Tourinho (2013), aponta que os efeitos entre inserir um custo de manutenção e a taxa de conveniência ou dividendos são distintos na dinâmica do derivativo. Nesse último trabalho, conduz para um aprimoramento do modelo de preços, sugerindo uma difusão geométrica não homogênea com reversão à média para o preço do petróleo (KLOEDEN; PLATEN, 1992, p.119) e uma discussão sobre o equilíbrio de mercado, em que tais questões são abordadas em TJ+OR.

Esse modelo é amplamente considerado em OR. No caso de exploração de petróleo, em fases iniciais, os custos de manutenção são relativamente baixos, já a taxa de conveniência ou os dividendos são normalmente considerados. Os custos de manutenção do bloco exploratório são pequenos comparados com o investimento em exploração e produção, que basicamente se resumem a um pequeno aluguel de área pago à agência, no caso a ANP no Brasil. Sobre a taxa de conveniência, é possível estimar pelo mercado futuro, como feita nesta dissertação e a taxa de dividendos pode ser em função do desenho de receitas 
líquidas do projeto em produção.

Brennan e Schwartz (1985) formalizam um modelo com o ativo base sendo um MGB para a avaliação de um recurso natural finito, com opções de abertura e abandono, aplicando em um caso hipotético de uma mina de cobre. Esse modelo pode ser usado em campos de petróleo não desenvolvidos, como em Oliveira (1990) e em Cortazar e Casassus (1998), porém, neste último foi adotado o processo geométrico de reversão à média para a difusão do ativo base.

Paddock, Siegel e Smith (1988) apresentam um modelo de OR para reservas de petróleo não desenvolvidas. Com o MGB como processo de difusão estocástica do preço do petróleo, obtêm o valor de mercado por barril, ou seja, o valor monetário da opção de investir por reserva desenvolvida. Para isso, calculam o dividendo para o campo de petróleo, o qual é igual à razão entre a margem de lucro e o fator da reserva desenvolvida multiplicada pelo declínio da curva de produção exponencial. O fator da reserva desenvolvida pode ser visto como a qualidade econômica do campo (q), sendo um conceito introduzido de maneira indireta nesse trabalho como a regra do one-third, apontada também em Bjerksund e Ekern (1990) e adotada por Dias (2004) no modelo paramétrico de valor da reserva.

Dias (2004) distingue os tipos de opções na exploração e produção de petróleo. Na fase inicial da cadeia produtiva de petróleo, o objetivo é encontrar hidrocarboneto nos reservatórios. Assim, o investidor detém uma opção de investir em exploração. Essencialmente, esse direito é exercido pela perfuração do poço pioneiro, também conhecido como poço exploratório. Nesse momento, além da estocasticidade do preço do petróleo, a principal variável incerta na valoração do prospecto a ser revelada pela perfuração do poço exploratório é o fator de chance geológico (FC), conceito estudado de forma detalhada em (ROSE, 2001, p.37), que apresenta uma escala de probabilidade de sucesso em função da confiança geológica. Na fase seguinte, conhecida como Plano de Avaliação de Descoberta (PAD), as variáveis endógenas em questão são o dimensionamento do volume recuperável (B) e a compreensão da qualidade econômica da jazida (q). As formas de reduzir as incertezas sobre essas variáveis são por investimentos em poços de delimitação e por testes, como por exemplo, um teste de longa duração. Assim, a empresa tem a opção de delimitar o seu campo. Caso a empresa avance além do PAD, a opção da empresa é de investir no desenvolvimento do campo, sendo essa fase com o dispêndio mais custoso. Durante o desenvolvimento, pode haver outras opções, como de expansão da produção por uma reserva marginal ao campo explotado ou uma parada temporária, além da opção de abandonar o campo. Em todas as fases, 
a incerteza do preço do petróleo é muito relevante.

Jafarizadeh e Bratvold (2015) apresentam um modelo para a opção de explorar um campo de petróleo, com o preço da commodity seguindo o modelo de dois fatores de Schwartz e Smith (2000). Já o trabalho de Guedes e Santos (2016), com o modelo binomial de Cox, Ross e Rubinstein (1979) e trinomial de reversão à média, modelam todas as opções conjuntas (explorar, delimitar e explotar) e analisam o incremento de valor pelo método de OR. Saito et al. (2001), a partir do modelo de Paddock, Siegel e Smith (1988), propuseram uma análise comparativa por simulações de diferentes técnicas de produção de petróleo, discutindo o benefício da TOR frente ao VPL para cada técnica.

\section{2}

\section{Portfólio de Opções Reais}

Brosch (2001) define que um portfólio em opções reais é um conjunto de OR. Essa série de decisões gerenciais poderiam ser aplicadas em um único projeto e as diversas opções possuiriam exercícios sequenciais, como os exemplos apresentados em Dixit e Pindyck (1994, Cap.7). Outra possibilidade seria que essas regras de decisões fossem aplicadas em diversos ativos da carteira, com a possibilidade dessas flexibilidades interagirem entre si.

A princípio, o portfólio de OR poderia ser classificado com qualidade aditiva, ou seja, o portfólio é a simples soma das opções reais, assim como ocorre com o conjunto de opções financeiras. Um portfólio de opções financeiras é uma distribuição de regras de contratos sobre um ativo base, como por exemplo, diversas opções de compra e de venda aplicadas a uma ação financeira. Porém, o exercício de uma opção financeira não afeta o valor de uma outra opção financeira e tão pouco o ativo base. Contudo, isso não acontece necessariamente em portfólio de OR, pois muitas vezes o ativo base já é propriedade do detentor da opção. Brosch (2001) esclarece esse ponto, com um exemplo de uma planta em produção, com a possibilidade de uma opção de abandono. A partir do exercício do abandono, a planta perde as outras opções de produção, como por exemplo, a opção de expansão ou a opção de redução de fabricação.

Trigeorgis (1993) apresenta um modelo com interações de diversas opções gerenciais. Usa um exemplo genérico em um único ativo base, com as opções de postergar, abandonar, contrair, expandir e trocar o projeto para um uso alternativo. Resulta que o valor incremental com a adição de uma nova opção é menor na presença de uma outra opção. Em alguns casos, pode haver a superaditividade do portfólio, ou seja, o valor com a interação entre as opções é maior que a soma individualizada dessas, ainda que na maioria dos casos o efeito é de subaditividade. 
Dias (2015b, Cap.24) esclarece essa questão. A superaditividade é possível e ocorre, por exemplo, quando a opção de expansão antecede outra opção de parada temporária ou de abandono. Isso acontece, pois se for atingido o gatilho da opção de expansão, o ativo base se amplia e consequentemente as outras opções sequenciais são em função desse novo ativo base já expandido. A aditividade pode acontecer em casos de opções opostas, por exemplo, uma opção de investir e outra de abandonar um projeto, em que os preços de exercício das opções são bem afastados. Isso ocorre, visto que a probabilidade condicional de uma opção ser exercida dada que a outra aconteceu é baixa, sendo mais baixa quanto maior o intervalo dos strikes. No caso de subaditividade, pode ocorrer, por exemplo, em duas opções de expansão, com a expansão de menor escala em preço mais baixo e de maior escala a preço mais alto. Caso aconteça a expansão, será necessariamente acionada a de menor escala, portanto, as duas opções concorrem entre si, já que possuem qualidades substitutivas. Dias (2015b, Cap.24) também indica, assim como Trigeorgis (1993), que é mais comum o efeito de substituição, ou seja, casos do portfólio com subaditividade dos seus projetos.

Bjerksund e Ekern (1990) usam o modelo de Paddock, Siegel e Smith (1988) para modelar a opção de investir em um campo de petróleo e também adicionam outras flexibilidades, como o abandono e a parada de produção. Os resultados apontam para aumentos marginais no valor do campo quando se adiciona outras flexibilidades além da opção de espera, mostrando a subaditividade dessas opções sequenciais. Ademais, mostram a relevância da opção de espera em relação as outras para o valor presente de um projeto em exploração. Com esse conceito em mente, esta dissertação modelou somente a opção de espera em portfólio, sem considerar as outras flexibilidades como o abandono ou a parada de produção.

Em casos de opções reais em ativos bases distintos, a percepção leva a considerar a diversificação como a melhor forma de diminuir o risco em uma carteira. Esse conceito se adere aos expostos em Markowitz (1959), que pela análise da correlação estocástica entre os ativos, é possível encontrar uma carteira que minimiza a variância dada a média do retorno deste portfólio. Com esse princípio, a variável relevante é a covariância dos fluxos de caixa entre os ativos.

Essa visão não é deixada de lado em ativos reais, já que a diversificação é algo relevante para a manutenção do lucro de longo prazo da empresa. Contudo, o questionamento sobre a administração de um portfólio por essa medida é legítimo. Primeiramente, o portfólio de Markovitz é expresso de forma simultânea, diferindo de muitos projetos reais que são exercidos ao 
longo de uma cronologia. Além disso, a diversificação feita por empresas e conglomerados empresariais é algo questionável, visto que essa ação de redução de risco poderia ser gerenciada pelo acionista, constituindo uma carteira variada ou por fundos de investimentos (BROSCH, 2001).

Além da relação estocástica dos fluxos de caixa dos ativos, os projetos reais se interagem uns com os outros por nível técnico ou físico, dados os seus atributos específicos. Os projetos podem, por exemplo, demandar da mesma fonte de insumos, incorrendo em restrições de entrada ou serem consequência de outros projetos, com uma dependência temporal nos investimentos. Por essa razão, Brosch (2001) define um contínuo entre a complementariedade e a substitutibilidade dos ativos reais.

Quando os projetos possuem suas funções técnicas idênticas, esses são considerados estritamente substitutos. Nesse caso, os investimentos disputam os recursos monetários ou até mesmo o mercado de venda, podendo gerar um subótimo para a empresa (VASSOLO; ANAND; FOLTA, 2004, proposição 1).

No caso de projetos que requerem a existência de um outro em funcionamento, esses são estritamente complementares. A complementariedade é dada quando os ativos possuem sinergia e fungibilidade (ARORA; GAMBARDELLA, 1990). Com isso, os recursos e os saberes técnicos são transmitidos de um projeto para o outro e conduzem a ganhos de escala e escopo. Brosch (2001) aponta que a interação pode ser mútua ou em um só sentido entre os projetos, sendo um ativo real mais favorecido que o outro nessa relação sinérgica. Afirma também, que no caso em que não há interações entre os ativos reais, os projetos são considerados independentes.

Para a geração de valor, a empresa deve se voltar para os projetos complementares (BROSCH, 2001). Dessa forma, a empresa deve constituir uma carteira com OR com esse perfil, pois podem propiciar uma melhor gestão dos recursos por saberes transmitidos de um projeto para o outro, possibilitando sinergias nas distintas produções e um aumento de escala na produção, melhorando a relação de receita agregada pelo investimento total. Esse conceito se conecta com o princípio de vantagem comparativa e a Teoria Baseada em Recursos apresentados em Peteraf e Barney (2003).

No setor de upstream da indústria do petróleo, o qual inclui a exploração de hidrocarboneto, Faiz (2000) aponta a importância de buscar a análise de portfólio com OR, notando que a mensuração stand-alone é diferente e incompleta em uma carteira de ativos exploratórios. Em Smith e McCardle (1998) indicam a possibilidade de projetos exploratórios em petróleo com proximidade geográfica possuírem um desenvolvimento ótimo em série de investimentos, devido à complementariedade dos ativos. Com essas concepções, 
Dias (2005a, Cap. 3) apresenta um modelo de portfólio em OR na exploração de petróleo, com a medida de aprendizado da incerteza técnica afetando a variável fator de chance geológico (FC). Na seção a seguir, são detalhados o conceito de aprendizado e a incerteza técnica, presentes na teoria do Valor da Informação (VOI).

\subsection{1}

\section{Valor da Informação - Incerteza Técnica}

$\mathrm{Na}$ última seção, os estudos apontam que além da importância da estocasticidade nos fluxos de caixa para a gestão de ativos, a administração de portfólios em OR mira nas qualidades técnicas, idiossincráticas de cada projeto em interação, oferecendo ao gestor o melhor dimensionamento do valor na consolidação da carteira. Assim, a compreensão da natureza da incerteza técnica é relevante para estimar melhor os efeitos aditivos no portfólio de OR.

Diferentemente da variável estocástica preço da commodity, em que o indexador da série é o tempo, ou seja, que a coleção de dados é ordenada ao longo do tempo, é mais apropriado considerar o indexador eventos para a incerteza técnica (DIAS, 2002). O evento é um investimento em conhecimento para compreender melhor a variável endógena à empresa. Cortazar, Schwartz e Casassus (2003) apresentam a incerteza técnica-geológica de uma mina de cobre como um processo estocástico temporal, similar a Slade (2001). A incerteza sobre a concentração mineral ou o tamanho do depósito é algo próprio de cada jazida e é somente reduzida com investimentos. Assim também ocorre na exploração e produção de petróleo, em que o investimento em perfuração de poços de exploração e delimitação não são contínuos no tempo e ocorrem por ações de gestão, sendo somente com esse tipo de dispêndio elegido a forma possível de dimensionar corretamente a variável técnica. Como esses gastos têm características de eventos, na maioria das vezes, o método de indexação temporal não é adequado para lidar com a variável estocástica técnica.

O dimensionamento da variável técnica perpassa obrigatoriamente pelo conhecimento e a sua relação com a revelação da informação. Segundo Lawrence (1999, p.3), o conhecimento é um estoque de crenças sobre a variável técnica, que pode ser acessado pela distribuição de probabilidade. Em um estado inicial, há um estoque de crenças de um conhecimento já estabelecido, representado quantitativamente pela função de probabilidade a priori. Para alterar o que está estabelecido sobre a variável, deve ocorrer o evento para revelar a informação, como por exemplo, o investimento em um poço exploratório, alterando o conhecimento da variável $\mathrm{FC}$ de um ativo dentro de um portfólio. Já a informação, segundo Lawrence (1999, p.3), é o estímulo que 
altera o estoque de conhecimento, sendo esse evento também denominado de sinal.

Todo o evento informativo deve ter os seguintes atributos: observável, relevante, material e econômico (BRATVOLD; BEGG, 2010, p.150; BRATVOLD; BICKEL; LOHNE, 2009). O teste informativo precisa ser observável para a tomada de decisão futura, além de ser relevante para ser possível mudar as crenças existentes. Por exemplo, ser observável é o investimento em um poço pioneiro, que possui a função principal de indicar a presença de hidrocarboneto. A variável fator de chance geológico (FC) é compreendida após o investimento do poço pioneiro, já que a presença de hidrocarboneto é binária, ou seja, ou há ou não há petróleo. Porém, um teste não observável é desejar que somente o investimento em sísmica indique a dimensão do reservatório. As sísmicas e os processamentos sísmicos de melhor qualidade contribuem para compreender o reservatório e a sua extensão, mas o investimento que delimita a dimensão da reserva é somente o poço de delimitação. Bratvold, Bickel e Lohne (2009) citam como um exemplo de relevância a relação entre o sinal sísmico e as propriedades petrofísicas do reservatório, sendo a sísmica um teste relevante para inferir as propriedades. A qualidade material é consequência da relevância, já que se houver mudanças nas crenças, pode estimular novas ações e definir o caráter econômico do teste. Um exemplo extremo de não materialidade é um teste desenhado que não contribui para compreender a variável em questão. Bratvold, Bickel e Lohne (2009) citam que deve ser gratuito um teste medicamentoso caso não tenha relação com o tratamento da doença que se deseja investigar. Por fim, o atributo econômico é o benefício do teste ser maior que o seu valor de custo.

A revelação da informação é a exposição da verdadeira dimensão da variável técnica e é representada pela esperança condicionada à informação (evento ou sinal) da variável a ser testada (DIAS, 2002). Caso a revelação seja completa, a distribuição da revelação da informação após o evento será igual à distribuição da variável incondicional a priori. Para compreender esse conceito, serão apresentados os dois momentos da distribuição de revelação no caso de informação completa: a esperança e a variância. A esperança da distribuição de revelação é a própria esperança da variável testada (DIAS, 2005a, p.199, eq.93), portanto, se apresentando como uma variável estocástica martingal. Isso pode ser entendido matematicamente pela lei das expectativas iteradas, posto que a esperança da esperança condicional, sendo a esperança condicional a própria distribuição de revelação, é a esperança incondicional da variável, visto que esta última é justamente a esperança a priori da variável a ser testada. Agora, a variância é compreendida pela lei da variância total, assim, 
a variância da variável técnica a priori (incondicional) é igual à esperança da variância da variável dada a informação somada a variância da esperança da variável técnica condicionada à informação (evento ou sinal), esta última, sendo a própria variância da distribuição de revelação da informação (DIAS, 2005a, p.199, eq.94). No caso de informação completa, revela-se tudo sobre a variável a ser testada, portanto, não há valor numérico para a esperança da variância da variável técnica condicionada à informação (DIAS, 2002). Logicamente, se conclui que a variância da distribuição de revelação é igual à variância da variável técnica a priori.

Na maioria dos eventos de investimento, a variável técnica não é completamente revelada (DIAS, 2002). Por exemplo, para delimitar um campo de petróleo, talvez seja necessário mais de um poço de delimitação da jazida. Com o aumento no número de eventos informativos, mais próximo se está da informação completa, assim, há uma relação com a diminuição da incerteza esperada, ou seja, a diminuição da esperança da variância da variável técnica condicionada à informação é em função do aumento da quantidade de sinais (DIAS, 2005a, p.197). No caso estudado nesta dissertação, a informação revelada é completa para o poço perfurado, mas incompleta para os FCs dos prospectos vizinhos. Como dito, o poço exploratório obtém uma informação binária de existência ou não de hidrocarboneto e assim revela tudo sobre a variável FC, portanto, sendo modelada por uma variável aleatória de Bernoulli. Dessa forma, com a revelação completa do FC, aprende-se com esse investimento e essa informação afeta um seguinte investimento justamente na variável FC. Assim, há uma implicação da informação na outra variável, ou seja, há uma relação condicionada entre o primeiro (o sinal) e o segundo fator de chance, sendo essa distribuição de revelação descrita pela distribuição bivariada de Bernoulli (DIAS, 2005a, p. 276).

Com esses princípios, Dias (2005a, p. 219) cria um parâmetro chamado de medida de aprendizado. Na situação em que a esperança da variância é reduzida para zero, ou seja, há completude na revelação da informação e por consequência há o conhecimento total da variável técnica em questão, a medida de aprendizado é máxima e igual a 1. No caso desta dissertação, segundo Dias (2005a, p.281), como a implicação do conhecimento da informação na outra variável é uma distribuição bivariada de Bernoulli, a medida de aprendizado é igual à correlação entre os prospectos. A importância da correlação entre as oportunidades geológicas também foi notada em Bickel, Smith e Meyer (2008), com aplicação de outro modelo de dependência para o fator de chance. Esse contorno, em que informações afetam decisões, é o que delimita a teoria do Valor da Informação (VOI). 
Murtha (1995) apresenta um dos primeiros trabalhos de dependência entre prospectos exploratórios. No caso, trata-se de diferentes reservatórios em um só poço. A dependência é pela probabilidade condicional dos elementos do sistema petrolífero. A partir dessas probabilidades, por um sistema de equações, são calculadas as probabilidades conjuntas e os resultados são comparados com e sem dependência entre os níveis de reservatório. Concluise que com o aumento da dependência eleva-se os casos de probabilidades degeneradas, ou seja, aumenta-se a probabilidade de casos com reservatórios secos ou com hidrocarboneto. Com isso, a variância sobe com o aumento da dependência e por outro lado, a média incondicional não se altera, assim como notado em (DIAS, 2005a, p.309). A média somente altera em ações condicionadas, como por exemplo, com critério de otimização gerencial de investimento.

Smith e Thompson (2008) apresentam um modelo geral em relação à dependência de prospectos exploratórios, considerando as probabilidades conjuntas, concentrando no valor adicionado pelo aprendizado no Valor Monetário Esperado (VME), com os custos exploratórios iguais e sem considerar o valor da opção de espera. Dentre as generalizações, as mais relevantes são: no caso de independência, o ótimo é perfurar simultaneamente as oportunidades. Em situação com $n$ prospectos, é melhor perfurar o prospecto de maior VME, caso esse também seja de maior probabilidade de sucesso. Contudo, por vezes, é melhor testar o caso de menor VME que possua probabilidade melhor, similar a uma das conclusões de Dias e Calvette (2017). Em prospectos que tenham o mesmo tamanho ou volume recuperável, é preferível testar primeiro o de maior probabilidade, e da mesma forma, caso tenham as mesmas probabilidades, o melhor é perfurar o de maior volume recuperável estimado. Ademais, quanto maior a interdependência, maior é o valor da opção de aprendizado.

Zan e Bickel (2013) apresentam o VOI em portfólio também sem o valor da espera. O exemplo é aplicado em otimização do Valor Presente Líquido (VPL), com um modelo de sinal de distribuição gaussiana, com as correlações iguais entre os projetos, incluindo uma restrição orçamentária. Os parâmetros dos sinais podem ser obtidos na forma de estimativas fornecidas pelo grupo técnico ou com resultados de um agregado de testes feitos por especialistas. Com um sinal, é gerada uma nova distribuição de probabilidade a posteriori e o algoritmo é otimizado em função de VPL >0. Em um exemplo hipotético de cinquenta ativos, classificam entre os projetos prioritários e os desfavoráveis da carteira. Concluem que em situações de restrições mais rígidas de recursos, se mostra mais relevante os conceitos de VOI para a decisão de investir em ativos pertencentes a um portfólio. 
Bickel e Smith (2006) apresentam um exemplo de portfólio exploratório sem o valor de espera. Analisam a partir das probabilidades conjuntas do FCs, sendo essa medida mais complexa de ser estimada pelo corpo técnico, em vez do FC incondicional das oportunidades exploratórias independentes e a correlação entre os prospectos. Por método de otimização usando lagrangiano, acham a sequência ótima de perfuração e as suas probabilidades condicionadas à informação. Além disso, adicionam um modelo de aversão ao risco, já que as análises de decisão por VOI são neutras ao risco (BRATVOLD; BICKEL; LOHNE, 2009). Bickel, Smith e Meyer (2008) ampliam a pesquisa apresentada em Bickel e Smith (2006), considerando os riscos do sistema petrolífero de diversos prospectos e pelas suas probabilidades conjuntas.

Calvette e Pacheco (2014) analisam o VOI de um portfólio exploratório em petróleo com a metodologia apresentada em (DIAS, 2005a, Cap.3) e com questões similares as discutidas em Bickel e Smith (2006). Com o auxílio de algoritmo genético, encontram o valor da carteira e a sequência ótima de perfuração sem a opção de espera. Dias e Calvette (2017) analisam até três ativos em portfólio exploratório em petróleo com o valor da espera pelo método binomial, com resultados importantes sobre a preferência de perfuração do poço pioneiro. Esse trabalho mostra a importância da análise conjunta de VOI com OR, pois há uma combinação entre o valor econômico do prêmio da espera com o incremento monetário pelo aprendizado exploratório. Com o uso de exemplos numéricos, um dos portfólios apresenta múltiplos momentos de espera em função do preço do petróleo, sendo que a depender do preço e do tempo no contrato exploratório, pode ser preferível perfurar o prospecto mais arriscado, o menos arriscado ou aguardar melhores condições do preço do petróleo.

A informação também é relevante na teoria dos jogos (TJ). Caso a informação seja pública, pode causar efeitos em ativos de outros agentes e sendo uma externalidade positiva, pode elevar a utilidade dos outros jogadores. Em virtude disso, o agente pode esperar além do momento que seria ótimo sem essa interação estratégica, aguardando a informação gratuita a ser revelada. Esse é o cenário desta dissertação e por isso, na próxima seção serão apresentados alguns estudos de dois importantes jogos e os efeitos da externalidade positiva nos agentes.

\section{3}

\section{Teoria dos Jogos: Guerra de Atrito e Barganha Cooperativa}

O jogo de guerra de atrito foi primeiramente apresentado por Smith e Price (1973). Trata-se de um jogo não cooperativo, no qual não há uma coalizão 
entre os agentes e segundo Nash (1951), os jogos desse tipo podem ter equilíbrio em estratégias mistas com $n$ jogadores. Esse jogo possui versões similares como o Hawk and Dove game (SMITH, 1976) e é estudado dentro da teoria de jogos evolucionários, conceito também delimitado em Smith e Price (1973). Segundo Smith (1982, p.1), a teoria dos jogos evolucionários é a forma de pensar a evolução no nível dos fenótipos quando a adaptação de um tipo particular depende da frequência da população. Sendo assim, possui um conceito próprio de equilíbrio, denominado de estratégia evolucionariamente estável (EEE). A EEE ocorre caso a estratégia de uma população de indivíduos for resistente às invasões ou mutações. Esse conceito de EEE tem benefícios em jogos dinâmicos com múltiplos equilíbrios, dando suporte na escolha entre os equilíbrios de Nash Perfeitos em Subjogos (ENPS) mais estáveis em função do tempo, como são os casos aplicados nesta dissertação.

Smith (1974) apresenta o conflito entre dois tipos de indivíduos, um agressivo e outro que recua, ambos lutando por um mesmo recurso. A luta causa danos, assim como a espera tem um custo de espera. Dessa maneira, os perfis agressivos podem lutar mesmo que os danos acumulados sejam maiores que o recurso e os perfis que recuam também podem definir uma disputa, que ocorre em função de um custo denominado de custo de espera (SMITH, 1976). Então, no jogo de guerra de atrito, as estratégias são os tempos de resistência que os jogadores suportam o conflito. Nesse jogo, a EEE ocorre em estratégias mistas entre os tipos luta e recua.

Esse modelo é importante em estudos econômicos, como por exemplo, em leilões do tipo all-pay, que são analisados nessa estrutura de jogo de guerra de atrito (KRISHNA; MORGAN, 1997). Ghemawat e Nalebuff (1985) apresentam um modelo de duopólio assimétrico em declínio de mercado, em que o conflito entre as firmas leva a um único equilíbrio de Nash perfeito em subjogos, onde a grande empresa abandona o negócio antes da pequena. Ghemawat (1997, Cap.7) exemplifica esse tipo de conflito entre duas empresas transmissoras de canais por satélite, a British Satellite Broadcasting e a Sky Television, com muitos danos financeiros às companhias, resultando na fusão das operações na iminência de falência após anos de disputa de mercado.

No estudo do exemplo real acima, houve a continuação da guerra de atrito, algo prejudicial para ambas as empresas. Em certas condições, caso houvesse negociações e a fusão dos projetos no início do conflito, poderia ser vantajoso para as duas companhias a cooperação, evitando tanta destruição de valor monetário. Brandenburger e Nalebuff (1996, Cap.1) argumentam que os negócios não possuem regras fixas como os jogos de poker ou de xadrez e podem ser alterados por força dos próprios jogadores. Também afirmam, em 
Brandenburger e Nalebuff (1996, Cap.4), que a mudança de jogo é a essência da estratégia dos negócios, sempre com o objetivo de gerar mais valor dada a melhor ação do outro agente. Na situação de perpetuação da guerra de atrito, tendo em vista certas condições de negociação, pode haver vantagens para ambas as empresas na mudança de jogo para a barganha cooperativa (DIAS; TEIXEIRA, 2009).

Nash (1953) apresenta a solução da barganha cooperativa, que é representada pela união dos ativos e na divisão dos prêmios para cada jogador do conflito. A formulação é definida por um ponto de desacordo entre os jogadores em relação a união dos prêmios e resulta na divisão cooperativa para cada jogador. A solução é obtida pela maximização do produto dos ganhos das utilidades entre os dois agentes.

Muitos dos modelos em teoria dos jogos são apresentados em simetria entre os jogadores. A assimetria entre os payoffs coloca esses jogos em um domínio mais realista. Segundo Hammerstein e Selten (1994, p.965), no jogo hawk-dove com $n$ jogadores e com informação incompleta, a estratégia estável evolucionária é pura em termos de equilíbrio de Nash, refletindo em uma situação sem conflito entre os tipos. Ademais, Hammerstein e Parker (1982), na análise do jogo de guerra de atrito assimétrico, apontam que a razão entre o benefício e o custo em perpetuar o conflito é determinante para definir a empresa ganhadora da disputa.

Hendricks, Weiss e Wilson (1988) formalizam a guerra de atrito em tempo continuo com informação completa aplicada em exploração de petróleo. Definem o conflito em função do tempo de exercício de dois jogadores, sendo o líder a empresa a exercer primeiro o investimento exploratório e o seguidor a depender do líder. Dias (1997) apresenta o conflito em exploração de petróleo com a incerteza de preços em tempo discreto, utilizando a solução binomial retro-indutiva. Dias e Teixeira (2009) analisam o jogo de guerra de atrito simétrico e com a incerteza de preços, considerando a migração para a barganha cooperativa, também apresentando reflexões sobre os jogos assimétricos. Devido à incerteza de preços, o campo teórico desses estudos está presente em option-games (CHEVALIER-ROIGNANT et al., 2011), aqui apresentado como teoria dos jogos com opções (TJ+OR).

\section{4}

\section{Teoria dos Jogos com Opções}

A TJ+OR contribui para a melhor formulação sobre o comportamento econômico dos agentes dadas as incertezas (GRENADIER, 2000). É uma teoria relevante, por exemplo, para modelar projetos de Pesquisa e Desenvolvimento 
(P\&D). Esses tipos de projetos possuem desdobramentos com investimentos sequenciais, sendo pesquisados pela teoria do VOI e dada a existência de incerteza exógena no desenvolvimento do projeto, a exemplo, a demanda incerta do mercado consumidor ou a incerteza de custo, normalmente se adota a modelagem pela TOR (BRANDÃO; FERNANDES; DYER, 2018). Quando se insere os efeitos da competição entre os agentes, algo muito comum em fases de pesquisa e desenvolvimento de produtos, deve-se modelar por TJ e TJ+OR (SMIT; TRIGEORGIS, 2006).

Chevalier-Roignant et al. (2011) fazem uma síntese dos trabalhos na área e sugerem uma classificação levando em conta as características da TJ, os conceitos de organização industrial e os princípios de OR.

Muitos dos modelos em TJ+OR analisam os mercados em duopólio, em oligopólio e em competição perfeita com choques de demanda. Leahy (1993) aponta que dadas a incerteza de demanda e a competição perfeita, o gatilho de entrada para um agente que considera a competição é igual ao agente míope monopolista, o qual investe como se não houvesse concorrentes. Essa coincidência no preço de entrada, em que o gatilho é igual para o míope e para o agente que considera a concorrência, ainda que os prêmios dos operadores nas suas funções lucro sejam distintos, é conhecida como Miopia de Leahy. Dixit e Pindyck (1994, Cap. 9) e Huisman e Kort (1999) apresentam um modelo de duopólio simétrico e com uma incerteza de demanda, tendo uma opção de expansão na produção do produto. O modelo resulta na entrada (expansão) da empresa líder no ponto de indiferença de valor entre a líder e a seguidora, levando a empresa seguidora a entrar no ótimo monopolista. Esse tipo de jogo tem um claro efeito de preempção de um dos agentes.

Dias e Teixeira (2010) trabalham com o mesmo problema acima, mas com a assimetria de custos entre as duas empresas. Nesse caso, a empresa líder de baixo custo não precisa exercer no ponto de indiferença, pois não há ameaça de preempção, já que nesse estado da natureza a empresa de alto custo não tem a atração financeira por expandir. Acontece que a ameaça de preempção é em função dos seus custos e caso estes sejam baixos, com vantagens comparativas elevadas em relação a outra empresa, seu exercício pode ser como de um agente monopolista, ignorando a rival.

Com os agentes interagindo, os projetos das empresas podem não estar deep-in-the-money, mas mesmo assim serem exercidos, ou seja, podem estar abaixo do ótimo do exercício da opção de investir e mesmo assim darem início aos projetos. Além do mais, como indica Grenadier (2000), a depender da competição, esse efeito pode até reduzir o prêmio de espera para zero. Nesse contexto, Grenadier (1996) apresenta um modelo em que novos empreendimen- 
tos imobiliários são construídos mesmo em momentos de queda na demanda, essencialmente devido ao efeito da preempção, por reflexo da competição e da incerteza de demanda.

A competição na exploração de petróleo pós-leilão é melhor analisada pelo ponto de vista das externalidades positivas. Nesse caso, a ação do outro agente e a divulgação da informação sobre a variável técnica para o mercado geram um benefício àquele que entra por último. Nesta dissertação, a ação entrar por último significa investir no poço exploratório após a divulgação obrigatória da informação pela empresa vizinha do resultado do investimento exploratório. A externalidade positiva existe, pois a informação afeta a variável técnica FC das oportunidades exploratórias correlacionadas e posiciona o investidor seguidor com mais informação. Esse efeito de externalidade positiva também ocorre em duopólios de mercado declinante, modelo apresentado por Ghemawat e Nalebuff (1985), no qual quem abandona por último tem vantagens advindas da fatia de mercado deixada pela empresa líder, sendo esta a primeira a sair do mercado.

No modelo de Hendricks, Weiss e Wilson (1988) usado em exploração de petróleo, a seguidora tem vantagem na ação posterior, ou seja, prefere aguardar por informações advindas da concorrente para tomar a decisão de perfuração no seu bloco exploratório. Dias e Teixeira (2009) apresentam um modelo com incerteza de preços, em que a seguidora obtém vantagem informacional advinda da ação da empresa líder. Desse modo, a informação sobre a variável técnica é o sucesso ou o fracasso do poço pioneiro e o ótimo da seguidora é em função dessa revelação da informação. Como já citado, o modelo usado nesta dissertação é baseado nesse trabalho.

Em especial, os modelos em TJ+OR são analisados pelo equilíbrio markoviano (EPM). Os jogos que possuem uma variável estocástica e que sua história pretérita não é relevante para o estado corrente, além dos estágios seguintes do jogo influenciarem o atual estado, devem ser analisados pelo Equilíbrio de Markov (KAPUR, 1995; MASKIN; TIROLE, 1988). Isso quer dizer que o EPM depende somente do estado corrente da variável. Como definição, o jogo é mapeado pelo conjunto de todos os estados possíveis para o conjunto de ações viáveis. Assim, o que é relevante é o momento da estratégia e o número de jogadores ativos. Dessa forma, se torna coincidente o estágio com o intervalo do tempo, representando cada estágio um subjogo. Portanto, o Equilíbrio Perfeito Markoviano (EPM) também é um Equilíbrio de Nash Perfeito em Subjogos (ENPS), sendo o EPM mais abrangente que o conceito de ENPS. 


\section{3 \\ Modelagem Matemática}

A situação estudada nesta pesquisa é de dois blocos exploratórios vizinhos, com o mesmo período de contrato e sem poço pioneiro obrigatório. Serão valorados até três prospectos em diversas combinações. Cada modelo considera 11 variáveis endógenas e exógenas. Este capítulo tem o objetivo de explicar as variáveis e suas relações em cada modelo.

\section{1}

\section{Apresentação das variáveis}

Os ativos exploratórios possuem as variáveis internas, apresentadas como endógenas e as variáveis externas, apresentadas como exógenas. As endógenas são próprias e vinculadas aos projetos. São elas: o volume recuperável de óleo, a qualidade da reserva, o fator de chance e a correlação entre os ativos. Já as exógenas são relacionadas às variáveis de mercado, como a taxa de juros, os hiperparâmetros do preço do petróleo e o período do contrato exploratório. No entanto, os investimentos são em função tanto das variáveis endógenas quanto das exógenas. Todas foram elencadas abaixo, sendo $n$ o número de oportunidades:

Endógenos:

- $B[1: n]$ - Volume Recuperável (bbl)

- $q[1: n]$ - Qualidade da Reserva (\%)

- FC[1:n] - Fator de Chance dos prospectos (\%)

- $\rho[n \times n]$ - Matriz de correlação dos prospectos (\%)

- dummy $[1: n]$ - Dummy de propriedade $(0 \vee 1)$

Exógenos:

- P( $\alpha, \sigma)$ - hiperparâmetros do Preço do petróleo (\%a.a., \%a.a.)

- $\delta$ - taxa de conveniência (\%a.a.)

- $r$ - Taxa livre de risco (\%a.a.)

- $\tau$ - Tempo do contrato exploratório - comum em todos os blocos (anos) 
E investimentos:

- $I_{w}[1: n]$ - Investimento no poço pioneiro $(\mathrm{M} \$)$

- $I_{d}(B)[1: n]$ - Investimento em desenvolvimento - função do Volume Recuperável $(\mathrm{M} \$)$

\section{2}

\section{Modelo Paramétrico - VPL e VME}

Os projetos de investimento possuem diversas incertezas. Em projetos de óleo e gás, o principal fator de incerteza é o preço de venda do hidrocarboneto (P). Esse está inserido dentro do fluxo de caixa operacional, aqui denominado de valor do projeto $(\mathrm{V})$. Como este trabalho trata da incerteza geológica na etapa inicial da exploração, a outra variável incerta considerada é o fator de sucesso de descoberta (FC). Esse parâmetro pondera tanto o valor do projeto do campo de petróleo quanto o investimento na produção $\left(I_{d}\right)$ e é revelado/compreendido com o exercício do investimento exploratório $\left(I_{w}\right)$. Todos os outros parâmetros que compõem o fluxo de caixa são valores esperados e não se alteram durante o contrato exploratório ou pela informação revelada na perfuração do poço pioneiro.

A relação linear entre o valor do projeto e o preço do ativo base é adotada em alguns trabalhos (DIXIT; PINDYCK, 1994, Cap.12, p.399; PADDOCK; SIEGEL; SMITH, 1988). O modelo paramétrico (business model) considera linear a relação do preço do petróleo com o valor das receitas líquidas dos custos operacionais em tempo presente (DIAS, 2004):

$$
V=q B P
$$

Sendo, $q$ a qualidade econômica da reserva, $B$ o volume recuperável da reserva e $P$ o preço do barril de petróleo. A qualidade econômica é um fator de desconto da reserva, com valor entre $[0,1]$. Esse parâmetro sintetiza as características próprias de cada reserva, como a qualidade do óleo, a viscosidade, a permeabilidade e a capacidade tecnológica de produção, além de fatores econômicos como o regime fiscal, os custos operacionais e a taxa de desconto. A equação linear é útil, pois o resultado é próximo de modelos completos de fluxo de caixa e é um facilitador de cálculo. Porém, em regimes de partilha, a aproximação linear não é adequada, visto que a transferência para o governo é distinta na fase inicial e final de produção e altera o valor das receitas líquidas (DIAS, 2002), sendo necessário um outro modelo. 
Diferentemente de Paddock, Siegel e Smith (1988), o valor desta equação não é unitária por reserva desenvolvida. Mas de forma análoga, os parâmetros multiplicativos determinísticos $q$ e $B$ da equação do valor do projeto (equação 3-1) não alteram a dinâmica estocástica (equação 3-6), se mantendo com os termos e modelo da difusão de preços, como pode ser visto na demonstração a seguir. Sendo o preço um Movimento Geométrico Browniano (MGB) como a equação abaixo, temos:

$$
d P=\alpha P d t+\sigma P d z
$$

Em que $\alpha$ é o termo de tendência do MGB, conhecido como drift do processo, $\sigma$ o termo de volatilidade que multiplica o incremento de Wiener, o qual $d z \sim N(0, d t)$. Como $\mathrm{V}$ é uma função de $\mathrm{P}$ igual à equação (3-1), então $\frac{\partial V}{\partial t}=0, \frac{\partial V}{\partial P}=q B$ e $\frac{\partial^{2} V}{\partial P^{2}}=0$. Assim, pela fórmula de Itô-Doeblin:

$$
d V=\frac{\partial V}{\partial t} d t+\frac{\partial V}{\partial P} d P+\frac{1}{2} \frac{\partial^{2} V}{\partial P^{2}} d[P, P]
$$

Sendo $d[P, P]$ a variação quadrática de P. Substituindo as derivadas:

$$
d V=q B d P
$$

Substituindo a equação estocástica dos preços (equação 3-2 em 3-4):

$$
d V=q B[\alpha P d t+\sigma P d z]
$$

E organizando a equação:

$$
d V=\alpha V d t+\sigma V d z
$$

Isso quer dizer que o projeto $V$ possui dinâmica similar ao ativo base $P$, em que o $V$ também segue um processo MGB com os mesmos hiperparâmetros de $P$, ou seja, com o drift $(\alpha)$ e a difusão $(\sigma)$ do preço do barril de petróleo.

O Valor Monetário Esperado (VME) é uma medida ponderada do Valor Presente Líquido (VPL) pelo fator de chance do projeto (FC). Essa medida de 
valor é amplamente aceita em projetos exploratórios (FAÚNDEZ et al., 2020; DIAS, 2004; ROSE, 1999, Cap. 3). Então:

$$
V M E=F C\left(V-I_{d}\right)-I_{w}
$$

Onde, $I_{d}$ é o investimento no desenvolvimento do campo de petróleo a valor presente, em que $V-I_{d}$ é o VPL do projeto. O investimento inicial é o poço pioneiro $I_{w}$, também podendo ser visto como o custo de obter a informação de existência de hidrocarboneto. O fator de chance (FC) é uma variável de incerteza técnica, apresentada com mais detalhes na seção (3.4). Ademais, assim como demonstrado nas equações (3-3 a 3-6), o termo $F C \cdot V$ da equação (3-7) possui o mesmo drift $(\alpha)$ e difusão $(\sigma)$ que o preço do petróleo $(P)$.

O investimento em desenvolvimento é a valor presente e pode ser em função do preço do ativo base e do volume recuperável (B). Aqui se optou por modelar em função do volume da reserva, similar a Dias (2006) e Dias e Teixeira (2009). Dessa forma, o investimento é uma função linear do volume recuperável, sendo o investimento marginal $k_{v}$ e o investimento fixo $k_{f}$. As justificativas da adoção desse modelo são apresentadas na seção (4.1.2).

$$
I_{d}(B)=k_{f}+k_{v} B
$$

Por último, o parâmetro de qualidade $(q)$ pode ser extraído a partir do fluxo de caixa descontado do projeto, pela derivação do VPL em relação à variável $P$, ou seja:

$$
q=\frac{\partial V P L}{\partial P} \frac{1}{B}
$$

\section{3}

\section{Incerteza de Preços}

A variável preço é a mais importante na construção do fluxo de caixa. Devido às incertezas sobre a oferta e a demanda em todo o tempo $(t)$, os preços dos produtos apresentam oscilações. Por vezes, possuem uma tendência de longo prazo, podendo ser ascendente ou, por exemplo, reverter a um valor médio de equilíbrio entre a oferta e a demanda de longo prazo, sendo particular para cada bem. O processo estocástico é uma forma usual de 
modelar os ativos com esses comportamentos. Assim, o processo estocástico é uma família, ou uma série de sequências de variáveis aleatórias, definido num espaço de probabilidade, o qual depende do espaço amostral, a sua filtração e a probabilidade dos eventos $(\Omega, \mathcal{F}, \mathcal{P})$. Esse processo, denominado nesta seção por $S_{t}$, é indexado a um domínio, sendo comum em finanças os ativos serem indexados ao tempo $(t)$.

O ativo $S_{t}$ pode ser modelado como um processo browniano padrão $(d z)$, que carrega a difusão estocástica das séries, ponderado por uma medida de desvio $\sigma$ e somado a um termo de incremento temporal multiplicado pela tendência, conhecida como drift $(\alpha)$. Esse processo estocástico é o Movimento Geométrico Browniano (MGB), modelo mais comum em finanças. O MGB apresenta diversas vantagens: $i$ ) aderência a muitos dados históricos de preços; ii) probabilidade zero de $S_{t}$ ser negativo, da mesma forma que os preços dos ativos negociados em mercado e iii) solução fechada da equação diferencial estocástica. Com esse modelo, Black e Scholes (1973) basearam a solução analítica da opção europeia de compra. Assim sendo, o modelo MGB pode ser visto na equação (3-10):

$$
d S_{t}=\alpha S_{t} d t+\sigma S_{t} d z
$$

Essa dinâmica pode representar os preços dos ativos de mercado, como as ações em bolsa de valores ou o preço spot de tipos de óleo por barril, como o óleo tipo WTI . Em ações, os dividendos $(\delta)$ são pagos para o detentor e a dinâmica de preços de tendência $\mu$ possui um desconto do dividendo, sendo $\alpha=\mu-\delta$. Esse comportamento também acontece em relação ao preço spot do óleo, mas esse desconto em ativos físicos é conhecido como a taxa de conveniência, também simbolizada por $\delta$. A taxa de conveniência é o benefício do proprietário do produto em detê-lo em relação ao detentor da posição comprada no mercado futuro. Esse benefício tem relação com a segurança de possuir fisicamente a commodity dado o risco de escassez. Essa taxa $(\delta)$ é uma variável não observada e pode ser estimada em contratos futuros, como foi feito neste trabalho.

A solução da equação diferencial (3-10) é dada pela transformação de $S_{t}$ e a aplicação da fórmula de Itô-Doeblin (ver Dixit e Pindyck, 1994, Cap.3, para mais detalhes). Considere $Y(S):=\ln S$, então $\frac{\partial Y}{\partial S}=\frac{1}{S}, \frac{\partial^{2} Y}{\partial S^{2}}=-\frac{1}{S^{2}}$ e a dinâmica de $Y$ é: 


$$
\begin{aligned}
d Y & =\frac{1}{S} d S-\frac{1}{2} \frac{1}{S^{2}} d[S, S](t) \\
& =(\mu-\delta) d t+\sigma d z-\frac{1}{2} \sigma^{2} d t \\
& =\left(\mu-\delta-\frac{1}{2} \sigma^{2}\right) d t+\sigma d z
\end{aligned}
$$

Integrando os dois lados da equação entre t e T:

$$
\ln S_{T}-\ln S_{t}=\left(\mu-\delta-\frac{1}{2} \sigma^{2}\right)(T-t)+\sigma z_{T-t}
$$

Sendo $z_{T-t} \sim N(0,1) \sqrt{T-t}$, a solução de $S_{T}$ dada a filtração em t é:

$$
S_{T}=S_{t} e^{\left(\mu-\delta-\frac{1}{2} \sigma^{2}\right)(T-t)+\sigma z_{T-t}}
$$

Com a solução (3-11), é possível calcular a média dada a filtração em t:

$$
\begin{aligned}
\mathbb{E}\left[S_{T} \mid \mathcal{F}_{t}\right] & \left.=\mathbb{E}\left[S_{t} e^{\left(\mu-\delta-\frac{1}{2} \sigma^{2}\right)(T-t)+\sigma\left(z_{T}-z_{t}\right.}\right) \mid \mathcal{F}_{t}\right] \\
& =S_{t} e^{\left(\mu-\delta-\frac{1}{2} \sigma^{2}\right)(T-t)} \mathbb{E}\left[e^{\sigma\left(z_{T}-z_{t}\right)} \mid \mathcal{F}_{t}\right] \\
& =S_{t} e^{\left(\mu-\delta-\frac{1}{2} \sigma^{2}\right)(T-t)} \mathbb{E}\left[e^{\sigma z_{T-t}}\right] \\
& =S_{t} e^{\left(\mu-\delta-\frac{1}{2} \sigma^{2}\right)(T-t)} e^{\frac{1}{2} \sigma^{2}(T-t)}
\end{aligned}
$$

Ou seja:

$$
\mathbb{E}\left[S_{T} \mid \mathcal{F}_{t}\right]=S_{t} e^{(\mu-\delta)(T-t)}
$$

Sendo a variância igual a $\operatorname{Var}[X]=E\left[X^{2}\right]-E[X]^{2}$, o cálculo de $E\left[X^{2}\right]$ é: 


$$
\begin{aligned}
\mathbb{E}\left[S_{T}^{2} \mid \mathcal{F}_{t}\right] & =\mathbb{E}\left[S_{t}^{2} e^{\left.2\left(\mu-\delta-\frac{1}{2} \sigma^{2}\right)(T-t)+2 \sigma\left(z_{T}-z_{t}\right) \mid \mathcal{F}_{t}\right]}\right. \\
& =S_{t}^{2} e^{2\left(\mu-\delta-\frac{1}{2} \sigma^{2}\right)(T-t)} \mathbb{E}\left[e^{2 \sigma\left(z_{T}-z_{t}\right)} \mid \mathcal{F}_{t}\right] \\
& =S_{t}^{2} e^{2\left(\mu-\delta-\frac{1}{2} \sigma^{2}\right)(T-t)} \mathbb{E}\left[e^{2 \sigma z_{T-t}}\right] \\
& =S_{t}^{2} e^{2\left(\mu-\delta-\frac{1}{2} \sigma^{2}\right)(T-t)} e^{2 \sigma^{2}(T-t)} \\
\mathbb{E}\left[S_{T}^{2} \mid \mathcal{F}_{t}\right] & =S_{t}^{2} e^{2\left(\mu-\delta+\frac{1}{2} \sigma^{2}\right)(T-t)}
\end{aligned}
$$

Assim, a variância dada a filtração em t é:

$$
\begin{aligned}
\operatorname{Var}\left[S_{T} \mid \mathcal{F}_{t}\right] & =\mathbb{E}\left[S_{T}^{2} \mid \mathcal{F}_{t}\right]-\mathbb{E}\left[S_{T} \mid \mathcal{F}_{t}\right]^{2} \\
& =S_{t}^{2} e^{2(\mu-\delta)(T-t)} e^{\sigma^{2}(T-t)}-S_{t}^{2} e^{2(\mu-\delta)(T-t)}
\end{aligned}
$$

Portanto:

$$
\operatorname{Var}\left[S_{T} \mid \mathcal{F}_{t}\right]=S_{t}^{2} e^{2(\mu-\delta)(T-t)}\left(e^{\sigma^{2}(T-t)}-1\right)
$$

Caso $\mu$ seja maior que $\delta$, a média é crescente ao longo do tempo e se $T \rightarrow \infty$, a variância também tende ao infinito quando $\sigma$ é diferente de zero. A propriedade da variância do MGB é desejável, visto que o tempo $t+\Delta t$ é mais incerto que o tempo $t$. Sobre a média desse processo, diversos estudos apontam um preço de equilíbrio de longo prazo em commodities, pois os preços se acomodam por forças de demanda e de oferta do produto, algo que não acontecesse nesse modelo. Dessa forma, desenvolveram modelos mais aderentes a esses tipos de ativos, como os modelos com dois e três fatores com reversões de curto e/ou de longo prazo (SCHWARTZ, 1997; SCHWARTZ; SMITH, 2000; CORTAZAR; SCHWARTZ, 2003; AIUBE; SAMANEZ, 2014).

Caso $\mu$ seja menor que $\delta$, temos uma média decrescente e se $T \rightarrow \infty$, a média tende para zero. Esse efeito ocorre em longo prazo (70 anos?), tornando aceitável o modelo com essa relação para o apreçamento financeiro de ativos reais. Contudo, a diferença $\mu-\delta$ não pode ser menor que $-\frac{1}{2} \sigma^{2}$, pois torna a variância decrescente a partir de um certo horizonte $t^{*}$, algo não desejável. Essa conclusão pode ser obtida com a derivação em relação ao tempo da equação (3-13), igualando a zero e analisando o tempo $t$ no ponto de máximo. Caso exista a relação $\mu-\delta<-\frac{1}{2} \sigma^{2}$, o estudo (opções, simulação, etc...) deve ser feito com o horizonte de tempo até o $t^{*}$ de variância máxima, evitando a variância decrescente.

Para a apresentação dos conceitos de opções e de mercado futuro, é 
necessário o conceito de mudança de medida. Sejam duas medidas, $P$ em $(\Omega, \mathcal{F})$ e $Q$ em $(\Omega, \mathcal{F})$, sendo que para todo $A \in \mathcal{F}, P(A)=0$, então $Q(A)=0$, além das duas medidas de probabilidade serem absolutamente contínuas $(Q<<P)$.

Assim, dada a hipótese de continuidade, existe uma variável aleatória não negativa $\nu$ que relaciona essas duas medidas (relaciona as densidades de probabilidade). Essa variável é conhecida como a derivada de Radon-Nikodym. Em processos estocásticos, essa conversão de medida do processo é enunciada pelo teorema de Girsanov, que adota a derivada de Radon-Nikodym.

Seja o processo estocástico em medida real $(\Omega, \mathcal{F}, P)$ apresentado pela equação abaixo:

$$
d S_{t}=(\mu-\delta) S_{t} d t+\sigma S_{t} d z
$$

define-se o incremento de Wiener em medida martingal:

$$
d \tilde{z}=\theta d t+d z
$$

e a derivada Radon-Nikodym:

$$
\nu=\exp \left[-\theta z-\frac{1}{2} \theta^{2} t\right]
$$

Onde, $d \tilde{z}$ é igual ao incremento de Wiener sob a medida equivalente $Q$, o preço do prêmio de risco é igual a $\theta=\frac{\mu-r}{\sigma}$, em que o prêmio de risco é $\pi=\mu-r$. Com isso, o processo estocástico (equação 3-14), em medida martingal equivalente $(\Omega, \mathcal{F}, Q)$ é:

$$
\begin{gathered}
d S_{t}=(\mu-\delta) S_{t} d t+\sigma S_{t}(-\theta d t+d \tilde{z}) \\
=(\mu-\delta) S_{t} d t+-(\mu-r) S_{t} d t+\sigma S_{t} d \tilde{z} \\
d S_{t}=(r-\delta) S_{t} d t+\sigma S_{t} d \tilde{z}
\end{gathered}
$$

Ou seja, há um desconto no processo pelo prêmio de risco (pois $r$ $\delta=\alpha-\pi)$, sendo que esse processo, em medida neutra ao risco, tem a média relacionada a taxa livre de risco (em tempo contínuo - $e^{r t}$ ) líquida do dividendo/taxa de conveniência. Sob a medida equivalente $Q$, a variância (ou a matriz de covariância em caso de processo estocástico multivariado) é igual 
à variância sob a medida real. A vantagem de trabalhar com essa medida é que o ativo $S_{t}$ e qualquer derivativo desse ativo base - $F\left(S_{t}\right)$, em medida martingal equivalente, pode ser descontado pela taxa livre de risco em análises de apreçamento de ativos. Esse artifício facilita a análise de opções, pois nesse derivativo a taxa de desconto ponderada ao risco não é útil, pois ela altera ao longo do tempo e é maior em opções de compra comparada com a taxa livre de risco e menor em opções de venda.

Isso quer dizer que a esperança do ativo base (ou do seu derivativo) sob a medida equivalente $Q$, descontada pela taxa livre de risco $\left(D_{T, t}=e^{-r(T-t)}\right)$ é um martingal $\left(D_{T, t} \mathbb{E}^{\mathbb{Q}}\left[S_{T} \mid \mathcal{F}_{t}\right]=S_{t}\right)$, por essa razão também chamada de medida martingal equivalente. Esse raciocínio é essencial para o apreçamento de opções. Por exemplo, seja uma opção de compra europeia com strike $K$, com vencimento em $T$ e em um tempo $t$, a opção vale:

$$
\begin{aligned}
c_{t} & =e^{-r(T-t)} \mathbb{E}^{\mathbb{Q}}\left[c_{T} \mid \mathcal{F}_{t}\right] \\
& =e^{-r(T-t)} \mathbb{E}^{\mathbb{Q}}\left[\left(S_{T}-K\right)^{+} \mid \mathcal{F}_{t}\right]
\end{aligned}
$$

Sendo a simbologia $(.)^{+}$a função máximo entre o resultado e zero.

O estudo dos preços futuros é importante para a estimação dos parâmetros do preço spot. No caso de commodity, o mercado futuro é bem desenvolvido e há diversos contratos com diferentes vencimentos de um mesmo ativo físico. A estimativa do preço spot é necessária em muitas commodities, visto que os contratos negociados em mercado são os contratos futuros, não o ativo de entrega imediata. Essa é a realidade do óleo tipo Brent ou WTI. Então, o preço do spot é desconhecido e estimado por diversos contratos do mercado futuro, sendo os parâmetros do preço spot relevantes para o apreçamento de OR.

A estrutura a termo dos preços futuros no tempo $t$ é definida como a esperança em medida martingal do preço do ativo base (spot) na data do término do contrato $(T)$, dadas as informações em $t$. Sendo a dinâmica do preço spot igual à equação diferencial estocástica (3-14), o mesmo processo em medida martingal será igual à equação (3-15) e a estrutura do preço futuro é igual à equação (3-17), com resolução bem parecida com a equação (3-12):

$$
F_{t, T}=\mathbb{E}^{\mathbb{Q}}\left[S_{T} \mid \mathcal{F}_{t}\right]=S_{t} e^{(r-\delta)(T-t)}
$$

Nesse modelo, o preço futuro é crescente no caso de $r-\delta>0$ em relação ao aumento de $T-t$ e decrescente no caso de $r-\delta<0$. Como a taxa livre de risco e a taxa de conveniência são parâmetros constantes, o modelo não capta 
a variação da estrutura a termo de contango para backwardation, ou vice e versa.

Como em Gibson e Schwartz (1990), considerando a taxa livre de risco constante, pode-se extrair em termos anuais a taxa de conveniência implícita $(\delta)$ por diferentes contratos futuros com diferença de $m$ meses, segundo a fórmula a seguir:

$$
\delta=r+\frac{12}{m} \ln \left[\frac{F_{t, T+m}}{F_{t, T}}\right]
$$

Agora, a dinâmica de difusão do preço futuro $\left(F_{t}\right)$ da equação (3-17) pode ser obtida pela fórmula de Itô-Doeblin. Sendo $\frac{\partial F}{\partial t}=-(r-\delta) F, \frac{\partial F}{\partial S}=e^{(r-\delta)(T-t)}=$ $\frac{F}{S}$ e $\frac{\partial^{2} F}{\partial S^{2}}=0$, e $d S$ em medida martingal, a difusão $d F$ é:

$$
\begin{aligned}
d F & =-(r-\delta) F d t+\frac{F}{S} d S \\
& =-(r-\delta) F d t+\frac{F}{S}[(r-\delta) S d t+\sigma S d \tilde{z}] \\
& =-(r-\delta) F d t++(r-\delta) F d t+\sigma F d \tilde{z} \\
\frac{d F}{F} & =\sigma d \tilde{z}
\end{aligned}
$$

Por isometria de Itô $\left(\mathbb{E}\left[\left(\int_{t}^{T} \sigma(u) d z_{u}\right)^{2}\right]=\mathbb{E}\left[\int_{t}^{T} \sigma^{2}(u) d u\right]\right.$, ver Aiube, 2013, p.117), a variância de $\frac{d F}{F}$ é igual a $\sigma^{2} d t$, portanto a volatilidade do retorno futuro $\left[\frac{1}{d t} \operatorname{Var}\left[\frac{d F}{F}\right]\right]^{1 / 2}$ é igual a $\sigma$. Isso quer dizer que a estrutura a termo da volatilidade é independente do prazo de vencimento do contrato $(T-t)$, sendo constante e igual à volatilidade do preço spot. Empiricamente, nos contratos futuros de petróleo e de muitas commodities, nota-se uma diminuição da volatilidade com o aumento do prazo do contrato. Por essa razão, foram desenvolvidos alguns modelos mais complexos como de dois e três fatores, tentando captar também esse efeito dos preços (SCHWARTZ, 1997; SCHWARTZ; SMITH, 2000; CORTAZAR; SCHWARTZ, 2003).

O Modelo MGB é um modelo de um fator $\left(S_{t}\right)$ e pode ser estimado pelo filtro de Kalman. Trata-se de um método recursivo, linear e de modelos gaussianos, com equações na forma de espaço-estado, com previsão e estimação das variáveis não observáveis. As equações de estado (3-20) e de transição (321) são apresentadas, segundo Harvey (1990, Cap. 3): 


$$
\begin{gathered}
y_{t}=Z_{t} \alpha_{t}+d_{t}+\epsilon_{t} \\
\alpha_{t}=T_{t} \alpha_{t-1}+c_{t}+R_{t} \eta_{t}
\end{gathered}
$$

O modelo discreto do MGB na forma de espaço-estado pode ser representado como as equações abaixo:

$$
\begin{aligned}
\ln F_{t+\Delta t} & =[1] \ln S_{t+\Delta t}+(r-\delta) \tau+\epsilon_{t} \\
\ln S_{t+\Delta t} & =[1] \ln S_{t}+\left(\mu-\delta-0.5 \sigma^{2}\right) \Delta t+\eta_{t}
\end{aligned}
$$

Sendo $\Delta t$ a discretização dos contratos futuros, $\tau$ o vencimento do contrato da variável medida, $\mathbb{E}\left[\epsilon_{t}\right]=0$ e $\operatorname{Var}\left[\epsilon_{t}\right]=H_{t}, \mathbb{E}\left[\eta_{t}\right]=0$ e $\operatorname{Var}\left[\eta_{t}\right]=Q_{t}$. A matriz $H_{t}$ precisa ser estimada, que é em função do número $n$ de contratos de entrada $\left(F_{1: n}-H_{t[n x n]}\right)$. Já a $\operatorname{Var}\left[\eta_{t}\right]$, no caso de um modelo MGB, é igual a $\sigma^{2} \Delta t$.

\section{4}

\section{Incerteza técnica - Fator de Chance}

Dentre as variáveis descritas nas equações (3-1 e 3-7), a qualidade econômica $(q)$, o volume recuperável $(B)$ e o fator de chance $(F C)$ são essencialmente características endógenas, dependentes da análise técnica e dos eventos de investimentos em conhecimento. Elas se diferenciam dos preços, justamente pois seus processos estocásticos são indexados aos eventos e não ao tempo, sendo que no caso aqui estudado o FC é associado ao evento de investimento do poço pioneiro $\left(I_{w}\right)$.

Os limites de atuação da atividade exploratória podem ser expandidos, mas basicamente a função principal é encontrar reservas. Assim sendo, o parâmetro volume recuperável após a perfuração do poço pioneiro continua incerto e essa incerteza é reduzida somente com os poços de delimitação. Por simplicidade, este trabalho considera que os investimentos de delimitação estão agregados em $I_{d}$. Ademais, o volume recuperável $B$ é um parâmetro médio estimado e não alterado pelo poço exploratório. Deve-se atentar ao caso de insucesso do poço exploratório, sendo que a revelação da informação indica que não existe reserva de petróleo, contudo, essa informação não altera a variável $B$, alterando de fato a variável $F C$ e levando-a para zero, portanto conduzindo para o valor econômico nulo.

As considerações acima sobre o volume recuperável valem também para a qualidade econômica da reserva (q). Esse parâmetro é uma simplificação 
e sumarização de outros parâmetros pertencentes no fluxo de caixa, incluindo até as características do reservatório (como por exemplo, a permo-porosidade), a taxa de desconto e o risco-país, com pouca redução de incertezas durante a campanha exploratória. Muitos dos parâmetros endógenos só são bem compreendidos no investimento de delimitação e na própria produção do hidrocarboneto.

Portanto, a incerteza técnica exploratória é representada na variável FC. O FC é uma medida de probabilidade subjetiva comum na exploração de recursos minerais, sobretudo na indústria de petróleo. Num modelo que considera outras empresas, o fator de chance de uma oportunidade pode ser afetado por investimento exploratório alheio ao seu portfólio, sendo, neste caso, uma medida de incerteza estratégica. Esse assunto será explicado na seção (3.5).

O FC é composto pela interseção das probabilidades independentes do sistema petrolífero. O sistema petrolífero pode ser definido de diversas maneiras, mas normalmente é expresso pelos seguintes fatores:

- Reservatório (R)

- Trapa $(\mathrm{T})$

- Selo

- Estrutura

- Geração (G)

- Migração (M)

- Sincronismo (S)

Reservatório - considera-se reservatório um espaço poroso e permeável que pode conter hidrocarboneto. A proposição da probabilidade subjetiva sobre a presença de reservatório vem do entendimento técnico do sistema deposicional na formação da rocha e as alterações ao longo do tempo geológico. Além da compreensão do sistema deposicional, um componente importante na análise da existência de um reservatório é o soterramento. Devido ao aumento da pressão e da temperatura pela carga litostática, a rocha reservatório começa a sofrer processos diagenéticos e quanto maior o soterramento, menor é o espaço poroso para ser preenchido pelo hidrocarboneto. Isso depende do tipo de depósito e das rochas na vizinhança (rochas encaixantes), relevantes na cimentação do espaço poroso. Como exemplo, no Brasil temos casos conhecidos de reservatórios, como os arenitos de Marlim e Roncador e os microbialitos do Pré-Sal. 
Trapa ou Armadilha- sem a existência de um trapeamento, o hidrocarboneto não se acumula. A compreensão da probabilidade subjetiva da trapa vem do entendimento dos especialistas em relação ao selo e à estrutura. $\mathrm{O}$ fator selo se refere à rocha encaixante, essencialmente as rochas acima e as laterais ao reservatório, que normalmente são folhelhos e evaporitos, sendo importante que essas rochas sejam pouco friáveis e resistam às pressões em armazenar o hidrocarboneto na rocha reservatório. A estrutura é parte importante no trapeamento, sendo a curvatura espacial (concavidade) necessária para o acúmulo. Ainda que haja contatos laterais estratigráficos, sempre há componentes estruturais na determinação da reserva. No fator estrutural, a atenção dos especialistas vai desde às falhas geológicas e aos dobramentos locais até os regimes de esforços regionais para qualificar melhor o trapeamento. Novamente, o componente soterramento é importante na definição dessa probabilidade subjetiva, em especial no selo, pois quanto menor o soterramento das rochas encaixantes, estas são menos resistentes às pressões internas do reservatório com fluído e consequentemente, pior é a trapa.

Geradora - para haver um reservatório de hidrocarboneto, deve haver rochas que geram petróleo. Algumas rochas têm maior potencial geradora que outras, sendo fundamentalmente os folhelhos ricos em matéria orgânica os grandes geradores de petróleo. A concentração da matéria orgânica pode ter relação com eventos globais de subsidência de bacias e/ou movimentos eustáticos, ou eventos locais da bacia estudada. Essa diferenciação entre o global e o local é essencial para a avaliação subjetiva da probabilidade de geração. Novamente, o soterramento também é um fator importante para a rocha geradora. Igualmente, a razão tem relação com a carga litostática sobre a rocha geradora, pois a geração e a expulsão do hidrocarboneto dependem da história de pressão e de temperatura que esta sofreu.

Migração - Esse parâmetro relaciona dois pontos no espaço, sendo a conexão entre a possível rocha geradora com a possível rocha reservatório. Estuda-se os prováveis caminhos de migração do hidrocarboneto da rocha geradora até a acumulação. Para isso, mapeia-se as falhas geológicas, elabora-se a história de evolução estrutural da bacia, mapeia-se os possíveis níveis carreadores, além de gerar subprodutos dos mapas, como o estudo de geopressão para identificar regiões de expulsão do fluido.

Por fim, o sincronismo envolve a história geológica dos elementos do sistema petrolífero. Esse fator se relaciona com a compreensão total da for- 
mação da bacia onde se pretende prospectar. Assim, não adianta ter uma boa rocha reservatório se ela foi formada após o momento máximo de expulsão do hidrocarboneto da rocha geradora, ou por exemplo, um excelente trapeamento de uma rocha reservatório formado após o momento de máxima geração do petróleo.

Para cada fator descrito, os técnicos ponderam de 0 a 1 (ROSE, 2001, p.37). Na consolidação do fator de chance geológico, não há valores extremos, pois se o FC é zero, não há uma oportunidade exploratória e se for igual a 1, não é exploração. Observa-se pela descrição do sistema petrolífero que os componentes do FC não são totalmente independentes (STABELL et al., 2000), contudo, para não tornar tão complexo o exercício, decidiu-se relevar essa questão nesta pesquisa.

A equação do fator de chance geológico é apresentada abaixo:

$$
F C=\operatorname{prob}(R) \cdot \operatorname{prob}(T) \cdot \operatorname{prob}(G) \cdot \operatorname{prob}(M) \cdot \operatorname{prob}(S)
$$

Onde, $\operatorname{prob}(R)$ é a probabilidade de existir a rocha reservatório, $\operatorname{prob}(T)$ é a probabilidade do armazenamento do hidrocarboneto, $\operatorname{prob}(G)$ é a probabilidade da existência da rocha geradora, $\operatorname{prob}(M)$ é a probabilidade da migração de hidrocarboneto para o reservatório e $\operatorname{prob}(S)$ é a probabilidade de ocorrência de sincronismo do sistema petrolífero. Nesta dissertação será empregado somente o FC geológico consolidado, sem considerar a análise separada das probabilidades do sistema petrolífero.

Além do FC geológico, a indústria do petróleo considera o fator de chance recuperável, o comercial e o econômico (ROSE, 2001, Cap.3, p. 3141), antes mesmo da perfuração do poço pioneiro. Esses fatores de chance desacoplam e carregam as incertezas dos parâmetros $q, B$ e $P$. O fator de chance recuperável agrupa as incertezas em relação a permo-porosidade, as qualidades do óleo como a densidade e a viscosidade, as incertezas na aplicação de técnicas de explotação, todos representados originalmente no parâmetro $q$, além da própria delimitação do campo, derivada do parâmetro $B$. Contudo, só é possível reduzir essas incertezas com investimento em conhecimento em função de especificidades de cada projeto, como os testes de longa duração, as aquisições sísmicas $4 \mathrm{D}$, a aplicação de tecnologia para melhorar a recuperação do hidrocarboneto e outros. Sobre o fator de chance comercial, este envolve as incertezas na economicidade do campo de petróleo, sendo relacionadas principalmente com o tamanho da reserva $(B)$ e a incerteza de preços $(P)$. Este trabalho não pretende adotar esses conceitos de fatores de chance, visto 
que separam a incerteza de sua variável estocástica. Chama a atenção, em especial, o fator de chance comercial, pois agrega as incertezas advindas da estocasticidade dos preços. Pelo método de valoração de OR, as variáveis de mercado possuem um prêmio de risco. Devido a isso, com o ajuste da probabilidade pela medida martingal equivalente, é possível descontar a tempo presente esse ativo ou qualquer outro derivativo deste ativo base pela taxa livre de risco, sem o uso da taxa ajustada ao risco (vide seção 3.3). Em virtude disso, é conflituoso adotar a metodologia de fator de chance comercialeconômico em concomitância à valoração por OR, visto que o prêmio de risco já foi determinado e descontado do processo estocástico dos preços. Para mais discussões relacionadas ao tema de fator de chance, podem ser encontradas em Murtha (1995) e as questões sobre os fatores de chance e opções reais em Dias (2005a, p. 272).

A avaliação do FC é feita para cada oportunidade exploratória. Em um bloco exploratório, pode haver diversas oportunidades com características semelhantes devido à mesma gênese na formação da acumulação ou fatores similares do sistema petrolífero, ainda que em plays distintos. Algo que não é comum na indústria, mas é bem intuitivo na consolidação do portfólio exploratório pelo corpo técnico, é considerar a correlação $(\rho)$ entre as oportunidades. Essa análise deve ser feita dois a dois, correspondendo, portanto, a $\left(\begin{array}{l}n \\ 2\end{array}\right)$ avaliações, em que $n \geq 2$, sendo $n$ o número de oportunidades do portfólio. Como os limites possíveis para esse parâmetro, as estimativas de correlação de $100 \%$ são improváveis, pois cada oportunidade possui uma idiossincrasia na acumulação do bem mineral, além de impossíveis matematicamente em situação de probabilidades de sucesso distintas, tanto do FC consolidado, quanto dos fatores de risco independentes do sistema petrolífero. Por outro lado, casos com correlação de $0 \%$ são possíveis, visto que a evolução geológica da bacia pode colocar oportunidades próximas em regimes hidráulicos distintos. Neste estudo, as correlações negativas não são consideradas, pois é difícil supor um sentido geológico para valores menores que zero para essa medida, ainda que matematicamente sejam possíveis.

Murtha (1995) trata a dependência em um único poço exploratório de diversas zonas potenciais. Esse conceito se equivale a dependência de diferentes prospectos no caso de sobreposição, em particular, as sobreposições de objetivos com o mesmo potencial exploratório na zona de maior confiança de ocorrência, conhecida como P90 (percentil 90 na distribuição de probabilidade de ocorrência de hidrocarboneto, sendo uma distribuição acumulada decrescente). Os casos desta dissertação se assemelhariam a essa hipótese somente se todos os contornos das oportunidades estivessem sobrepostos e em diferen- 
tes soterramentos, sendo possível perfurar todas as zonas de maior confiança somente com um poço exploratório. Como será detalhado na seção (4.2.1), os prospectos dos casos aqui estudados não se sobrepõem. Na hipótese de sobreposição dos contornos dos P90 e um só poço exploratório, não há escolha ótima sequencial, pois um prospecto necessariamente seria perfurado antes do outro. Contudo, poderia haver uma parada ótima, caso as primeiras oportunidades não tivessem hidrocarboneto e devido à correlação dos prospectos, a probabilidade do último objetivo de ter petróleo seria baixa ou nula, interrompendo a perfuração antes desta zona de fraco potencial. Esse portfólio teria diferença na valoração comparado ao apresentado nesta dissertação, pois aqui o estudo considera a existência de otimização de perfuração sequencial pela escolha gerencial (escolha ótima) dada a incerteza dos preços e o valor da informação. Por outro lado, o portfólio com sobreposição possui custos exploratórios de perfuração menores. Assim, os estudos que comparam esses dois modelos são relevantes para a melhor gestão da carteira. De qualquer forma, a relação de dependência entre os prospectos é importante em qualquer caso e será apresentada em detalhes na próxima seção.

\subsection{1}

\section{Dependência - Função Bernoulli Bivariada}

Só existem dois possíveis resultados na perfuração de um poço exploratório de petróleo: a descoberta de hidrocarboneto ou o fracasso. Por essa razão, a distribuição binária de Bernoulli é usada na modelagem de ocorrência de hidrocarboneto, representada na variável FC. Além disso, o valor da informação é o valor em função de um investimento prévio e é obtido pela probabilidade de ocorrência dada a ocorrência de um outro evento, sendo aqui esse investimento prévio um outro poço exploratório. Como esse sinal também é binário, visto que esse poço também tinha o objetivo de verificar a existência ou não de hidrocarboneto em seu prospecto, a representação do aprendizado de uma oportunidade na outra é uma função Bernoulli bivariada.

Sejam dois prospectos: $\mathrm{X}$ e $\mathrm{Y}$, com respectivos fatores de chance, $F C_{X}$ e $F C_{Y}$. O sucesso será definido como a ocorrência do valor 1 e o insucesso como o valor 0 . A probabilidade de $\mathrm{X}$ ser sucesso e $\mathrm{Y}$ também ser sucesso é $F C_{11}$ $(=P(X=1, Y=1))$. Já a probabilidade de $\mathrm{X}$ ser fracasso e de $\mathrm{Y}$ também ser fracasso é $F C_{00}(=P(X=0, Y=0))$. As outras interseções podem ser vistas na tabela (3.1).

O objetivo é apresentar a correlação $\rho_{X Y}$ e as probabilidades condicionais $P(Y=1 \mid X=1)$ e $P(Y=1 \mid X=0)$. Uma melhor leitura dessas probabilidades é: dado que $\mathrm{X}$ foi sucesso, qual é o novo fator de chance de $\mathrm{Y}$ e dado que $\mathrm{X}$ foi 


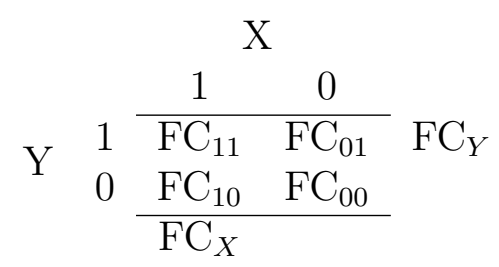

Tabela 3.1: FC e Aprendizado: Distribuição Bivariada de Bernoulli

fracasso, qual é o novo fator de chance de Y? Essas probabilidades condicionais representam o aprendizado dado o investimento em $\mathrm{X}$, ou seja, o quanto a revelação da informação X afeta $\mathrm{Y}$. Como a realização $\mathrm{X}$ condiciona o espaço amostral de $\mathrm{Y}$ e as perfurações ocorrem normalmente de forma sequencial, as análises dos ativos são mais adequadas quando são feitas por probabilidades condicionais, ou em termos de VOI, em função da medida de aprendizado. Como apresentado por Dias (2005a, p. 276), a correlação é uma boa medida de aprendizado de um ativo exploratório em relação a um investimento prévio em um outro ativo exploratório.

A esperança matemática é calculada por $\mathbb{E}[Z]=\sum_{i} z_{i} f\left(z_{i}\right)$, sendo $z_{i}$ os possíveis valores da variável aleatória $Z$ e $f\left(z_{i}\right)$ as suas probabilidades de ocorrência. Dessa forma, para a variável $X$, a esperança $(\mathbb{E}[X])$, a variância $(\operatorname{Var}[X])$ e o desvio padrão $\left(\sigma_{X}\right)$ são:

$$
\begin{gathered}
\mathbb{E}[X]=1 \cdot F C_{11}+1 \cdot F C_{10}+0 \cdot F C_{01}+0 \cdot F C_{00} \\
\mathbb{E}[X]=F C_{11}+F C_{10}=F C_{X} \\
\operatorname{Var}[X]=\mathbb{E}\left[X^{2}\right]-\mathbb{E}[X]^{2} \\
\mathbb{E}\left[X^{2}\right]=1^{2} \cdot F C_{11}+1^{2} \cdot F C_{10}+0^{2} \cdot F C_{01}+0^{2} \cdot F C_{00} \\
\mathbb{E}\left[X^{2}\right]=F C_{11}+F C_{10}=F C_{X}=\mathbb{E}[X] \\
\operatorname{Var}[X]=F C_{X}-F C_{X}^{2}=F C_{X}\left(1-F C_{X}\right) \\
\sigma_{X}=\sqrt{F C_{X}\left(1-F C_{X}\right)}
\end{gathered}
$$

De forma similar a $X$, os momentos da variável $Y$ são:

$$
\begin{gathered}
\mathbb{E}[Y]=1 \cdot F C_{11}+1 \cdot F C_{01}+0 \cdot F C_{10}+0 \cdot F C_{00} \\
\mathbb{E}[Y]=F C_{11}+F C_{01}=F C_{Y} \\
\mathbb{E}\left[Y^{2}\right]=F C_{11}+F C_{01}=F C_{Y}=\mathbb{E}[Y] \\
\operatorname{Var}[Y]=F C_{Y}-F C_{Y}^{2}=F C_{Y}\left(1-F C_{Y}\right)
\end{gathered}
$$




$$
\sigma_{Y}=\sqrt{F C_{Y}\left(1-F C_{Y}\right)}
$$

Para calcular a correlação, é necessária a covariância. Assim:

$$
\operatorname{Cov}(X, Y)=\mathbb{E}[X Y]-\mathbb{E}[X] \mathbb{E}[Y]
$$

Primeiro, calcula-se a $\mathbb{E}[X Y]$ :

$\mathbb{E}[X Y]=(1 \cdot 1) \cdot F C_{11}+(1 \cdot 0) \cdot F C_{10}+(0 \cdot 1) \cdot F C_{01}+(0 \cdot 0) \cdot F C_{00}=F C_{11}$

Então, a covariância é:

$$
\operatorname{Cov}(X, Y)=F C_{11}-F C_{X} F C_{Y}
$$

Portanto, a correlação é:

$$
\rho_{X Y}=\frac{\operatorname{Cov}(X, Y)}{\sigma_{x} \sigma_{Y}}=\frac{F C_{11}-F C_{X} F C_{Y}}{\sqrt{F C_{X}\left(1-F C_{X}\right) F C_{Y}\left(1-F C_{Y}\right)}}
$$

Pela probabilidade condicional, o $F C_{11}$ é:

$$
F C_{11}=P(X=1, Y=1)=P(Y=1 \mid X=1) P(X=1)=P(Y=1 \mid X=1) F C_{X}
$$

Substituindo a última equação em (3-24), a $P(Y=1 \mid X=1)$ é :

$$
P(Y=1 \mid X=1)=F C_{Y}+\frac{\sqrt{F C_{X}\left(1-F C_{X}\right) F C_{Y}\left(1-F C_{Y}\right)}}{F C_{X}} \rho_{X Y}
$$

Nota-se que a probabilidade condicional de sucesso de $\mathrm{Y}$ dado o sucesso de $\mathrm{X}$ é a soma de um grande termo com a probabilidade incondicional de $\mathrm{Y}$ $\left(F C_{Y}\right)$. Esse grande termo é proporcional à correlação $\left(\rho_{X Y}\right)$, além de ponderar a multiplicação dos desvios padrões de $\mathrm{X}$ e $\mathrm{Y}$ pelo sucesso incondicional de $\mathrm{X}$ $\left(F C_{X}\right)$.

Para obter a probabilidade condicional $P(Y=1 \mid X=0)$, deve-se lembrar que o $F C_{Y}=F C_{11}+F C_{01}$ e

$F C_{01}=P(X=0, Y=1)=P(Y=1 \mid X=0) P(X=0)=P(Y=1 \mid X=0)\left(1-F C_{X}\right)$

Substituindo na equação (3-24) o $F C_{11}$ em função de $F C_{Y}$ e de $F C_{01}$, além de aplicar a última equação para $F C_{01}$, a $P(Y=1 \mid X=0)$ é: 


$$
P(Y=1 \mid X=0)=F C_{Y}-\frac{\sqrt{F C_{X}\left(1-F C_{X}\right) F C_{Y}\left(1-F C_{Y}\right)}}{1-F C_{X}} \rho_{X Y}
$$

$\mathrm{Na}$ probabilidade condicional de sucesso de $\mathrm{Y}$ dado o fracasso de $\mathrm{X}$ se subtrai um grande termo da probabilidade incondicional de $\mathrm{Y}\left(F C_{Y}\right)$. Esse termo é proporcional à correlação $\left(\rho_{X Y}\right)$, tendo também a multiplicação dos desvios padrões de $\mathrm{X}$ e $\mathrm{Y}$, mas agora ponderada pelo fracasso incondicional de $\mathrm{X}\left(1-F C_{X}\right)$. Comparando a equação (3-25) com a equação (3-26), quanto maior a correlação entre X e Y, maior será a diferença entre as probabilidades condicionais de $\mathrm{Y}$ dado $\mathrm{X}$.

Essa formulação aplicada na exploração de petróleo em investimentos sequenciais é extremamente aderente à realidade. Dados dois prospectos, se são extremamente parecidos, ou seja, de alta correlação, e no caso do insucesso na descoberta de hidrocarboneto de um prospecto, o segundo terá uma grande probabilidade de fracasso e sendo um sucesso no primeiro, o segundo terá uma grande probabilidade de sucesso. Se a similaridade entre os prospectos for pequena, ou seja, a correlação for baixa entre os ativos, quase nada se altera no cálculo da probabilidade condicional comparada com a probabilidade incondicional de sucesso geológico (FC). Por essa razão, que a correlação é uma boa medida de aprendizado, sendo um aprendizado alto quando houver uma alta correlação e um baixo aprendizado na situação de uma baixa correlação entre os prospectos.

Dias e Calvette (2017), Dias (2005b) e Joe (1997, p. 210) apresentam os limites pela inequação Fréchet-Hoeffding, aqui em função de $F C_{11}$ e as probabilidades incondicionais $F C_{X}$ e $F C_{Y}$ :

$$
\max \left[0, F C_{X}+F C_{Y}-1\right] \leq F C_{11} \leq \min \left[F C_{X}, F C_{Y}\right]
$$

Esse intervalo deve ser respeitado, porém, a preocupação com os limites deve ser da equipe técnica que avalia os projetos. Na prática, deve-se estimar a correlação por uma avaliação subjetiva e verificar se pertence ou não aos limites. Caso não pertença, deve-se rever tanto os fatores de chance dos dois projetos quanto a correlação entre eles.

A seguir, é apresentado um estudo dessa medida de aprendizado. Propõese um exemplo simples, onde há 6 oportunidades sequenciais de investimentos, em que os FCs (incondicionais) de todas são iguais a $30 \%$ e as correlações dois a dois são de 50\%. O método de cálculo é similar ao binomial não recombinado, resultando no número de FCs condicionais de 32 casos para o 
sexto investimento $\left(=2^{n-1}\right)$. Verifica-se na tabela (3.2) que a média não se altera e o desvio padrão aumenta em cada evento revelado. Como o FC é um parâmetro do VME, não só o FC dispersa com o aumento do número de revelações (investimentos), mas também o VME quanto mais prospectos são perfurados. Em estratégia sequencial, esse efeito de manutenção da média e aumento da variância foram notados por Murtha (1995) e Smith e Thompson (2008).

\begin{tabular}{|c|c|c|c|}
\hline Investimentos & Média & Desvio Padrão & $\begin{array}{c}\text { Cenários } \\
\text { Condicionais de FC }\end{array}$ \\
\hline 1 & 0,3 & 0,0 & 1 \\
\hline 2 & 0,3 & 0,23 & 2 \\
\hline 3 & 0,3 & 0,30 & 4 \\
\hline 4 & 0,3 & 0,35 & 8 \\
\hline 5 & 0,3 & 0,38 & 16 \\
\hline 6 & 0,3 & 0,40 & 32 \\
\hline
\end{tabular}

Tabela 3.2: FC e Aprendizado: Exemplo de 6 poços sequenciais

Essas médias em cada evento de investimento podem ser explicadas pela lei das expectativas iteradas. Sendo X o primeiro poço e Y o segundo poço, além do sucesso ser 1 e o fracasso ser 0 , a média incondicional de Y é:

$$
\mathbb{E}[Y]=1 \cdot F C_{Y}+0 \cdot\left(1-F C_{Y}\right)=1 \cdot 30 \%+0 \cdot 70 \%=30 \%
$$

Já a média condicional de $\mathrm{Y}$ dado $\mathrm{X}=1$, sendo o $\left(F C_{Y} \mid X=1\right)$ pela equação (3-25):

$$
\mathbb{E}[Y \mid X=1]]=1 \cdot\left(F C_{Y} \mid X=1\right)+0 \cdot\left(1-F C_{Y} \mid X=1\right)
$$

E a média condicional de $\mathrm{Y}$ dado $\mathrm{X}=0$, sendo o $\left(F C_{Y} \mid X=0\right)$ pela equação (3-26):

$$
\mathbb{E}[Y \mid X=0]]=1 \cdot\left(F C_{Y} \mid X=0\right)+0 \cdot\left(1-F C_{Y} \mid X=0\right)
$$

Assim, a média incondicional das médias condicionais é:

$$
\begin{aligned}
\mathbb{E}[\mathbb{E}[Y \mid X]]=F C_{X} \cdot\left[1 \cdot\left(F C_{Y} \mid X=1\right)+0 \cdot\left(1-F C_{Y} \mid X=1\right)\right]+ \\
\left(1-F C_{X}\right) \cdot\left[1 \cdot\left(F C_{Y} \mid X=0\right)+0 \cdot\left(1-F C_{Y} \mid X=0\right)\right]
\end{aligned}
$$




$$
\begin{aligned}
\mathbb{E}[\mathbb{E}[Y \mid X]] & =30 \% \cdot[1 \cdot 65 \%+0 \cdot 35 \%]+70 \% \cdot[1 \cdot 15 \%+0 \cdot 85 \%] \\
& =30 \% \cdot 65 \%+70 \% \cdot 15 \%=30 \% \\
\mathbb{E}[\mathbb{E}[Y \mid X]] & =\mathbb{E}[Y]
\end{aligned}
$$

No caso em que as variáveis aleatórias são intercambiáveis $\left(F C_{X}=\right.$ $F C_{Y}$ ), o cálculo condicional (equações 3-25 e 3-26) pode ser simplificado:

$$
\begin{gathered}
P(Y=1 \mid X=1)=F C+(1-F C) \rho \\
P(Y \mid X=0)=F C(1-\rho)
\end{gathered}
$$

A figura (3.1) apresenta uma análise da distribuição de revelação dados cinco investimentos sequenciais, sendo este histograma referente à última linha da tabela (3.2). Como muita informação seria revelada até esse evento, expondo 32 possíveis cenários de FC para o último investimento, nota-se que a distribuição condicional do FC para o sexto prospecto é praticamente degenerada, concentrando altas probabilidades de fatores de chance próximas a zero e de $100 \%$. Esse efeito foi notado por Dias (2005a, figura 53, p.309) em uma modelagem similar a esta. Nessa etapa de investimento numa bacia, após cinco poços perfurados, não se deve ter muita dúvida geológica da existência ou não de hidrocarboneto. Esse é o efeito das informações reveladas pelos poços exploratórios de 1 a 5 . A partir das informações até este estado, um gestor decidiria investir em um prospecto que tivesse, por exemplo, a probabilidade de sucesso acima de $60 \%$, visto que o conhecimento na bacia após tantos investimentos é bem avançado. Outra forma seria uma decisão em função de um critério ótimo de valor, ou seja, os estados da natureza em que o VME condicional é maior que zero. Esse é o princípio da formulação da opção de aprendizado através de uma função máximo, sem aversão a risco, em que somente se otimiza valores monetários. Ademais, se forem considerados os prospectos com os FCs e as correlações distintas, pode acontecer que certos poços perfurados antes de outros apresentarem informações mais valiosas, ordenando uma sequência ótima de perfuração que maximiza o valor do portfólio. Acrescenta-se a esse problema a oscilação dos preços, podendo afetar a ordem da sequência ótima, ou até mesmo sugerindo aguardar e não investir, algo extremamente comum em exploração de petróleo. E caso essa informação seja revelada por um investimento no bloco vizinho, poderia se configurar uma 
guerra de atrito?

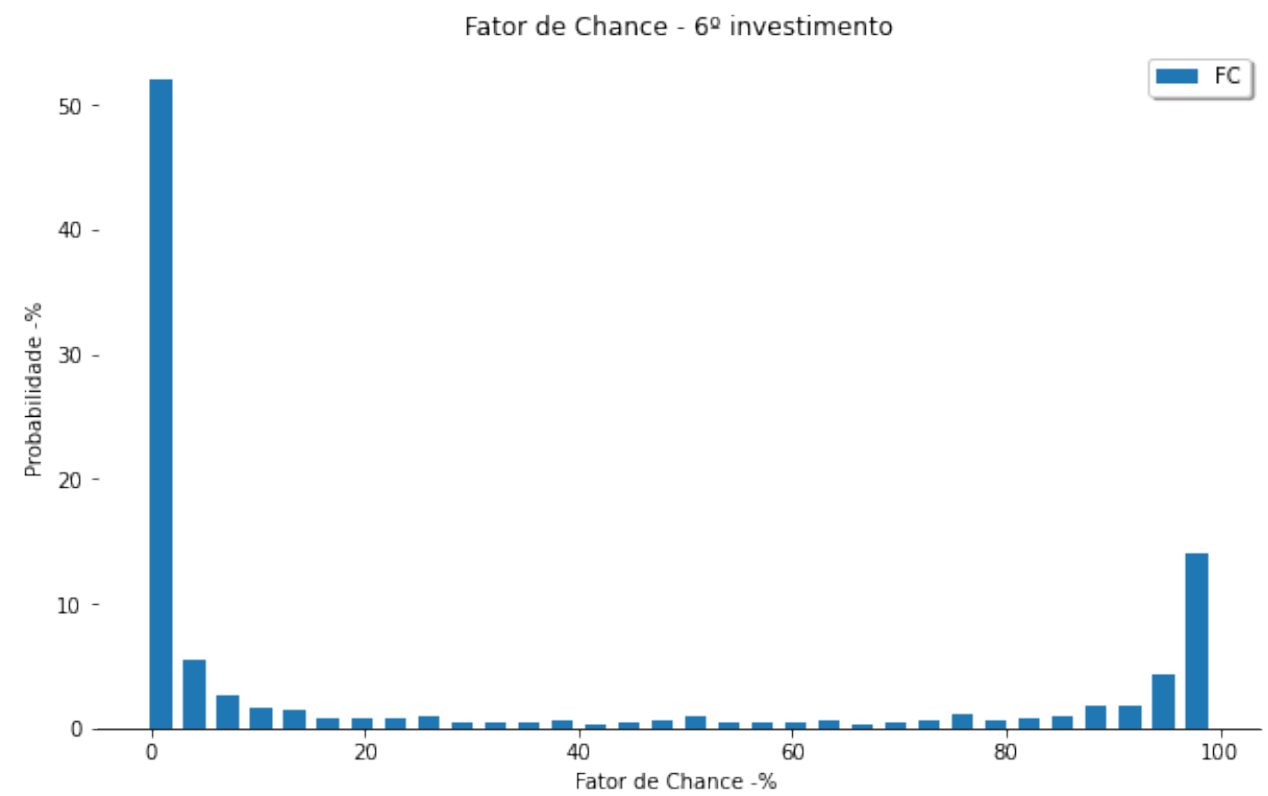

Figura 3.1: Revelação no sexto investimento - FC e Probabilidades

\section{5 \\ Incerteza estratégica}

A teoria das opções reais não adiciona a incerteza da ação de outros agentes ao ótimo de cada investidor. Já a "teoria dos jogos é o estudo de problemas de decisão por mais de um indivíduo" (GIBBONS, 1992, prefácio), sendo a forma correta de abordar a incerteza estratégica no estudo. Para incluir essa complexidade, ao final desta seção será apresentado um modelo discreto de TJ em uma situação recorrente na exploração de petróleo pós-leilão de blocos exploratórios, sendo os payoffs da matriz obtidos pela TOR. Essa intersecção de teorias, que combina a teoria dos jogos com a teoria das opções reais é denominada de option-games (CHEVALIER-ROIGNANT et al., 2011).

Nos próximos parágrafos serão apresentados um modelo básico de guerra de atrito em jogos dinâmicos, as suas implicações e algumas intuições. Depois são introduzidos os conceitos de jogos evolucionários, além da formulação do replicador dinâmico nos casos simétrico e assimétrico para a seleção do equilíbrio estável. Como a TOR considera as variáveis estocásticas nas análises de investimentos e essas valorações serão os payoffs dos jogos, são necessárias as delimitações dos conceitos de jogos markovianos e de equilíbrio perfeito markoviano. Por último, serão apresentados o jogo de guerra de atrito na exploração de petróleo e a divisão do prêmio para cada jogador na barganha cooperativa, conceitos baseados no modelo de Dias e Teixeira (2009). 
O primeiro jogo de guerra de atrito desta seção é um modelo simplificado, sendo um jogo dinâmico e repetido, de informação imperfeita e completa (GIBBONS, 1992, p.117-119), discreto e simétrico. Outros jogos com aspectos similares a esse são encontrados na literatura, normalmente denominados de hawk and dove game e chicken game.

No jogo de guerra de atrito, há uma disputa de dois jogadores por um recurso que vale $v$. As duas ações desse jogo são: a luta pelo recurso, apresentada como Escalada (E) ou o abandono do jogo, apresentada como Recuo (R). Caso ambos os agentes escalarem (E,E), o jogo continua ad infinitum, e para cada estado, ocorre um custo $c$ para cada jogador $(c<v)$ por manter a estratégia de escalada, sendo o custo acumulado crescente com a perpetuação da escalada. Caso um recue $((E, R)$ ou $(R, E))$, o que atacar recebe o recurso $v$ e o outro nada recebe, sendo que ambos os payoffs são descontados pelos custos acumulados da guerra ${ }^{1}$.

A melhor forma de analisar esse jogo é em estrutura de árvore e em duas etapas (figura 3.2). Os conceitos extraídos da simplificação do jogo em duas etapas podem ser facilmente levados à generalização do jogo infinito. Primeiro, a simbologia da linha pontilhada indica que os dois nós estão no mesmo conjunto de informações, sendo, por essa razão um jogo de informação imperfeita e isso representa que há ações simultâneas em cada passo. Nos parênteses são expostos os payoffs, sendo o primeiro valor representando a utilidade do primeiro jogador e o segundo valor, a utilidade do segundo jogador. Nessa árvore, caso ambos os agentes escalarem até o segundo momento, há um custo $c$ para os dois por ser uma situação terminal do modelo.

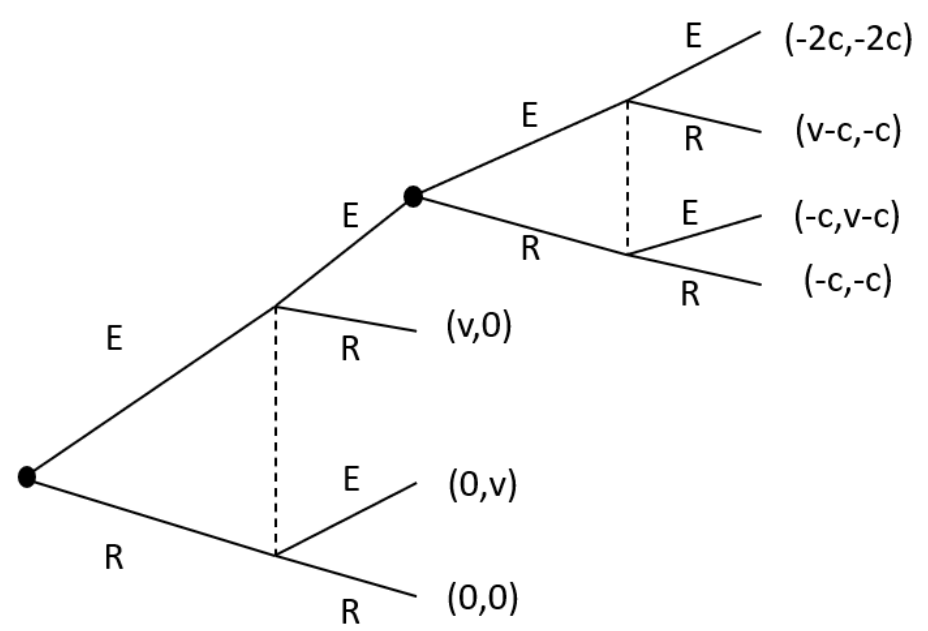

Figura 3.2: Jogo Dinâmico: Guerra de Atrito

\footnotetext{
${ }^{1}$ Esse modelo básico da guerra de atrito foi baseado em Bonatti (2015).
} 
O equilíbrio em jogos dinâmicos precisa ser equilíbrio perfeito em todos os subjogos (ENPS). Então, os dois subjogos são: [ $\left(E_{2}, E_{2}\right),\left(E_{2}, R_{2}\right),\left(R_{2}, E_{2}\right)$, $\left.\left(R_{2}, R_{2}\right)\right]$ e o jogo completo. O número subscrito em cada ação representa o momento da estratégia e a posição nos parênteses do par ordenado indica se a estratégia é do primeiro ou do segundo jogador, respectivamente. Por exemplo, o par de estratégias $\left(R_{2}, E_{2}\right)$ indica que no segundo momento o jogador 1 recuou, porém o jogador 2 escalou. Esse par de estratégias leva o payoff para o primeiro jogador de $-c$ e para o segundo $v-c$, representado pelo par ordenado $(-c, v-c)$.

O jogo deve ser analisado por indução retroativa (backward) começando pelo último momento, contudo, o jogador 2 no segundo momento não sabe em qual ramo está. Então, podemos representar esse "subjogo estático" na forma normal:

$$
\begin{array}{ccccc} 
& & & \multicolumn{2}{c}{\text { Jogador } 2} \\
& & & q & 1-q \\
& & & \text { Escala } & \text { Recua } \\
\text { Jogador } 1 & p & \text { Escala } & -2 c ;-2 c & v-c ;-c \\
& 1-p & \text { Recua } & -c ; v-c & -c ;-c
\end{array}
$$

Tabela 3.3: Subjogo 2 - Guerra de Atrito

A tabela (3.3) apresenta a forma normal desse subjogo, os payoffs, as ações e as probabilidades de cada ação para cada jogador, sendo $p$ a probabilidade do jogador 1 em escalar e $q$ a probabilidade do jogador 2 em escalar. Observa-se que há uma quantidade de custo $c$ igual em todos os payoffs. Essa quantidade $c$ é irrelevante no sentido estratégico neste estado, e por essa razão é considerada como um custo afundado pelos jogadores. Assim, é possível analisar esse momento de uma outra forma, como o subjogo da tabela (3.4):

$$
\begin{aligned}
& \text { Escala Recua } \\
& \begin{array}{ccc}
\text { Escala } & -\mathbf{c} ;-c & \underline{v} ; \underline{0} \\
\text { Recua } & -\mathbf{c}+\underline{v} & 0 ; 0
\end{array}
\end{aligned}
$$

Tabela 3.4: Subjogo 2 - Guerra de Atrito - Custo afundado

As linhas sublinhadas sob os payoffs indicam a melhor ação de cada jogador, assim, é possível observar dois equilíbrios puros no subjogo 2: $\left\{E_{2}, R_{2}\right\}$ e $\left\{R_{2}, E_{2}\right\}$. Há um terceiro equilíbrio neste subjogo, que será analisado depois.

No processo de indução retroativa, é necessário levar esses payoffs de continuação com o seu custo afundado para o primeiro momento e assim considerando o jogo como um todo. Primeiro, levando o equilíbrio $\left\{E_{2}, R_{2}\right\}$ para o par de estratégias $\left(E_{1}, E_{1}\right)$, os payoffs $(v, 0)$ precisam ser somados pelo 
custo afundando $-c$, portanto, o jogo completo pode ser representado na forma normal abaixo:

$$
\begin{array}{ccc} 
& \text { Escala } & \text { Recua } \\
\text { Escala } & \frac{v-c}{0} ;-c & \underline{v} ; \underline{0} \\
\text { Recua } & 0 \quad \underline{v} & 0 ; 0
\end{array}
$$

Tabela 3.5: Jogo Completo - Guerra de Atrito - $\left\{E_{2}, R_{2}\right\}$

Pela mesma lógica aplicada no equilíbrio anterior, no caso do equilíbrio puro $\left\{R_{2}, E_{2}\right\}$, o jogo completo é representado pela forma normal abaixo:

$\begin{array}{ccc} & \text { Escala } & \text { Recua } \\ \text { Escala } & -c ; \underline{v-c} & \underline{v} ; 0 \\ \text { Recua } & \underline{0} ; \quad \underline{v} & 0 ; 0\end{array}$

Tabela 3.6: Jogo Completo - Guerra de Atrito - $\left\{R_{2}, E_{2}\right\}$

Para o jogo da tabela (3.5), o equilíbrio é $\left\{E_{1}, R_{1}\right\}$, mas como o jogo é a representação do jogo todo (ver figura 3.2), o equilíbrio perfeito em subjogos (ENPS) é $\left\{E_{1}, E_{2} ; R_{1}, R_{2}\right\}$. A simbologia \{\} representa o equilíbrio, em que o subscrito numérico indica o momento e o símbolo ; separa as ações do primeiro e do segundo jogador. Dessa forma, neste jogo, o ENPS é dado pela ação de escalada do primeiro jogador no primeiro e no segundo momento e o recuo do segundo jogador nos dois momentos.

Agora, para o jogo da tabela (3.6), o equilíbrio é $\left\{R_{1}, E_{1}\right\}$, mas como a representação é o jogo completo, o ENPS é $\left\{R_{1}, R_{2} ; E_{1}, E_{2}\right\}$. Note que nos dois jogos das tabelas (3.5 e 3.6) não há estratégias $E_{1} ; E_{1}$ como equilíbrio, ou seja, no primeiro momento em nenhum equilíbrio apresentado, o primeiro e o segundo jogadores escalam juntos. Portanto, nesses ENPS, os jogos terminam sempre no primeiro momento e sem custo. Ou seja, no primeiro momento, caso o jogador saiba que o outro vai desistir, ele vai escalar quantos forem os estados e se for para recuar, deve-se recuar imediatamente para não ter o custo $c$.

Por vezes, de antemão, essa certeza sobre a ação não existe. Assim, será analisado novamente o subjogo da tabela (3.4) em busca do equilíbrio em estratégias mistas. Esse equilíbrio é a probabilidade de um jogador tomar uma ação em que o outro jogador esteja indiferente em qual ação tomar. Esse é um dos princípios da teoria dos jogos, ou seja, o conjunto de estratégias em que não há incentivo ao desvio de nenhum agente. Considerando a probabilidade do jogador 1 escalar igual a $p$, temos as utilidades do jogador 2 de escalar e recuar de: 


$$
\begin{aligned}
& U 2(E)=p^{*}(-c)+\left(1-p^{*}\right) v \\
& U 2(R)=p^{*} 0+\left(1-p^{*}\right) 0
\end{aligned}
$$

Igualando as duas utilidades devido à indiferença entre as ações destacadas no parágrafo anterior, chegamos em $p^{*}=\frac{v}{v+c}{ }^{2}$, sendo $0 \leq p^{*} \leq 1$. Como se trata de um jogo simétrico, a probabilidade do jogador 2 em escalar $q$, na qual deixa indiferente o jogador 1 em qual ação tomar também é igual a $q^{*}=\frac{v}{v+c}$. Isso quer dizer que quanto maior o prêmio $v$, maior é a probabilidade do jogador atacar e quanto maior for o custo $c$, maior a probabilidade dele recuar.

Como o jogo é simétrico e as probabilidades são iguais, os prêmios dos dois jogadores são iguais no subjogo do momento 2. Visto que eles são indiferentes em qual ação tomar, é só substituir a probabilidade em equilíbrio na equação (3-28 ou 3-29), resultando no par de payoff $(0,0)$. Assim, carregando o custo com os payoffs em estratégias mistas do subjogo 2 para o jogo total, similar ao que foram feitos nas tabelas (3.5 e 3.6), resulta no jogo total na forma normal abaixo:

$\begin{array}{ccc} & \text { Escala } & \text { Recua } \\ \text { Escala } & -c ;-c & v ; 0 \\ \text { Recua } & 0 ; v & 0 ; 0\end{array}$

Tabela 3.7: Jogo Completo - Guerra de Atrito - Estratégia mista

Note que o jogo com estratégias mistas da tabela (3.7) é igual ao subjogo 2 da tabela (3.4), exceto pelo custo c. Esse jogo já foi resolvido, com três equilíbrios, dois puros $\left(\left\{E_{1}, R_{1}\right\},\left\{R_{1}, E_{1}\right\}\right)$ e um misto com probabilidades $\left\{p^{*}, q^{*}\right\}$. Essa constatação facilita a percepção da repetitividade do jogo. Diante disso, é possível analisar no primeiro momento na forma normal os equilíbrios de um jogo de guerra de atrito, seja um jogo de dois períodos ou infinitos períodos, considerando o valor esperado do custo como um custo afundado dos agentes.

Portanto, nesse jogo, temos três equilíbrios de Nash perfeitos em subjogos: $\left\{E_{1}, E_{2} ; R_{1}, R_{2}\right\},\left\{R_{1}, R_{2} ; E_{1}, E_{2}\right\}$ e $\left\{p_{1}^{*}, p_{2}^{*} ; q_{1}^{*}, q_{2}^{*}\right\}$. Dentre eles, o equilíbrio em estratégias mistas é o único que dá continuidade ao jogo. Como se trata de um jogo infinito, o jogo é definido quando o primeiro jogador deflete, lembrando que, no caso de exploração de petróleo o jogo é finito, pois existe um prazo do contrato de exploração do bloco. A escolha do equilíbrio em estraté-

${ }^{2} \mathrm{~A}$ probabilidade poderia ser encontrada maximizando a utilidade total do jogador $1 \mathrm{ou}$ 2. Esse método será utilizado na apresentação do modelo final desta dissertação. 
gias mistas como equilíbrio estável será feita com suporte da teoria dos jogos evolucionários e com a definição do término do jogo, que serão apresentadas mais adiante.

Agora serão apresentadas algumas características desse modelo básico, sendo os dados de entrada iguais a 50 para o prêmio $v$ e 10 para o custo $c$. Isso leva a probabilidade $p^{*}=q^{*}$ para ação escalar de $83 . \dot{3} \%$. A probabilidade do jogo de se prolongar é dada pela probabilidade independente dos dois jogadores escalarem em cada estado $t\left(t \in \mathbf{N}^{*}\right)$ com a probabilidade $p^{*}$ :

$$
\operatorname{Pr}(\text { jogo }- \text { avançar })=p^{2 t}=e^{2 t \ln p}
$$

Como $\ln p^{*}$ é negativo, no infinito a série tende para zero. Ou seja, com o passar do tempo, é mais improvável que os jogadores continuem a escalada na guerra de atrito, similar a formulação em Bishop e Cannings (1978). Nota-se esse efeito na figura (3.3), também no caso de aumento do prêmio para 70 e o aumento do custo para 20:

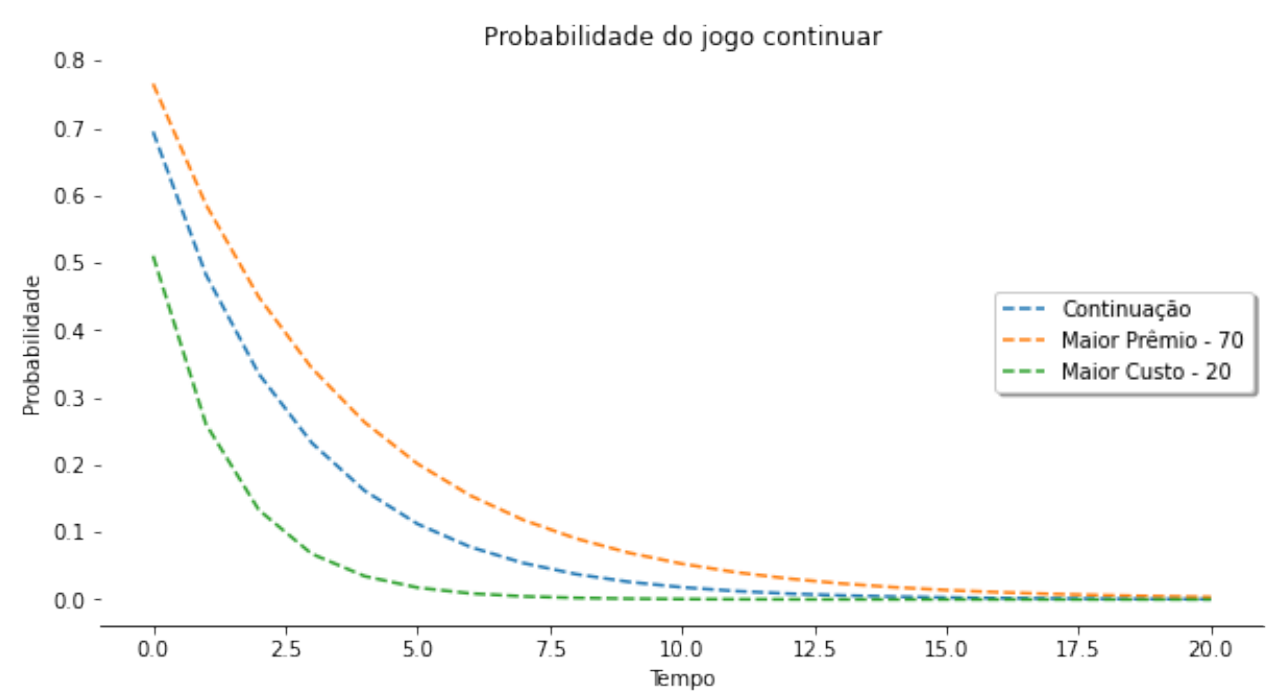

Figura 3.3: Modelo Básico - Guerra de Atrito - Prob. de Continuar

A probabilidade de jogar e fracassar é a probabilidade de não ganhar. Já a probabilidade de ganhar é dada pelo jogador escalar e o outro recuar, ou seja, $2 p(1-p)$. Assim, no primeiro estado, a probabilidade de fracassar é $72 . \dot{2} \%$, maior que a probabilidade de continuar $\left(p^{2}=69 . \dot{4} \%\right)$. A figura (3.4) apresenta as duas probabilidades, sendo que a diferença entre elas diminui quanto maior o tempo. 


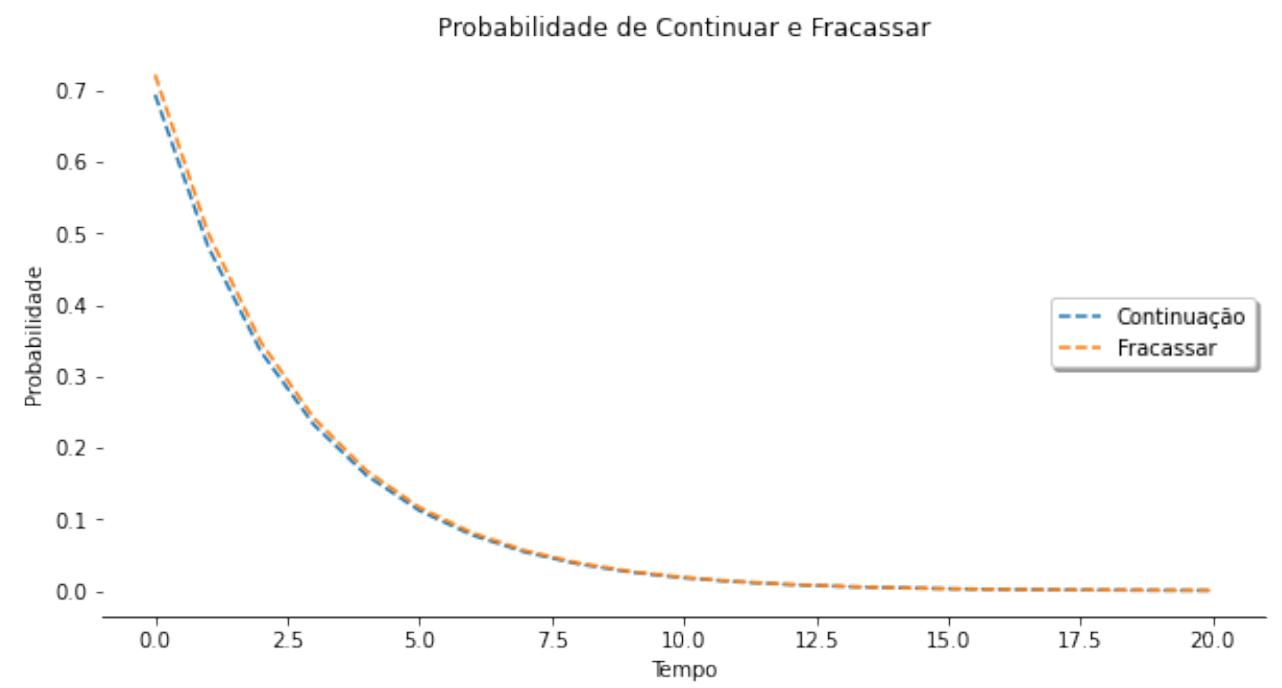

Figura 3.4: Modelo Básico - Guerra de Atrito - Prob. de Fracassar

Para cada jogador, o custo esperado de um jogo infinito pode ser calculado com as seguintes equações:

$$
\begin{aligned}
& \mathbb{E}[\text { custo }]=c p^{2}+2 c p^{4}+3 c p^{6}+\ldots=c \sum_{t=1}^{\infty} t p^{2 t} \\
& \mathbb{E}[\text { custo }]=c \frac{p^{2}}{\left(1-p^{2}\right)^{2}}
\end{aligned}
$$

A fórmula (3-32) é a solução da série aritmética-geométrica da equação (3-31) conhecida como Gabriel's staircase. A figura (3.5) mostra o custo esperado, também no caso de aumento do prêmio para 70 e no caso do custo subir para 20. Em todos os cenários têm uma feição de patamar quando o tempo de competição é longo. Com o aumento do prêmio $v$, eleva-se a razão $\frac{p^{2}}{\left(1-p^{2}\right)^{2}}$ e por consequência eleva-se o patamar do custo esperado da guerra de atrito. Com o aumento do custo unitário $c$, ainda que o $c$ seja diretamente proporcional ao custo esperado, a razão $\frac{p^{2}}{\left(1-p^{2}\right)^{2}}$ diminui e por consequência reduz o patamar do custo esperado. No caso base de prêmio $v$ de 50 , os valores do custo $c$ em cada estágio que levam o custo esperado ser menor que o prêmio $v$ são valores maiores que 17 . 


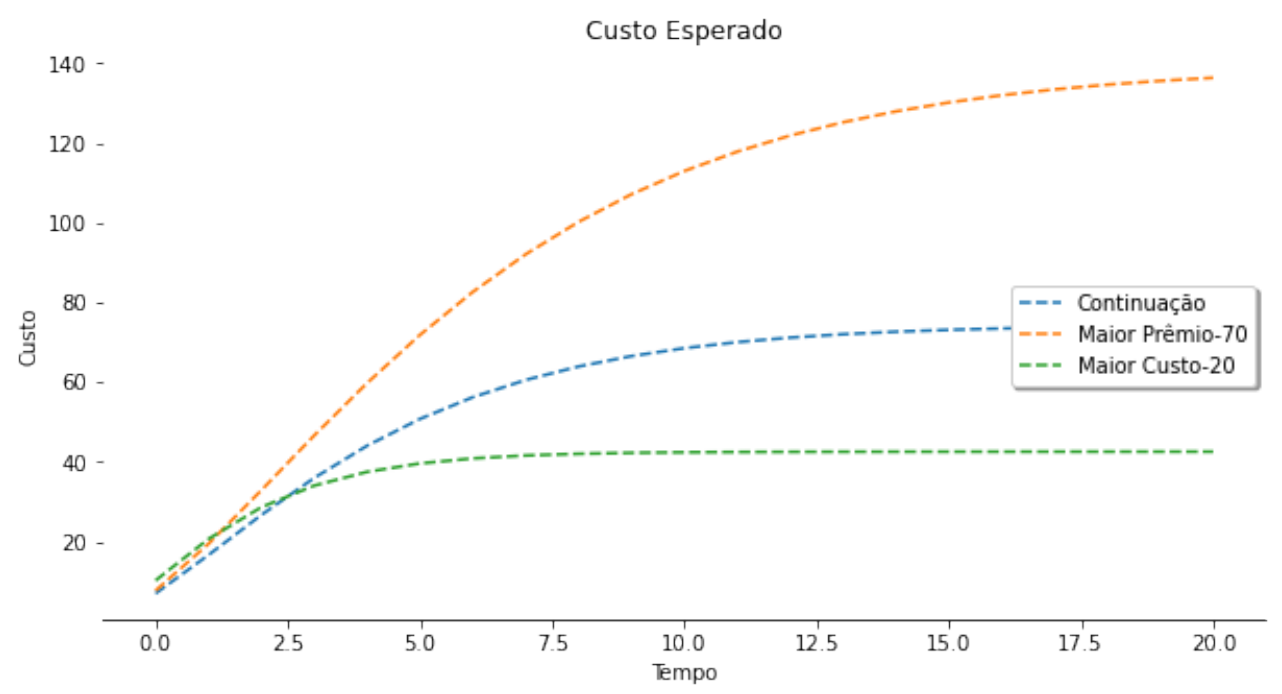

Figura 3.5: Modelo Básico - Guerra de Atrito - Custo Esperado

Em parágrafos anteriores, concluiu-se que o modelo básico possui três equilíbrios de Nash perfeitos em subjogos (ENPS): dois puros, que não dão continuidade ao jogo de guerra de atrito e um equilíbrio em estratégias mistas, que dá continuidade ao jogo. Decerto, a teoria dos jogos evolucionários contribui para selecionar dentre esses equilíbrios o equilíbrio estável. Dessa maneira, a seguir, se pincela alguns conceitos sobre essa teoria.

A Estratégia Evolucionariamente Estável (EEE) é um conceito de jogos evolucionários aplicado em biologia para explicar o equilíbrio das proporções das espécies na natureza. Mesmo sem racionalidade dos animais, os efeitos estatísticos populacionais são compatíveis com os equilíbrios em estratégias mistas da teoria dos jogos. No caso da guerra de atrito ou hawk and dove game, propõe-se uma população, com os perfis ou os tipos de agressividade e passividade em que os indivíduos assimilam a estratégia do outro, e mesmo com pequenas alterações/mutações das populações em $\epsilon$, pode haver uma resistência à estabilidade em uma estratégia, denominada de EEE. Segundo Smith (1974), para que ocorra a EEE na estratégia $s$, a utilidade da estratégia $s$ dado que todos os indivíduos têm a estratégia $s$ deve ser maior que a utilidade da invasora $x$ dado que os outros indivíduos jogam $s$. Esse já é um critério de não perpetuação da invasão, como um mecanismo de eliminação da estratégia invasora. Ademais, se essas utilidades forem iguais, a utilidade $s$ dado que os outros indivíduos jogam $x$ precisa ser maior no caso de todos jogarem a estratégia invasora $x$. Em fórmulas, esses conceitos são iguais às equações abaixo: 


$$
\begin{aligned}
& U(s, s)>U(x, s) \\
& U(s, s)=U(x, s) \quad \text { e } \quad U(s, x)>U(x, x)
\end{aligned}
$$

O jogo de guerra de atrito, como apresentado em Smith (1974), é condicionado pelo tempo em que os jogadores resistem ao conflito. No caso de oponentes que não podem causar muitos danos, como os pombos do hawk and dove game, a vitória vai para aquele que continua por mais tempo no conflito. Mas para isso, deve haver uma medida de custo de espera em função do tempo (SMITH, 1976). Sendo $V$ o prêmio, $t_{i}$ o tempo de parada do jogador $i$ e $m$ o custo em função do tempo, a utilidade do primeiro tipo no caso em que os tempos de resistência sejam iguais ou distintos é:

$$
u_{1}\left(t_{1}, t_{2}\right)=\left\{\begin{array}{ccc}
V-m\left(t_{2}\right), & \text { se } & t_{1}>t_{2} \\
-m\left(t_{1}\right), & \text { se } & t_{1}<t_{2} \\
\frac{V}{2}-m\left(t_{1}\right), & \text { se } & t_{1}=t_{2}
\end{array}\right.
$$

Também nesse modelo, a única EEE é uma estratégia mista de probabilidade $p(x)=\frac{1}{V} e^{-x / V}$. Essa formulação tem a mesma estrutura da equação (3-30), sendo $x$ um valor de custo como a função $m$, que esta possui uma relação com $t$, evidenciada na utilidade apresentada acima ${ }^{3}$. No modelo básico, concluiu-se que há três ENPS, dois puros e um em estratégias mistas. A teoria dos jogos evolucionários ajuda a encontrar EEE pela equação do replicador dinâmico.

O replicador dinâmico contribui para entender o aprendizado ou a mudança que ocorre numa população ao longo do tempo. Em jogos evolucionários, sua função é para compreender, dentre algumas estratégias, quais delas prevalecem ao longo do tempo. O replicador dinâmico é descrito por uma equação diferencial temporal e apresenta a relação da estratégia em relação à média de uma população infinita. A proporção da estratégia $(x)$ ao longo do tempo $(t)$ pode ser explicitada pela integração da equação diferencial, como será feita a seguir. Dessa forma, a estratégia que perdurar ao longo do tempo é a EEE. Assim, como pode ser visto na equação (3-37) do replicador dinâmico em jogos simétricos, há um ajuste na proporção da ação $x$ ao longo do tempo $t$, que é em função de uma proporção prévia de $x$ e a diferença da utilidade da melhor resposta $f$ em relação a utilidade média $\phi$, como pode ser visto abaixo:

\footnotetext{
${ }^{3}$ Dedução em Smith (1974).
} 


$$
\begin{gathered}
f=A x \\
\phi=f x \\
\frac{d x}{d t}=x(f-\phi)
\end{gathered}
$$

O jogo da tabela (3.4) pode ser aplicado nas equações do replicador dinâmico, com a matriz $A$ correspondendo a:

$$
A=\left(\begin{array}{cc}
-c & v \\
0 & 0
\end{array}\right)
$$

A figura (3.6) corresponde à integração da equação do replicador dinâmico de uma população infinita no modelo básico, com valores de $v=50 \mathrm{e}$ $c=20$. Nota-se que a EEE ocorre em estratégias mistas quando ambos os tipos jogam $p^{*}=q^{*}(=83 . \dot{3} \%)$ no jogo de guerra de atrito, resultando na proporção/probabilidade igual à calculada anteriormente.

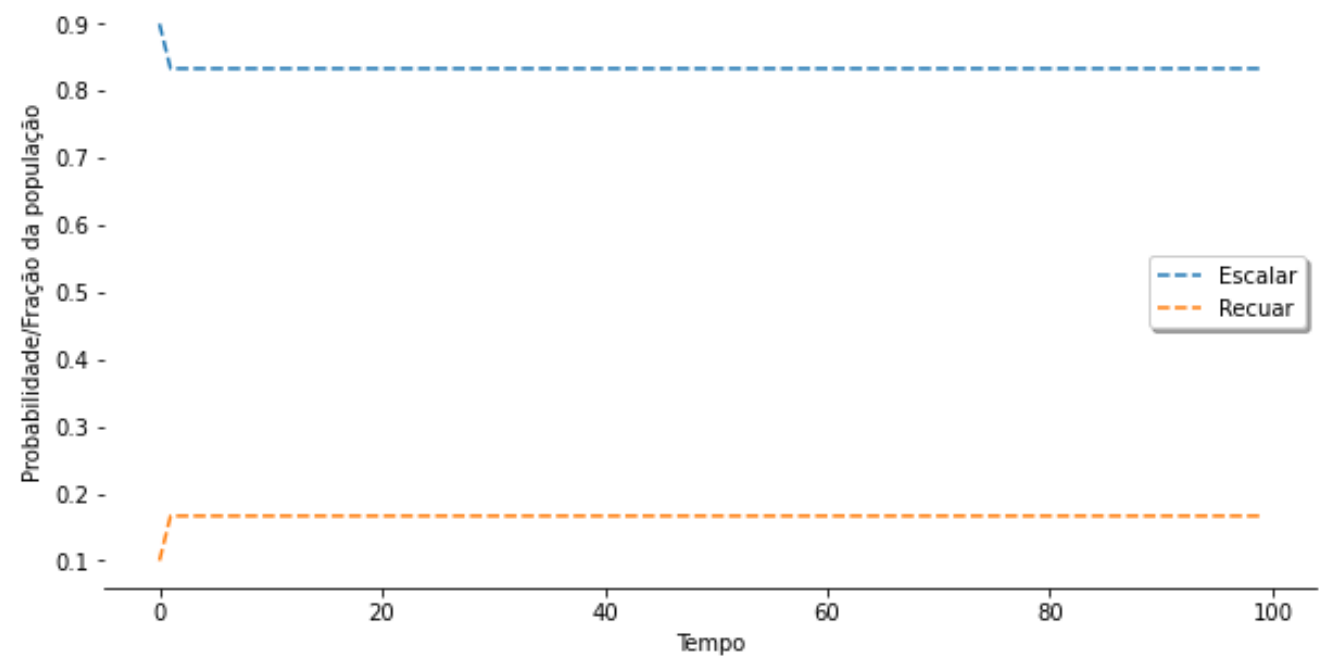

Figura 3.6: Jogo Evolucionário - Guerra de Atrito - Modelo Básico

O jogo da tabela (3.3) pode ser analisado em um plano de fase, que se trata das derivadas das equações (3-46 e 3-47). As setas da figura representam a magnitude e a direção da inclinação. No mapa, a região de probabilidades ou proporções em que as setas se reduzirem a pontos, indica que a derivada é igual a zero. Dessa maneira, o equilíbrio estável é representado na região em que a derivada é igual a zero e as utilidades são máximas, sem nenhum incentivo ao desvio do conjunto de estratégias naquelas probabilidades ou proporções, mesmo com um pequeno distúrbio $\epsilon$. A figura (3.7) indica justo no ponto de 
probabilidades iguais a $p^{*}=q^{*}$. Note que os vetores, vindo de todas as direções, indicam justo essa região em que $p^{*}=q^{*}$, sendo, em virtude disso, um máximo global.

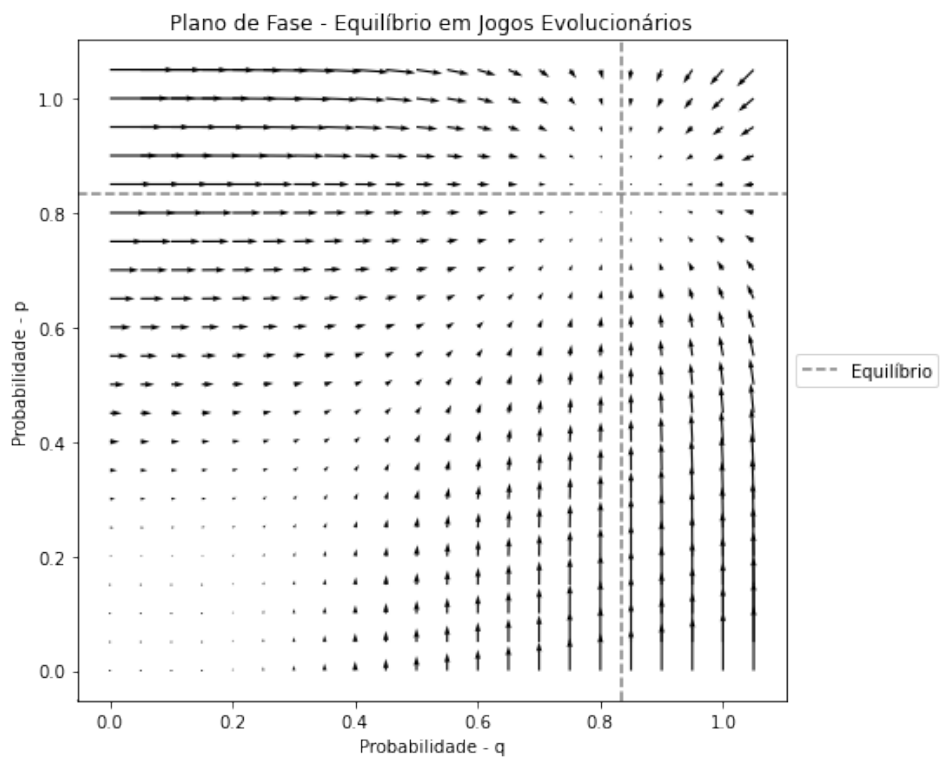

Figura 3.7: J. Evol. - Plano de Fase - Simétrico -Modelo Básico

Adensando as setas (figura 3.8), observa-se que se trata de um ponto de máximo de todo o domínio. Isso indica que nenhum jogador tem o estímulo de sair do ponto $p^{*}=q^{*}$, mesmo com pequenas perturbações $\epsilon$.

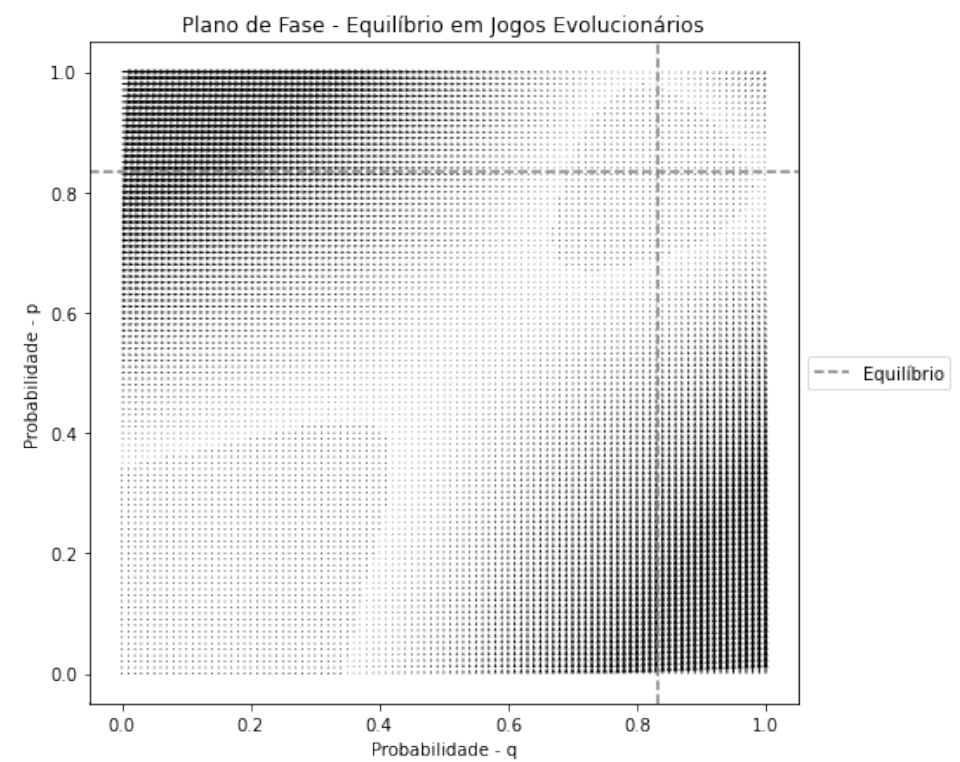

Figura 3.8: J. Evol. - P.de Fase Denso - Simétrico -Modelo Básico

O jogo proposto nesta dissertação é um pouco distinto, mas tem os elementos até então apontados. Esse jogo foi apresentado em Dias e Teixeira 
(2009), um paper sobre a guerra de atrito por informações em exploração de petróleo e com uma mudança de jogo para a barganha cooperativa. O jogador tem duas ações: perfurar ou esperar. A princípio, a espera tem dois significados. Caso o preço do petróleo esteja abaixo do ótimo em OR, ou seja, abaixo do gatilho (detalhes sobre o gatilho de investimento na seção 3.7), ambos os jogadores esperam independentemente da informação gratuita. É um estado em que os agentes não têm interesses econômicos na guerra de atrito por informações. Com os preços do petróleo acima do gatilho do ativo exploratório, aciona-se um custo de espera e o valor informacional do vizinho começa a ficar mais importante para a decisão. Comparando com o que foi apresentado até aqui, a espera é a ação agressiva do jogador e ele é "punido" pelo custo de esperar, tendo esse custo uma relação com o ativo que foi acionado no gatilho e não foi investido. Por outro lado, o jogador ambiciona a informação gratuita, pois há um combinado favorável: evitar o custo de perfuração e ainda assim obter a informação necessária para o seu portfólio. A tabela (3.8) apresenta o jogo de guerra de atrito por informações exploratórias na forma normal:

$$
\begin{array}{ccccc} 
& & & \multicolumn{2}{c}{\text { Jogador } 2} \\
& & & q & 1-q \\
& & & \text { Investe } & \text { Espera } \\
\text { Jogador } 1 & p & \text { Investe } & S_{1} ; S_{2} & L_{1} ; F_{2} \\
& 1-p & \text { Espera } & F_{1} ; L_{2} & W_{1} ; W_{2}
\end{array}
$$

Tabela 3.8: Forma normal: Guerra de Atrito por Informações

Onde, $S$ é o prêmio de exercício simultâneo das oportunidades, $W$ é o prêmio quando ambos os operadores esperam, $F$ é o payoff do seguidor, o qual espera por informações e $L$ é o prêmio do líder, aquele que investe sem informações do vizinho, sendo $p$ e $q$ as probabilidades dos jogadores 1 e 2 de investirem nos seus prospectos.

O payoff $W$ tem uma função associada que depende do estado corrente da variável estocástica preço do petróleo. Abaixo do gatilho exploratório, $W$ vale o prêmio da opção exploratória, e no caso em que o preço corrente esteja acima do preço do gatilho, terá um desconto $c$ em função do prêmio mensal da reserva não perfurada. Já o payoff $S$ é justo o prêmio da perfuração instantânea da reserva. $\mathrm{O}$ modelo considera $F$ o agente seguidor, em que este pode esperar a perfuração do outro e obter a informação exploratória gratuita. O $L$ é o payoff do líder, que ignora a possibilidade de informação alheia e perfura sua oportunidade exploratória desprezando a informação que poderia ser revelada pelo vizinho.

Abaixo do preço do gatilho de $\mathrm{OR}\left(P^{* *}\right.$ e $P^{* * L}$, na seção 3.7$)$, a relação $S=L<W<F$ é verdadeira e acima do gatilho, vale a seguinte relação: 
$W<S=L<F$. Quando o preço do petróleo estiver acima de um preço denominado de perfuração simultânea ( $P^{s}$, também na seção 3.7$)$, em que $P^{* *} \leq P^{s}$, a relação válida é a seguinte: $W<S=L=F$.

Como esse jogo depende do estado da natureza da variável estocástica preço do petróleo, as definições do jogo devem adotar os conceitos de jogos estocásticos e o equilíbrio perfeito de Markov (EPM). Os jogos estocásticos são jogos repetidos, com um conjunto de estados, de ações finitas e com probabilidade de transição para esses estados. Agora, o EPM depende somente do estado corrente dos preços e das ações dos jogadores nesse momento. Assim, é possível estudar os jogos na forma normal no estado inicial do jogo, em vez de todos os possíveis subjogos até o término do contrato. Ademais, o EPM é perfeito em subjogos, sendo um conceito mais abrangente que o trabalhado até agora (ENPS).

Como um método complementar de solução, o equilíbrio em estratégias mistas do jogo guerra de atrito por informações na exploração de petróleo será apresentado pela maximização da utilidade. Sendo a utilidade do jogador 1 dada a ação do jogador 2 em perfurar com probabilidade $q$ e esperar com probabilidade $1-q$, então:

$$
\begin{aligned}
U\left[1 \mid 2=q^{*}\right] & =p^{*} S_{1}+\left(1-p^{*}\right) F_{1} \\
U\left[1 \mid 2=1-q^{*}\right] & =p^{*} L_{1}+\left(1-p^{*}\right) W_{1}
\end{aligned}
$$

Assim, a utilidade incondicional do jogador 1 é:

$$
\begin{aligned}
U[1] & =q^{*} U\left[1 \mid 2=q^{*}\right]+\left(1-q^{*}\right) U\left[1 \mid 2=1-q^{*}\right] \\
& =q^{*}\left[p^{*} S_{1}+\left(1-p^{*}\right) F_{1}\right]+\left(1-q^{*}\right)\left[p^{*} L_{1}+\left(1-p^{*}\right) W_{1}\right]
\end{aligned}
$$

E a maximização da utilidade $U_{1}$ é dada por:

$$
\begin{aligned}
\frac{\partial U[1]}{\partial p^{*}} & =0 \\
q^{*}\left(S_{1}-F_{1}\right)+\left(1-q^{*}\right)\left(L_{1}-W_{1}\right) & =0 \\
q^{*}\left(S_{1}-F_{1}\right)+\left(q^{*}-1\right)\left(W_{1}-L_{1}\right) & =0 \\
q^{*}\left(S_{1}-F_{1}+W_{1}-L_{1}\right) & =W_{1}-L_{1} \\
q^{*}\left(F_{1}-S_{1}+L_{1}-W_{1}\right) & =L_{1}-W_{1}
\end{aligned}
$$




$$
q^{*}=\frac{L_{1}-W_{1}}{F_{1}-S_{1}+L 1-W_{1}}
$$

E o ótimo $p^{*}$ pela maximização da utilidade do jogador 2 é:

$$
p^{*}=\frac{L_{2}-W_{2}}{F_{2}-S_{2}+L_{2}-W_{2}}
$$

Sendo um jogo simétrico, então:

$$
p^{*}=q^{*}=\frac{L-W}{F-S+L-W}
$$

Com os preços correntes do barril do petróleo acima do gatilho da OR $\left(P^{* *}\right)$, o prêmio do líder $(L)$ será maior que o da espera simultânea $(W)$, dado o desconto $c$ da reserva não perfurada no payoff $W$, portanto, $L-W>0$. Se o preço corrente estiver abaixo de $\left(P^{s}\right)$, a diferença entre o prêmio do seguidor $(F)$ e a perfuração simultânea $(S)$ é positiva, assim, $F-S>0$. Então, em um intervalo de preço de petróleo entre $P^{* *}$ e $P^{s}$, o valor de $p^{*}=q^{*}$ é entre $[0,1]$, sendo valores possíveis de probabilidade. Ainda que haja outros equilíbrios no jogo, a EEE é a estratégia mista $p^{*}=q^{*}$. É nesse quadro que se define a guerra de atrito por informações na exploração de petróleo, em que há a probabilidade dos dois operadores em perfurarem e de aguardarem informações exploratórias gratuitas.

Como o jogo de atrito é um jogo de tempo de parada ótima, então a estratégia do líder é o menor tempo em que o preço do petróleo é maior ou igual ao gatilho exploratório. Assim, o seu tempo de parada é:

$$
t_{L}=\inf \left\{t \mid P(t) \geq P^{* *}(t)\right\}
$$

Já a seguidora, após a revelação da informação da líder, irá decidir em seu novo gatilho exploratório, denominado $P^{F}$. Caso a informação revelada da perfuração do prospecto da líder seja positiva, o preço $P^{F}$ será menor que $P^{* *}$, pois irá alterar positivamente o valor do prospecto da seguidora, descendo o preço do gatilho exploratório com a informação. Nessa condição, em prospectos iguais, a seguidora irá perfurar logo depois da informação positiva recebida da operadora vizinha. Caso a revelação da informação seja negativa, ocorrerá o contrário, descendo o valor do projeto da seguidora e elevando o valor do gatilho exploratório com informação $\left(P^{F}>P^{* *}\right)$. A decisão de investimento da seguidora será quando o preço corrente do petróleo $P(t)$ for maior que o novo gatilho exploratório $P^{F}$ e isso ocorrerá no tempo $t_{F}$, sendo maior que $t_{L}$ : 


$$
t_{F}=\inf \left\{t \mid P(t) \geq P^{F}\right\}
$$

No caso simétrico do jogo de atrito por informações, o replicador dinâmico segue as equações (3-35, 3-36 e 3-37) e tem a matriz $A$ igual à equação (3-45), sendo:

$$
A=\left(\begin{array}{cc}
S & L \\
F & W
\end{array}\right)
$$

Já nos casos de jogos assimétricos, o replicador dinâmico é um sistema de equações, como destacado abaixo:

$$
\begin{aligned}
& \frac{d x}{d t}=x(1-x)\left(f a_{x}-f b_{x}\right) \\
& \frac{d y}{d t}=y(1-y)\left(f b_{y}-f a_{y}\right)
\end{aligned}
$$

E no caso estudado, os termos são iguais às equações abaixo:

$$
\begin{aligned}
& f a_{x}=y S_{1}+(1-y) L_{1} \\
& f b_{x}=y F_{1}+(1-y) W_{1} \\
& f a_{y}=x S_{2}+(1-x) L_{2} \\
& f b_{y}=x F_{2}+(1-x) W_{2}
\end{aligned}
$$

Sendo os subscritos $a$ e $b$ referentes aos diferentes tipos ou ações das duas populações, $(x, 1-x)$ e $(y, 1-y)$ as proporções ou frações dos tipos de cada população e $f$ o prêmio da ação dado o ótimo da outra população. Da mesma forma que no replicador dinâmico com uma população infinita em jogos simétricos, busca-se o ponto de máximo representado pela derivação igual a zero, em que um certo conjunto de estratégias com as probabilidades ou as frações de $x^{*}$ e $y^{*}$ das populações não tenham incentivos ao desvio. Nesse último sistema de equações (3-48 até 3-51), caso o jogo volte a ser simétrico $\left(S_{1}=S_{2}, F_{1}=F_{2}, L_{1}=L_{2}\right.$ e $\left.W_{1}=W_{2}\right)$, replica-se a equação (3-37).

A situação de conflito é desvantajosa para o desenvolvimento local, pois pode-se perpetuar até o final do contrato sem perfuração de poços, mesmo que os payoffs dos projetos sejam positivos. Por isso, há o interesse geral na mudança de jogo, em que os agentes percebam vantagens no término do conflito e adotem um programa conjunto de investimento exploratório na área. O jogo de barganha cooperativa é um caminho para isso e trata-se da unitização dos 
ativos e a melhor divisão deles entre os agentes. A solução de Nash para a barganha cooperativa tem os pesos para os dois jogadores iguais às equações abaixo:

$$
\begin{aligned}
& w_{i}=\frac{1}{2}+\frac{\left(d_{i}-d_{j}\right)}{2 \Pi_{i, j}} \\
& w_{j}=1-w_{i}
\end{aligned}
$$

Sendo o par $(d i, d j)$ o ponto de discordância e $\prod_{i, j}$ a unitização dos ativos. O ponto de discordância é devido ao impasse, correspondendo à utilidade de cada jogador no equilíbrio de Nash perfeito em subjogos na guerra de atrito. Em caso de um jogo simétrico, as coordenadas de discordância dos dois jogadores são iguais, assim, $w_{i}=w_{j}=50 \%$. Agora, no jogo assimétrico, as utilidades se diferenciam. Portanto, sendo um tempo $t$ do contrato, a discordância não levará a um ponto na divisão da unitização $\left(w_{i}, w_{j}\right)$, mas para um vetor que é em função do preço do petróleo, visto que a variável preço pode assumir qualquer valor positivo $\left(P \in \mathbf{R}_{+}\right)$.

Para a formalização do modelo de option-games na guerra de atrito por informações na exploração de petróleo e na unitização dos ativos na barganha cooperativa, são necessários apresentar os princípios de avaliação de carteira em exploração de petróleo (seção 3.6) e as equações diferenciais de OR (seção $3.7)$.

\section{6 \\ Portfólio}

Neste trabalho são consideradas três formas de analisar uma carteira de ativos exploratórios em petróleo. A mais tradicional é adotar que os prospectos são independentes, assim, a carteira é a soma do VMEs $\left(\sum V M E(P)\right.$ ou $\left.\sum V M E(P, t)\right)$ ou a soma das opções de explorar $\left(\sum E(P, t)\right)$. A forma que considera somente a revelação da informação sem o valor da espera é denominada de portfólio $(\pi(P))$, que por vezes é simbolizada somente por $\pi$. Por último, a forma que considera o valor da espera em conjunto com o valor da informação é denominada de portfólio exploratório, simbolizada por $(\Pi(P, t))$ ou somente $\Pi$. Nesta seção serão apresentados os detalhes do portfólio $(\pi)$.

O portfólio $(\pi)$ pode ser composto por no mínimo um prospecto. Os ativos são consolidados na carteira pela ponderação do risco geológico (FC), de acordo com as formulações da seção (3.2).

- No caso de um ativo na carteira: 


$$
-\pi=V M E_{1}(P)
$$

- Sendo 2 ativos independentes na carteira:

$-\pi_{1,2}=V M E_{1}+V M E_{2}=\sum V M E(P)$

$-\pi_{1,2}=\pi_{2,1}$

- Em que $\pi_{i, j}$ simboliza o portfólio com a sequência de perfuração do prospecto $i$ anterior à oportunidade $j$.

- Quando há $n$ ativos independentes na carteira:

$-\pi_{n}=\sum_{i=1}^{n} V M E_{n}(P)$

O valor do portfólio de ativos não correlacionados independe da ordem na sequência de perfuração. Para ativos correlacionados, a equipe técnica estima os FCs incondicionais e as correlações entre ativos, sendo que na consolidação do portfólio é necessário calcular os fatores de chance condicionais, como apresentados na seção (3.4). Em decorrência disso, o Valor Monetário Esperado também é condicional no caso de uma sequência de perfuração de prospectos correlacionados. Como exemplo, a figura (3.9) apresenta uma das duas possíveis sequências de portfólio para dois ativos exploratórios.
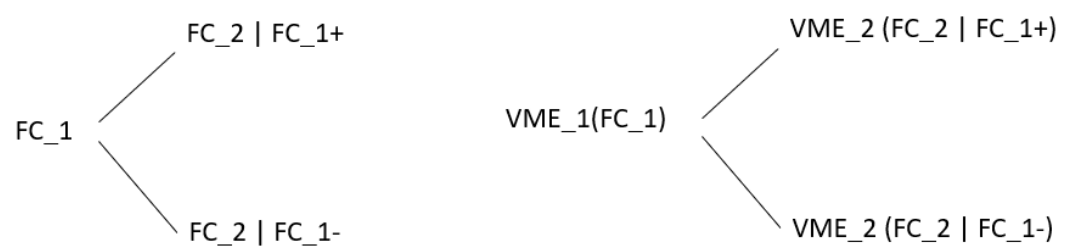

Figura 3.9: FC e VME condicionais

A figura (3.1) da seção (3.4.1) mostra que quanto maior o número de revelações, maior é a probabilidade do próximo investimento ter 0 ou $100 \%$ de chance de possuir hidrocarboneto. Esse efeito também é notado na tabela (3.2), em que a dispersão do FC aumenta com o aumento da quantidade de eventos, representado pelo aumento do desvio padrão da medida. Em análise de portfólio com ativos correlacionados, casos com baixos FCs condicionais podem ter VMEs condicionais negativos e por otimização, não devem ser perfurados. Pela mesma razão, os FCs condicionais altos, devido às revelações positivas, podem levar VMEs que sem informação eram negativos para VMEs condicionais positivos e por otimização, devem ser perfurados. Por isso, o 
portfólio que considera a correlação de ativos deve ter a função máximo nos VMEs condicionais e é maior ou vale tanto quanto o portfólio que considera as oportunidades independentes.

A vantagem de um portfólio com ativos correlacionados é que, devido à informação a priori e um modelo de revelação (Bernoulli bivariado), é possível otimizar o portfólio de forma sequencial caso os valores monetários esperados condicionais sejam negativos. Esse é o sentido do aprendizado, pois dada uma notícia ruim revelada, o gestor e o corpo técnico aprendem com essa informação e abandonam os projetos desvantajosos. Da mesma forma, caso haja uma notícia boa revelada, o aprendizado pode conduzir na manutenção dos projetos que originalmente seriam descartados. Além disso, por otimização, pode acontecer de haver a preferência em perfurar um prospecto antes do outro, pois um ativo pode possuir valor informacional maior para o seguinte do que a situação inversa. Isso acontece, pois o VME condicional do segundo dada a informação negativa advinda do primeiro é menor que zero e menor do que o VME condicional do primeiro dada a informação negativa do segundo. Então, a otimização também é feita em função da ordem dos projetos, porém, não são em todas as condições de preço de longo prazo (P) que essa análise faz diferença.

A equação (3-27) apresenta que a média incondicional das médias condicionais dos FCs é igual à média incondicional dos FCs, princípio conhecido com a lei das expectativas iteradas. Esse resultado também pode ser visto na tabela (3.2), em que a média incondicional do FC não muda com o avanço dos investimentos. Caso o preço de longo prazo (P) seja elevado, mesmo com cenários negativos sobre a existência de hidrocarboneto $\left(F C_{i}^{-}\right)$, pode acontecer da saída da função máximo ser o próprio $\operatorname{VME}(\mathrm{VME}=\max (0, \mathrm{VME}))$ em todos os cenários. Nesse tipo de situação, os portfólios sequenciais podem ser iguais $\left(\pi_{i, j}=\pi_{j, i}\right)$, sem preferência de perfuração para o primeiro poço. Ademais, com os valores altos de $\mathrm{P}$, o portfólio de aprendizado pode ter o mesmo valor de um portfólio analisado com as oportunidades independentes, pois nessa situação é como se fosse aplicada diretamente a lei das expectativas iteradas, ou seja, uma ponderação condicional sem a função máximo nos VMEs condicionais. Na seção (4.2.1) será apresentada essa situação por meio de um exemplo.

Poderia ser diferente caso o investimento no desenvolvimento do campo $\left(I_{d}\right)$ fosse em função do preço de longo prazo, como feito em Dias e Calvette (2017), que não é o modelo usado nesta dissertação (seção 3.2 e equação 3-8). Isso acontece, pois há um ajuste do investimento com o preço do petróleo, que normalmente é diretamente proporcional, elevando o dispêndio junto com o aumento do valor do projeto. Dessa forma, pode ocorrer mais estados da 
natureza em que os VMEs condicionais são negativos, acionando a função máximo a ter mais saídas iguais a zero.

- Então, o caso de 2 ativos dependentes na carteira:

$-\pi_{12}=V M E_{1}+F C_{1}\left[\operatorname{Max}\left(0 ; V M E_{2}^{+}\right)\right]+\left(1-F C_{1}\right)\left[\operatorname{Max}\left(0 ; V M E_{2}^{-}\right)\right]$

$-\pi_{12} \neq \pi_{21}$

- Não necessariamente os portfólios sequenciais são distintos, podendo ser iguais a depender do preço

$-\pi=\operatorname{Max}\left(\pi_{12} ; \pi_{21} ; 0\right)$

- Esse portfólio pode ser uma função de entrada para o cálculo de OR. Como a opção não tem valor negativo, é necessário fazer o cálculo do máximo entre as possíveis sequências do portfólio e zero.

Como apresentado, a ordem de perfuração pode importar em portfólios com os ativos correlacionados. Na formulação abaixo é apresentada uma das seis possíveis sequências de perfuração no caso de três ativos exploratórios dependentes na carteira:

$$
\begin{aligned}
& \pi_{123}=V M E_{1} \\
+ & F C_{1}\left\{\operatorname{Max}\left[0 ; V M E_{2}^{+}+F C_{2}^{+}\left(\operatorname{Max}\left(0 ; V M E_{3}^{++}\right)\right)+\left(1-F C_{2}^{+}\right)\left(\operatorname{Max}\left(0 ; V M E_{3}^{+-}\right)\right)\right]\right\} \\
+ & \left(1-F C_{1}\right)\left\{\operatorname{Max}\left[0 ; V M E_{2}^{-}+F C_{2}^{-}\left(\operatorname{Max}\left(0 ; V M E_{3}^{-+}\right)\right)+\left(1-F C_{2}^{-}\right)\left(\operatorname{Max}\left(0 ; V M E_{3}^{--}\right)\right)\right]\right\}
\end{aligned}
$$

Sendo as probabilidades condicionais:

$$
\begin{aligned}
& F C_{2}^{+}=F C_{2 \mid 1} \\
& F C_{2}^{-}=F C_{2 \mid \overline{1}}
\end{aligned}
$$

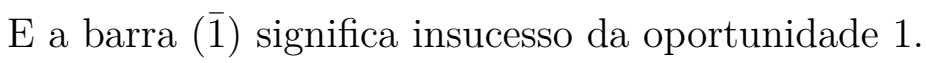

- Dessa forma, o portfólio $\pi$ com três ativos:

$-\pi_{123} \neq \pi_{132} \neq \pi_{213} \neq \pi_{231} \neq \pi_{312} \neq \pi_{321}$

- Não necessariamente os portfólios sequenciais são distintos, podendo ser iguais a depender do preço

$-\pi=\operatorname{Max}\left(\pi_{123} ; \pi_{132} ; \pi_{213} ; \pi_{231} ; \pi_{312} ; \pi_{321} ; 0\right)$

- Sendo $\pi$ uma entrada para o cálculo de OR, o portfólio não pode ter valor negativo, então aplica-se outra função máximo entre as possíveis sequências do portfólio e zero, selecionando a melhor dentre as opções.

- Caso o bloco tenha ativos dependentes e independentes, então: 


$$
-\pi_{\text {bloco }}=\pi \text { dependente }+\pi \text { independente }
$$

A seguir, é apresentado o valor do portfólio de uma possível sequência de dois ativos no caso de revelação da informação pela perfuração de um prospecto pelo vizinho $i$ :

$$
\begin{aligned}
& \pi_{12 \mid i}=F C_{i}\left\{\operatorname{Max}\left[0 ; V M E_{1}^{+}+F C_{1}^{+}\left(\operatorname{Max}\left(0 ; V M E_{2}^{++}\right)\right)+\left(1-F C_{1}^{+}\right)\left(\operatorname{Max}\left(0 ; V M E_{2}^{+-}\right)\right)\right]\right\} \\
& +\left(1-F C_{i}\right)\left\{\operatorname{Max}\left[0 ; V M E_{1}^{-}+F C_{1}^{-}\left(\operatorname{Max}\left(0 ; V M E_{2}^{-+}\right)\right)+\left(1-F C_{1}^{-}\right)\left(\operatorname{Max}\left(0 ; V M E_{2}^{--}\right)\right)\right]\right\} \\
& -\pi_{12 \mid i} \neq \pi_{21 \mid i} \\
& - \text { Não necessariamente os portfólios sequenciais com informações do vizi- } \\
& \quad \text { nho são distintos, podendo ser iguais a depender do nível de preço de } \\
& \quad \text { longo prazo. }
\end{aligned}
$$

O estudo de otimização de carteira pode ser feito sem o valor da espera, como foi apresentado nesta seção. Contudo, sabe-se que o valor da espera é importante em análise de portfólio, pois são raras as decisões de agora ou nunca. Sendo assim, considerando o prazo dos contratos exploratórios e a incerteza do preço do petróleo, as valorações apresentadas neste tópico seriam exercidas somente no vencimento do contrato ou quando o valor do petróleo fosse alto, ou seja, quando o valor intrínseco é igual ao valor da espera. Além disso, a vantagem de considerar o valor do portfólio com o aprendizado junto com a espera é a função implícita extraída da solução por diferenças finitas, conhecida como o gatilho exploratório. Essa curva de gatilho apresenta a ação ótima em função do preço do petróleo e do momento do contrato, sendo uma ferramenta útil para as decisões de investimento no ativo ou na carteira. Inclusive, essa curva é importante no jogo de guerra de atrito, especialmente quando o preço do petróleo estiver acima do ótimo de investir no prospecto ou no portfólio e se aciona um custo por esperar, sendo este custo devido ao não investimento e pelo aguardo da informação gratuita do vizinho.

Nas seguintes seções serão definidas as equações diferenciais para a valoração por OR com e sem o efeito do aprendizado no portfólio (seção 3.7). Os resultados que comparam essas diversas métricas de análise de portfólio podem ser vistos na seção (4.2.1), em essência na tabela (4.7). Essas métricas são entradas para os jogos com opções, incluindo os modelos de valor de espera com ativos correlacionados com os prospectos vizinhos, denominado de agente seguidor, apresentados nas equações (3-59 e 3-61) e a empresa líder, que perfura no momento do seu ótimo, com valorações iguais às equações (3-58 e 3-62). 


\section{7}

\section{Modelos}

\subsection{1}

\section{Um, Dois e Três prospectos: Um bloco}

O campo de hidrocarboneto a ser explotado $(R)$ pode ser visto como um derivativo do ativo base preço do barril do petróleo $P$. Como o ativo base $P$ é estocástico, usando o método de portfólio sem risco (Apêndice A), que nada mais é que o princípio de não arbitragem, similar ao aplicado por Black e Scholes (1973) e baseado na ideia de Merton (1973), chega-se na equação diferencial abaixo:

$$
\frac{\partial R}{\partial t}+(r-\delta) \frac{\partial R}{\partial P} P+\frac{1}{2} \frac{\partial^{2} R}{\partial P^{2}} \sigma^{2} P^{2}=r R
$$

A seguir, são apresentadas as condições de contorno dessa equação diferencial, sendo as duas últimas conhecidas como as condições de continuidade e suavidade (DIXIT; PINDYCK, 1994, Cap. 4, p.119):

- Caso $P=0, R(0, t)=0$

- Caso $t=T, R(P, T)=\max (V P L, 0)$

- Caso $P=P^{*}, R\left(P^{*}, T\right)=V P L\left(P^{*}\right)$

- Caso $P=P^{*}, \frac{\partial R\left(P^{*}, t\right)}{\partial P}=\frac{\partial V P L}{\partial P}=q B$

Em que $\sigma$ e $\delta$ são a volatilidade e a taxa de conveniência do ativo base $P$ e $r$ é a taxa livre de risco. Nas condições de contorno, o VPL é calculado segundo a equação (3-1) menos o investimento da equação (3-8). Além disso, $P^{*}$ simboliza o gatilho de desenvolvimento, ou seja, o preço do barril do petróleo em que o projeto está deep in the money para se investir na produção.

Também, o ativo exploratório $(E)$ pode ser compreendido pela equação diferencial abaixo:

$$
\frac{\partial E}{\partial t}+(r-\delta) \frac{\partial E}{\partial P} P+\frac{1}{2} \frac{\partial^{2} E}{\partial P^{2}} \sigma^{2} P^{2}=r E
$$

Com as seguintes condições de contorno:

- Caso $P=0, E(0, t)=0$

- Caso $t=T, E(P, T)=\max \left(-I_{w}+F C \cdot V P L, 0\right)$ 
- Caso $P=P^{* *}, E\left(P^{* *}, T\right)=-I_{w}+F C \cdot V P L\left(P^{* *}\right)$

- Caso $P=P^{* *}, \frac{\partial E\left(P^{* *}, t\right)}{\partial P}=F C \cdot \frac{\partial V P L}{\partial P}$

Sendo $P^{* *}$ o preço do gatilho de explorar, ou seja, o preço do barril do petróleo em que o projeto exploratório está atraente em termos da TOR para investir no poço pioneiro.

O investidor pode tomar a decisão de investir em um campo de petróleo usando a métrica $R(P, t)$, que é mais rigorosa que o Valor Presente Líquido, visto que o VPL é somente a condição terminal da equação diferencial, ou seja, vale somente na situação de "agora ou nunca". Caso haja um risco exploratório, o investidor deve tomar como medida a equação (3-55). Contudo, pode-se analisar o investimento no poço exploratório nos moldes do VME, ou seja, em vez da ponderação do VPL pelo risco geológico (FC) como na equação (3-7), deve-se ponderar a opção de investimento em desenvolvimento (equação 3-56). Essa nova medida denominada $V M E(P, t)$ é mais rigorosa que o Valor Monetário Esperado da equação original, pois considera a incerteza de preços no projeto de investimento no campo de petróleo. Nos jogos em opções reais, é considerada a medida $V M E(P, t)$ como a ação imediata de perfuração em um poço exploratório.

$$
\operatorname{VME}(P, t)=-I_{W}+F C \cdot R(P, t)
$$

Da mesma forma que o ativo exploratório, o portfólio exploratório (П) pode ser visto como um derivativo do ativo base $P$. Como o ativo base $P$ é estocástico, pelo método de portfólio sem risco, determina-se a equação abaixo:

$$
\frac{\partial \Pi}{\partial t}+(r-\delta) \frac{\partial \Pi}{\partial P} P+\frac{1}{2} \frac{\partial^{2} \Pi}{\partial P^{2}} \sigma^{2} P^{2}=r \Pi
$$

E com as condições de contorno:

- Caso $P=0, \Pi(0, t)=0$

- Caso $t=T, \Pi(P, T)=\max (\pi, 0)$

- Caso $P=P^{* * L}, \Pi\left(P^{* * L}, T\right)=\pi\left(P^{* * L}\right)$

- Caso $P=P^{* * L}, \frac{\partial \Pi\left(P^{* * L}, t\right)}{\partial P}=\frac{\partial \pi\left(P^{* * L}\right)}{\partial P}$

Sendo que o gatilho que considera a aprendizagem em portfólio é simbolizado por $P^{* * L}$ e $\pi$ foi definido na seção (3.6). 
Pelas mesmas razões apontadas entre $R(P, t)$ e VPL, o portfólio é melhor analisado em $\Pi(P, t)$ que em $\pi(P)$, justamente pois o último é somente a condição terminal do primeiro.

\subsection{2}

\section{Dois prospectos: Um em cada bloco}

A empresa líder $L_{i}$ irá perfurar antes da informação da concorrente, portanto, é igual à equação $V M E(P, t)$ (equação 3-56):

$$
L_{i}(P, t)=-I_{W i}+F C_{i} \cdot R_{i}(P, t)
$$

Essa valoração também ocorre no payoff de perfuração imediata $S_{i}$.

O payoff da espera $W_{i}$ é igual à opção de explorar $\left(E_{i}\right)$ (equação 3$55)$, quando o preço está abaixo do gatilho $\left(P^{* *}\right)$. Quando o preço está acima do gatilho de explorar, é acionado um custo de espera igual a $c_{i}(P, t)=$ $V M E_{i}(P, t)\left(1-e^{-r / 12}\right)$, como proposto em Dias e Teixeira (2009). Esse custo é uma penalização mensal do prêmio não adquirido pela empresa, que no caso é o valor da perfuração imediata $V M E(P, t)$ do seu prospecto. Como se trata do adiamento de uma opção deep-in-the-money, sendo esta uma valoração na medida neutra ao risco, é usada a taxa livre de risco anual $r$ como desconto.

Como já comentado, o seguidor terá a informação de ocorrência de hidrocarboneto fornecida pelo líder $\left(L_{j}\right)$. O valor do seguidor $\left(F_{i}\right)$ é uma ponderação pelo FC incondicional da concorrente $j$ aplicado às opções de explorar $\left(E_{i}\right)$ condicionadas pelo fator de chance dada a informação da concorrente (equação 3-59). Essa é a mesma lógica aplicada em aprendizado em portfólio $(\pi)$.

$$
F_{i}(P, t)=\mathbb{E}\left[E_{i}(P, t) \mid j\right]=F C_{j} \cdot E_{i}\left(P, t, F C_{i \mid j}^{+}\right)+\left(1-F C_{j}\right) \cdot E_{i}\left(P, t, F C_{i \mid j}^{-}\right)
$$

Sendo os $F C_{i \mid j}^{+}$e $F C_{i \mid j}^{-}$funções de $F C_{i}, F C_{j}$ e $\rho$, apresentados em detalhes na seção (3.4), em especial na seção (3.4.1).

Com todas essas métricas, a forma normal do jogo de atrito por informação (tabela 3.8) é representada por:

Jogador 2

\begin{tabular}{ll|c|c|}
\multicolumn{2}{c}{ Investe } & \multicolumn{1}{c}{ Espera } \\
\cline { 3 - 4 } Jogador 1 & Investe & $V M E_{1} ; V M E_{2}$ & $V M E_{1} ; E_{2 \mid 1}$ \\
\cline { 3 - 4 } & Espera & $E_{1 \mid 2} ; V M E_{2}$ & $E_{1}-c_{1} ; E_{2}-c_{2}$ \\
\cline { 3 - 4 } & & &
\end{tabular}

Tabela 3.9: Forma normal: Payoffs- 2 prospectos 
Em que $V M E_{i}=V M E_{i}(P, t)$ e $c_{i}$ é o custo de espera.

No jogo de guerra de atrito, há um preço acima do gatilho de explorar $\left(P^{* *}\right)$ que delimita de forma superior o conflito por informações. Esse preço do barril de petróleo é chamado de gatilho simultâneo $\left(P^{s}\right)$ e é definido para cada jogador, sendo que acima desse valor o operador é indiferente entre aguardar por informações ou perfurar imediatamente. Portanto, pela igualdade a seguir, temos:

$$
E_{i \mid j}\left(P^{s}, t\right)=V M E_{i}\left(P^{s}, t\right)
$$

Após apresentada essa indiferença do jogador entre perfurar e aguardar a informação gratuita, é importante salientar que quando os preços são suficientemente altos, todas as métricas são iguais e valem exatamente o VME original (equação 3-7). Isso ocorre, pois todas as métricas apresentadas são derivações do Valor Monetário Esperado, como poderá ser visto na prática na seção (4.2.1).

\subsection{3}

\section{Três prospectos: Carteira com 2 e um prospecto vizinho}

Detendo um portfólio, a empresa seguidora $F$ aplica a equação diferencial abaixo. Essa formulação adota os conceitos de VOI da equação (3-59) em portfólio. A diferença em relação à equação (3-57) é somente nas condições de contorno, em que $j$ é o ativo do vizinho a ser perfurado primeiro:

$$
\frac{\partial \Pi \mid j}{\partial t}+(r-\delta) \frac{\partial \Pi \mid j}{\partial P} P+\frac{1}{2} \frac{\partial^{2} \Pi \mid j}{\partial P^{2}} \sigma^{2} P^{2}=r \Pi \mid j
$$

As condições de contorno são:

- Caso $P=0, \Pi(0, t) \mid j=0$

- Caso $t=T, \Pi(P, T) \mid j=\max (\pi \mid j, 0)$

- Caso $P=P^{* * L j}, \Pi\left(P^{*}, T\right)\left|j=\pi\left(P^{* * L j}\right)\right| j$

- Caso $P=P^{* * L j}, \frac{\partial \Pi\left(P^{* * L j}, t\right) \mid j}{\partial P}=\frac{\partial \pi\left(P^{* * L j}\right) \mid j}{\partial P}$

Onde o gatilho que considera a aprendizagem no portfólio por um ativo vizinho é simbolizado por $P^{* * L j}$.

Para o payoff da líder $L$, assim como na perfuração simultânea $S$, deve haver uma versão de $\operatorname{VME}(P, t)$ para o portfólio. Essa medida consiste na 
busca do ótimo do portfólio, em que é feito a perfuração do ativo menos custoso ou mais informativo e o aprendizado para os outros ativos. Difere da equação (3-57), pois não são todos os ativos que estão na função máximo. Pelo mesmo motivo, difere da equação (3-56), pois tem ativos na função de otimização ponderados pelo risco geológico. A seguir, a equação diferencial com as condições de contorno, em que $i$ é o ativo a ser perfurado primeiro e $-i$ todos os outros:

$$
\frac{\partial V M E_{\pi}}{\partial t}+(r-\delta) \frac{\partial V M E_{\pi}}{\partial P} P+\frac{1}{2} \frac{\partial^{2} V M E_{\pi}}{\partial P^{2}} \sigma^{2} P^{2}=r V M E_{\pi}
$$

E as condições de contorno são:

- Caso $P=0, V M E_{\pi}(0, t)=-\min \left(I_{w i}\right)$

- Caso $t=T, V M E_{\pi}(P, T)=\max \left(\pi_{-i}, 0\right)+F C_{i} . V P L_{i}(P, t)-I_{w i}$

- Caso $P=P^{* * L i}, V M E_{\pi}\left(P^{* * L i}, T\right)=\pi_{-i}\left(P^{* * L i}\right)+F C_{i} \cdot V P L_{i}\left(P^{* * L i}, t\right)-$ $I_{w i}$

- Caso $P=P^{* * L i}, \frac{\partial V M E_{\pi}\left(P^{* * L i}, t\right)}{\partial P}=\frac{\partial \pi_{-i}\left(P^{* * L i}\right)}{\partial P}+F C_{i} \frac{\partial V P L_{i}}{\partial P}$

Nota-se que diferentemente das outras equações diferenciais parciais, a primeira condição de contorno é o negativo da função mínimo do custo de um poço pioneiro. Isso leva a valores negativos de $V M E_{\pi}$ em situações de preços baixos do barril de petróleo, sendo o valor mínimo igual ao menor custo do poço pioneiro do portfólio, ideia similar à formulação do $V M E(P, t)$ (equação $3-56)$.

Com essas novas métricas, a forma normal do jogo de atrito por informação em portfólio (tabela 3.8) é representada por:

Jogador 2

\begin{tabular}{|c|c|c|c|}
\hline \multirow{3}{*}{ Jogador 1} & \multirow{3}{*}{$\begin{array}{l}\text { Investe } \\
\text { Espera }\end{array}$} & Investe & Espera \\
\hline & & $V M E_{\pi_{1}} ; V M E_{2}$ & $V M E_{\pi_{1}} ; E_{2 \mid 1}$ \\
\hline & & $\Pi_{1 \mid 2} ; V M E_{2}$ & $\Pi_{1}-c_{1} ; E_{2}-c_{2}$ \\
\hline
\end{tabular}

Tabela 3.10: Forma normal: Payoffs no caso de Portfólio

Onde, $V M E_{2}=V M E_{2}(P, t)$ e $c_{i}$ é o custo de espera. Para o detentor do portfólio, o custo de espera é acionado pelo gatilho do portfólio $\left(P^{* * L}\right)$, mas o custo não é em função do valor do portfólio como um todo $(\Pi(P, t))$, sendo somente em função do $\operatorname{VME}(P, t)$ do poço não perfurado. 
Como no caso de dois ativos (equação 3-60), o preço $P^{s}$ define o limite superior da guerra de atrito por informações em situação de portfólio, sendo esse preço definido para cada jogador. Então:

$$
E_{i \mid j}\left(P^{s}, t\right)=V M E_{i}\left(P^{s}, t\right)
$$

$\mathrm{Ou}$

$$
\Pi_{i \mid j}\left(P^{s}, t\right)=V M E_{\pi_{i}}\left(P^{s}, t\right)
$$




\section{4}

\section{Estudo de Caso e Resultados}

A precificação dos ativos exploratórios pela métrica de OR tem como entradas os parâmetros de mercado, as estimativas dos parâmetros geológicos e de produção de cada prospecto. No começo desta seção serão apresentadas as estimativas dos parâmetros de mercado e os fatores particulares de cada oportunidade (seção 4.1).

Com essas informações, é possível analisar os prospectos separadamente e em carteira com efeito do aprendizado (seção 4.2.1), destacando as diferentes métricas usadas nos jogos nas seções seguintes.

Nos estudos dos option-games, primeiramente é analisado um jogo simétrico (seção 4.2.2.1) para depois apresentar um jogo assimétrico (seção 4.2.2.2), sendo esta uma situação mais realista na exploração de petróleo. Neste último caso, são verificadas as condições necessárias para a ocorrência da guerra de atrito, feita pela mudança de um dos parâmetros que compõe o valor do projeto de um dos jogadores. Após explorar as condições e os intervalos do conflito, é apresentado o jogo final com portfólio (seção 4.2.3). Em todos os jogos é proposta a mudança para a barganha cooperativa e são analisadas as condições para isso.

\section{1}

\section{Dados de Entrada}

\subsection{1}

\section{Hiperparâmetros do Preço do Petróleo: MGB}

As bases de dados da US Energy Information Administration, IMF e FRED apresentam as séries históricas do preço spot dos óleos tipo Brent e WTI. Essas informações são trabalhadas por essas agências (bancos e organizações), sendo estimativas do preço spot, médias e coletâneas de informações de organizações que pesquisam o preço à vista. O preço à vista não é negociado em bolsa e sim os contratos futuros (CME Group). Normalmente, o que é apresentado em painéis como Trading Economics, Oil Price, Bloomberg e outros são os contratos com o vencimento em um mês, uma proxy razoável do preço à vista. Ciente disso, como uma estimativa inicial dos parâmetros, 
será trabalhada a série da US Energy Information Administration do óleo tipo $W T I$. Após essa análise, será feito um estudo com alguns contratos futuros para a estimativa dos hiperparâmetros do preço spot.

Os dados da EIA (2020) são semanais e janelados no intervalo de 1996-2016 (figura 4.1). O teste Dickey-Fuller Aumentado (ADF) foi aplicado nessa série histórica. Não é possível rejeitar a hipótese nula $\left(H_{0}\right)$ de nãoestacionariedade da primeira diferença dos preços dado o p-valor de 0.21149. Isso quer dizer que não é possível rejeitar o MGB para esse intervalo frente a outros modelos como de reversão à média. Notando as feições estilizadas da série, além dos saltos referentes à crise de 2008, a tendência de crescimento exponencial dos preços é um bom indicativo de não rejeição do modelo MGB.

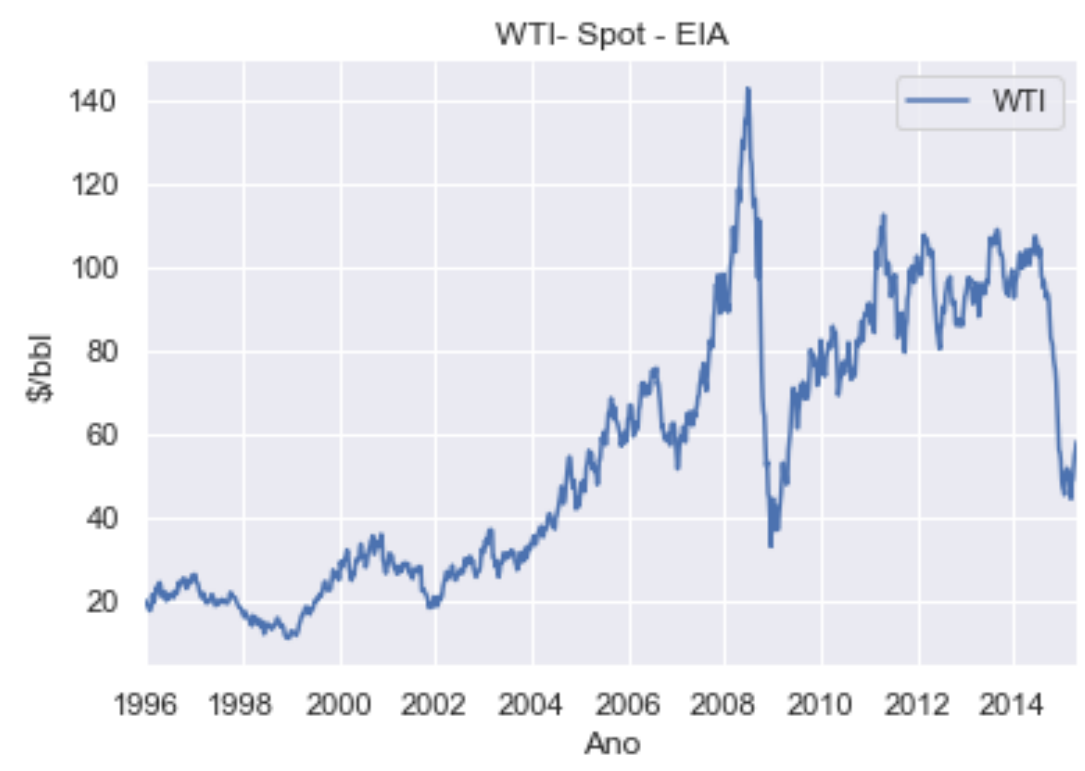

Figura 4.1: Preço Spot- WTI- EIA

Nesse caso, em um modelo de preço $\left(S_{t}\right)$ igual à equação (3-10), o retorno é estacionário em que o erro estimado é uma distribuição normal, ou seja, $\epsilon_{t}$ $\sim N\left(0, \sigma^{2}\right)$, sendo $\sigma^{2}$ igual a:

$$
\sigma^{2}=\operatorname{Var}\left[\ln \left(S_{t-1} / S_{t}\right)\right]
$$

e o drift $\alpha$ é

$$
\alpha=\mathbb{E}\left[\ln \left(S_{t-1} / S_{t}\right)\right]+\frac{1}{2} \sigma^{2}
$$

Aplicando essas equações nessa série temporal, o parâmetro $\sigma$ é igual a $31.15 \%$ e o parâmetro $\alpha$ é igual a $10.43 \%$ ao ano.

Os 20 contratos futuros são do óleo tipo WTI, entre os períodos de 1996-2016, com informações semanais, de vencimento CL1 a CL20, possíveis 
de serem acessados em Quandl-CME (2020). Os dados trabalhados já estão tratados, sem informações faltantes e eliminados os efeitos de saltos em situações do tipo short-squeeze. A figura (4.2) apresenta 2 contratos, o CL1 e o $C L 20$.

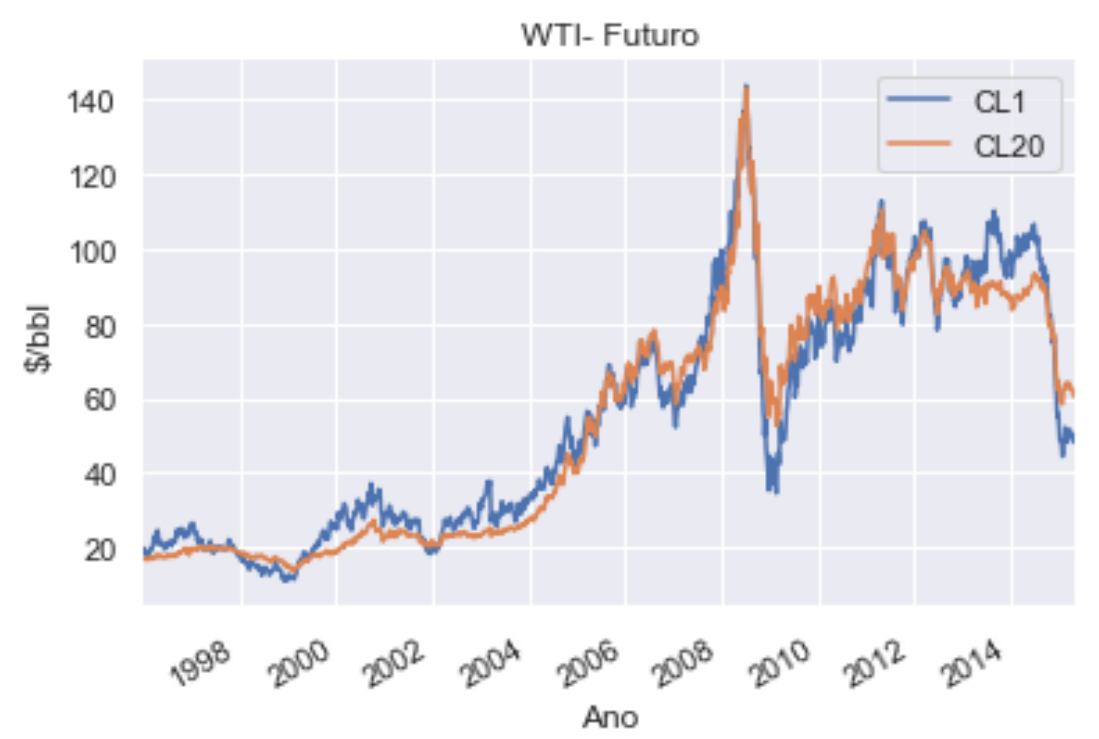

Figura 4.2: Preços Futuros - WTI

Note a diferença de estocasticidade entre as duas séries, sendo a série mais curta com uma maior volatilidade. Ademais, a séria mais longa (CL20), até por volta do ano de 2006, é mais barata que a série de um mês. Essa feição é típica de backwardation e em situação inversa, como entre 2008 e 2012, a série $C L 20$ é mais cara que a série $C L 1$, efeito conhecido como contango. Como visto na seção (3.3) e na demonstração da equação (3-17), no modelo em que o preço spot segue um MGB, a característica crescente ou decrescente da estrutura a termo do preço futuro só depende da relação $r-\delta$. Por outro lado, os modelos mais sofisticados, como os de dois ou mais fatores, tentam captar essas variações temporais na estrutura a termo dos preços (SCHWARTZ, 1997).

A figura (4.3) mostra a estrutura a termo da volatilidade desses contratos, demonstrando uma queda na volatilidade com o aumento dos prazos. Como visto na seção (3.3) e na demonstração da equação (3-19), a estrutura a termo da volatilidade em um modelo MGB para o preço spot não varia em relação ao vencimento do contrato e é igual a volatilidade do preço spot. Para captar esse decréscimo da volatilidade com o aumento do prazo, foram desenvolvidos outros modelos, como de um fator com reversão à média dos logaritmos dos preços e de dois e três fatores (SCHWARTZ, 1997). 


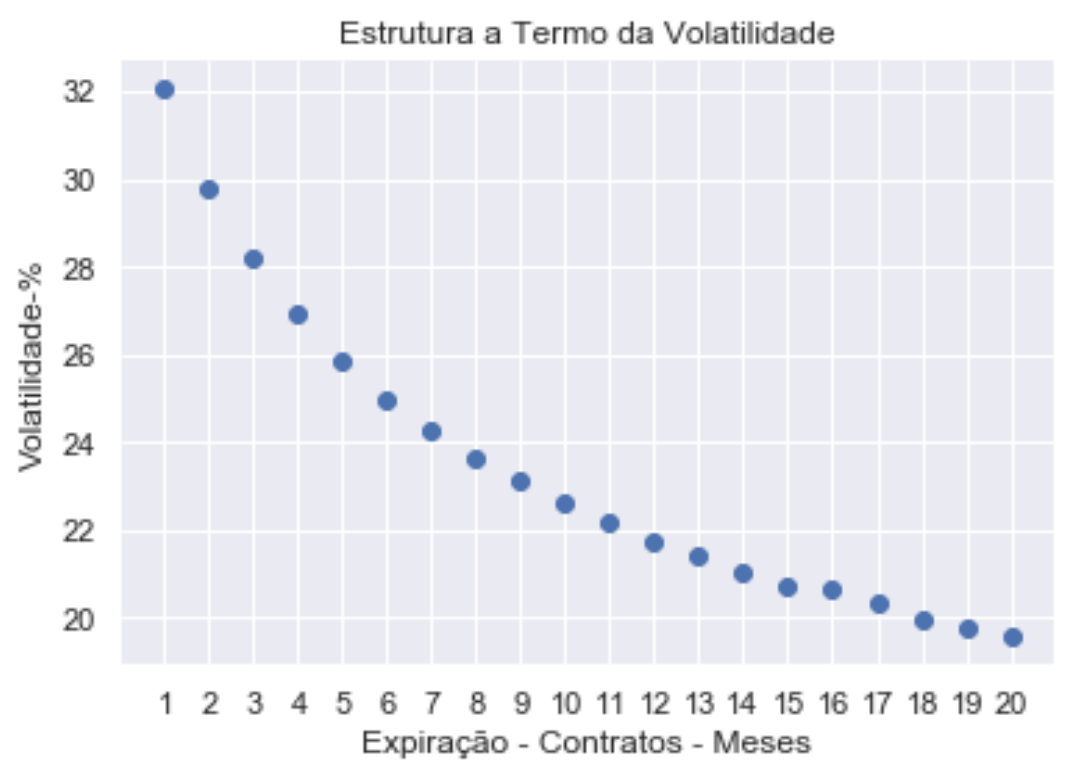

Figura 4.3: Estrutura a Termo da Volatilidade

Considerando o contrato CL1 como proxy do preço spot, foi aplicado o teste ADF para esta série. Não é possível rejeitar a hipótese nula $\left(H_{0}\right)$ de nãoestacionariedade da primeira diferença dos preços dado o p-valor de 0.2207. Aplicando as equações (4-1 e 4-2), obtêm $\sigma=32.07 \%$ e $\alpha=9.14 \%$ ao ano, resultados bem próximos da estimativa com a série histórica do spot da EIA (2020).

Pelas equações (3-17 e 3-18) da seção (3.3), caso a taxa livre de risco seja constante, é possível obter a taxa de conveniência implícita (GIBSON; SCHWARTZ, 1990). Os dados de taxa de juros de curto prazo são acessíveis em Quandl-FRED (2020), aplicativo vinculado ao FRED. Trata-se da TreasuryConstant-Maturity de três meses não dessazonalizada e em porcentagem, com as informações diárias desde 1981, janelada entre 1996 e 2015 (figura 4.4). 


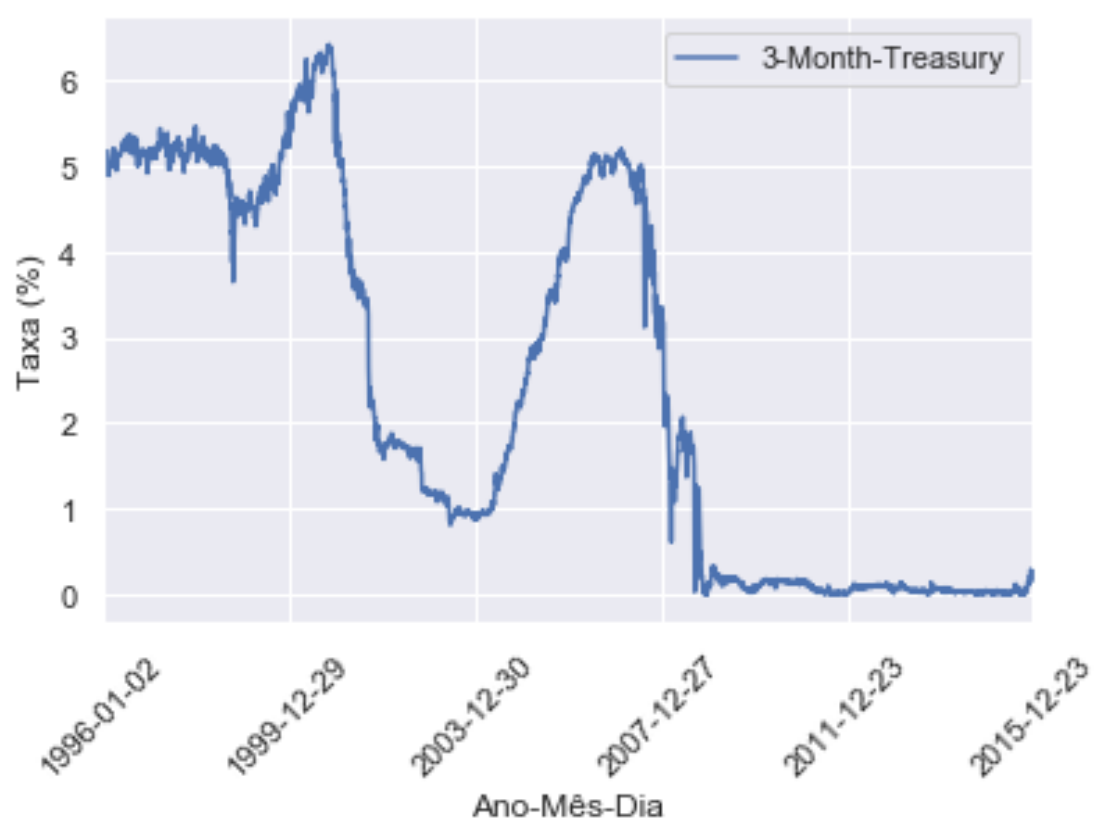

Figura 4.4: Taxa livre de Risco - Treasury 3 meses

Nota-se uma instabilidade dos juros americanos de curto prazo nas décadas de noventa e nos anos 2000. O intuito não é gerar um modelo estocástico para a taxa de juros, mas somente estudar os momentos, sendo a média igual a $2.4056 \%$ e o desvio padrão de $2.21 \%$ ao ano. Esse valor médio de $r$ foi aplicado na equação (3-18) para os contratos $C L 1$ e $C L 2$, que pode ser visto na figura (4.5).

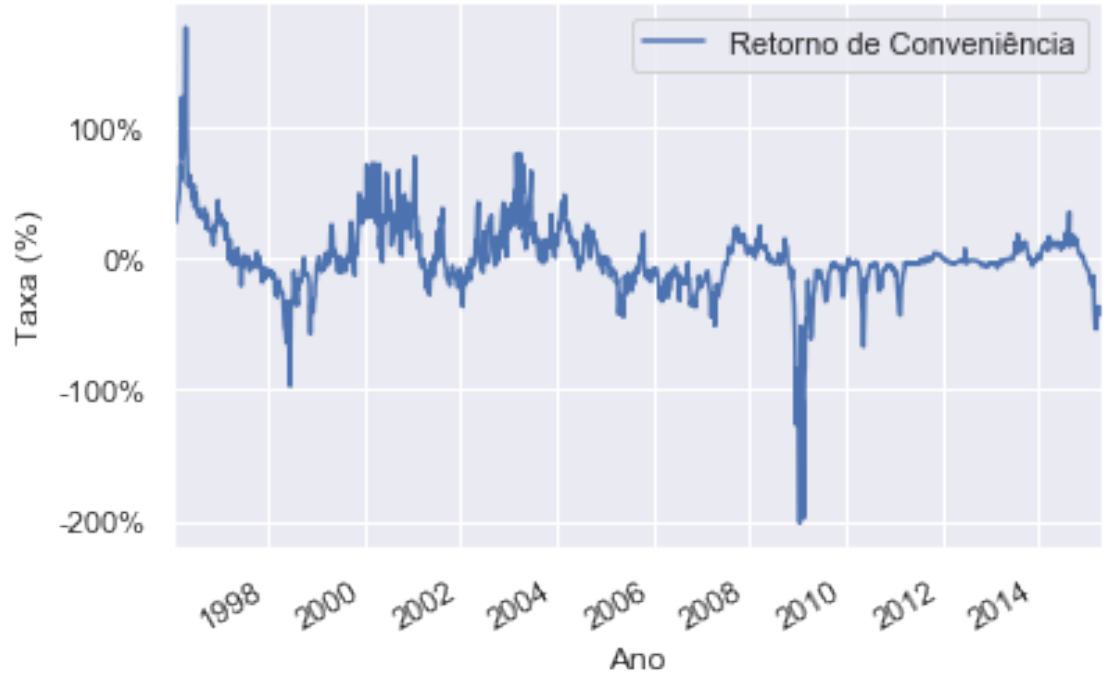

Figura 4.5: Retorno de Conveniência Implícito - $\delta$

A série da taxa de conveniência implícita de curto prazo $(C L 2 / C L 1)$ mostra feições estilizadas de um processo estocástico. Três características 
chamam a atenção dessa série temporal: uma alta volatilidade, um efeito de reversão para valores próximos de zero e uma forte reversão para esse valor. Nesse intervalo, possui o valor máximo de $176 \%$, o mínimo de $-201.6 \%$, a média de $0.76 \%$ a.a. e o desvio padrão de $26.8 \%$ ao ano.

Usando o primeiro contrato como a aproximação do preço spot, a partir da média das séries do retorno de conveniência implícito, é possível montar a estrutura a termo desses retornos. A figura (4.6) apresenta a estrutura a termo com a média das séries. Nota-se um aumento da taxa média com o aumento do prazo dos contratos, estabilizando-se em torno de $4.88 \%$ ao ano.

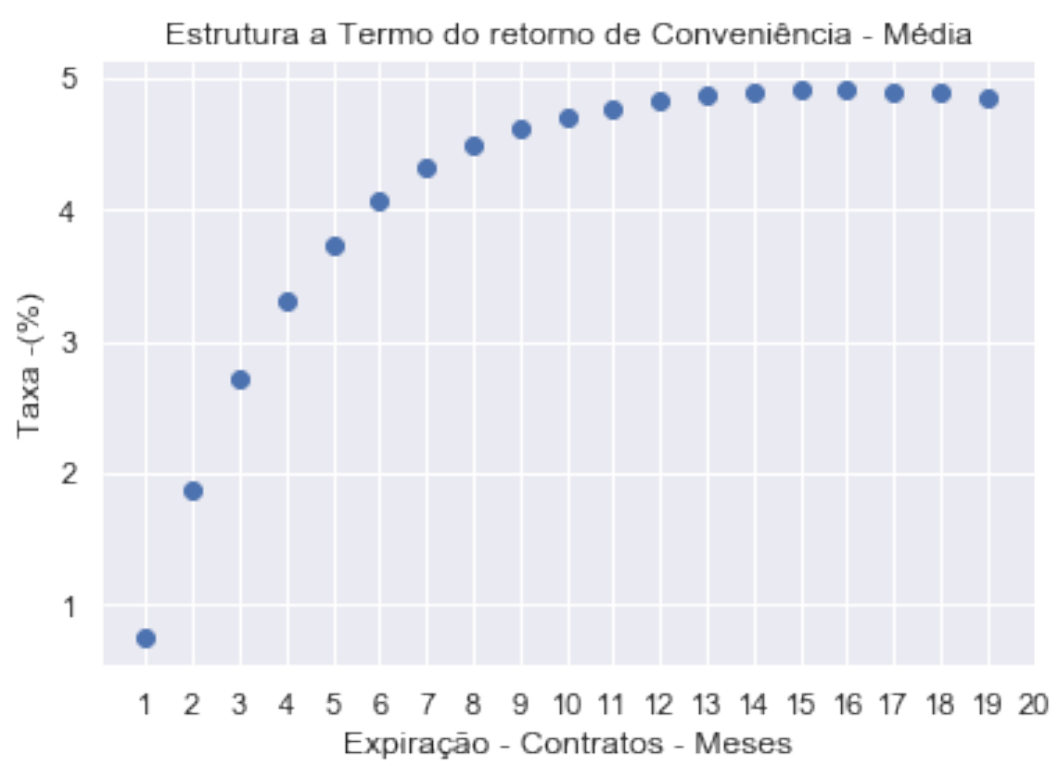

Figura 4.6: Estrutura a termo do Retorno de Conveniência - Média

Os projetos na área de óleo e gás são de longa duração. Considerando um modelo MGB para o preço spot do petróleo, a taxa de conveniência (carry) é uma medida relevante e deve ser estimada para a modelagem de OR, contudo, as medidas de curto prazo interferem pouco nas decisões de investimentos. Portanto, na implementação de um modelo de OR, é importante considerar as médias da taxa de conveniência de longo prazo, evitando as taxas instantâneas.

O retorno de conveniência da figura (4.5) pode ser modelado como um processo estocástico de reversão à média de Ornstein-Uhlenbeck, com um parâmetro de velocidade de reversão $\kappa$, uma média de longo prazo $\bar{\delta}$, como pode ser visto na equação (4-3) e a sua discretização na equação (4-4).

$$
\begin{gathered}
d \delta_{t}=\kappa(\bar{\delta}-\delta) d t+\sigma d z_{t} \\
\delta_{t}-\delta_{t-1}=a+b \delta_{t-1}+\varepsilon_{t} \quad \epsilon_{t} \sim \mathbf{N}\left(0, \sigma_{\varepsilon}^{2}\right)
\end{gathered}
$$


Onde, $\kappa \bar{\delta} d t$ é referente ao coeficiente $(a)$ da aproximação, $-\kappa d t$ se refere ao coeficiente $(b)$ e o termo browniano é associado ao $\varepsilon_{t}$ da regressão. Sendo o intervalo de $\Delta t=1 / 52$ ano, os parâmetros do modelo são:

$$
\begin{gathered}
\kappa=-b / \Delta t \\
\bar{\delta}=a /-b \\
\sigma=\sigma_{\epsilon} / \sqrt{\Delta t}
\end{gathered}
$$

Como dito, o parâmetro $\bar{\delta}$ representa a reversão de longo prazo. Dessa forma, é possível montar a estrutura a termo com esse parâmetro, sendo mais rigoroso que o uso da média como apresentado na figura (4.6). A figura (4.7) mostra essa estrutura a termo do retorno de conveniência. Nota-se que essa nova série é assintótica em valores próximos de $\bar{\delta}=3.80 \%$ a.a..

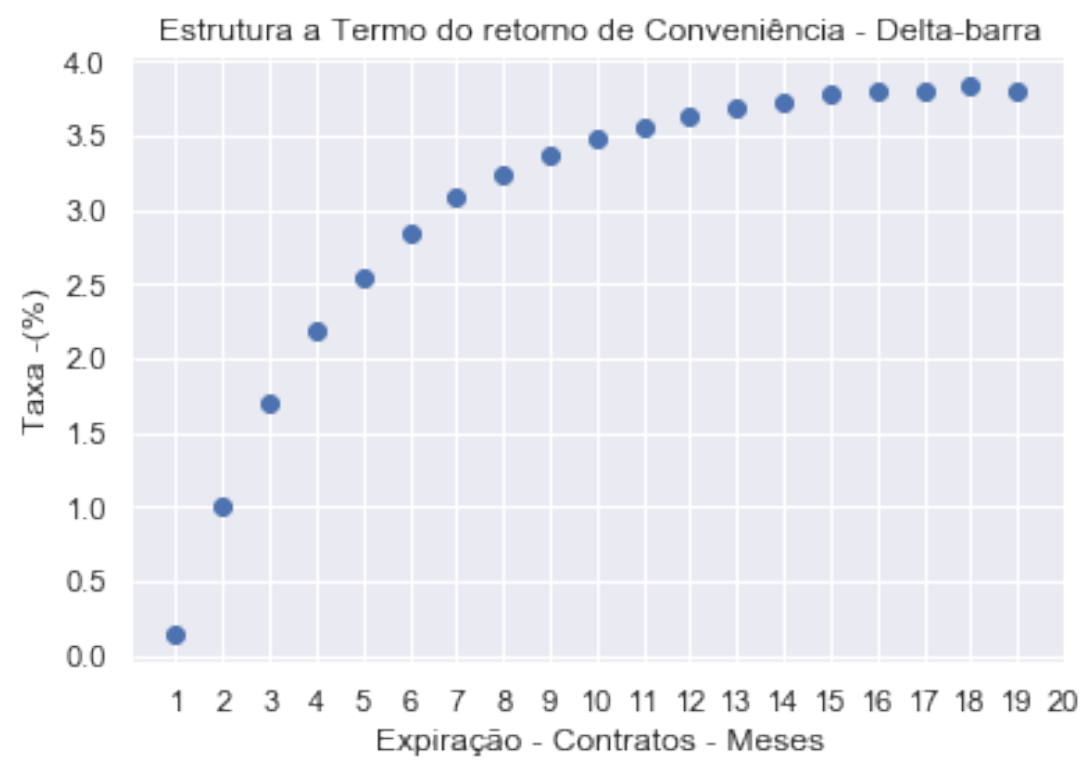

Figura 4.7: Estrutura a termo do Retorno de Conveniência - $\bar{\delta}$

Com os contratos futuros, é possível estimar pelo filtro de Kalman os hiperparâmetros do preço à vista. O Modelo MGB foi apresentado na forma de espaço-estado na seção (3.3), com as equações (3-21 e 3-20). Como o MGB não capta bem os efeitos da volatilidade e dos preços ao longo dos contratos, decidiu-se utilizar somente três contratos, sendo os mais próximos do preço à vista (CL1, CL2 e CL3). A aplicação seguiu Shumway e Stoffer (2017, Cap. 7).

A volatilidade $(\sigma)$ é o único hiperparâmetro significativo, já que os outros têm estatística t menor que 1.96 dado $5 \%$ de significância (tabela 4.1). A volatilidade estimada pelo filtro de Kalman é bem próxima ao mesmo 


\begin{tabular}{|c|c|c|}
\hline Parâmetros & Estimativa & teste-t \\
\hline \hline$\sigma$ & 0.2981 & 47.960 \\
\hline$\mu$ & 0.1287 & 0.0006 \\
\hline$r$ & 0.0867 & 0.0004 \\
\hline$\delta$ & 0.0846 & 0.0004 \\
\hline
\end{tabular}

Tabela 4.1: Parâmetros estimados - Filtro de Kalman

parâmetro estimado pelo preço spot da série da EIA (2020) e da aproximação do contrato $C L 1$ para o preço à vista. A figura (4.8) apresenta o dado estimado (azul), o suavizado (preto) e o observado CL1 (vermelho) no intervalo de tempo entre 2011 e 2015.

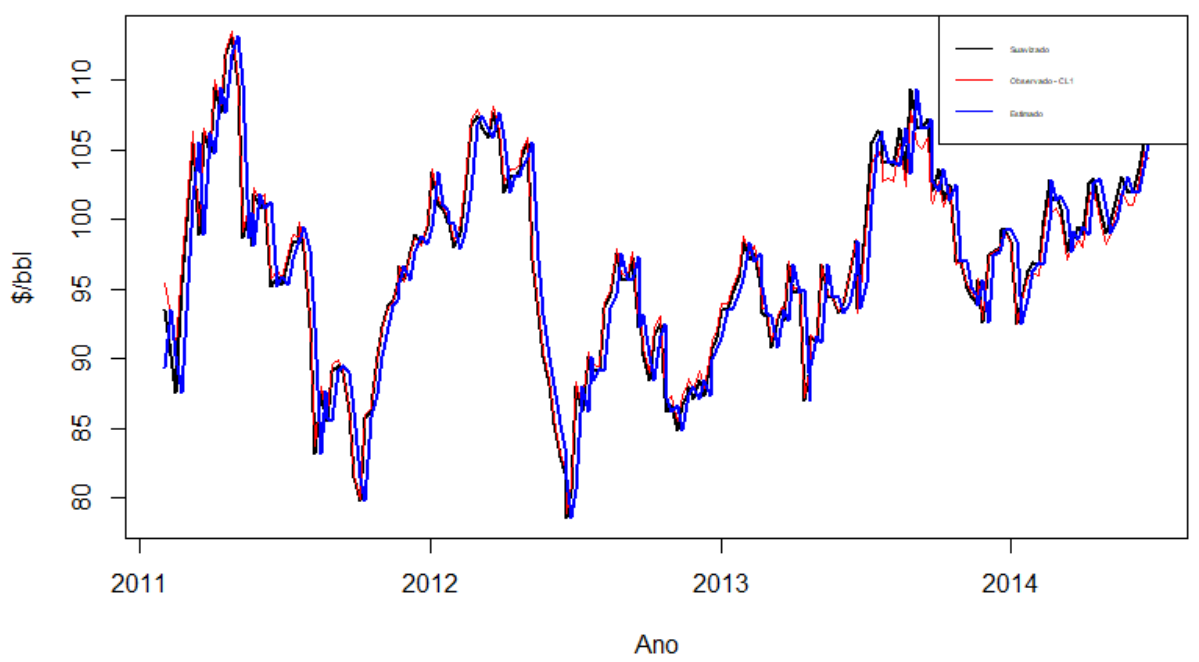

Figura 4.8: Filtro de Kalman - Estimado, Suavizado e Observado

A volatilidade é o principal parâmetro de entrada em precificação pelo método de OR. É nela que se materializa a incerteza e como provado na seção (3.2), a volatilidade do valor do projeto de um campo de petróleo em um modelo linear é igual à volatilidade do barril de petróleo (equação 3-6). Neste sentido, caso haja um aumento na volatilidade do preço do barril, mais incerto é o exercício do investimento na jazida, elevando o prêmio da espera da opção de explorar e devido a isso, o investidor vai postergar o início do investimento. Desse modo, a mudança da volatilidade afeta o valor da opção de explorar e por consequência, no caso de um jogo de guerra de atrito, afeta o início do possível conflito.

A taxa de conveniência pode ser lida como um dividendo pago ao detentor do ativo barril de petróleo. Essa taxa também afeta o valor da OR, e caso 
haja um aumento, menor é o prêmio de espera da opção de exploração e mais atraente é em investir no poço pioneiro. Dessa forma, no caso de uma guerra de atrito, a mudança desse parâmetro vai afetar o momento de investir e consequentemente, vai alterar o intervalo do conflito por informação.

\subsection{2}

\section{Investimento em Desenvolvimento - Volume Recuperável}

O investimento em desenvolvimento $(I d)$ é uma variável que depende das características próprias do projeto e do preço de mercado. Os preços dos insumos, como o aço e as tubulações, são relevantes para a construção de módulos, tanto em unidades flutuantes de produção (FPSO) quanto em estruturas menores como subsea tie-back. A oferta e a demanda dessas estruturas também modulam os preços de mercado e esses mercados são aquecidos essencialmente pela variação do preço do barril de petróleo, portanto, as séries de preços dos insumos da produção possuem uma correlação com o preço spot do barril de petróleo.

Por outro lado, os fatores locais também são relevantes para o investimento na produção. A lâmina d'água determina se a plataforma é fixa, semisubmerssível ou flutuante e implica em distintas ordens de investimento. As características do hidrocarboneto também determinam o projeto, como por exemplo, os campos que predominam gás possuem investimentos distintos comparados aos campos que possuem predominantemente óleo. Considerando todos os parâmetros descritos constantes, o fator interno que é dominante na determinação do valor de investimento é o volume recuperável do campo $(B)$. Desse modo, pela equação (3-8), foi estimada a correlação entre essas duas grandezas.

As informações analisadas sobre o investimento no desenvolvimento do campo de petróleo foram obtidas de relatórios da IHS Markit. Na plataforma dessa consultoria foram estudados treze projetos de investimento de extração de óleo, sendo todos no mesmo contexto geológico, com programas de investimentos atualizados e execução em momentos próximos. O gráfico dessa análise pode ser visto na figura (4.9) e a regressão é apresentada pela equação (4$5)$, sendo o volume recuperável $B$ em milhões de barris e o investimento em milhões de dólares. 


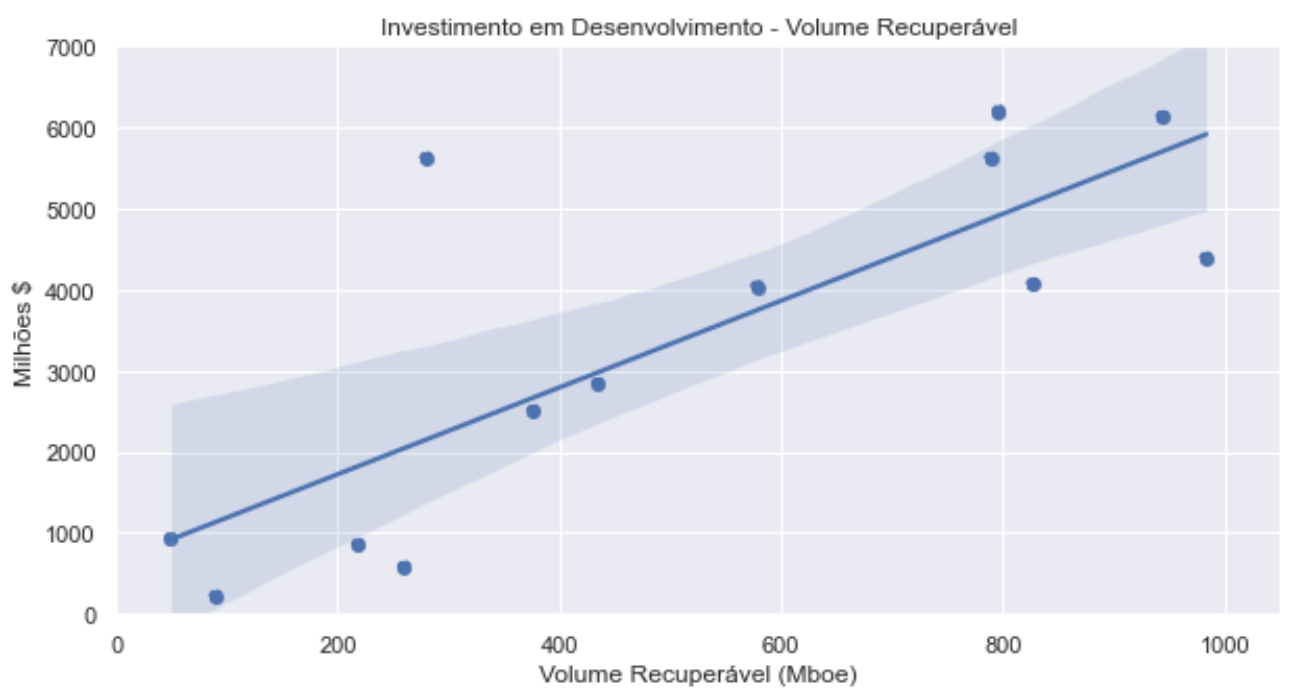

Figura 4.9: Investimento em Desenvolvimento - Volume Recuperável

$$
I_{d}(B)=650+5.35 B \quad\left(R^{2}=0.628\right)
$$

Essa relação entre o custo do investimento no campo e o volume recuperável é importante nos jogos assimétricos da guerra de atrito (seção 4.2.2.2 e 4.2.3). Com essa função afim, caso os técnicos reavaliem o volume recuperável esperado dos prospectos, é possível alterar a quantidade investida para desenvolver a jazida. Nos exercícios feitos para compreender o intervalo de preços de petróleo que ocorre o conflito, o parâmetro $B$ é alterado, tornando a oportunidade mais atraente para o investimento, consequentemente mudando o momento ótimo de explorar e modificando os equilíbrios do jogo.

\subsection{3}

\section{Taxa livre de risco}

Como descrito anteriormente, os projetos em OR são de longo prazo, por conseguinte, o estudo das séries históricas de título público deve privilegiar períodos de longo prazo. A taxa do título público americano com vencimento de 20 anos pode ser encontrada em FRED (2020). A figura (4.10) apresenta essa taxa desde o ano de 1994 até o tempo presente. Como os dados do preço do mercado futuro do petróleo estão limitados até o ano de 2016, a análise da taxa livre de risco também será limitada até essa data. 


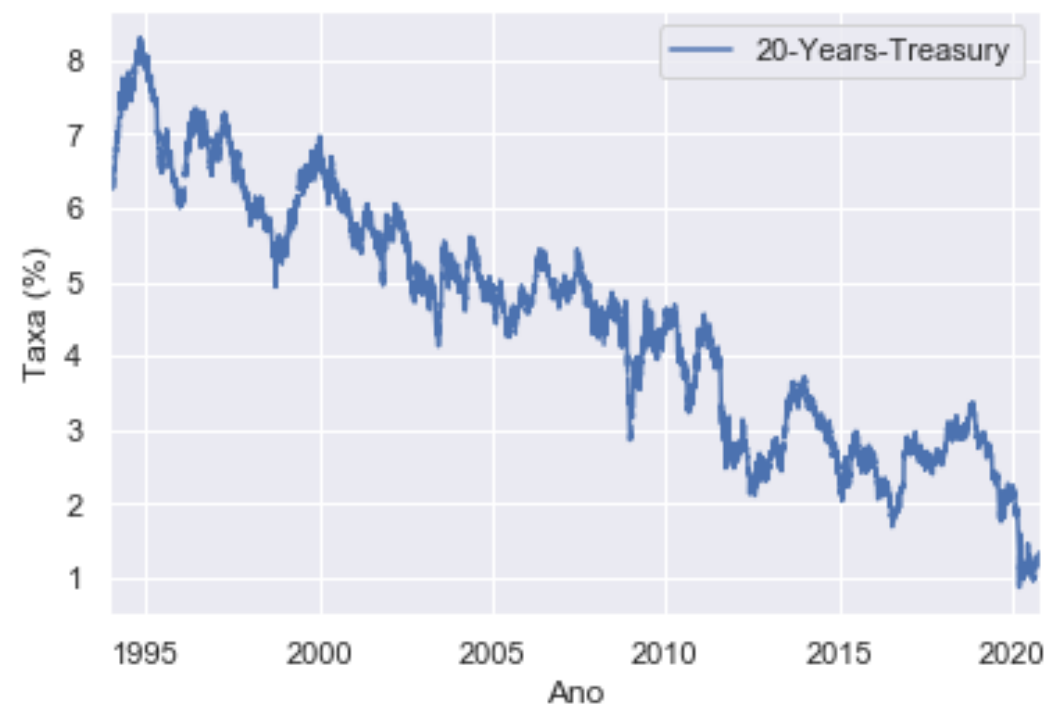

Figura 4.10: Título público Americano - 20 anos

Aqui não se pretende considerar um modelo estocástico para a taxa livre de risco. Assim, esta análise é simplesmente a média em um intervalo de tempo. Para isso, foi determinado que o período não fosse maior que dez anos, visto que a opção de espera é de 3 anos. Por essa razão, optou-se por uma janela entre 2010 e 2016, com a média igual a $3.02 \%$ ao ano.

Como a modelagem em OR é feita em medida martingal $Q$ (seção 3.3), os projetos não consideram a taxa ponderada ao risco e adotam a taxa livre de risco. Quando a taxa livre de risco sobe, a atração por investir em projetos cai e consequentemente o prêmio da espera aumenta. Pela mesma razão, o preço do gatilho em explorar sobe e fica mais improvável investir no poço pioneiro, também afetando o intervalo da possível guerra de atrito.

\subsection{4}

\section{Parâmetros Exógenos}

A tabela (4.2) consolida os parâmetros exógenos estimados em valores arredondados. Esses serão as entradas para os cálculos das diversas opções reais.

\begin{tabular}{|c|c|c|}
\hline$r(\%)$ & $\delta(\%)$ & $\sigma(\%)$ \\
\hline \hline 3.00 & 3.80 & 30.00 \\
\hline
\end{tabular}

Tabela 4.2: Parâmetros Exógenos Estimados - (\%) a.a.

Em suma, na seção (3.3), discutiu-se sobre as qualidades do MGB, basicamente sobre a média e a variância do processo (equações 3-12 e 3-13). No caso do movimento sob medida martingal (equação 3-15), as propriedades 
ótimas em relação à variância ocorrem quando $r-\delta>-\frac{1}{2} \sigma^{2}$. Com os hiperparâmetros da tabela (4.2), essa relação se mantém $(-0.008>-0.0450)$, ou seja, a variância é monotônica e crescente. Já a média do processo estocástico sob medida $Q$ é decrescente, visto que $r<\delta$. Como um exemplo, tendo um valor inicial de $S_{0}=\$ 50$ e considerando os parâmetros da tabela (4.2), a esperança sob medida martingal em 3 anos é de $\$ 48.81$ o barril $\left(\mathbb{E}^{\mathbb{Q}}\left[S_{T}\right]=S_{0} e^{(r-\delta) T}\right)$.

\subsection{5}

\section{Parâmetros Endógenos}

Os parâmetros endógenos são relacionados aos prospectos existentes nos dois blocos exploratórios. Como pode ser visto na tabela (4.3), os blocos possuem somente três prospectos: DogFish, Feather e Head, em que o volume recuperável $B$ está em milhões de barris $(M b b l)$ e os investimentos estão em milhões de dólares $(M \$)$. Os prospectos DogFish e Feather fazem parte do bloco operado pela empresa $A$ e o prospecto Head é a única oportunidade do bloco operado pela empresa $B$. Nos jogos, muitas vezes a operadora $A$ será designada de jogador 1 e a operadora $B$ de jogador 2 .

\begin{tabular}{|c|c|c|c|c|c|c|}
\hline Denominação & Operador & $B(M b b l)$ & $\mathrm{q}(\%)$ & $\mathrm{FC}(\%)$ & $I_{w}(\mathrm{M} \$)$ & $I_{d}(\mathrm{M} \$)$ \\
\hline \hline DogFish & $A$ & 620 & 20.00 & 30.00 & 80.00 & 3967.00 \\
Feather & $A$ & 310 & 21.00 & 25.00 & 60.00 & 2308.50 \\
\hline Head & $B$ & 950 & 18.00 & 20.00 & 80.00 & 5732.50 \\
\hline
\end{tabular}

Tabela 4.3: Parâmetros Endógenos dos Prospectos

Como apresentado na seção (4.1.2), o investimento em desenvolver o campo de petróleo $\left(I_{d}\right)$ é em função do volume recuperável esperado $(B)$, de acordo com a equação (4-5).

Todos os prospectos têm correlações dois a dois. Como são três prospectos, então são 3 correlações $=\left(\begin{array}{l}3 \\ 2\end{array}\right)$.

\begin{tabular}{|c|c|c|c|}
\hline$\rho$ & DogFish & Feather & Head \\
\hline DogFish & 1 & - & - \\
\hline Feather & 0.6 & 1 & - \\
\hline Head & 0.5 & 0.6 & 1 \\
\hline
\end{tabular}

Tabela 4.4: Correlação dos prospectos da bacia

Todas as oportunidades estão no mesmo play geológico. Os prospectos DogFish e Head estão na mesma profundidade, por isso têm o mesmo custo no poço exploratório $\left(I_{w}\right)$. Contudo, possuem menor correlação entre si, devido ao distanciamento entre eles. Ainda que a oportunidade Head tenha o maior volume recuperável esperado, a qualidade econômica é menor, devido às 
características permoporosas inferiores estimadas pelos técnicos. Além disso, a Head tem suas características mais fracas de indicador direto de presença de hidrocarboneto (DHI), já que o contorno estimado por mapas de amplitude sísmica não é compatível com o contorno estrutural, tendo, por essa razão, um FC menor que os outros prospectos. Já a oportunidade DogFish possui um volume recuperável estimado e as propriedades de qualidade intermediárias, com um DHI melhor de todos, portanto com o FC mais alto. Agora, o prospecto Feather possui um volume esperado menor, então seu custo de desenvolvimento da produção também é menor (equação 4.9). Dessa forma, não é tão atraente do ponto de vista de receita líquida, mas é importante no conjunto das oportunidades, visto que possui uma interessante correlação com as outras duas. Além do mais, possui uma vantagem exploratória, dado que o custo do poço pioneiro é menor, pois o soterramento do topo da oportunidade é mais raso comparado com as outras oportunidades. Isso, em termos de VOI, quer dizer que a oportunidade Feather tem o menor custo de aquisição da informação.

Como dito na seção (3.2), o parâmetro $q$ é a sumarização das características presentes no fluxo de caixa. Essa medida pode ser estimada do próprio fluxo de caixa pela equação (3-9). Para obtê-la, monta-se o fluxo de caixa com o preço constante do hidrocarboneto em todos os anos de produção. Depois, muda-se os preços de venda do hidrocarboneto de forma constante para todos os anos, tomando nota o Valor Presente Líquido resultante. O coeficiente angular dessa regressão entre o preço do hidrocarboneto e os VPLs resultantes é o produto $q B$. Como o volume recuperável médio é entrada para a montagem do fluxo de caixa, é só dividir o coeficiente angular por $B$ para obter a qualidade econômica $q$.

\section{2 \\ Modelos}

A figura (4.11) apresenta as três oportunidades em um mapa de localização. Os contornos das oportunidades representam em área o limite de ocorrência dos prospectos, sendo as linhas retangulares os perímetros dos blocos exploratórios e o contorno diagonal e curvilíneo fora dos blocos representa a linha de costa litorânea. Como todos os prospectos estão no mesmo nível estratigráfico, a cor é igual para todas as oportunidades e por conseguinte, a mesma cor indica que há uma correlação entre os prospectos. Considera-se essa apresentação como o modelo geral e que também será o último caso analisado na dissertação. Antes serão feitas diversas considerações, no caso de somente um bloco exploratório e em situações de até três oportunidades, além de um 
caso de conflito em que se varia o volume recuperável do prospecto. Todos esses modelos intermediários são importantes para auxiliar a compreensão do modelo geral e as condições para a guerra de atrito e a barganha cooperativa.

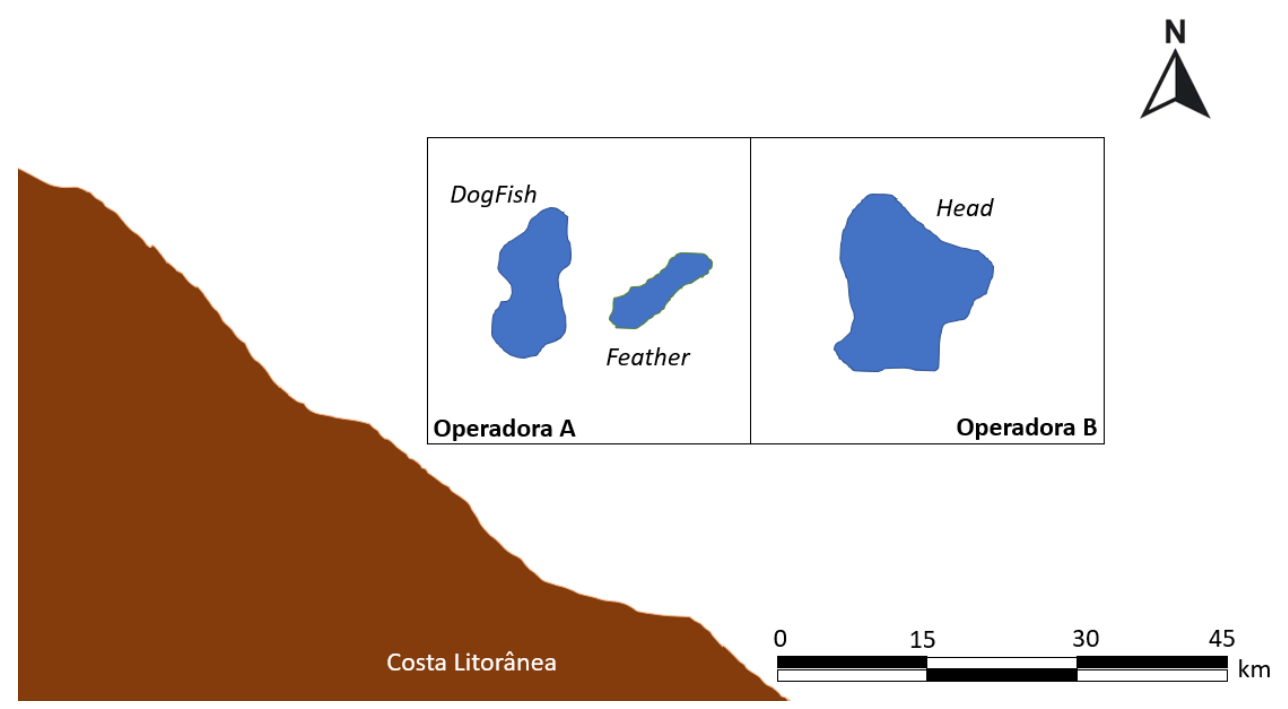

Figura 4.11: Modelo Geral - Blocos Exploratórios

\subsection{1}

\section{Um, Dois e Três prospectos: Um bloco}

Nesta seção serão apresentadas as soluções das três oportunidades, considerando os prospectos de forma independente e de forma conjunta, com o efeito do aprendizado entre os prospectos. Na apresentação dos prospectos de forma independente (stand-alone), a primeira oportunidade será analisada de forma mais minuciosa, detalhando as opções existentes. Nas demais, serão apresentados somente os resultados.

Os parâmetros aplicados nos prospectos estão na seção (4.1.5) e os parâmetros exógenos estão na seção (4.1.4), incluindo o preço do barril no tempo inicial de $\$ 50(P)$ e o prazo de 3 anos do contrato exploratório $(\tau)$.

Em todos os ativos e avaliações foi aplicada uma taxa de desconto ao modelo paramétrico ( $V$ - equação $3-1)$ e ao investimento em desenvolvimento $\left(I_{d^{-}}\right.$ equação 4-5), da mesma forma que em Dias e Teixeira (2009). A justificativa é que há um prazo de aproximadamente dois anos para começar a produção. Após a tomada de decisão de investir no poço pioneiro, nesse período de dois anos, o operador perde valor em uma taxa $\delta$ por decidir produzir e não poder, pois ainda não detém uma planta de produção e um desconto por uma taxa $r$ pelo capital aplicado na construção da FPSO, a qual ainda não produz. Por- 
tanto, para o $V$, foi aplicado o desconto de $e^{-2 \delta}$ e para o $I_{d}$, um desconto de $e^{-2 r}$, sendo as taxas em termos anuais.

Para cada oportunidade, o investidor tem em mãos duas opções encadeadas: a opção de explorar o prospecto e a opção de investir no desenvolvimento do campo (figura 4.12). Caso o operador ignore a opção de explorar, terá em mãos somente a opção de investir na produção do campo. É uma hipótese remota e funciona como se o investidor não tivesse dúvidas exploratórias. Essa situação pode acontecer caso uma outra empresa já tenha feito a exploração no prospecto a ser valorado e esta tenha as informações necessárias para produzir. Além disso, deve contar que ainda há um prazo no contrato exploratório e assim, o investidor tem a opção de investir ou não na extração do recurso $R(P, t)$. Nesse contorno, a equação diferencial a ser solucionada é a equação $(3-54)$.

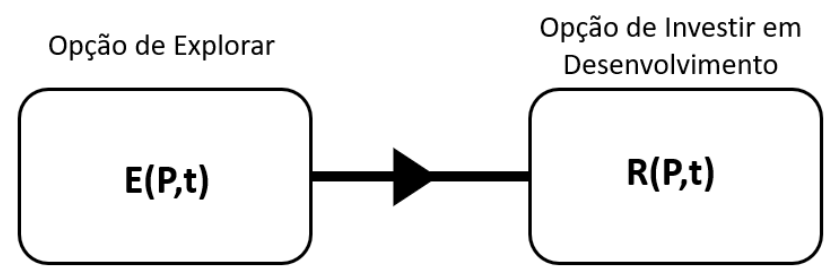

Figura 4.12: Opções em Petróleo - Conceitos em Dias (2015b, Cap .27)

Como em todos os exemplos desta dissertação, há um risco exploratório $(F C)$ em cada ativo, então a malha de soluções $R(P, t)$ deve ser ponderada pelo fator de chance líquido do custo do poço exploratório $I_{w}$, como na equação (3-56). Essa construção de valoração foi denominada $V M E(P, t)$ e se difere da valoração que será apresentada adiante $(E(P, t))$, pois ainda que considere o risco geológico, somente leva em conta a opção de investir em desenvolvimento, sem considerar a opção de explorar. Isso representa, na construção da valoração, que o risco exploratório e o investimento do poço pioneiro não são considerados na equação diferencial e sim posteriormente. Além disso, comparando o $V M E(P)$ ao $V M E(P, t)$, este último é mais rigoroso, dado que essas métricas são iguais somente acima do gatilho de investir $\left(V M E\left(P^{*}\right)=V M E\left(P^{*}, t\right)\right)$. Explicando de outra forma, a formulação $V M E(P, t)$ considera a opção de investir em desenvolvimento e assim é mais completa, pois insere alguma incerteza de preços, sendo que a formulação $V M E(P)$ é uma métrica de investimento de "agora ou nunca", em que não insere a incerteza de preços na valoração.

Já a opção de explorar $E(P, t)$ considera o risco e o investimento exploratório nas condições de contorno da equação diferencial, ou seja, na função 
máximo da condição terminal, a ponderação pelo FC do projeto líquido dos seus investimentos em produção deve ser maior que o custo do poço pioneiro (equação 3-55). Trata-se, no vencimento, do máximo entre zero e o $V M E(P)$ e por essa razão, a opção de explorar nunca é menor que zero. Portanto, a opção de explorar tem característica mais conservadora que o $V M E(P)$ e o $V M E(P, t)$, visto que este último também pode ser menor que zero e só considera a opção de investir em produção. Além do mais, o gatilho de investir em exploração é mais alto do que o gatilho do preço de investir no projeto de desenvolver o campo $R(P, t)$, com isso, a opção de explorar inclui a opção de investir em desenvolvimento, questão que será vista mais adiante por meio de um exemplo (figura 4.13). Esse efeito da função máximo e do ótimo entre esperar e investir em cada tempo do contrato são sumarizados no valor adicionado da espera comparado com o valor monetário esperado. Na tabela (4.5), os resultados da oportunidade exploratória DogFish foram consolidados nessas diversas métricas no início do contrato exploratório.

\begin{tabular}{|c|c|c|}
\hline DogFish & $\mathrm{M} \$$ & $\%$ \\
\hline \hline $\mathrm{VME}(\mathrm{P})$ & 523.08 & - \\
\hline $\mathrm{VME}(\mathrm{P}, \mathrm{t})$ & 558.23 & 6.72 \\
\hline $\mathrm{E}(\mathrm{P}, \mathrm{t})$ & 581.28 & 11.13 \\
\hline
\end{tabular}

Tabela 4.5: Avaliação de DogFish $-\tau=3$ anos $-P=\$ 50$

O valor da opção de explorar é $11.13 \%$ acima do $V M E(P)$. Esse valor acrescido é devido à espera, ou seja, a decisão de não investir. Mesmo que tenha um $\operatorname{VME}(\mathrm{P})$ positivo e alto, o investimento em exploração não está dentro do dinheiro e só estaria, no início do contrato, caso o preço do barril estivesse acima de $\$ 69.62$ (figura 4.13), porém está em $\$ 50$ /bbl. Esse valor de preço define o gatilho de investimento exploratório no momento inicial do contrato.

O gatilho é uma função implícita da opção americana e é em função das variáveis de estado preço e tempo (figura 4.13). É possível notar graficamente que é uma função decrescente com o tempo, sendo que no vencimento é o valor do preço do petróleo que faz com que o $\mathrm{VME}(\mathrm{P})$ seja igual a zero, ou seja, o break-even do VME. Nota-se, com esse exemplo, a superioridade da curva de gatilho ao break-even, visto que o gatilho é uma função e o breakeven é só um ponto no espaço preço x tempo. A curva de gatilho, também conhecida como fronteira ótima, é contínua, mas o serrilhado da figura é devido ao método numérico de solução. Contudo, uma descontinuidade pode acontecer no vencimento do contrato, caso $r>\delta$ (DIAS, 2015b, Capítulo 20, p. 259), em que não é o caso dos parâmetros estimados neste trabalho. Essa curva é 
afetada pelos parâmetros exógenos, assim sendo, com a subida do $\sigma$ do ativo base $(\mathrm{P})$, ou da relação $r-\delta$ ou de $\tau$, a curva de gatilho também se eleva, e por consequência sobe o prêmio por esperar, ou seja, elevando a porcentagem indicada na tabela (4.5).

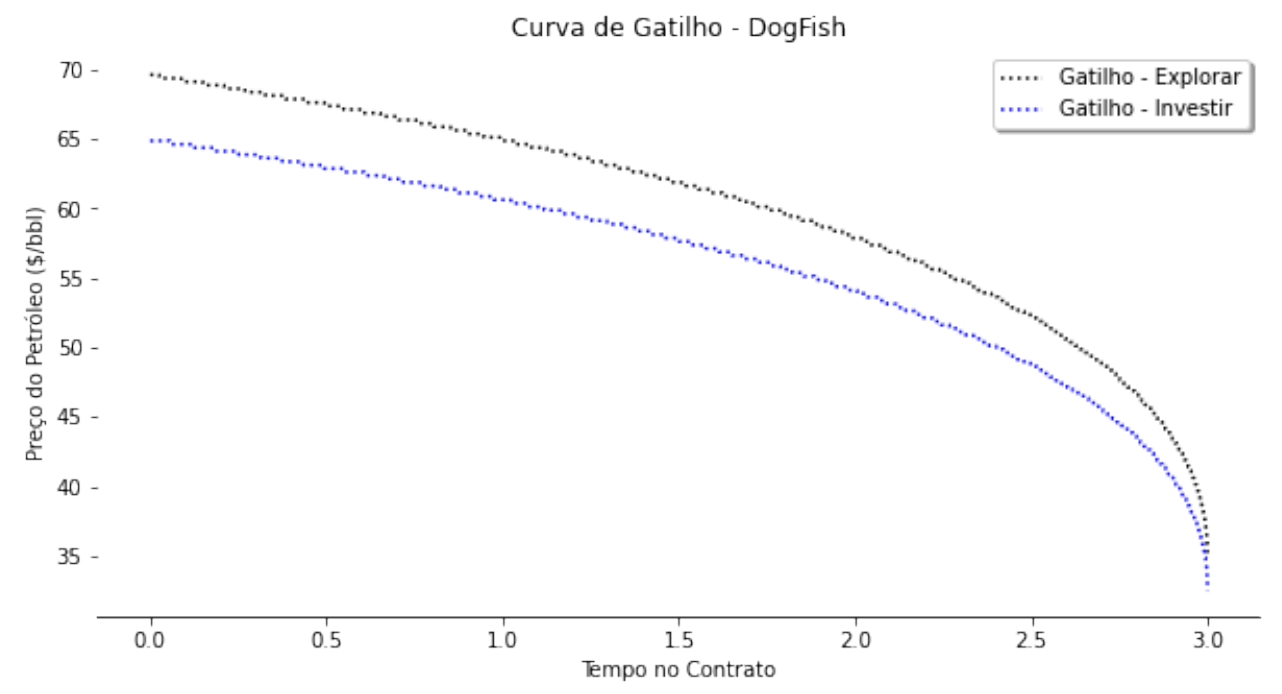

Figura 4.13: Curvas de Gatilho - DogFish

Nota-se que a curva de gatilho de explorar está sempre acima da curva de gatilho de investir em desenvolvimento. Portanto, considerar o gatilho de explorar já inclui a opção de investir na produção da jazida, pois a opção de explorar antecede a opção de investir em produção (figura 4.12) e caso exerça no gatilho de explorar, a opção de investir no campo de petróleo estará deepin-the-money.

Na figura (4.14) é apresentada a opção de explorar em dois momentos, no vencimento e no início do contrato. Note que a opção é convexa, maior ou igual a zero e no vencimento a opção é o máximo entre zero e a função VME(P) (comparar com a figura 4.15). Na avaliação da opção americana, verifica-se, em todo o instante de tempo, se o valor intrínseco é menor ou não do que o valor de postergar a decisão (não exercer imediatamente). Com o preço de $\$ 50$ o barril, a opção de explorar é viva, pois $\$ 581.28$ milhões é maior que $\$ 523.08$ milhões (tabela 4.5 e figura 4.13). Ou seja, deve-se aguardar melhores condições das variáveis de estado para investir em exploração. Nesse gráfico, pode-se extrair o gatilho no momento inicial do contrato. O gatilho ocorre quando a opção toca suavemente na função $\operatorname{VME}(\mathrm{P})$, sendo o $\operatorname{VME}(\mathrm{P})$ também o valor intrínseco da opção. Essas condições de contorno são exploradas em Dixit e Pindyck (1994, Capítulo 4, p.119) e em outros livros de OR. 


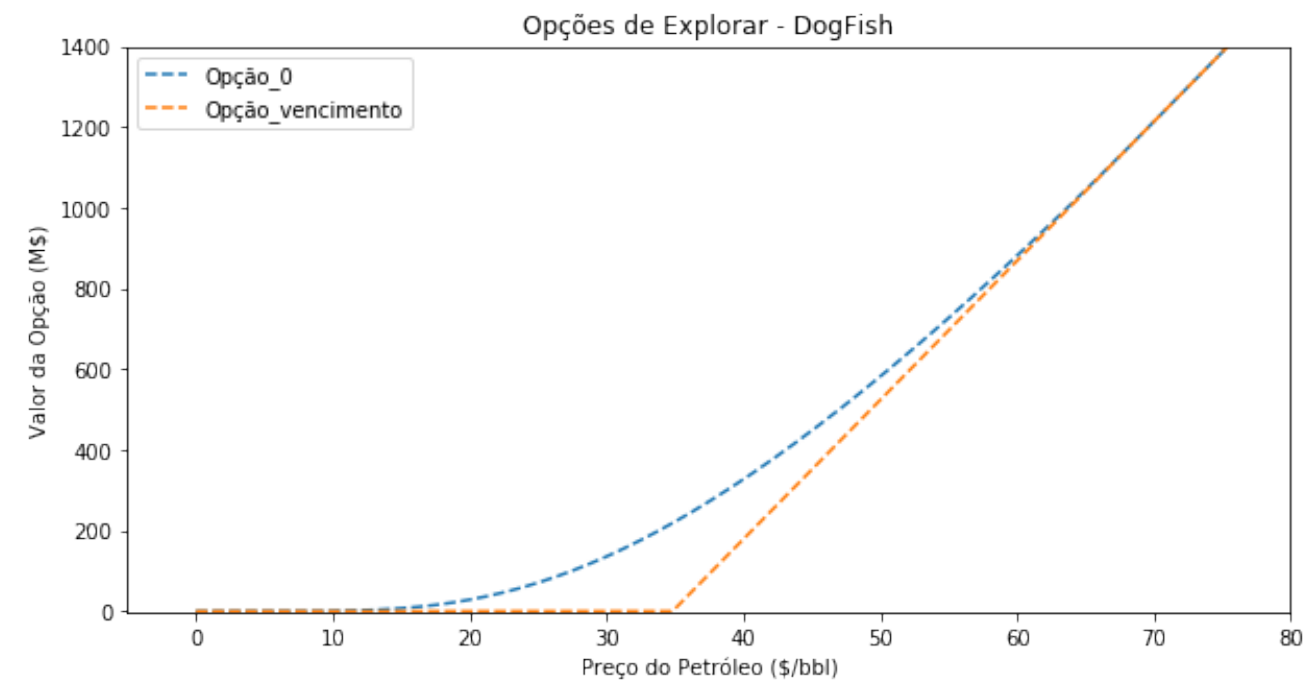

Figura 4.14: Opção de Explorar - DogFish

Segundo a tabela (4.5), o valor do $V M E(P, t)$ é $6.72 \%$ acima do $V M E(P)$. Esse valor acima vem do prêmio da esperar da opção de investir no desenvolvimento da reserva $R(P, t)$. A função $V M E(P, t)$, no tempo inicial do contrato pode ser vista na figura (4.15), em conjunto com a opção de explorar e o $\operatorname{VME}(\mathrm{P})$.

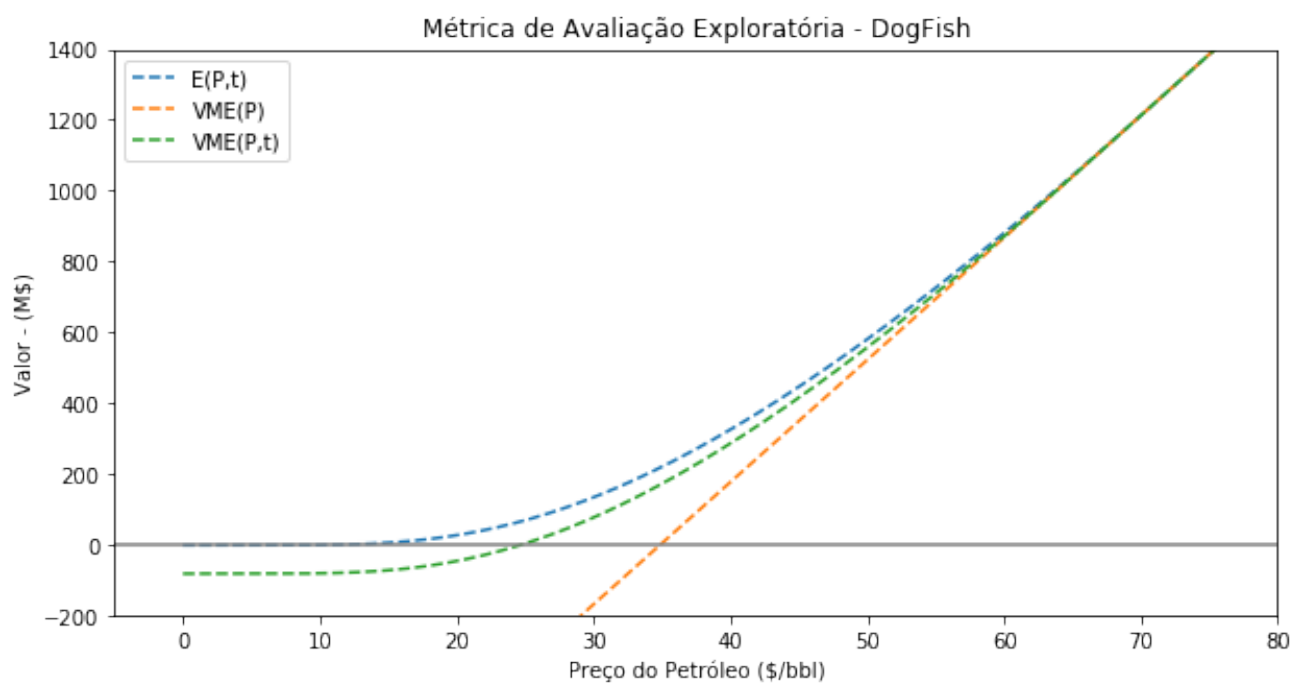

Figura 4.15: Métricas de Avaliação Exploratória - DogFish - $\tau=3$ anos

Nota-se, assim como o $\operatorname{VME}(\mathrm{P})$, que a função $V M E(P, t)$ também pode ser negativa, sendo o seu mínimo o investimento no poço exploratório ( $\$ 80$ milhões). Além disso, observa-se que a opção de explorar é igual ao $V M E(P, t)$ a partir do gatilho da opção de explorar, ou seja, a partir de $\$ 69.62$ o barril em 
$t=0(\tau=3)$. De fato, acima desse preço, as três funções possuem o mesmo valor, sendo todas iguais ao $\operatorname{VME}(\mathrm{P})$.

Em suma, o $V M E(P)$ e o $V P L(P)$ são medidas estáticas, que não consideram o prazo do contrato. A métrica $V M E(P, t)$ não considera a opção de explorar, mas considera a opção de investir no desenvolvimento da reserva, sendo mais adequada que o $V M E(P)$. Agora, a opção de explorar $E(P, t)$ já inclui a opção de investir em $R(P, t)$, porque o seu gatilho de explorar é superior ao gatilho de investir em desenvolvimento. Portanto, a métrica $E(P, t)$ é adequada à exploração de petróleo, já que considera o risco geológico (FC) na formulação do derivativo e considera todas as opções. A tabela (4.6) sintetiza os resultados das três oportunidades em avaliação stand-alone, com o preço do barril a $\$ 50(\mathrm{P})$, sendo $P^{*}$ o gatilho da opção de investir em desenvolvimento e $P^{* *}$ o gatilho da opção de explorar, analisados no tempo $t=0($ ou $\tau=3)$ :

\begin{tabular}{|c|c|c|c|c|c|c|}
\hline Métrica & \multicolumn{2}{|c|}{ DogFish } & \multicolumn{2}{|c|}{ Feather } & \multicolumn{2}{|c|}{ Head } \\
\hline & $\$ \mathrm{M}$ & $\%$ & $\$ M$ & $\%$ & $\$ \mathrm{M}$ & $\%$ \\
\hline VME(P) & $\bar{~} 523.08$ & - & 150.68 & 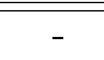 & $\bar{~} 425.12$ & - \\
\hline $\operatorname{VME}(\mathrm{P}, \mathrm{t})$ & 558.23 & 6.72 & 182.23 & 20.94 & 471.13 & 10.82 \\
\hline $\mathrm{E}(\mathrm{P}, \mathrm{t})$ & 581.28 & 11.13 & 206.14 & 36.81 & 497.71 & 17.08 \\
\hline \multicolumn{3}{|c|}{$\$ \$$ /bbl } & $\$$ \$/bbl & \multicolumn{3}{|c|}{$\$ / \mathrm{bbl}$} \\
\hline$\overline{P P^{*}}$ & 64.875 & - & 72.125 & - & 68.125 & 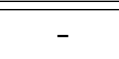 \\
\hline$P^{* *}$ & 69.625 & 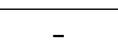 & 79.875 & - & 73.125 & - \\
\hline
\end{tabular}

Tabela 4.6: Aval. das oport. stand-alone $-\tau=3$ anos- $P=\$ 50$

A oportunidade Feather tem $36.81 \%$ de valor de espera em relação ao exercício imediato $(V M E(P))$, a Head tem $17.08 \%$ e a DogFish possui $11.13 \%$. Por essa razão, a DogFish está mais próxima do dinheiro e por consequência, tem o gatilho exploratório menor $\left(P^{* *}\right)$. Com a mesma justificativa, dado o prêmio de espera alto da oportunidade Feather, o gatilho exploratório é o mais elevado, ou seja, numa análise stand-alone, essa é a última oportunidade a ter investimento em exploração. O gatilho de investir em desenvolvimento $\left(P^{*}\right)$ não é tão analisado nessa etapa, pois ainda há um risco geológico envolvido e o dispêndio em um poço exploratório não é considerado no cálculo do derivativo. É possível notar que em todos os casos, o gatilho de investir em desenvolvimento é menor que o gatilho de explorar. Inclusive, o exercício da opção $E(P, t)$ no preço do gatilho de investir em desenvolvimento $P^{*}$ não possui lógica, pois caso fosse perfurado e descoberto uma jazida, o operador ficaria esperando por preços melhores para produzir o campo, dado que o 
gatilho $P^{*}$ não considera o dispêndio no investimento exploratório $I_{w}$. No caso de esperar, é melhor esperar sem ter o gasto do poço pioneiro e por essa razão que o gatilho de explorar é mais alto que o gatilho de investir em produção.

O estudo das oportunidades stand-alone é o primeiro passo para compreender a economicidade de um bloco exploratório. Na seção (3.6) foi apresentada a importância da análise em conjunto de um portfólio dada a correlação dos prospectos. Nos próximos passos, os modelos são iguais a Dias e Calvette (2017), a diferir do modelo de investimento na produção (equação 3-8). Esse paper analisa um portfólio exploratório com dois e três ativos usando o método binomial, sendo aqui as soluções apresentadas pelo método de diferenças finitas explícitas (Apêndice B). Os casos a seguir são situações hipotéticas para melhor analisar os exemplos nas situações com incerteza estratégica e para compreender as condições da guerra de atrito e da barganha cooperativa.

Como destacada na seção (3.6), devido à correlação dos ativos, o portfólio $(\pi(P))$ de maior valor pode depender da ordem de perfuração das oportunidades. Isso ocorre dado o maior poder de revelação de uma oportunidade em relação a outra. Como a revelação da informação interfere no fator de chance da seguinte oportunidade a perfurar, decide-se em função do máximo entre zero e o valor monetário da seguinte oportunidade dadas as informações reveladas, evitando valores negativos adicionados na carteira. Assim, certas ordens na sequência de prospectos correlacionados evitam mais cenários negativos que outras ordens.

Porém, essa análise é estática, pois não considera o efeito da incerteza de preços na carteira. Portanto, primeiramente será apresentado um exemplo do caso de portfólio $(\pi(P))$ e posteriormente serão apresentados diversos casos com o portfólio exploratório $(\Pi(P, t))$, o qual considera o valor do portfólio com o valor da espera. No final da seção, como uma sumarização dos resultados, será feita uma comparação das diferentes métricas de análise de carteira.

A primeira situação é o bloco exploratório operado pela empresa $A$, composto pelas oportunidades DogFish e Feather, como pode ser visto na figura (4.16). 


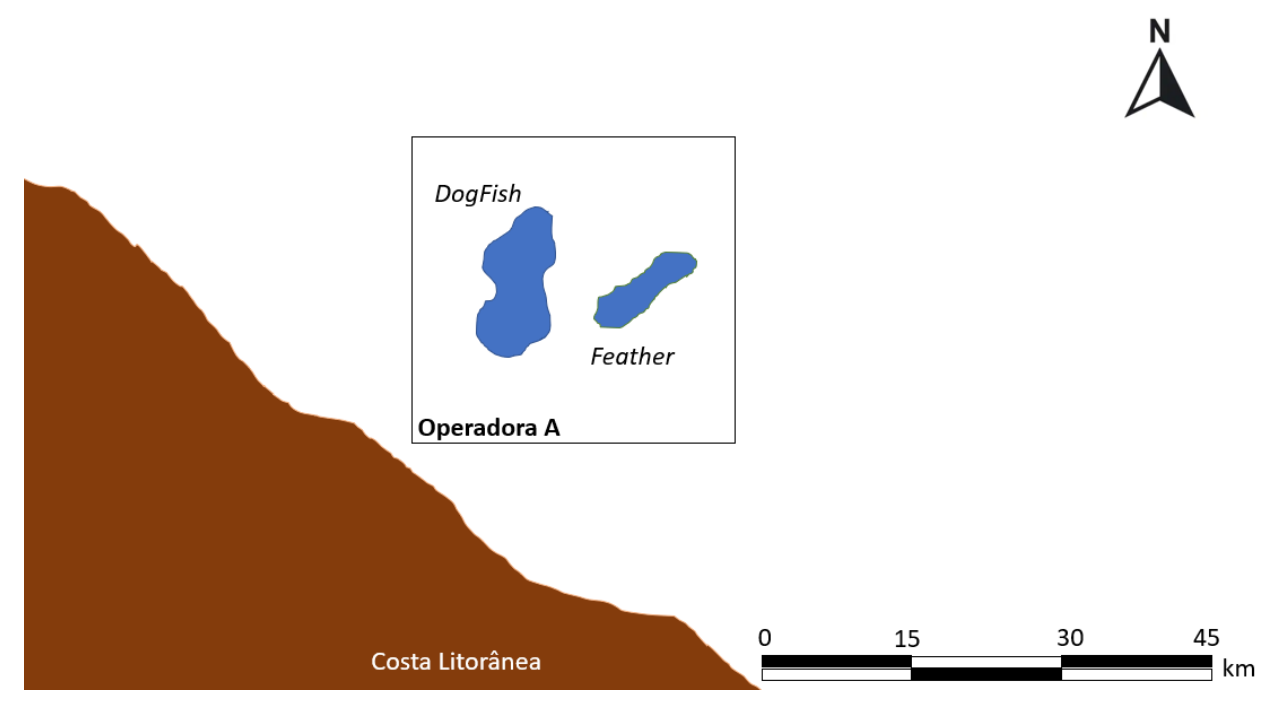

Figura 4.16: Bloco A- DogFish e Feather

Na situação estática, caso não considere a correlação entre as oportunidades, o portfólio pode ser avaliado como a soma dos valores monetários esperados $\left(\sum V M E(P)\right)$. Nesse bloco exploratório, com o preço do barril igual a $\$ 50$, a soma dos VME(P)s é de \$ 673.76 M. Contudo, dado o valor da informação, pode se ter a preferência de perfurar uma das oportunidades antes da outra. Dado o preço do barril igual a $\$ 50$, caso considere a primeira perfuração do portfólio sendo a oportunidade DogFish $\left(\pi_{D+F}(P)\right)$, o valor é igual a $\$ 673.76$ $\mathrm{M}$ e caso seja primeiramente perfurado a oportunidade Feather $(\pi F+D(P))$, o valor do portfólio também é igual a \$673.76 M! Ou seja, aparentemente os valores independem da ordem de perfuração e também da correlação entre os ativos! Essa situação ocorre devido ao alto preço do barril de petróleo e aos FCs condicionais não tão baixos, em que não resultam em VMEs condicionais (dada a revelação da informação) com valores negativos. Porém, existe algum nível de preço $(\mathrm{P})$ em que o portfólio $(\pi(P))$ é acima da soma dos VMEs? E a ordem de perfuração importa para encontrar o maior valor adicionado para a carteira?

A figura (4.17) apresenta a diferença entre o valor dos dois portfólios sequenciais $\left(\pi_{D+F}(P)\right.$ e $\left.\pi_{F+D}(P)\right)$ com a soma dos VMEs $\left(\sum_{i} \max \left(0, V M E_{i}(P)\right)\right)$ para diversos preços de longo prazo $(\mathrm{P})$. Na sumarização da tabela (4.7), essa métrica é denominada por valor da informação $(\operatorname{VOI}(P))$, apresentada somente para o preço de longo prazo de $\$ 50$ o barril. Nota-se que entre $\$ 35$ e $\$ 48 / \mathrm{bbl}$, a sequência $\pi_{D+F}(P)$ adiciona mais valor ao portfólio pela informação revelada, com o valor máximo de $\$ 54.18 \mathrm{M}$ e sempre com VOI(P) maior que a carteira $\pi_{F+D}(P)$. Então, a níveis distintos no preço 
do barril, o valor da informação pode ser diferente, inclusive alterar a ordem de perfuração da carteira. Dessa forma, a análise que considera os efeitos da incerteza de preços na carteira com ativos correlacionados é importante, pois os preços do barril de petróleo entre $\$ 35$ e $\$ 48$ têm probabilidade de ocorrer em 3 anos $(\tau)$. Assim sendo, os próximos casos serão apresentados somente com a medida de portfólio exploratório $(\Pi(P, t))$. Da mesma forma que a opção de explorar $E(P, t)$, essa medida apresenta a vantagem de possuir as curvas de gatilho de investimento, sendo um ótimo guia para a gestão de ativos e da carteira.

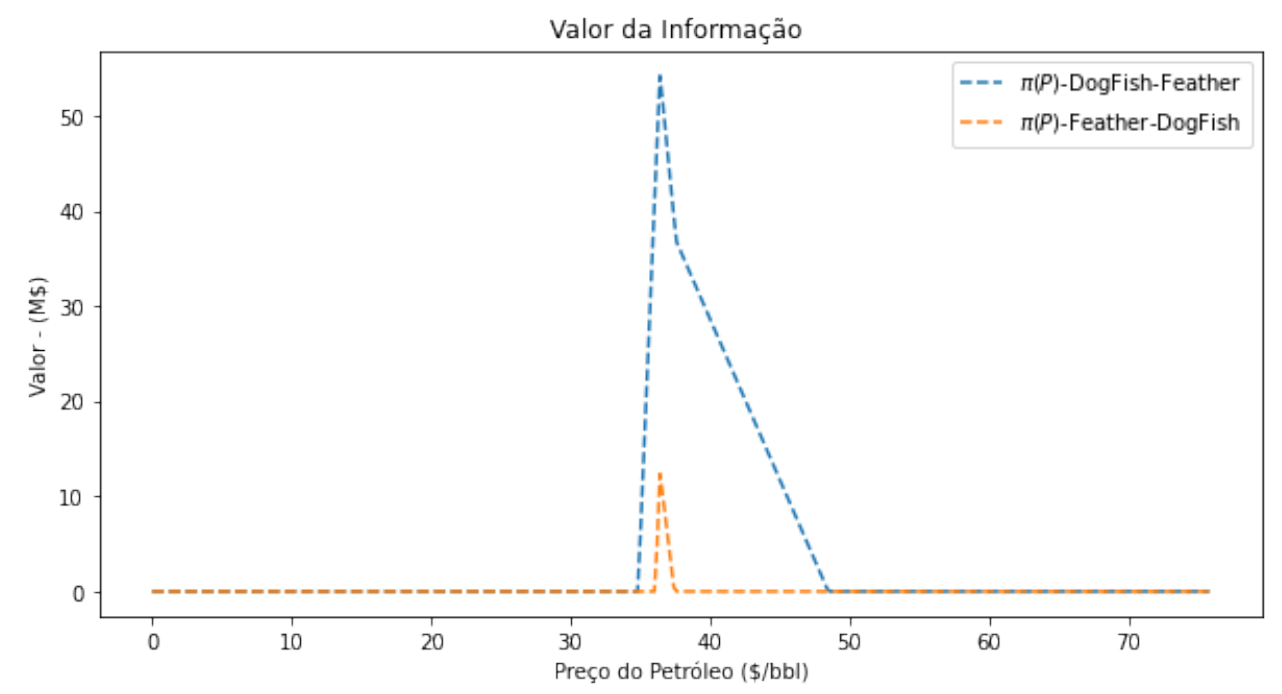

Figura 4.17: Valor da Informação $-\pi_{D+F}(P)$ e $\pi_{F+D}(P)$

A solução para o portfólio exploratório (П) foi feita pela equação (3-57). No caso do bloco operado pela empresa $A$, existem três possíveis sequências da carteira exploratória: DogFish-Feather, Feather-DogFish e a espera, identificada nas figuras de gatilhos em portfólio como Wait. A quantidade de possibilidades na ordem da carteira é a permutação das oportunidades mais a opção de espera, ou seja, $n !+1$, sendo $n$ o número de ativos. O resultado do portfólio exploratório (П) é o seu valor e a decisão associada, em função do momento no contrato e o preço $P$. A decisão pode ser observada da mesma forma que na avaliação stand-alone da opção de explorar, por um mapa de preço de petróleo e tempo de contrato, formado por curvas de decisões (curvas de gatilho). O valor de $\Pi$ deve ser maior ou igual a soma das opções de explorar standalone $\left(\sum E(P, t)\right)$ e a soma dos valores monetários estáticos $\left(\sum V M E(P)\right)$, esta última medida referência em estudo de carteiras, portanto, sendo uma boa métrica de comparação com o portfólio exploratório.

Com o preço do barril em $\$ 50$ e no momento inicial do contrato $(\tau=3$ anos), a gestão do portfólio exploratório $\Pi_{D, F}$ deve aguardar (Wait) melho- 
res momentos do preço do petróleo. Seu valor é de 796.60 milhões de dólares, maior que a soma das opções de explorar (=787.42 milhões de dólares) e do $\sum V M E(P)$ (=673.76 milhões de dólares). O excedente de 9.18 milhões de dólares em relação as opções de explorar é devido à correlação entre as oportunidades combinada com a opção de aguardar o investimento exploratório.

A figura (4.18) apresenta os gatilhos do portfólio DogFish e Head. O gatilho de investimento exploratório no início do contrato é $\$ 73.25$ o barril $\left(P^{* * L}\right)$, sendo esse preço entre os dois gatilhos stand-alone (tabela 4.6). Nesse tempo do contrato e acima desse preço do barril de petróleo, o gatilho predominante de decisão é de perfurar primeiro a oportunidade DogFish, com pequenas zonas de preferência na primeira perfuração para o prospecto Feather. É possível notar que na zona próxima do vencimento do contrato e ao redor de \$ 45 o barril, há uma região em que a curva de espera (zona verde) deixa de ser côncava. Esse intervalo no vencimento do contrato corresponde à análise do VOI da figura (4.17) em que o portfólio $\pi_{D+F}$ é preferível, mas aqui essa preferência é mapeada na dimensão do tempo do contrato e dada a incerteza no preço do petróleo, sendo uma análise mais completa que o resultado estático.

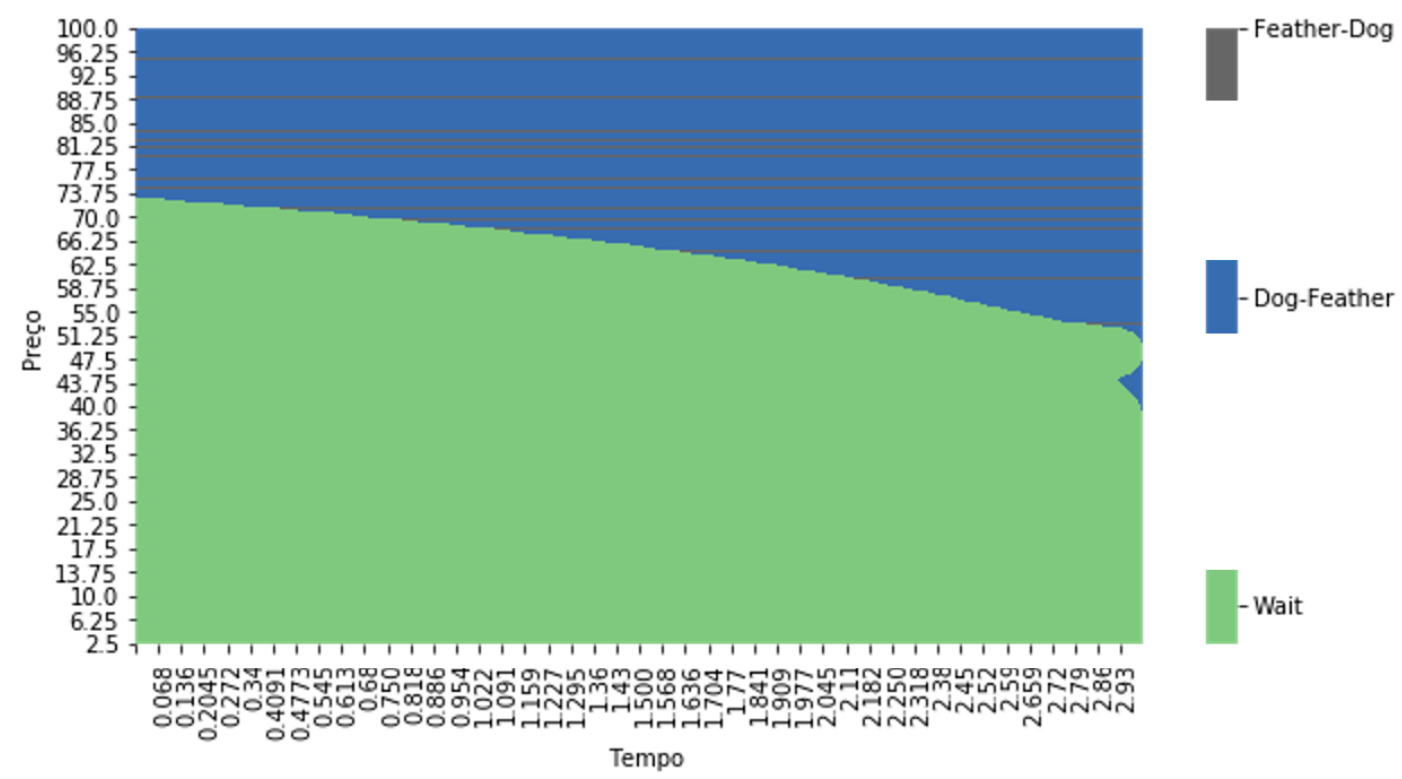

Figura 4.18: Gatilho do Portfólio - DogFish e Feather

$\mathrm{Na}$ próxima situação, considera-se a hipótese de um grande bloco exploratório operado pela Empresa X. Além disso, a oportunidade Feather foi reavaliada pelo grupo técnico, sendo considerada sem probabilidade de sucesso, eliminando-a da carteira (figura 4.19). Essa situação pode acontecer, por exemplo, caso identifiquem numa nova interpretação sísmica que não se trata de um 
reservatório e dessa forma, o FC a priori é zero. Esse caso foi criado pois será utilizado em um modelo de barganha cooperativa da seção (4.2.2.2).

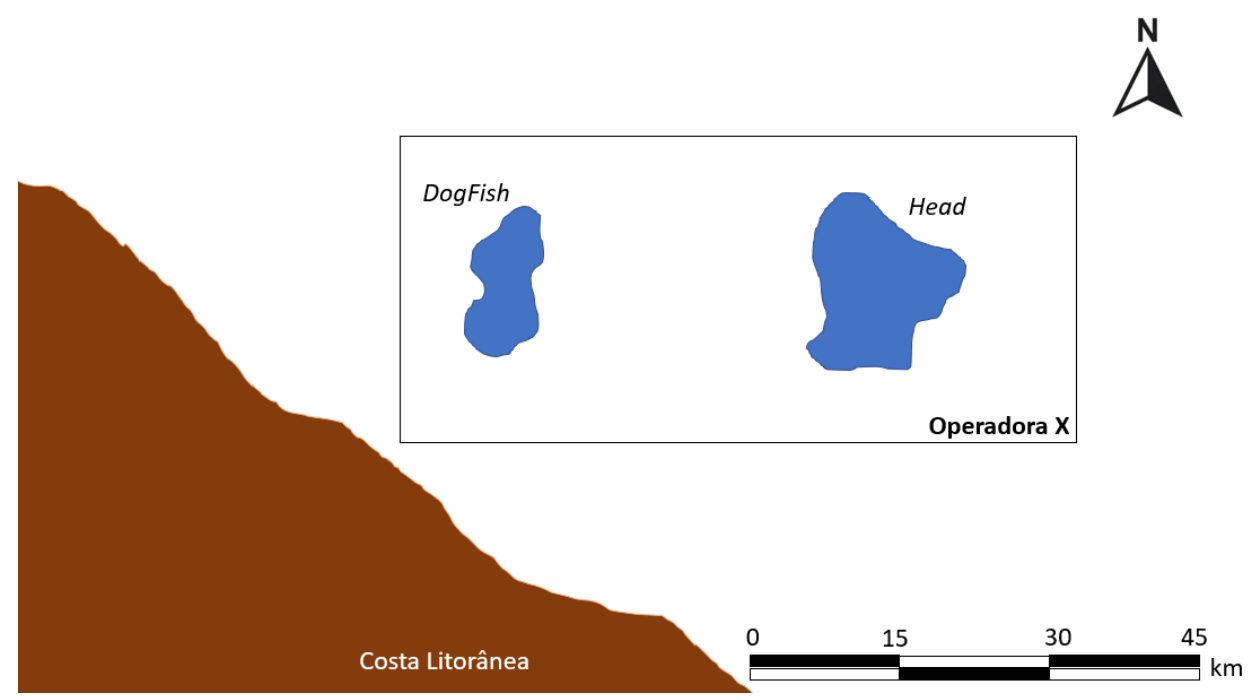

Figura 4.19: Único Bloco - DogFish e Head

O valor do portfólio exploratório $\left(\Pi_{D, H}\right)$ é igual a $\$ 1092.98$ milhões, dados o preço atual de longo prazo de $\$ 50$ o barril e $\mathrm{t}=0(\tau=3)$, sendo ótimo aguardar melhores condições futuras (Wait). A soma das opções de explorar os ativos DogFish e Head é igual a \$ 1078.99 milhões (tabela 4.6), sendo a diferença de $\$ 14$ milhões devido à vantagem da dependência entre ativos combinada com a espera em situação de portfólio. Quando comparado com a soma do valor monetário esperado das duas oportunidades, a diferença é de 144 milhões de dólares $\left(\sum V M E=\$ 948.20 \mathrm{M}\right)$.

A figura (4.20) apresenta as curvas de gatilho do portfólio. No tempo presente e a preço $\mathrm{P}$ corrente de $\$ 50$ o barril, a decisão é de espera (Wait), com o gatilho exploratório em $\$ 71.50$ dólares $\left(P^{* * L}\right)$ para a primeira perfuração sendo a oportunidade DogFish. A figura indica que há uma dominância na preferência para a primeira perfuração da DogFish, contudo, numa análise entre o primeiro e o segundo portfólio preferido, a diferença é bem pequena quando o preço do petróleo está acima do gatilho de espera. As diferenças significativas a favor da oportunidade Dogfish ser a primeira perfuração ocorrem essencialmente próximo ao vencimento, entre os preços de $\$ 35$ e $\$ 41$ o barril. Essa indiferença em preços altos é importante na prioridade de perfuração no jogo da barganha cooperativa. 


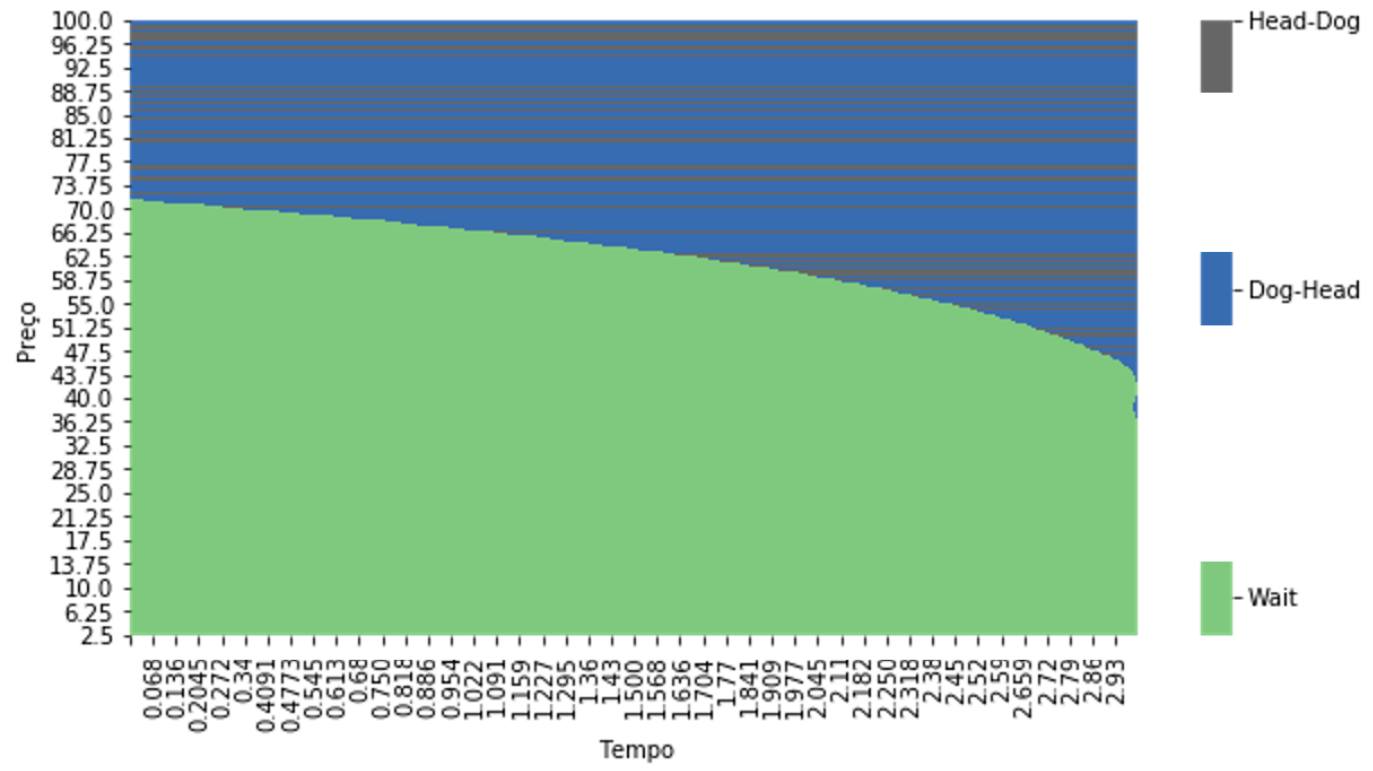

Figura 4.20: Gatilho do Portfólio - Head-DogFish

Em uma nova reavaliação da carteira, o operador X e o seu grupo técnico alteraram o volume recuperável médio da oportunidade Head. Esse exemplo está sendo criado, pois será útil nas análises de assimetria na guerra de atrito por informação e na barganha cooperativa (seção 4.2.2.2).

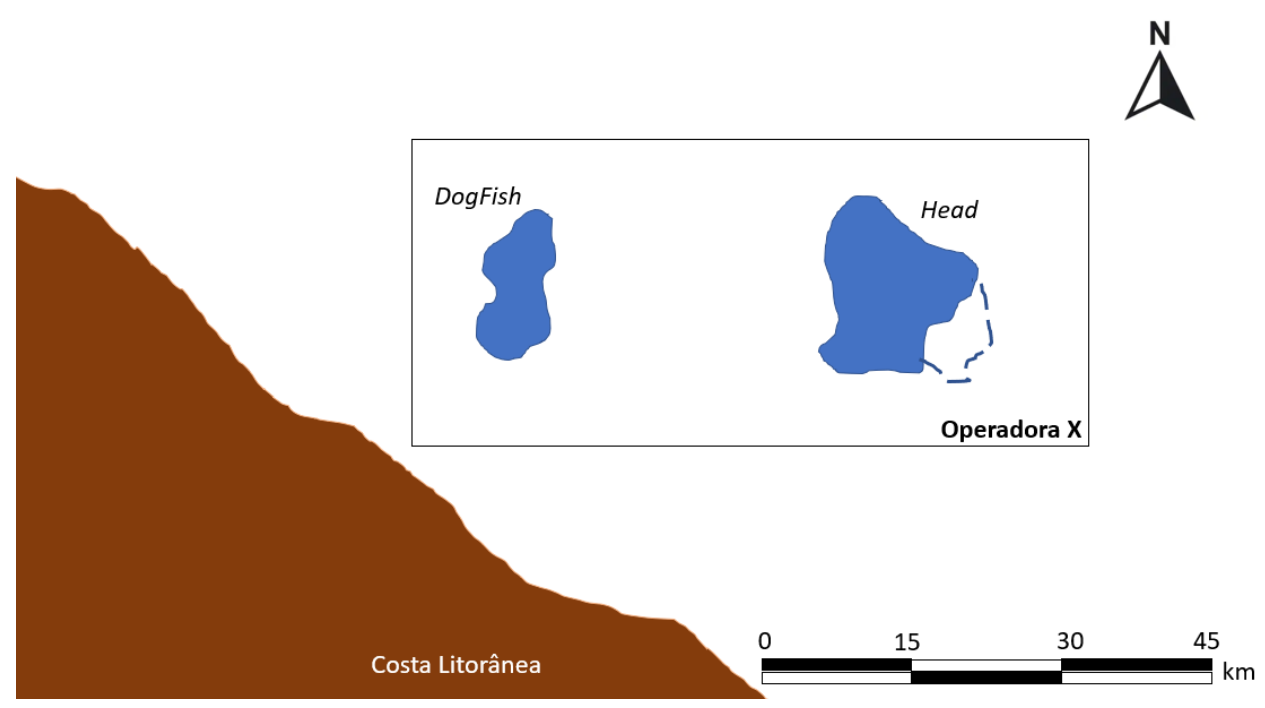

Figura 4.21: Único Bloco - DogFish e Head com Volume Maior

Caso eleve em $37 \%$ o $B$ da oportunidade Head, o portfólio exploratório no tempo inicial do contrato e com o preço de longo prazo do barril em $\$ 50$ é avaliado em $\$ 1334.70$ milhões, com a decisão de aguardar (Wait) para investir em exploração. Comparando com a soma das opções de explorar a DogFish e 
a oportunidade Head com o volume expandido, a diferença é \$ 16 milhões, e novamente, esse valor adicionado é devido ao efeito dos ativos correlatados combinado com o valor da espera. O gatilho para investir primeiramente na oportunidade DogFish no tempo inicial do contrato reduz quando comparado à situação anterior com o volume recuperável (B) menor, indo para \$69.75 o barril $\left(P^{* * L}\right)$. Isso representa que o portfólio exploratório é mais atraente para o exercício com o aumento da reserva, o que é bem intuitivo. Além disso, a pequena área de exercício próxima ao vencimento de preferência para perfurar primeiro a DogFish diminuiu, agora entre $\$ 35$ e $\$ 38$ dólares o barril. Assim como no caso original (figura 4.19), em valores altos do preço do petróleo, o investidor é indiferente entre qual ativo irá perfurar antes, sendo esse perfil relevante para o estudo da barganha cooperativa.

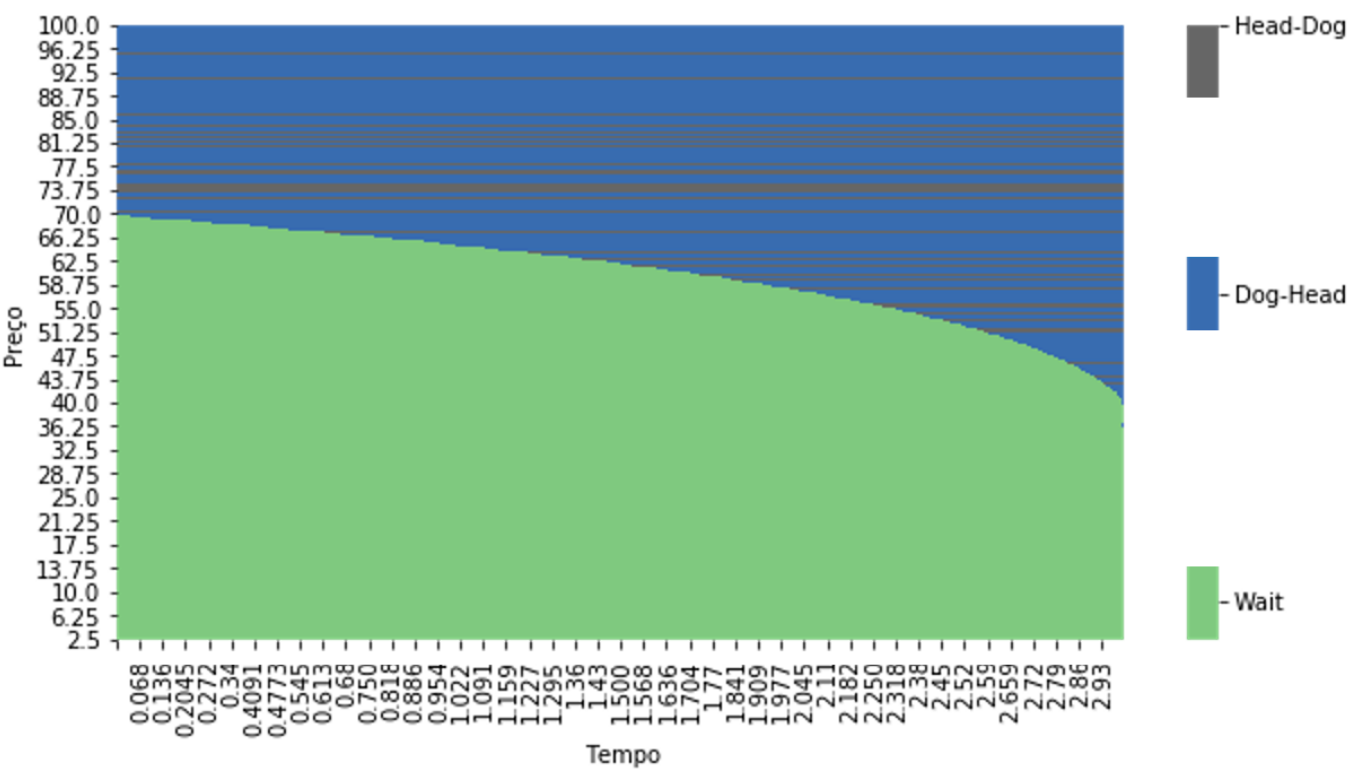

Figura 4.22: Gatilho - $\Pi$ - DogFish e Head com expansão de $37 \%$ de $B$

Finalmente, a figura (4.23) apresenta o último caso dessa seção, com um portfólio com as três oportunidades operadas pela empresa X. Essa também é uma situação de unitização útil no estudo da barganha cooperativa da seção (4.2.3). 


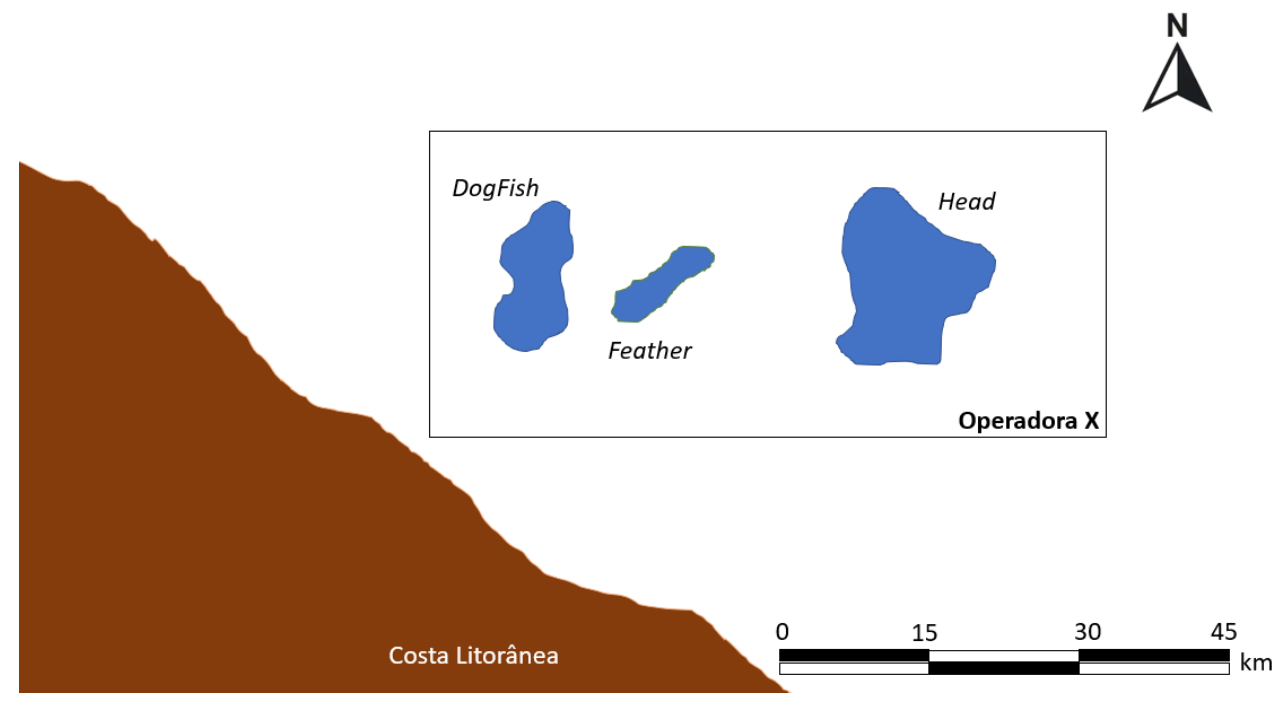

Figura 4.23: Modelo - Único Bloco

No início do contrato e com o P igual a $\$ 50$ /bbl, o portfólio exploratório $\Pi_{D, F, H}$ tem a decisão de aguardar para investir (Wait) e vale $\$ 1309.54$ milhões, sendo maior que a soma das opções de espera stand-alone $(=\$ 1285.13$ M). Novamente, a diferença de $\$ 24.41$ milhões é devido à otimização do melhor momento de investir e o valor advindo da revelação da informação. Agora, as curvas de gatilho são bem interessantes (figura 4.24), sendo que no tempo presente e a preço de $\$ 72\left(P^{* * L}\right)$, o investidor deixa de aguardar para primeiro perfurar o ativo Feather. Contudo, a zona de espera volta a aparecer em todo o tempo do contrato, entre $\$ 72.75$ e $\$ 74.50$ dólares o barril. Outro fato interessante é que acima do gatilho côncavo, a preferência é de primeira perfuração do ativo Feather. A oportunidade Feather possui o gatilho mais alto entre as oportunidades quando analisada sozinha (\$79.87, tabela 4.6) e até em portfólio exploratório do bloco operado pela empresa A (DogFish e Feather), pois naquele há a preferência dominante de primeira perfuração da oportunidade DogFish (figura 4.18), mesmo que a oportunidade Feather tenha o menor custo de aquisição da informação pelo poço pioneiro $\left(I_{w}\right)$. A preferência pela oportunidade Feather no portfólio exploratório unitizado acontece porque ela é estratégica para os outros dois ativos. Observando a tabela de correlação das oportunidades (tabela 4.4), esse ativo tem correlação alta com os outros dois, porém, os outros dois têm correlação baixa entre si. Ou seja, a perfuração do prospecto Feather revela muita informação para o portfólio, mesmo tendo o VME mais baixo e a maior porcentagem de espera no caso stand-alone (tabela 4.6). Agora, em caso de preços muito elevados como acima de 74.50 dólares o barril, não importa a ordem da perfuração, 
ocorrendo diversas preferências com diferenças marginais do valor adicionado para a carteira.

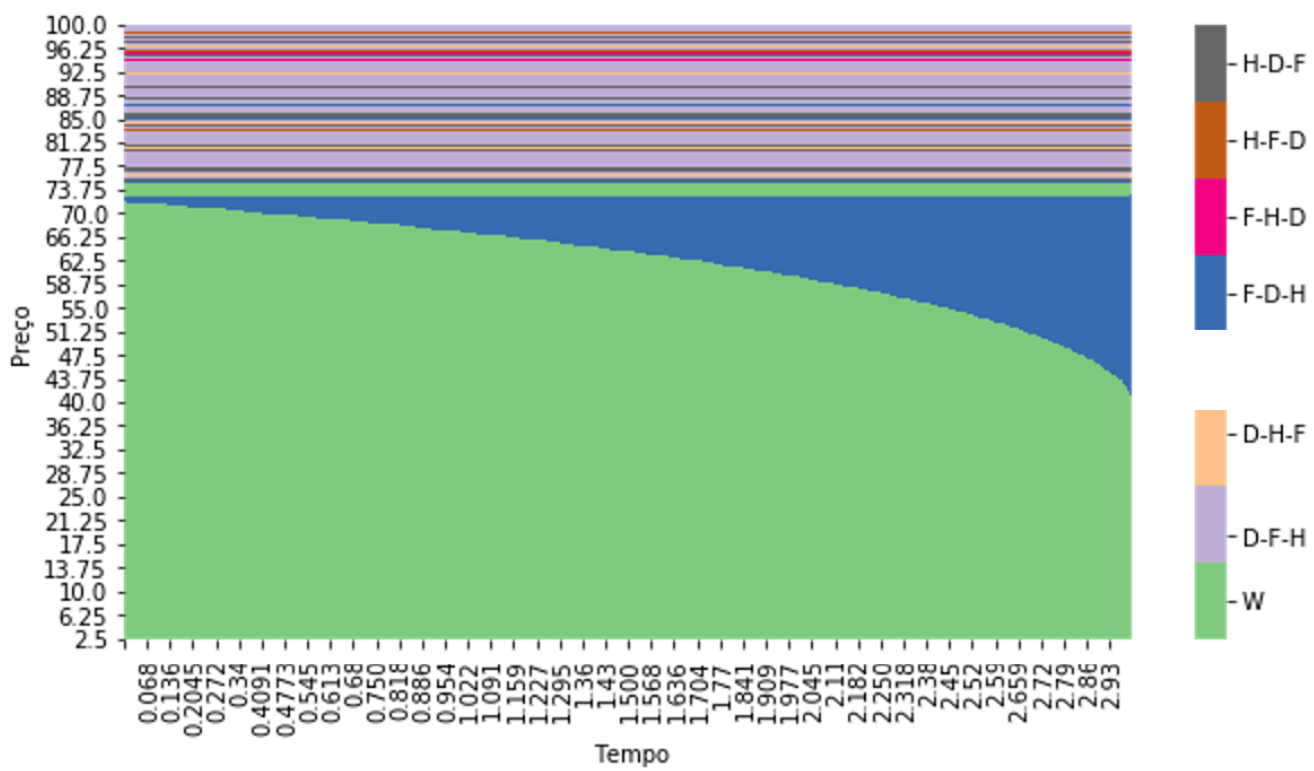

Figura 4.24: Gatilho do Portfólio - DogFish, Feather e Head

Neste momento, cabe a comparação conjunta dos tipos de avaliações da carteira, reforçando as diferenças entre eles. A avaliação estática $(\pi(P)$ e $\left.\sum V M E(P)\right)$ serve no momento do vencimento do contrato ou se for considerado um investimento no estilo "agora ou nunca". Essa não é a realidade da exploração de petróleo, sendo relevante o prazo do contrato e a incerteza dos preços para os ativos e a carteira exploratória. Com o preço de longo prazo $(\mathrm{P})$ de $\$ 50$ o barril e observando as métricas estáticas das carteiras $D-H$ e $D-F$, não há preferência de primeira perfuração dos prospectos pelo valor da informação $\operatorname{VOI}(P)$, pois os valores dos portfólios com aprendizado $\pi_{D, H}(P)$ e $\pi_{H, D}(P)$ são iguais à soma dos respectivos $V M E(P)$ s (tabela 4.7). Contudo, como se notou nos casos apresentados, esses portfólios apresentam valores incrementais dada a combinação da incerteza de preços, com o prazo de contrato e o aprendizado entre os ativos. Isso é exposto na tabela pela diferença entre $\Pi$ e $\sum E$, resultando na linha $\operatorname{VOI}(P, t)$. Assim, é possível comparar que o portfólio exploratório $\Pi_{D, H}(P, t)$ possui maior valor da informação combinado com a dinâmica de preços que o portfólio exploratório $\Pi_{D, F}(P, t)$, algo não observado na comparação entre os portfólios estáticos $(\pi(P))$. Decerto, esse acréscimo é devido ao valor da informação dadas as probabilidades de diversos preços no futuro com aplicação da regra ótima de valor maior que zero. 


\begin{tabular}{|c|c|c|c|}
\hline Métrica & $D, H$ & $D, F$ & $D, F, H$ \\
\hline \hline \multicolumn{4}{|c|}{$\$$ Milhões } \\
\hline \hline$\pi(P)$ & 948.20 & 673.76 & 1129.69 \\
\hline$\sum V M E(P)$ & 948.20 & 673.76 & 1098.88 \\
\hline$V O I(P)$ & - & - & 30.81 \\
\hline \hline$\Pi(P, t)$ & 1092.98 & 796.60 & 1309.54 \\
\hline$\sum E(P, t)$ & 1078.99 & 787.42 & 1285.13 \\
\hline$V O I(P, t)$ & 13.99 & 9.18 & 24.41 \\
\hline \hline \multicolumn{4}{|c}{$\$ / \mathrm{bbl}$} \\
\hline \hline$P^{* * L}$ & 71.50 & 73.25 & $72-74.75$ \\
\hline
\end{tabular}

Tabela 4.7: Aval. dos Portfólios $-\tau=3$ anos $-\mathrm{P}=\$ 50$

Em suma, a comparação entre os modelos estáticos com os modelos de opções, sobretudo as opções de explorar com ou sem dependência de portfólio, aponta a superioridade dos modelos com incerteza técnica-geológica combinada com a incerteza de preços. Ademais, os métodos que consideram a opção de explorar possuem mais vantagens, pois o gatilho de investimento no poço pioneiro é mais alto e por isso, inclui a opção de investir em desenvolvimento. Dentre as opções de explorar, é melhor a análise pelo portfólio exploratório $(\Pi(P, t))$ comparada com a soma simples das opções de explorar. A preferência não é somente pelo valor agregado final ser superior ou igual a soma das opções de explorar, mas também pela vantagem da análise que as curvas de gatilho do portfólio consolidado oferecem, visto que as curvas de gatilho do somatório das opções de explorar são independentes. 


\subsection{2}

\section{Dois prospectos: Um em cada bloco}

Os resultados desta seção ampliam o desenvolvimento de Dias e Teixeira (2009), adequados aos prospectos apresentados na seção (4.1.5) e aos parâmetros exógenos da seção (4.1.4), considerando o preço do barril no tempo inicial em $\$ 50$ e o tempo de contrato igual a 3 anos $(\tau)$. No primeiro passo da apresentação do problema, a situação foi simplificada para melhor explicar a guerra de atrito e nas etapas adiantes os exemplos são modificados até finalizar o estudo no modelo original das figuras (4.11 ou 4.53) e com os parâmetros das tabelas (4.3 e 4.4).

\subsubsection{1}

\section{Jogo Simétrico: do Atrito à Barganha}

O modelo contempla dois blocos exploratórios adquiridos no mesmo leilão por companhias distintas, com os prazos síncronos de três anos $(\tau)$, sem compromisso de poço exploratório e com áreas vizinhas uma a outra. Cada bloco tem somente um prospecto, com características iguais à oportunidade DogFish (figura 4.25). Os dois agentes precificam o investimento da produção com a mesma equação (4-5) e com o mesmo dispêndio para o poço exploratório. O jogo é de informação completa e simétrico, pois os dois agentes possuem ativos diferentes, mas com as mesmas características geológicas e de produção. Contudo, a correlação dos prospectos é diferente de 100\%, sendo a princípio, $\rho$ igual a $60 \%$.

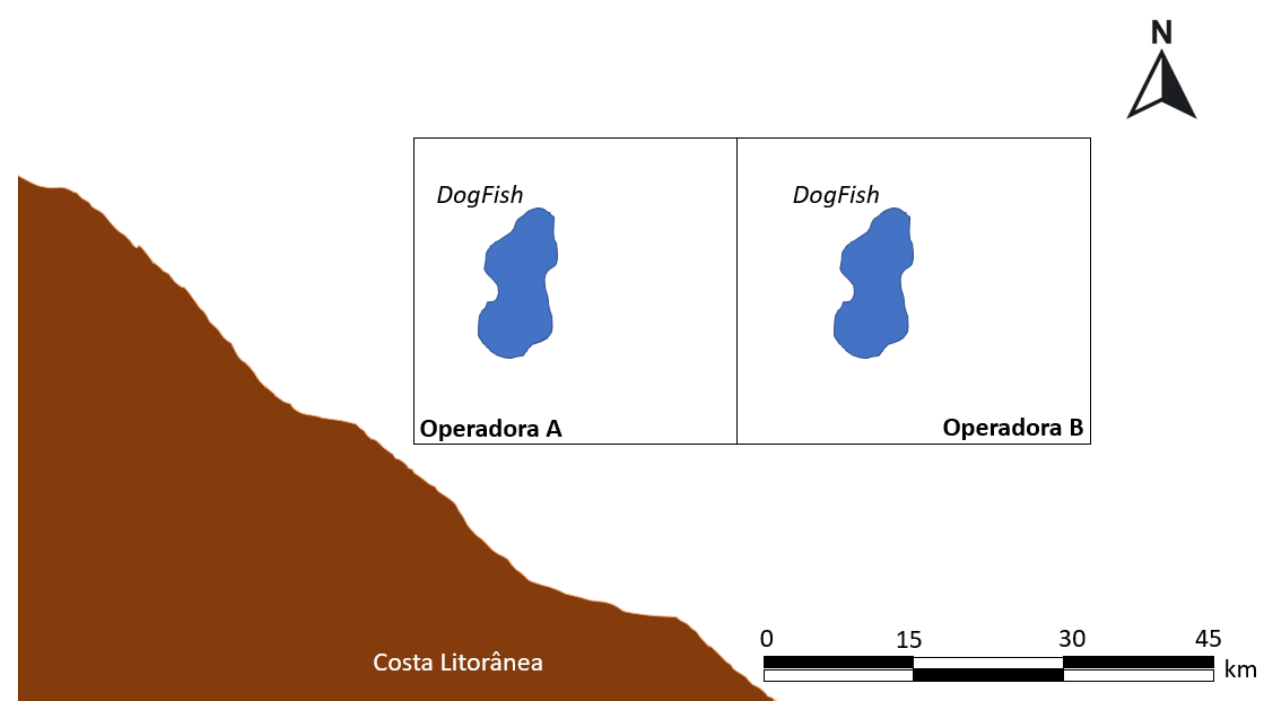

Figura 4.25: Modelo - DogFish x DogFish 
O jogo envolve somente dois jogadores e os conjuntos de estratégias são: $s_{i,-i}=\{$ esperar, esperar $\} ;\{$ esperar, investir $\} ;\{$ investir, esperar $\} \mathrm{e}$ \{investir, investir\}. Nesse jogo há uma variável incerta no tempo, então será considerado o equilíbrio markoviano (EPM). Abaixo é apresentada a forma normal do jogo (tabela 4.8):

\begin{tabular}{ccccc} 
& & & \multicolumn{2}{c}{ Jogador 2} \\
& & & & \\
& & & $1-q$ \\
Jogueste & Espera \\
& $p$ & Investe & $S_{1} ; S_{2}$ & $L_{1} ; F_{2}$ \\
& $1-p$ & Espera & $F_{1} ; L_{2}$ & $W_{1} ; W_{2}$
\end{tabular}

Tabela 4.8: Forma normal: Guerra de Atrito

O EPM é um equilíbrio perfeito em subjogos (ENPS), sendo em função do estado corrente da variável incerta. O estado corrente a ser analisado é o momento inicial do contrato $t=0$ ( $\tau=3$ anos $)$.

O equilíbrio em estratégias puras $\left\{W_{1}, W_{2}\right\}$ ocorre quando os dois jogadores não têm interesses em perfurar devido ao preço baixo do petróleo $\left(<P^{* *}\right)$. O payoff é representado pela opção de explorar e a melhor ação ocorre devido ao alto valor da espera de $E_{i}(P, 0)$. Quando o prêmio da espera é nulo e a cotação da commodity está acima do preço do gatilho, pode haver o interesse do jogador continuar esperando, mas agora devido à obtenção de informação pela perfuração do outro jogador. Contudo, o operador incorre em um custo de espera pelo prospecto não explorado, calculado com uma perda mensal de valor, ou seja, $c_{i}\left(P>P^{* *}, 0\right)=V M E_{i}\left(P>P^{* *}, 0\right)\left(1-e^{-r / 12}\right)$, como sugerido em Dias e Teixeira (2009). Como neste primeiro exemplo o jogo é simétrico, então $W_{i}=W_{1}=W_{2}$.

O caso do equilíbrio $\left\{S_{1} ; S_{2}\right\}$ ocorre devido ao exercício imediato dos jogadores e somente em situações de preços suficientemente elevados. É necessário que o preço ultrapasse o preço do gatilho da opção exploratória $\left(P^{* *}\right)$ e fique acima do preço que delimita superiormente a guerra de atrito por informação entre os jogadores $\left(P^{s}\right)$. Esse limite é quando o operador desconsidera o valor da informação da perfuração pela outra empresa, definido pela equação (3-60). Isso ocorre, pois mesmo com uma revelação negativa do vizinho, a qual reduz o FC e consequentemente o VME, o prospecto ainda estaria deep-in-the-money e seria ótimo perfurar. Na prática, a decisão de perfurar seria independente da informação que poderia ser revelada. Novamente, como este primeiro exemplo é um jogo simétrico, então o $V M E_{1}(P, 0)=V M E_{2}(P, 0)=S_{i}$.

As estratégias puras de equilíbrio $\left\{F_{1} ; L_{2}\right\}$ e $\left\{L_{1} ; F_{2}\right\}$ ocorrem simultaneamente devido à simetria do jogo. A líder $\left(L_{i}\right)$ é a empresa que não aguarda a informação da empresa vizinha, portanto, possui o payoff igual ao $V M E_{i}(P, 0)$. 
Já a seguidora $F_{i}$ valora em função da informação do outro jogador, ou seja, pela equação (3-59).

Em qualquer jogo, quando há dois equilíbrios puros, sempre há um equilíbrio em estratégias mistas. Com dois equilíbrios puros $\left\{F_{1} ; L_{2}\right\}$ e $\left\{L_{1} ; F_{2}\right\}$ há um outro equilíbrio em estratégias mistas com probabilidades $\left\{p^{*}, q^{*}\right\}$. Com o uso dos conceitos de jogos evolucionários (seção 3.5), a única estratégia evolucionariamente estável (EEE) é o equilíbrio em estratégias mistas. Nessa circunstância de indecisão em que os operadores $i$ e $j$ têm probabilidades críveis de perfurarem e aguardarem por informação gratuita é que se configura a guerra de atrito por informação. Além do mais, esse conflito pode perdurar enquanto o preço corrente não alterar ou não sair do intervalo em que esse equilíbrio em estratégias mistas ocorre.

Na tabela (4.9) é apresentado o jogo na forma normal, agora com os payoffs de cada jogador em cada estratégia:

$$
\begin{array}{cc|c|c|}
\multicolumn{2}{c}{\text { Jogador } 2} \\
\cline { 3 - 4 } \text { Jogador } 1 & \text { Investe } & \text { Espera } \\
\cline { 3 - 4 } & \text { Espera } & V M E_{1} ; V M E_{2} & V M E_{1} ; E_{2 \mid 1} \\
\cline { 3 - 4 } & & E_{1 \mid 2} ; V M E_{2} & E_{1}-c_{1} ; E_{2}-c_{2} \\
\cline { 3 - 4 } & &
\end{array}
$$

Tabela 4.9: Forma normal: Payoffs

As melhores respostas serão sublinhadas em todos os jogos (exemplo na tabela 4.10). Como esse primeiro jogo é analisado com o preço do petróleo corrente, alguns prêmios já foram apresentados na seção de estudo sem incerteza estratégica (seção 4.2.1 e tabela 4.5). Para o preço do petróleo igual a 50 dólares o barril, a ação esperar é dominante para qualquer jogador. Essa espera é somente devida às características dos seus próprios ativos, sem os efeitos do aguardo pela externalidade positiva em relação à perfuração do poço vizinho.

$$
\begin{array}{llcc} 
& & \multicolumn{2}{c}{\text { Jogador } 2} \\
& & \text { Investe } & \text { Espera } \\
\text { Jogador 1 } & \text { Investe } & 558.23 ; 558.23 & 558.23 ; \underline{583.37} \\
& \text { Espera } & \underline{583.37} ; 558.23 & \underline{581.28} ; \underline{\underline{581.28}}
\end{array}
$$

Tabela 4.10: Forma normal: Jogo Simétrico- $P=\$ 50, \rho=60 \%, \tau=3$

Se o preço do petróleo subir acima do gatilho exploratório $P^{* *}$ de $\$ 69.62$ o barril, o equilíbrio do jogo muda. Com o preço a 72 dólares o barril, há dois equilíbrios puros de Nash e um equilíbrio em estratégias mistas (tabela 4.11). As probabilidades do equilíbrio misto são em função dos payoffs da tabela e calculados pela equação (3-42), sendo que neste caso o jogador $i$ tem $81.42 \%$ de 
investir e $18.58 \%$ de esperar. A utilidade esperada no equilíbrio em estratégias mistas em um jogo simétrico é igual para ambos os jogadores e a este preço de petróleo vale $U_{i}\left(p^{*}, q^{*}\right)=\$ 1281.59 \mathrm{M}$, calculadas a partir dos payoffs da tabela e pela equação (3-39). Nota-se que o prêmio em equilíbrio é igual a um dos prêmios em estratégias puras, podendo ser tanto o payoff da ação espera quanto da ação investe. Em jogos evolucionários, a única estratégia estável nesse tipo de jogo se dá em estratégias mistas, visto que as estratégias degeneradas $\left\{F_{1} ; L_{2}\right\}$ e $\left\{L_{1} ; F_{2}\right\}$ são instáveis, pois têm os payoffs distintos para cada jogador. É neste contexto de equilíbrio em estratégias mistas, com as probabilidades de aguardar e perfurar, que ocorre a guerra de atrito por informações.

$$
\begin{array}{lccc} 
& & \multicolumn{3}{c}{\text { Jogador } 2} \\
\text { Jogador } 1 & \text { Investe } & 1281.59 ; 1281.59 & \underline{1281.59} ; \underline{1282.32} \\
\cline { 3 - 4 } & \text { Espera } & \underline{1282.32} ; \underline{1281.59} & 1278.39 ; 1278.39
\end{array}
$$

Tabela 4.11: Forma normal: Jogo Simétrico - $P=\$ 72, \rho=60 \%, \tau=3$

Nesse jogo no tempo zero, o intervalo de guerra de atrito é até o preço $\$ 76.25$ o barril $\left(P^{s}\right)$, obtido pela igualdade apresentada na equação (3-60). É o ponto no espaço preço do barril versus payoff que o prêmio de ser seguidor é igual ao valor de ser líder, que pode ser visto graficamente mais adiante na figura (4.32). Na tabela (4.12) é apresentado o jogo em que o barril está em $\$ 80$ no tempo presente, ou seja, acima do limite superior $\left(P^{s}\right)$ da guerra de atrito:

$$
\begin{array}{llcc} 
& & \multicolumn{2}{c}{\text { Jogador } 2} \\
\text { Jogador } 1 & \text { Investe } & \underline{1557.41} ; \underline{1557.41} & \underline{1557.41} ; \underline{1557.41} \\
& \text { Espera } & \underline{1557.41} ; \underline{1557.41} & 1553.52 ; 1553.52
\end{array}
$$

Tabela 4.12: Forma normal: Jogo Simétrico - $P=\$ 80, \rho=60 \%, \tau=3$

Neste último jogo, se o outro jogador tem a ação de investir, o jogador é indiferente entre investir e esperar, ou seja, a espera não traz nova informação para o agente. Se o outro jogador esperar, este vai preferir investir e em virtude disso, a ação investir é fracamente dominante em relação a ação espera. Pela simetria do jogo, a estratégia fracamente dominante \{investir, investir\} é o equilíbrio de Nash provável, em que os dois operadores perfuram simultaneamente.

Com o uso da teoria dos jogos evolucionários, é possível selecionar o equilíbrio estável. A solução é por integração da equação diferencial do 
replicador dinâmico para uma população infinita (equações 3-35, 3-36, 3-37 e a matriz 3-45).

Dado o jogo com preço de $\$ 50$ dólares /bbl (tabela 4.10), a figura (4.26) apresenta a solução do replicador dinâmico para mais de mil passos. É possível notar que em poucos passos a fração da população se estabiliza, estabelecendose na ação degenerada esperar (100\%). Esse resultado é concordante com o equilíbrio \{esperar, esperar $\}$ encontrado na forma normal da tabela (4.10).

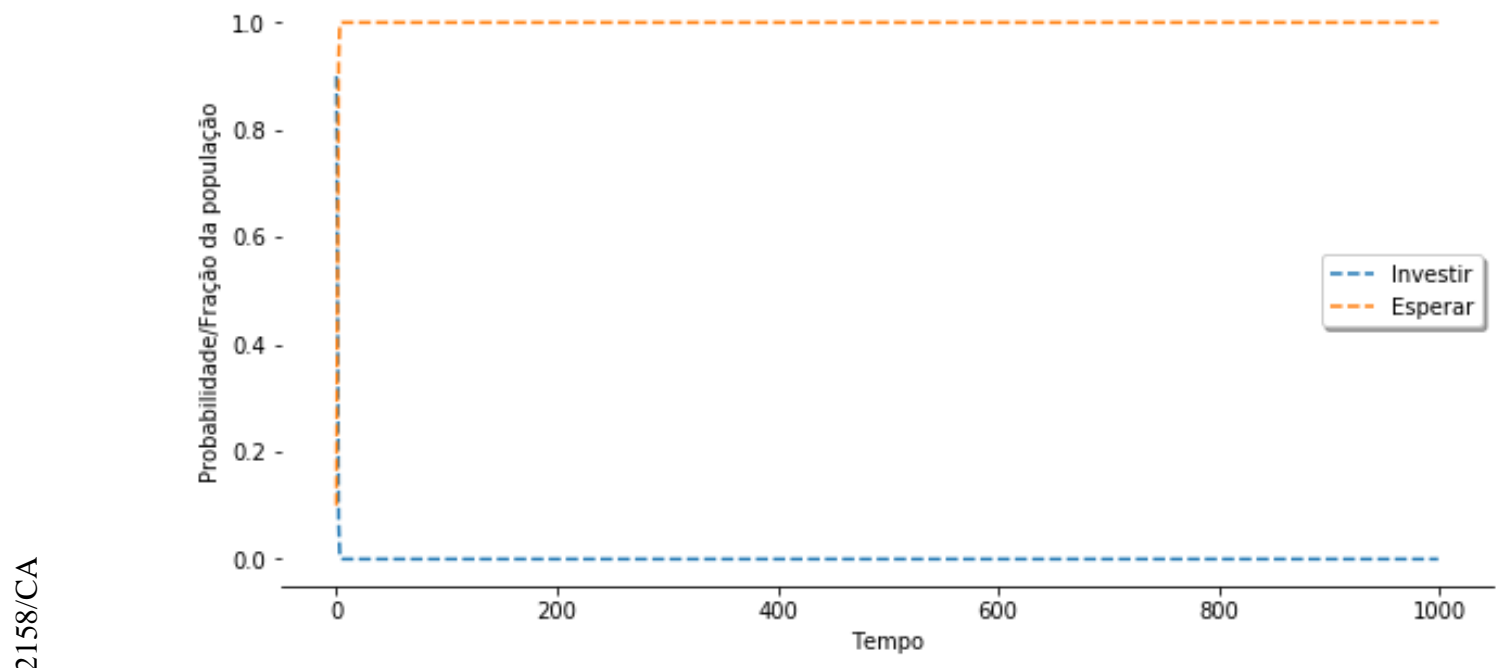

Figura 4.26: Jogo Evolucionário de população infinita - \$ 50/bbl

Esse resultado também pode ser observado em um plano de fase, sendo constituído pelas equações (3-48 a 3-51).

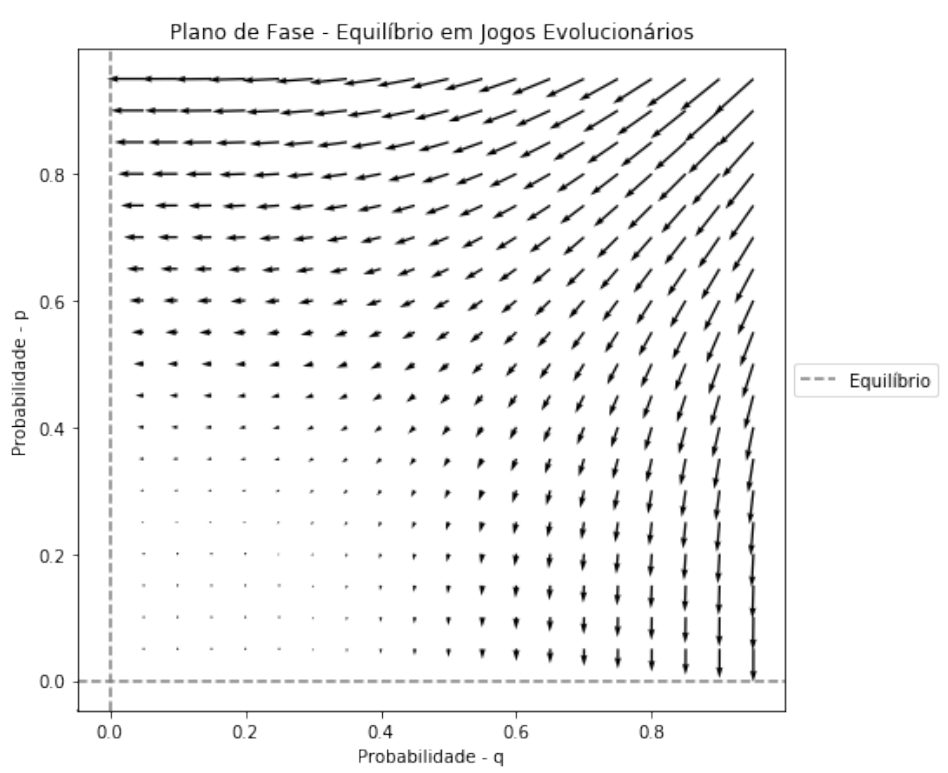

Figura 4.27: Jogo Evol. - P. de Fase - Simétrico - \$ 50/bbl 
Com as informações do jogo da tabela (4.10), os vetores do plano de fase na figura (4.27) apontam para o par $p^{*}, q^{*}$ igual a $(0,0)$, que é a estratégia \{esperar, esperar\}.

Usando a solução de jogos evolucionários para o jogo com o preço do barril em $\$ 72$ dólares (tabela 4.11), a população se estabiliza em frações de $81.42 \%$ em investir e de $18.58 \%$ em esperar (figura 4.28), sendo essas as probabilidades do equilíbrio em estratégias mistas. Ou seja, a solução por replicador dinâmico selecionou dentre três equilíbrios, dois puros e um misto, o equilíbrio em estratégias evolucionariamente estável, sendo este o equilíbrio em estratégias mistas. Como não se trata de um jogo cooperativo, em que uma porcentagem de vezes um jogador espera e a diferença dos momentos o jogador investe, os preços neste nível se configuram num impasse, ou seja, uma guerra de atrito por informações.

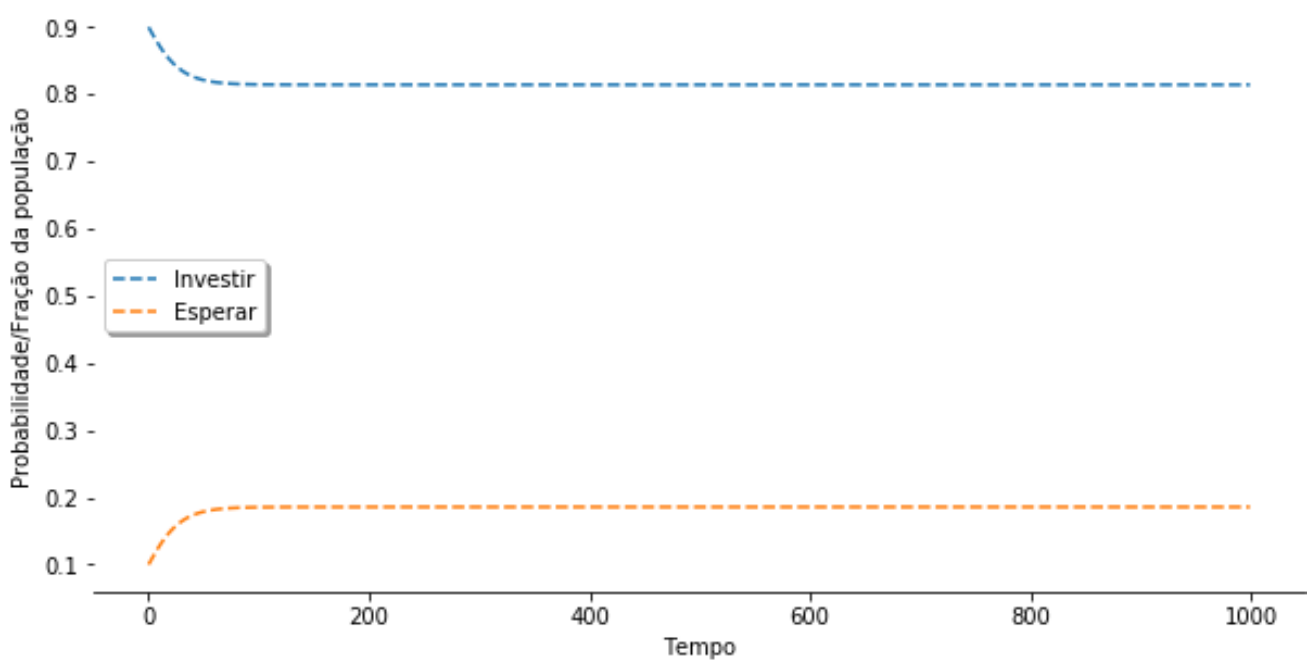

Figura 4.28: Jogo Evolucionário de população infinita - \$72/bbl

Da mesma forma que no estado de preço anterior, o resultado também pode ser observado no plano de fase (figura 4.29). O cruzamento das linhas pontilhadas indicam o equilíbrio em estratégias mistas $\left\{p^{*}, q^{*}\right\}$ do jogo da tabela (4.11). Esse ponto coincide com a direção e sentido dos vetores do mapa de fase. O detalhe pelo adensamento da malha reforça que esse ponto é acima de tudo um ponto de máximo global, com fechamento em todas as direções e com vetores direcionados para ele. Dessa forma, o equilíbrio em estratégias mistas $\left\{p^{*}, q^{*}\right\}$ é o equilíbrio evolucionariamente estável (EEE). 


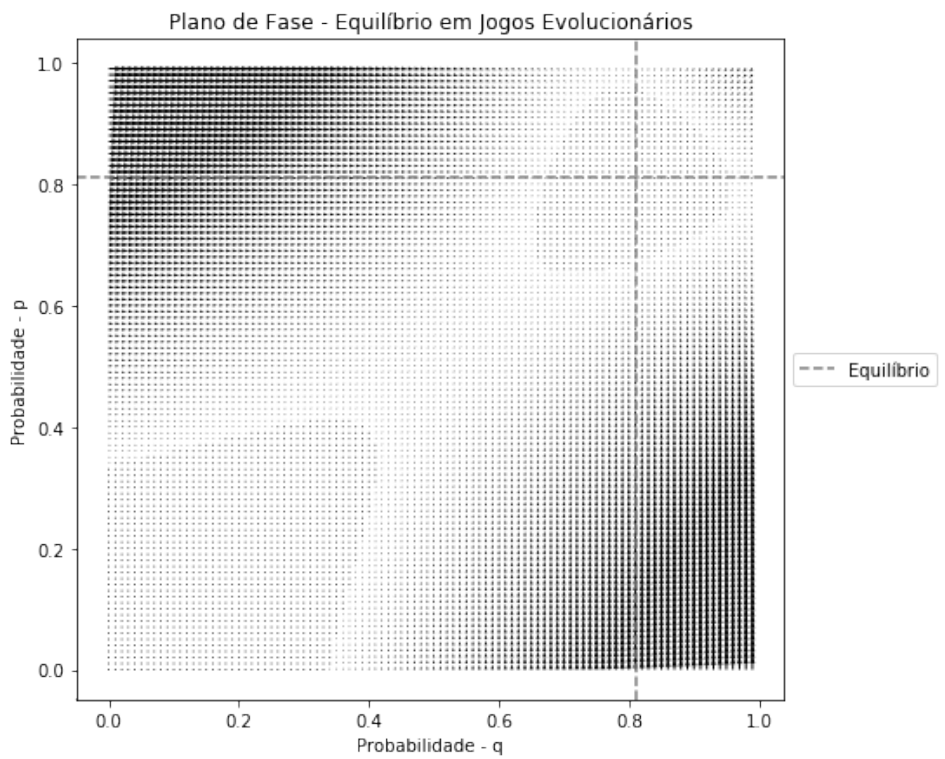

Figura 4.29: Jogo Evol. - P. de Fase - Simétrico -\$72/bbl

Na análise pelo replicador dinâmico do jogo com o preço do barril $P$ em $\$ 80$ dólares (tabela 4.12), a proporção da população se estabiliza na ação degenerada investir (figura 4.30), como concluído na forma normal do jogo pelo equilíbrio de dominância fraca da ação investir.

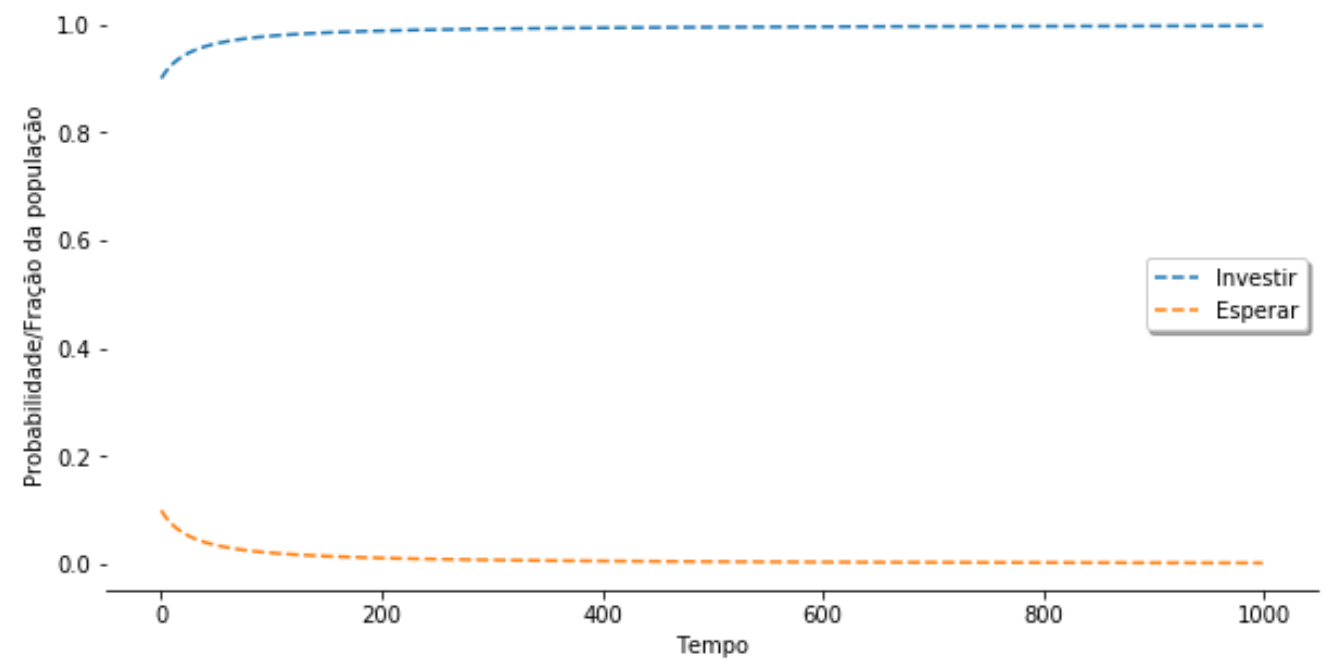

Figura 4.30: Jogo Evolucionário de população infinita - \$ 80/bbl

No plano de fase em $\$ 80$ dólares o barril (figura 4.31), os vetores indicam para o ponto de máximo na situação de canto de $\left\{p^{*}, q^{*}\right\}$ igual a $\{1,1\}$, sendo o mesmo que o par de estratégias $\{$ investir, investir $\}$. 


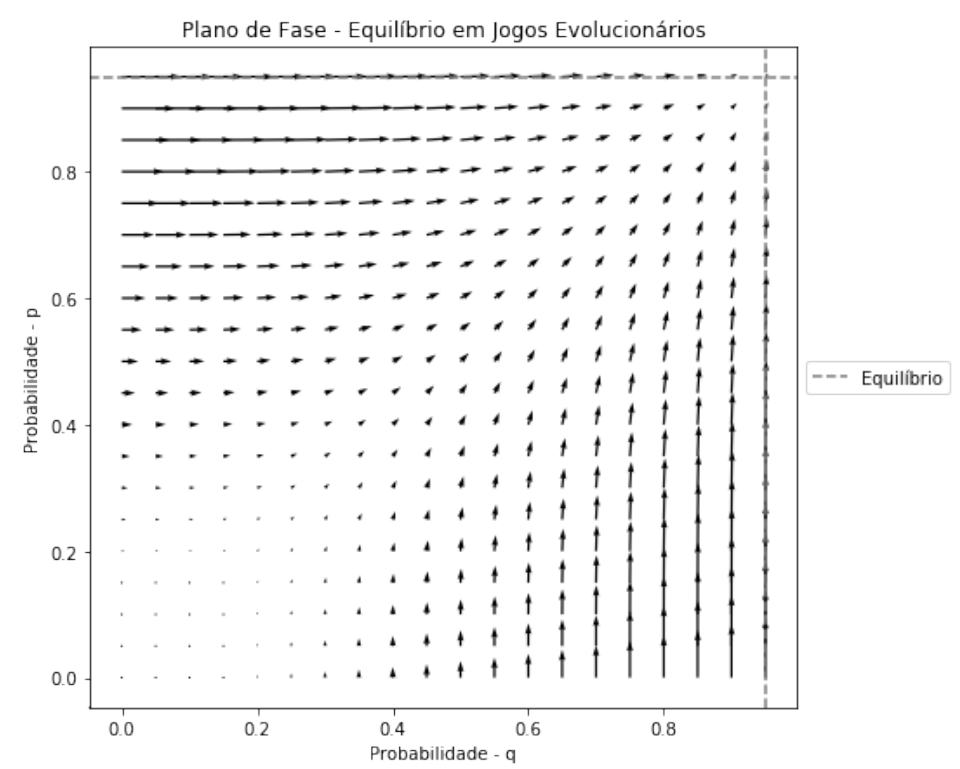

Figura 4.31: Jogo Evol. - P. de Fase - Simétrico -\$ 80/bbl

Outra forma de analisar esse conflito é pelo gráfico do prêmio do líder e do seguidor em função do preço do petróleo (figura 4.32). As linhas verticais indicam o intervalo da guerra de atrito, sendo que neste jogo e no momento inicial do contrato ocorre entre $\$ 69.62$ e 76.25 o barril. O preço inferior do conflito por informação é definido quando os operadores acreditam que é ótimo investir e isso se dá no gatilho único de explorar $P^{* *}$, visto que é um jogo simétrico. É nesse momento que se aciona o custo de espera para o payoff $W_{i}$, sendo melhor para o jogador migrar para a ação investir e podendo se tornar a operadora líder. Contudo, o payoff de aguardar por informação vizinha e ser o agente seguidor é maior, colocando os dois operadores, dada a simetria, em uma situação com probabilidade de aguardar e perfurar. Além disso, é importante reforçar que os contornos gerais para que aconteça esse exato intervalo de preços de petróleo com conflito dependem das variáveis exógenas e endógenas dos projetos de ambas as empresas. 


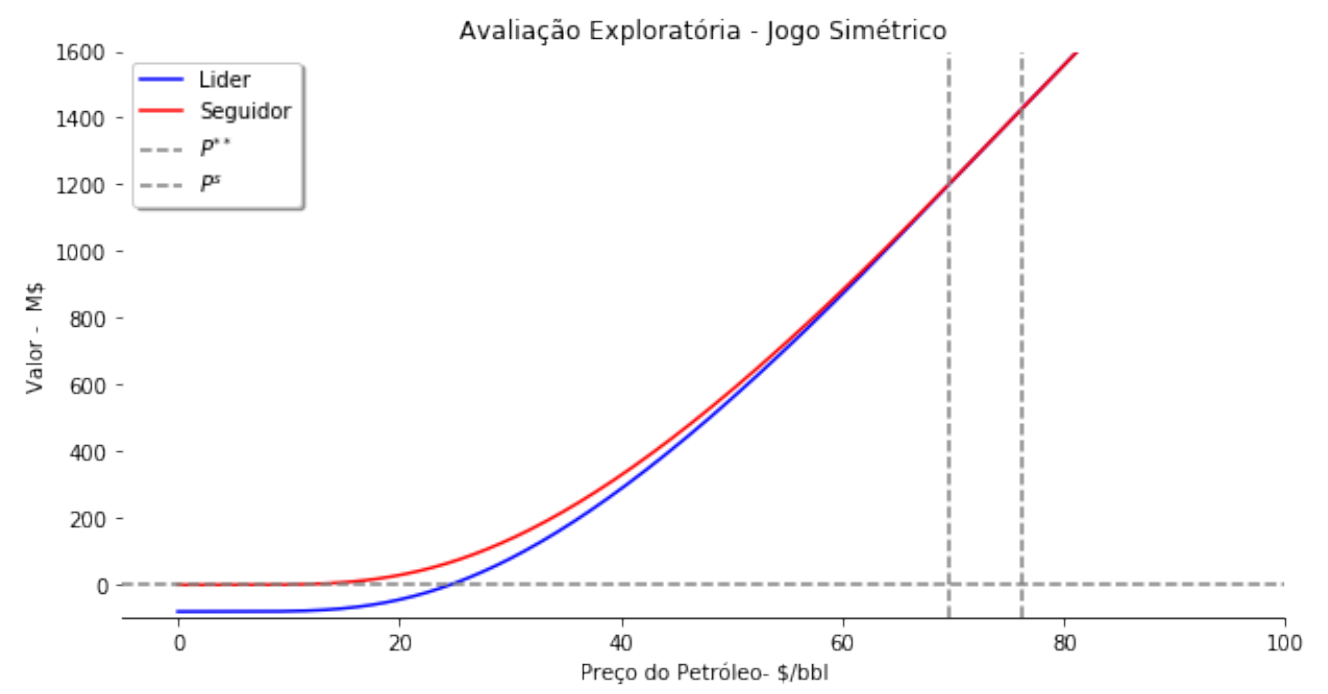

Figura 4.32: Guerra de Atrito: DogFish x DogFish - $\rho=60 \%$

No detalhe da figura (4.33), quando há a sobreposição efetiva do prêmio do seguidor e do líder se define o limite superior da guerra de atrito, este denominado de gatilho de perfuração simultânea $\left(P^{s}\right)$ e descrito na equação $(3-60)$.

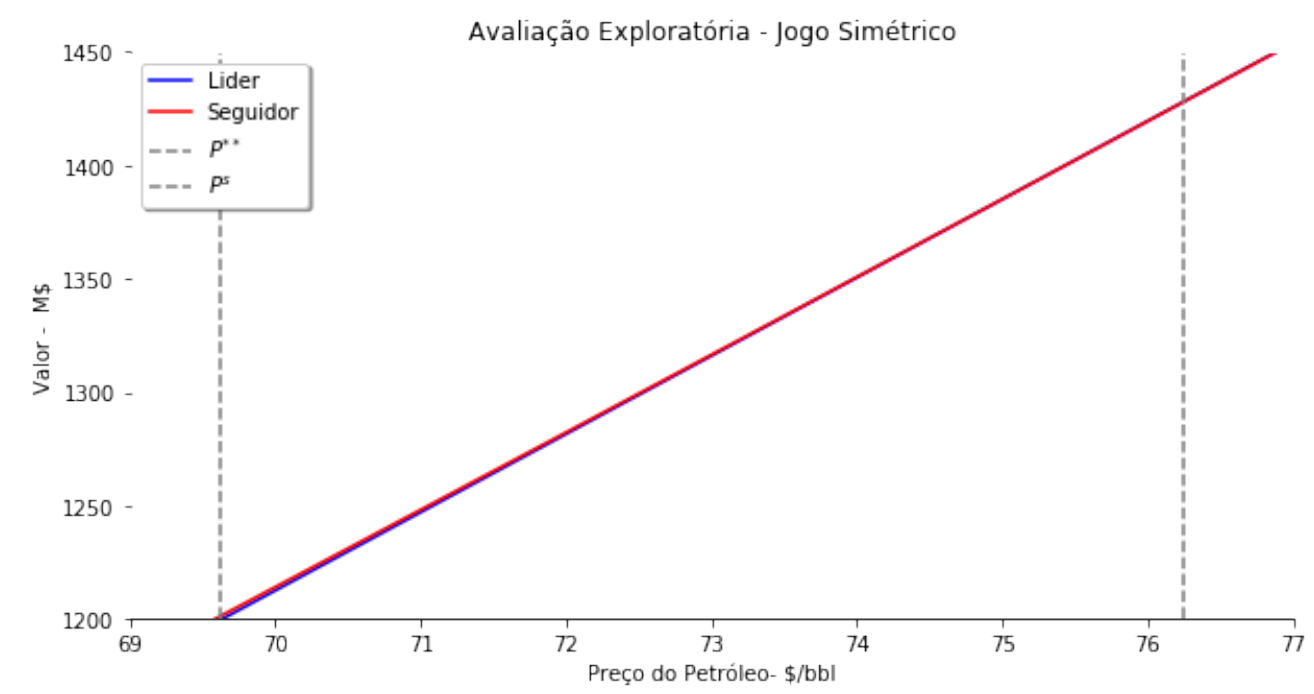

Figura 4.33: Detalhe - G. de Atrito: DogFish x DogFish - $\rho=60 \%$

Como mencionado, o limite inferior é o gatilho exploratório, que é a condição ótima de investimento em OR, com resultados apresentados na seção (4.2.1). Já o limite superior considera uma indiferença entre aguardar a informação e perfurar imediatamente. Essa indiferença pode ser coletada e estudada pelo benefício da espera ou também denominado de prêmio da informação, sendo um atributo mais explorado nos exemplos de assimetria (seção 
4.2.2.2 e 4.2.3). Esse limite superior pode diminuir ou aumentar dada a correlação entre os prospectos (tabela 4.13). Note que quanto mais correlacionados são os prospectos, maior é o limite superior, sendo $\infty$ no caso de correlação de 100\% (DIAS; TEIXEIRA, 2009). Como discutido na seção (3.4), não existem ativos $100 \%$ correlacionados.

\begin{tabular}{|c|c|c|c|}
\hline$\rho$ & $30 \%$ & $60 \%$ & $80 \%$ \\
\hline \hline Intervalo & ] $69.63,71.5]$ & ] $69.63,76.25]$ & ] $69.63,87.50]$ \\
\hline
\end{tabular}

Tabela 4.13: Intervalo da G. de Atrito - Efeito do $\rho$ no $P^{s}$

E quando essa guerra de atrito pode começar? Como o preço do petróleo é um processo estocástico, não é possível saber a priori o momento exato que o preço vai atingir a curva de gatilho (figura 4.13). A guerra de atrito pode começar muito próximo do início do contrato ou nunca acontecer, já que o preço da commodity pode ficar sempre abaixo da curva. A simulação de Monte Carlo é útil para obter uma estimativa do momento inicial do conflito. Para a entrada da simulação, são necessários a curva de gatilho da opção de explorar (figura 4.13), a discretização temporal da solução por diferenças finitas, a equação de simulação do processo MGB (similar a equação 3-11) e os parâmetros exógenos usados na solução por diferenças finitas (tabela 4.2). Como a simulação é em medida real, é necessário o drift do processo, adotando $\alpha$ igual a $9 \%$ a.a. (estimado na seção 4.1).

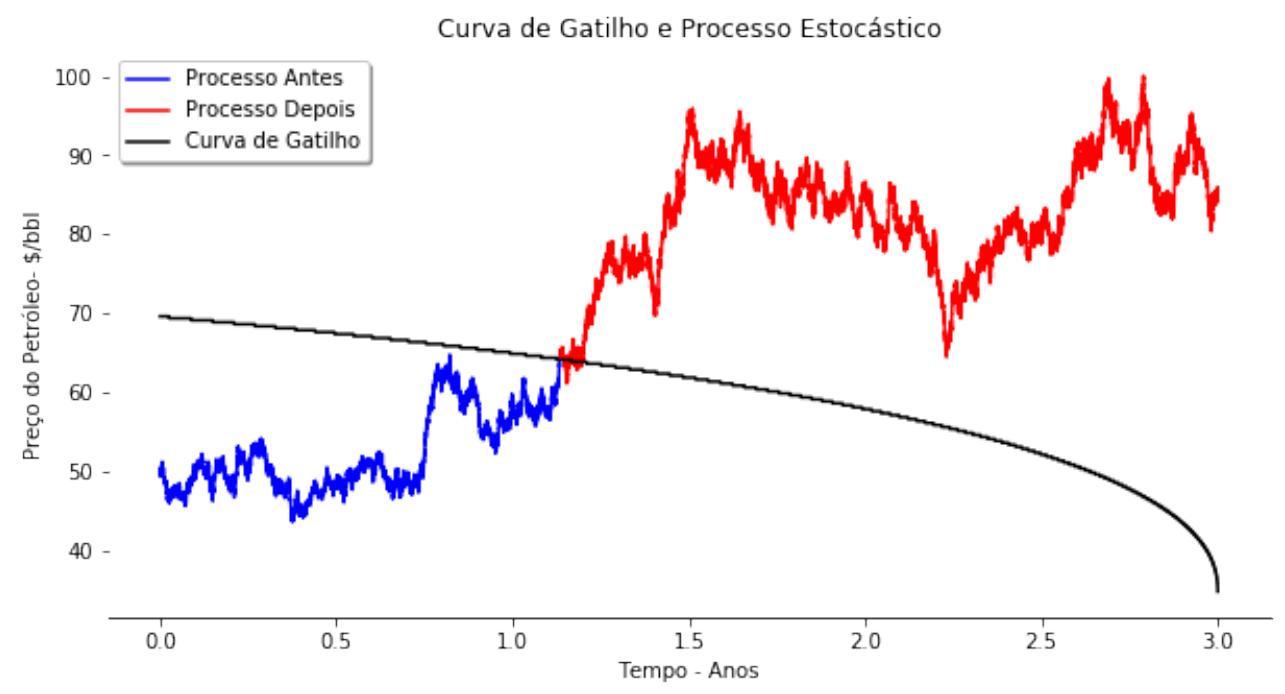

Figura 4.34: Simulação de Monte Carlo e Gatilho

A figura (4.34) apresenta uma possível simulação de um caminho. Veja que quando o processo atinge a curva de gatilho, o caminho altera de cor. Nesse processo, a primeira chegada ocorreu no tempo 1.13 ano. Foram feitas 
10000 simulações para a análise estatística (figura 4.35). Como verificação, a esperança matemática do MGB em medida real no prazo de três anos é de $\$$ 65.498 o barril (equação 3-12) e a média das 10000 simulações no vencimento do contrato é de $\$ 65.613$ o barril, bem próxima da esperança matemática.

Histograma - Primeira Chegada - Início da Guerra de Atrito

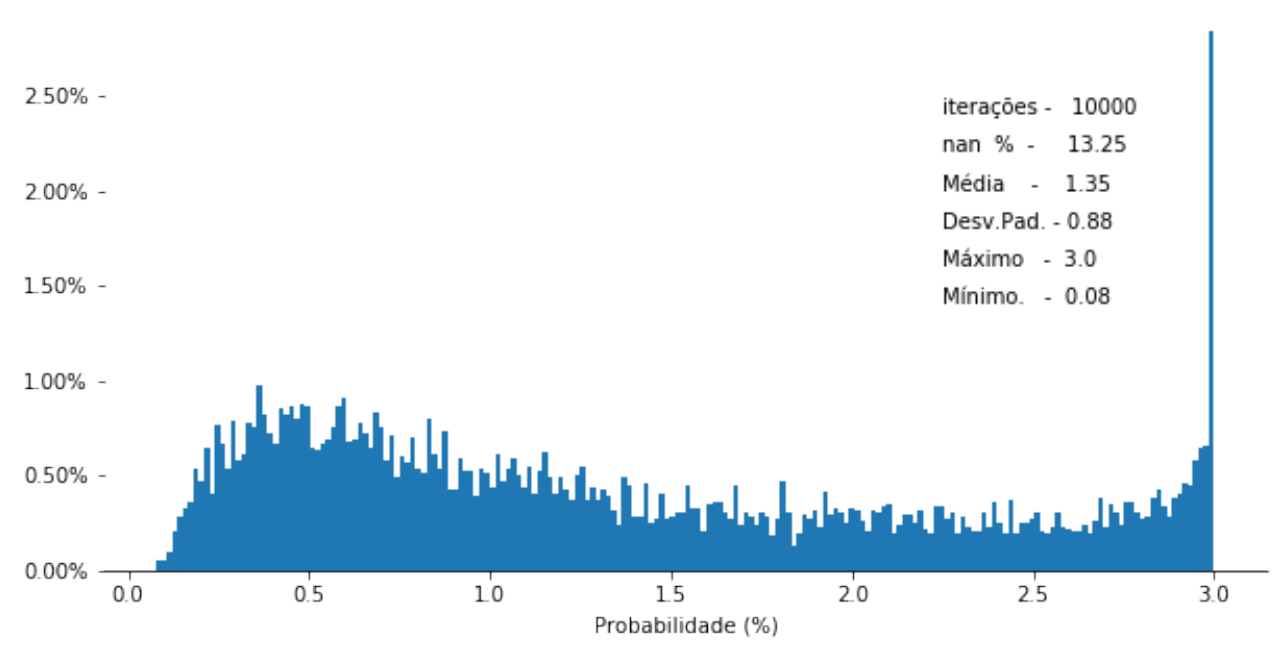

Figura 4.35: Histograma - Início da Guerra de Atrito

O tempo médio para o início da guerra de atrito é de 1 ano e 4 meses. Na figura (4.35), nota-se uma grande dispersão dos eventos, com o desvio padrão de dez meses. A probabilidade de não perfurar o prospecto é de $13.25 \%$ independente da guerra de atrito, posto que essa porcentagem representa os caminhos que não atingiram a curva de gatilho. Por outro lado, a probabilidade de começar a guerra de atrito antes do primeiro ano é de $38.88 \%$. Já a probabilidade de esperar o prospecto valorizar e começar a guerra de atrito nos últimos 6 meses do contrato é 13.8\%. Somando esta probabilidade com a probabilidade de não investir por nunca atingir o gatilho, obtém-se o valor de $27.05 \%$, mostrando que há uma grande chance de colocar a decisão de investimento nos últimos momentos do contrato. Essa alta proporção de decisões no final do contrato também é devido à forte inclinação da curva de gatilho próximo ao vencimento.

Uma outra forma de estudar os equilíbrios e as condições para o conflito é por um gráfico de estratégias em função do preço do petróleo. Segundo a tabela (4.14), o conjunto de estratégias degeneradas \{investe, investe\} será representado na figura (4.36) com o valor 1, assim como \{investe, espera\}, \{espera,investe\} e \{espera,espera\} serão representados respectivamente pelos números 2,3 e 4 . Números racionais não negativos simbolizam as estratégias mistas entre investir e esperar e que no caso estudado, indicam que 
ocorre a guerra de atrito nesses preços.

\begin{tabular}{cccc} 
& & \multicolumn{2}{c}{ Jogador 2 } \\
& & \multicolumn{1}{c}{ Investe } & \multicolumn{1}{c}{ Espera } \\
\cline { 3 - 4 } Jogador 1 & Investe & 1 & 2 \\
\cline { 3 - 4 } & Espera & 3 & 4 \\
\cline { 3 - 4 } & & &
\end{tabular}

Tabela 4.14: Simbologia do conflito em Quadrantes

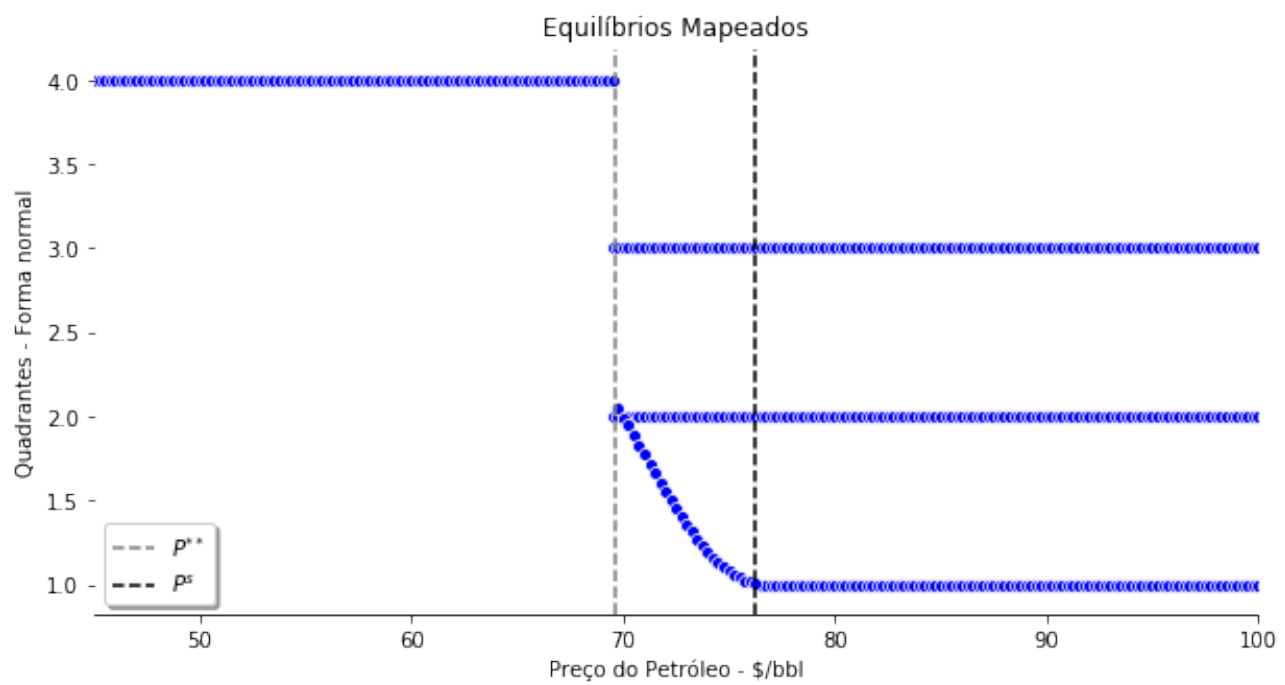

Figura 4.36: Equilíbrios Mapeados - Jogo Simétrico

As conclusões feitas até agora também podem ser observadas desse mapeamento. As estratégias puras de espera (quadrante 4) são EPM (e também ENPS) em preços baixos até o gatilho exploratório. Após o gatilho $\left(P^{* *}\right)$, há dois equilíbrios puros $\left\{F_{i}, S_{j}\right\}$ e um equilíbrio em estratégias mistas. Com a elevação dos preços, a probabilidade dos jogadores de investirem aumenta no intervalo de ocorrência do equilíbrio em estratégias mistas (valores entre os quadrantes 1 e 2). Esse equilíbrio em estratégias mistas é o único EEE nesse intervalo, o qual suporta pequenas oscilações populacionais comparado com os outros dois equilíbrios degenerados (quadrantes 2 e 3). Quando se ultrapassa o gatilho simultâneo, três equilíbrios são notados, contudo o equilíbrio fracamente dominante é a perfuração simultânea (quadrante 1) e o único EEE, como visto nas figuras (4.30 e 4.31).

Com o passar do tempo no contrato exploratório, o intervalo da guerra de atrito se altera. Como o limite inferior é o gatilho exploratório $\left(P^{* *}\right)$, o preço inferior diminui em função do tempo, pois se trata de uma função côncava, sendo o máximo no momento inicial do contrato e o mínimo no término e igual ao break-even do $\mathrm{VME}(\mathrm{P})$ (figura 4.13). Igualmente, o limite superior 
$P^{s}$ também diminui com o passar do tempo e também se aproxima do break even do VME. Ou seja, o intervalo de preços do conflito, simbolizado na figura (4.36) pelas retas pontilhadas verticais, se desloca para a esquerda e diminui a janela de ocorrência com o andamento do tempo no contrato, colapsando no break-even do $\operatorname{VME}(\mathrm{P})$ no valor igual a $\$ 34.83$ o barril no vencimento.

Como a guerra de atrito é um jogo de parada ótima, o equilíbrio é definido em função do tempo. O tempo de conflito para o líder é até o acionamento do seu gatilho exploratório e no caso do operador seguidor, somente ocorre após a revelação da informação, em que se redefine o novo preço de gatilho $\left(P^{F}\right)$. Caso a informação seja positiva, o preço do $P^{F}$ será menor que $P^{* *}$ e instantaneamente o seguidor irá perfurar sua oportunidade. Caso a informação seja negativa, $P^{F}$ será maior que $P^{* *}$, e como o preço do petróleo é uma variável estocástica, pode acontecer da seguidora nunca perfurar seu prospecto. Como o jogo é simétrico, o equilíbrio se dá nas estratégias puras $\left\{t_{L}, t_{F}\right\}$ e $\left\{t_{F}, t_{L}\right\}$ simultaneamente, sendo o EEE uma combinação dessas duas estratégias num equilíbrio em estratégias mistas, além de ser um Equilíbrio Perfeito Markoviano. As equações abaixo representam os momentos das estratégias do líder e do seguidor:

$$
\begin{gathered}
t_{L}=\inf \left\{t \mid P(t) \geq P^{* *}(t)\right\} \\
t_{F}=\inf \left\{t \mid P(t) \geq P^{F}\right\}
\end{gathered}
$$

As situações de impasse podem provocar a ausência de investimento exploratório na bacia petrolífera, mesmo com os indicadores de valor dos projetos bem favoráveis. A mudança na ação dos operadores deve ser acompanhada com uma alteração no comportamento, passando de um conflito para um ambiente colaborativo. Agora, nesse novo ambiente deve haver incentivos para ser crível essa mudança de jogo e dessa forma são acompanhadas por condições para que haja essa migração. Diferentemente da guerra de atrito, a barganha cooperativa é um jogo na busca de um ganha-ganha. Esse jogo se concebe na fusão dos portfólios dos dois operadores e a partir do ponto de discordância que há entre eles, determina-se a melhor divisão dos prêmios entre as empresas.

A solução da barganha cooperativa segue as equações (3-52 e 3-53). No caso estudado, como o jogo é simétrico, a divisão não precisa considerar o ponto de discordância e é simplesmente $50 \%$ para cada operador (figuras 4.37 e 4.38). As negociações poderiam começar a partir de $\$ 21.25$ dólares o barril de petróleo, já que abaixo desse valor a parte que cabe da barganha cooperativa para cada jogador é nula (figura 4.37). Contudo, deve-se comparar com o ótimo de cada empresa no jogo de guerra de atrito, sendo no intervalo estudado o 
ENPS do conflito. Os prêmios pela barganha são apresentados na primeira linha da tabela (4.15), mas também podem ser acompanhados nas duas figuras seguintes. Isso posto, na situação de preço inicial em $\$ 50$ /bbl, o valor do prêmio seria de $\$ 570.80$ milhões (comparar com o jogo da tabela 4.10), abaixo do equilíbrio \{espera, espera $\}$. Em $\$ 72$ dólares o barril, sendo este o preço do petróleo contido no intervalo da guerra de atrito, o valor para cada jogador ficaria em $\$ 1281.95$ milhões, melhor que a ação de investir $L_{i}$ dos equilíbrios $\left\{F_{1}, L_{2}\right\}$ e $\left\{L_{1}, F_{2}\right\}$ (comparar com tabela 4.11 ), mas pior que a espera $F_{i}$. Em \$ 80 dólares, o valor da barganha seria de $\$ 1557.411$ milhões, igual à ação de investir, sendo desnecessária a negociação (comparar com tabela 4.12). Ou seja, não há vantagens para nenhum dos jogadores na simples divisão dos ativos, porém, se houver a possibilidade de um ganho marginal fruto da negociação entre as empresas, poderia haver um intervalo contendo o intervalo de preços da guerra de atrito, e por conseguinte, a divisão pela barganha seria escolhida em relação ao conflito por informação.

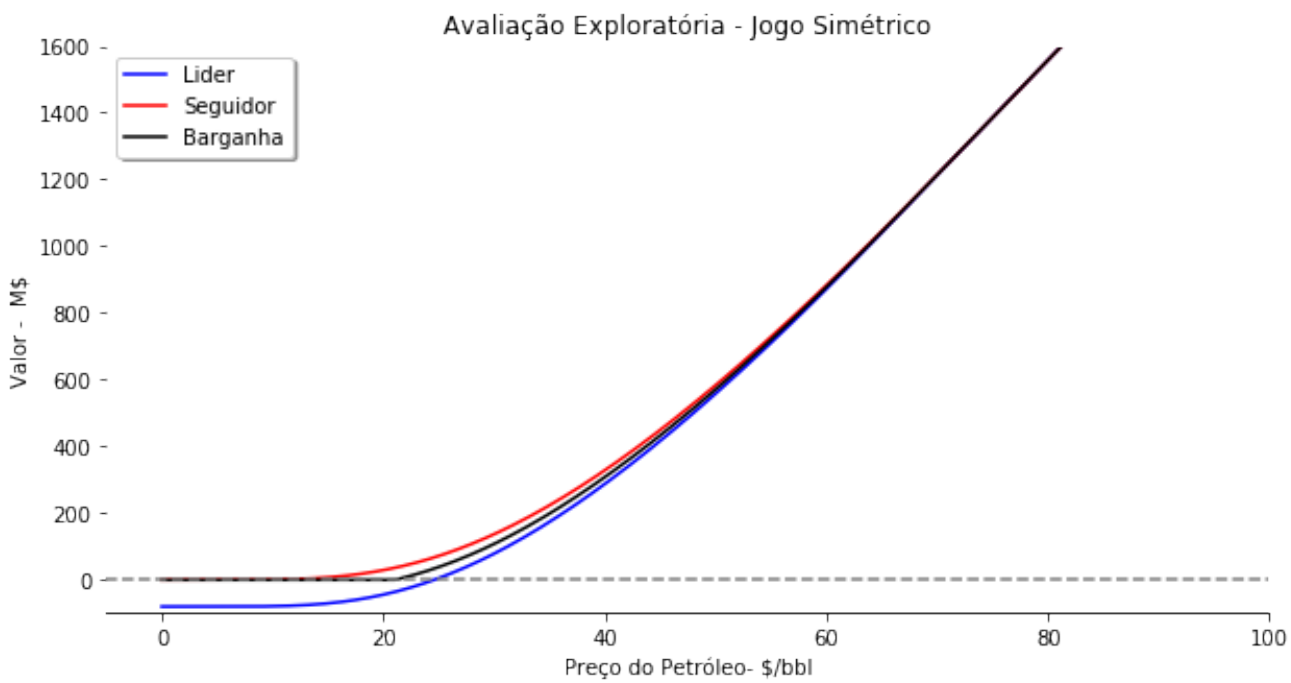

Figura 4.37: Barganha Cooperativa: DogFish x DogFish $-\rho=60 \%$ 


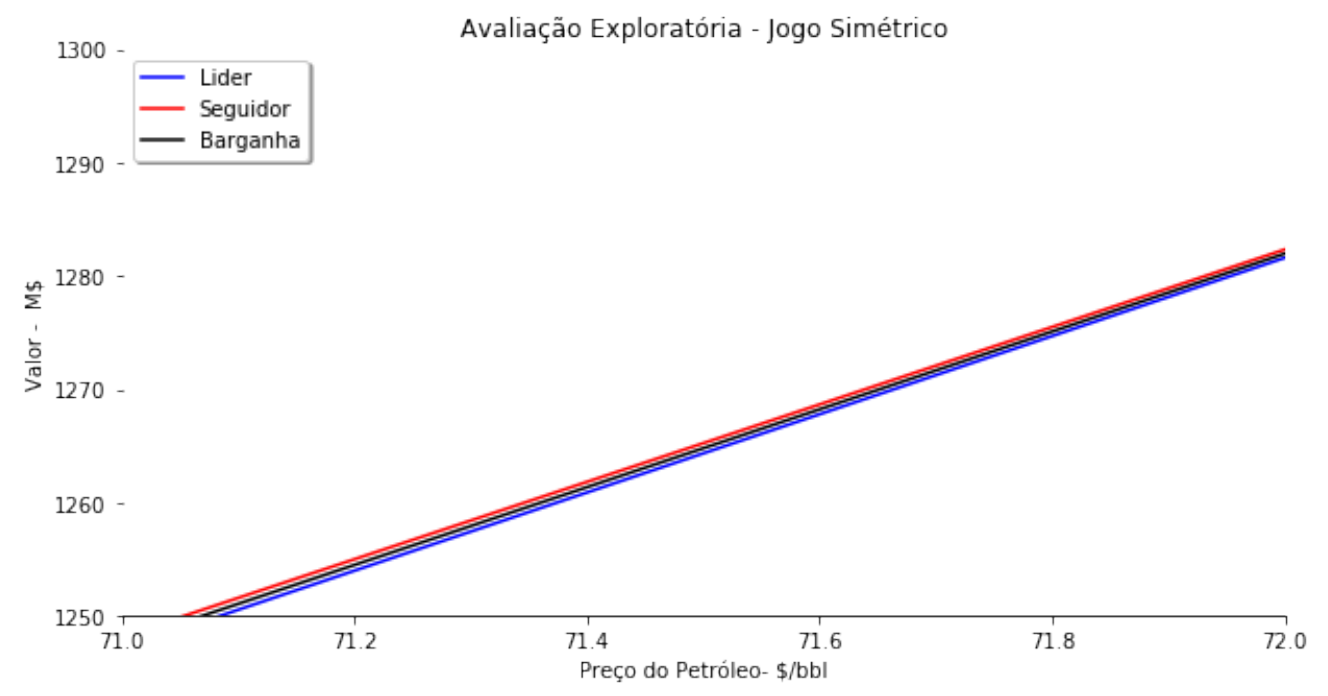

Figura 4.38: Detalhe - Barganha: DogFish x DogFish - $\rho=60 \%$

Como apresentado em seções anteriores, a informação obtida pelo sucesso ou fracasso do poço é pública. Neste trabalho, a revelação da informação é medida pela variável $\rho$ entre os prospectos. Essa variável é relevante na barganha cooperativa, visto que a unitização dos blocos exploratórios provoca uma análise em portfólio e dessa forma, a medida de aprendizado tem um peso no valor e na divisão dos prêmios. Inclusive, no processo de negociação, devido à interação cooperativa entre os dois jogadores, a percepção de correlação pode ser positivamente avaliada entre os dois prospectos. Isso ocorre em função de incorporação de conhecimentos prévios dos dois operadores, que são compartilhados nesse processo de troca de informações. Além disso, é comum em negociação ou em reavaliação de carteiras o redesenho dos projetos, com otimização dos dispêndios esperados e até um desenho de produção em cluster. Isso quer dizer que em ambiente cooperativo há uma tendência em revelar a informação privada dos agentes, o que seria uma informação adicional ao que normalmente é divulgado pelas empresas por exigência da ANP. À vista disso, as informações privadas revelam tanto quanto ou mais informações que o conhecimento público e obrigatório.

Como a revelação da informação privada é considerada de melhor qualidade, esse diferencial qualitativo é materializado por um aumento da variável correlação entre as oportunidades, em consequência da correlação representar a medida de aprendizado da incerteza técnica (DIAS; TEIXEIRA, 2009). Por isso, foi elevado o $\rho$ de $60 \%$ para $80 \%$ dada a interação dos agentes em ambiente de negociação. Nessa situação, comparando com a situação da guerra de atrito no início do contrato e com o barril a $\$ 50$ (tabela 4.10 ), o 
payoff da barganha cooperativa é de 572.67 milhões de dólares, ainda pior que o equilíbrio \{espera, espera\}. Em $\$ 72$ o barril (tabela 4.11), a utilidade da barganha é de $\$ 1283.65$ milhões, sendo um valor de payoff melhor que as estratégias puras e mistas $(=\$ 1281.59 \mathrm{M})$. Em $\$ 80$ o barril (tabela 4.12 ), as condições de negociação ainda são preferidas, visto que o valor esperado da utilidade na barganha para cada jogador é de $\$ 1557.91 \mathrm{M}$, sendo melhor que a estratégia pura de investir simultaneamente $(=\$ 1557.41 \mathrm{M})$.

\begin{tabular}{|c|c|c|c|}
\multicolumn{4}{c}{$w_{i} \Pi_{i, j}$} \\
\hline$P(\$ / b b l)$ & 50 & 72 & 80 \\
\hline \hline$\rho=60 \%$ & 570.80 & 1281.95 & 1557.41 \\
\hline$\rho=80 \%$ & 572.67 & 1283.65 & 1557.91 \\
\hline
\end{tabular}

Tabela 4.15: $w_{i} \Pi_{i, j}$ - Divisão da Barganha Cooperativa - $\mathrm{M} \$$

A figura (4.39) explicita o detalhe das curvas com os prêmios da seguidora, da líder e da barganha cooperativa contra o preço do barril de petróleo, em que a utilidade da barganha é superior a todas as outras. O intervalo contínuo de cooperação em que é melhor cooperar que qualquer outra ação é de $\$ 66.25$ até 88 o barril. Esse intervalo contém o intervalo do conflito $] P^{* *}, P^{s}$ ] (] $69.63,76.25])$, sendo viável a substituição do jogo da guerra de atrito pela barganha cooperativa.

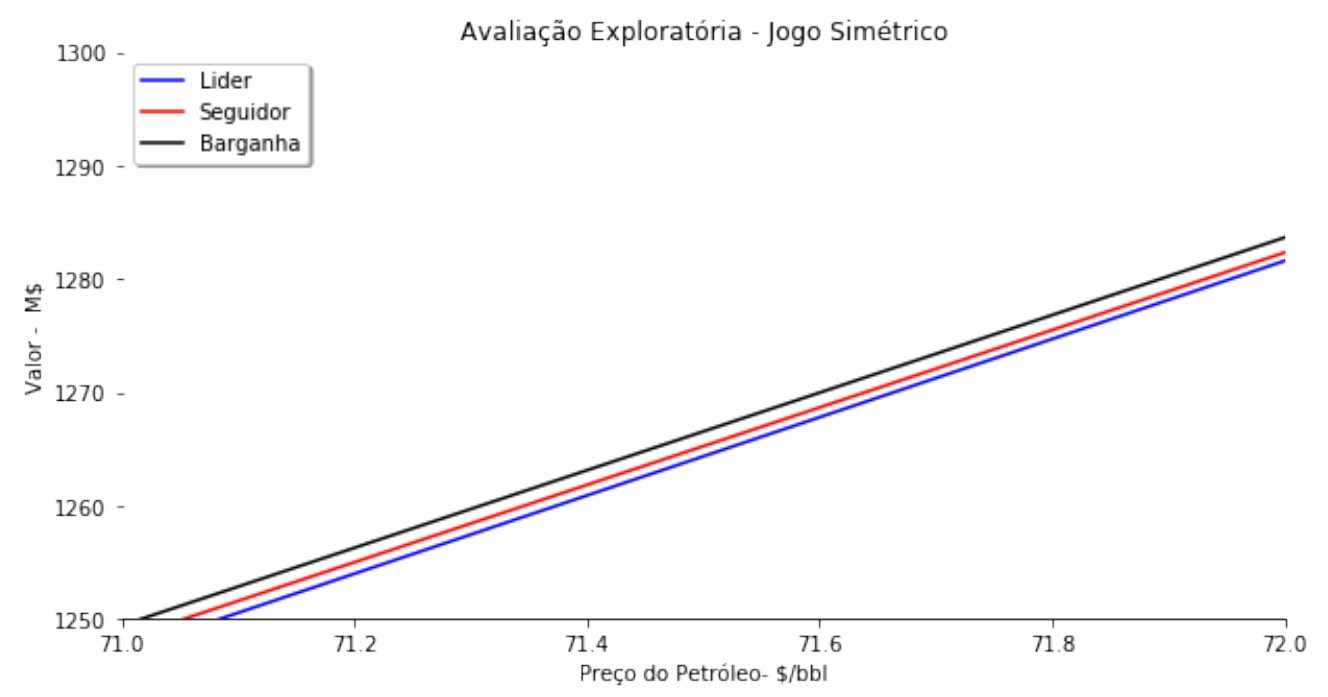

Figura 4.39: Detalhe - Barganha: DogFish x DogFish - $\rho=80 \%$

Dessa forma, pelo exemplo de um jogo simétrico, foi possível explorar muitas das condições para a guerra de atrito e a mudança para a barganha cooperativa. No caso a seguir, será analisado um jogo assimétrico e investigado 
as condições para um possível conflito na situação de ativos distintos. No último caso, como já comentado, será um conflito com um portfólio em um dos blocos, sendo naturalmente um jogo assimétrico.

\subsubsection{2}

\section{Jogo Assimétrico: do Atrito à Barganha?}

O próximo jogo a ser analisado envolve dois ativos, cada um em um bloco exploratório, sendo a oportunidade DogFish operada pela empresa A e a Head pela empresa B (figura 4.40).

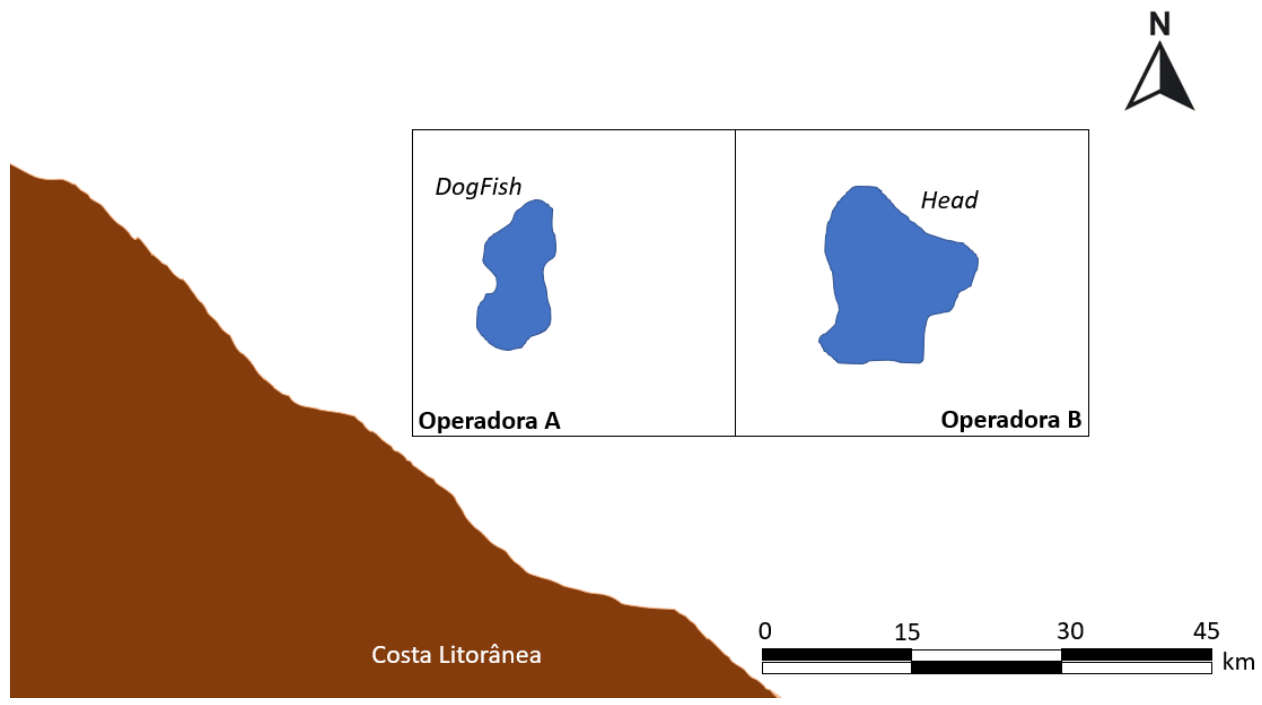

Figura 4.40: Modelo - 2 Blocos - DogFish e Head

Com essas oportunidades e o contrato no tempo presente $(\tau=3)$, foram destacados os intervalos de preços importantes para estudar o conflito. Esses intervalos são relacionados com os preços dos gatilhos exploratórios e de perfuração simultânea de cada oportunidade. A simbologia $(\mathrm{H})$ é referente à oportunidade Head e a simbologia (D) com a oportunidade DogFish, em que todos os payoffs e gatilhos foram calculados com a metodologia proposta na seção (3.7):

- $\left[0 ; 69.62\left[-\left[0 ; P^{* *}(D)[\right.\right.\right.$

- $\left[69.62 ; 72.25\left[-\left[P^{* *}(D) ; P^{s}(D)[\right.\right.\right.$

- [72.25; 73.12[ - $\left[P^{s}(D) ; P^{* *}(H)[\right.$

- $\left[73.12 ; 82.25\left[-\left[P^{* *}(H) ; P^{s}(H)[\right.\right.\right.$

- $\left[82.25 ; \infty\left[-\left[P^{s}(H) ; \infty[\right.\right.\right.$ 
A seguir, serão apresentados diversos jogos na forma normal em diferentes preços do barril no tempo presente e as discussões dos equilíbrios em cada jogo, os quais representam cada intervalo mencionado acima.

Como no jogo simétrico, quando o preço do barril do petróleo está abaixo do gatilho da oportunidade DogFish, o equilíbrio de Nash perfeito em subjogos é $\{$ esperar, esperar $\}$ (tabela 4.16). Com esse preço corrente, nenhuma empresa visa perfurar sua oportunidade, pois os ativos não estão deep-in-the-money.

$$
\begin{array}{llcc} 
& & \multicolumn{2}{c}{\text { J2- Head }} \\
& & \text { Investe } & \text { Espera } \\
\text { J1 - DogFish } & \text { Investe } & 558.23 ; 471.13 & 558.23 ; \underline{500.48} \\
& \text { Espera } & \underline{582.19} ; 471.13 & \underline{581.28} ; \underline{497.72}
\end{array}
$$

Tabela 4.16: Forma normal: Jogo Assimétrico - $P=\$ 50, \tau=3$

Quando o preço do barril do petróleo está acima do gatilho da oportunidade DogFish e abaixo do preço de perfuração simultânea desta oportunidade $P^{s}(D)$ (tabela 4.17), a espera é dominante em relação à ação investir para o jogador 2, diferentemente da situação simétrica (tabela 4.11), tendo somente um ENPS em \{investir; esperar . Isso quer dizer que o jogador 2 não vai perfurar neste preço corrente. Consequentemente, logo no momento em que o preço do petróleo é igual ao gatilho da oportunidade DogFish, o jogador 1 exerce sua opção e perfura este prospecto, sem aguardar a perfuração do concorrente, porque ele sabe que não vai obter a informação gratuita do vizinho. Já a operadora $B$ espera o resultado e com a nova informação adéqua a sua decisão, ou descendo seu gatilho exploratório e podendo investir imediatamente na oportunidade Head ou caso seja uma notícia ruim, elevará seu gatilho e vai aguardar um melhor momento para investir. Caso a informação seja positiva advinda da operadora $A$, a oportunidade Head terá o gatilho exploratório saindo de $\$$ 73.12 para $\$ 67.37$ o barril e consequentemente a operadora $B$ irá perfurar de imediato, uma vez que o preço corrente do barril do petróleo já atingiu o valor de $\$ 69.62$, este último sendo o gatilho exploratório da oportunidade DogFish.

$$
\begin{array}{lccc} 
& & \multicolumn{2}{c}{\text { J2- Head }} \\
& & \text { Investe } & \text { Espera } \\
\text { J1 - DogFish } & \text { Investe } & 1281.59 ; 1122.46 & \underline{1281.59} ; \underline{1125.43} \\
& \text { Espera } & \underline{1281.61} ; 1122.46 & 1278.39 ; \underline{1122.63}
\end{array}
$$

Tabela 4.17: Forma normal: Jogo Assimétrico - $P=\$ 72, \tau=3$

Em jogos assimétricos, o equilíbrio se dá pela relação entre os prêmios das opções (porcentagens na tabela 4.6 para o preço de $\$ 50 / \mathrm{bbl}$ ), ou seja, quão longe do dinheiro o ativo está. A mudança da ação de esperar para 
perfurar do jogador 1 ocorre devido ao acionamento do gatilho exploratório combinado com o surgimento do custo de espera, que possui uma relação com o investimento não exercido, ou seja, o $V M E(P, t)$. Portanto, a empresa que tiver o gatilho mais baixo vai perfurar e a empresa que tem o gatilho exploratório com o preço mais alto vai esperar a informação gratuita. Caso a empresa de gatilho mais baixo não perfure no momento ótimo, ela vai incorrer no custo de espera e não vai ter a informação gratuita, pois a oportunidade vizinha tem o gatilho com o preço mais alto e essa operadora não vai investir logo. Nessa situação, a operadora vizinha irá aguardar até o seu momento ótimo chegar e sem qualquer custo, porque, como dito, o custo só é acionado acima do seu gatilho exploratório. Portanto, não faz sentido a empresa aguardar acima do seu gatilho de investir no poço pioneiro, pois só terá custo por aguardar e não terá informação gratuita do vizinho.

Em suma, a relação entre a ação investir e esperar tem um vínculo com o prêmio da espera (gatilho exploratório) e o custo de espera, não com o valor do ativo ou do portfólio em si. Como pode ser visto na tabela (4.17), os payoffs da oportunidade DogFish têm valores maiores que os da oportunidade Head em qualquer estratégia, porém tem a decisão de investir a preços de petróleo mais baixos que a concorrente. Ou seja, não é porque o portfólio é maior em valor monetário que a empresa vai conseguir aguardar por informações gratuitas, mas na verdade é porque seu portfólio ainda não está deep-in-the-money.

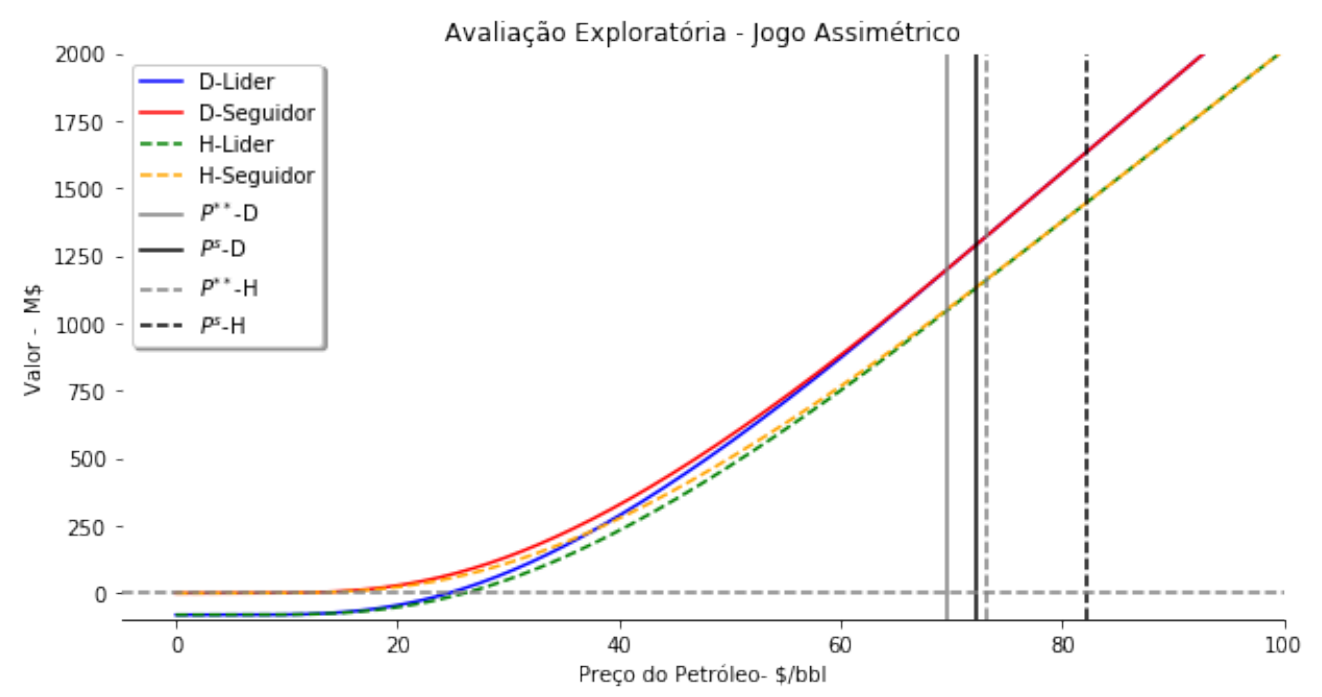

Figura 4.41: Jogo Assimétrico: Preço x Valor - DogFish e Head

A figura (4.41) apresenta os payoffs das operadoras $A$ e $B$ em relação ao preço do petróleo, com e sem vantagens pela informação. Comparando com o jogo simétrico (figura 4.32), a assimetria desacopla os gatilhos de explorar e de 
perfuração simultânea formando dois intervalos, sendo esses já apresentados no início da seção. Uma outra métrica importante especialmente em um jogo assimétrico é o benefício da espera, que pode ser calculado pela diferença entre os payoffs de ser seguidor e líder para cada oportunidade (figura 4.42). Primeiramente, nota-se que o benefício da espera cai com o aumento dos preços, visto que quanto maior o preço do petróleo, mais atraente é o investimento. Em especial, a oportunidade Head tem o benefício maior em qualquer preço, inclusive após o gatilho da oportunidade DogFish, chegando a zero em seu gatilho simultâneo $P^{s}(H)$.

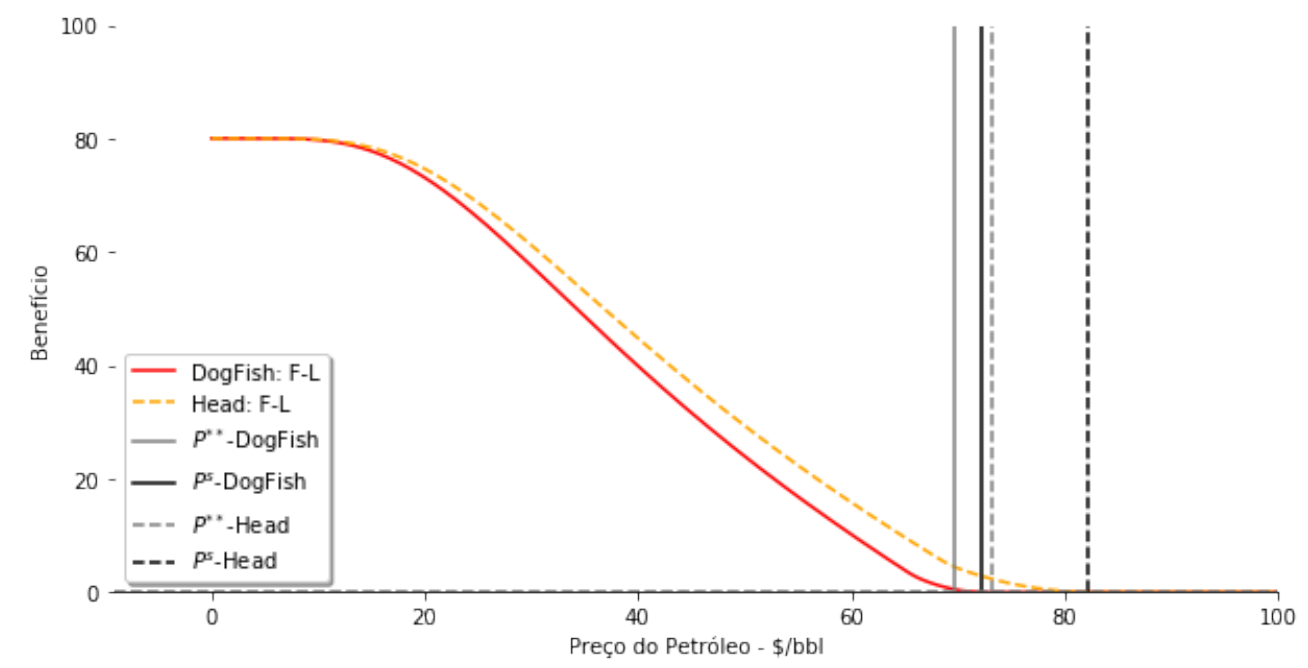

Figura 4.42: Jogo Assimétrico: Benefício da Espera

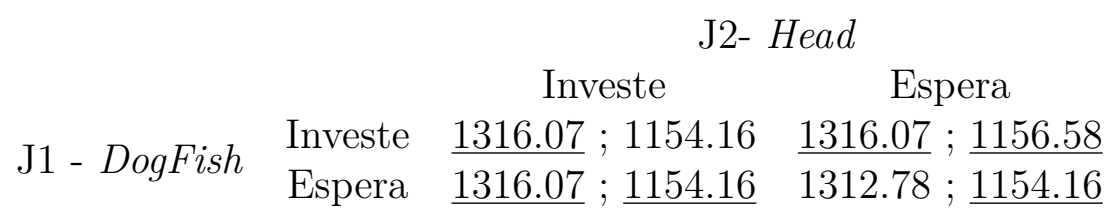

Tabela 4.18: Forma normal: Jogo Assimétrico - $P=\$ 73, \tau=3$

Continuando a análise na forma normal, é interessante o caso em $\$ 73$ dólares o barril (tabela 4.18), em que ocorrem dois equilíbrios de Nash puros, podendo haver um equilíbrio de Nash em estratégias mistas e assim, uma possível guerra de atrito. Contudo, para o Jogador 2 a ação esperar é fracamente dominante em relação a ação investir, ou seja, a estratégia \{esperar; investir $\}$ não é o equilíbrio mais provável. Ademais, a ação investir para o jogador 1 domina fracamente em relação a ação de esperar. Isso quer dizer que o equilíbrio de Nash mais provável é o jogador 1 investir em DogFish e o jogador 2 aguardar a informação e perfurar no seu momento ótimo, sendo o ENPS igual à estratégia $\{$ investir; esperar $\}$. A dominância da ação esperar para o 
jogador 2 acontece, pois não há um custo na espera para esse jogador dado que o preço corrente está abaixo do seu gatilho exploratório de $\$ 73.125$ o barril (tabela 4.6). Devido às mesmas razões, a dominância da ação investir para o jogador 1 acontece, pois o preço está acima do seu gatilho exploratório, ou seja, há um custo de espera. Dado o custo, o payoff $W_{1}$ fica abaixo de qualquer outro payoff. Contudo, como o preço do barril está acima do seu gatilho simultâneo $\left(P^{s}(D)\right)$, a opção com informações vale tanto quando o exercício imediato $\operatorname{VME}_{1}(P, t) \sim E_{1}(P, t) \mid 2$, ou seja, $S_{1}=L_{1}=F_{1}>W_{1}$. Desse modo, o jogador 1 escolhe a ação investir independente da ação do jogador 2 .

$$
\begin{array}{llcc} 
& & \multicolumn{2}{c}{\text { J2- Head }} \\
\text { J1 - DogFish } & \text { Investe } & \underline{1557.41} ; 1376.04 & \underline{1557.41} ; \underline{1376.23} \\
& \text { Espera } & \underline{1557.41} ; \underline{1376.04} & 1553.52 ; 1372.60
\end{array}
$$

Tabela 4.19: Forma normal: Jogo Assimétrico - $P=\$ 80, \tau=3$

Na tabela (4.19), com o valor de $\$ 80$ o barril do petróleo, a informação acrescenta pouco ao jogador $2(\$ 190 \mathrm{mil}=1376.23$-1376.04) e nada ao jogador 1. Isso acontece, pois o preço do barril está próximo ao gatilho simultâneo para o jogador 2 e acima do gatilho simultâneo do jogador 1 . Similar ao jogo com o preço em 73 dólares o barril (tabela 4.18), a estratégia \{espera, investe\} não é equilíbrio mais provável, pois para o jogador 1 a ação investe domina de forma fraca a ação espera. Contudo, a ação espera não é dominante para o jogador 2 , visto que o preço corrente do barril do petróleo está acima do seu gatilho exploratório $\left(P^{* *}(H)\right)$ e o fato de não investir gera um custo para o operador $B$. Dessa maneira, ainda com um custo de espera, o jogador 2 aguarda por informação geológica gratuita do vizinho.

$$
\begin{array}{lccc} 
& & \multicolumn{3}{c}{\text { J2- Head }} \\
\text { J1 - DogFish } & \text { Investe } & \underline{1729.80} ; \underline{1534.52} & \underline{1729.80} ; \underline{1534.52} \\
& \text { Espera } & \underline{1729.80} ; \underline{1534.52} & 1725.48 ; 1530.69
\end{array}
$$

Tabela 4.20: Forma normal: Jogo Assimétrico - $P=\$ 85, \tau=3$

No jogo com o preço a 85 dólares o barril (tabela 4.20), existem três equilíbrios, mas somente a estratégia \{investe, investe $\}$ é o equilíbrio de Nash mais provável, pois para os jogadores 1 e 2, a ação investe domina fracamente a ação espera. 


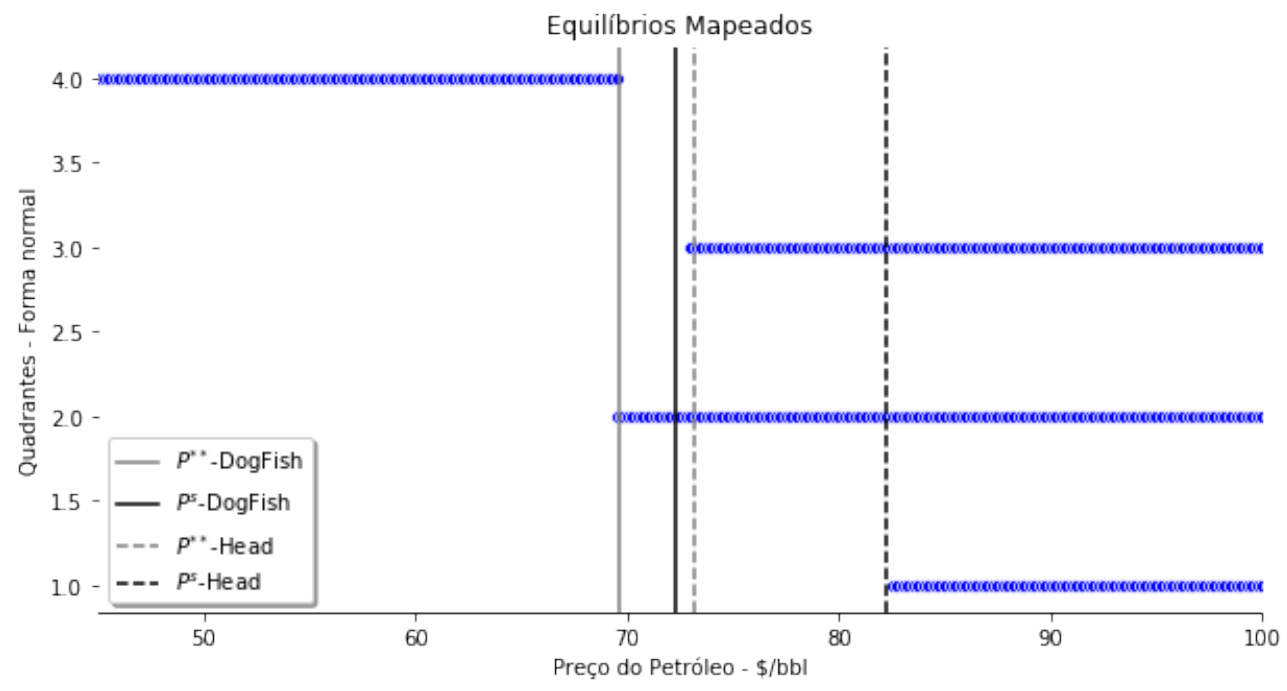

Figura 4.43: Equilíbrios Mapeados - Jogo Assimétrico

Como no jogo simétrico (figura 4.36), os equilíbrios podem ser mapeados preço a preço (figura 4.43). Com o mesmo critério da tabela (4.14), em preços baixos até o $P^{* *}(D)$, o equilíbrio se dá na estratégia $\{$ espera, espera $\}$ (quadrante 4). Como discutido, após a esse preço, a estratégia fracamente dominante é \{investe, espera\} (quadrante 2) até o gatilho simultâneo do jogador 2 em $P^{s}(H)$. Em preços maiores, o equilíbrio se dá na estratégia \{investe, investe $\}$ (quadrante 1 ). Como se trata de um jogo de parada ótima, o EEE é $\left\{t_{L}, t_{F}\right\}$ sendo também um EPM, e diferentemente do jogo simétrico, não há equilíbrio em estratégias mistas, ou seja, não há conflito por informações. Essa situação é similar ao modelo básico da Escalada e Recuo apresentado na seção (3.5), em que um agente sabe que o outro irá escalar (100\% de chance de escalar), dessa forma, o primeiro agente recua e não ocorre a guerra de atrito.

Nesta próxima etapa se explora a possibilidade da operadora $B$ reavaliar a oportunidade Head. Os técnicos refazem a avaliação volumétrica da oportunidade e mudam a expectativa do volume recuperável. Com o aumento do valor médio da reserva, também se eleva o investimento na produção, em função da relação entre essas grandezas exposta na equação (4-5). 


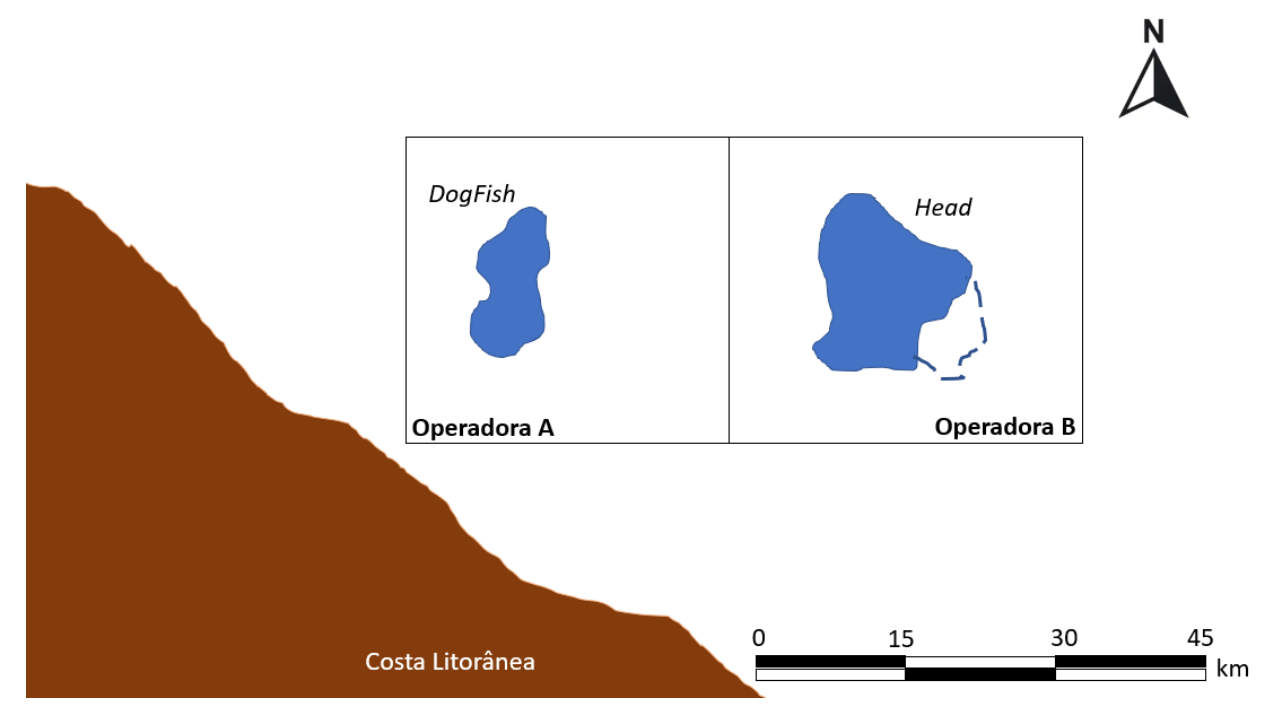

Figura 4.44: Modelo - 2 Blocos - DogFish e Head Expandido

$\mathrm{Na}$ primeira reavaliação, a expectativa do volume recuperável da oportunidade Head foi elevada em torno de 15\%, com o valor médio (B) de 1100 milhões de barris. A figura (4.45) mostra os equilíbrios mapeados e comparando com a figura (4.43), o gatilho exploratório da oportunidade Head alterou $\left(P^{* *}(H)\right)$, agora com um preço entre o gatilho de explorar e o gatilho simultâneo da oportunidade DogFish (]$\left.\left.P^{* *}(D), P^{s}(D)\right]\right)$. Note que por essa mudança, na janela de preços $\left[P^{* *}(H), P^{s}(D)[\right.$, há ocorrência de equilíbrio em estratégias mistas de combinações das ações de investir e esperar (valor fracionado na figura 4.45), podendo ocorrer a guerra de atrito. Para os preços acima de $P^{s}(D)$, os equilíbrios são iguais aos discutidos no caso original, sendo para os preços abaixo de $P^{s}(H)$, o equilíbrio mais provável é a estratégia fracamente dominante $\{$ investe, espera $\}$ e acima de $P^{s}(H)$, o equilíbrio de Nash provável é $\{$ investe, investe $\}$. 


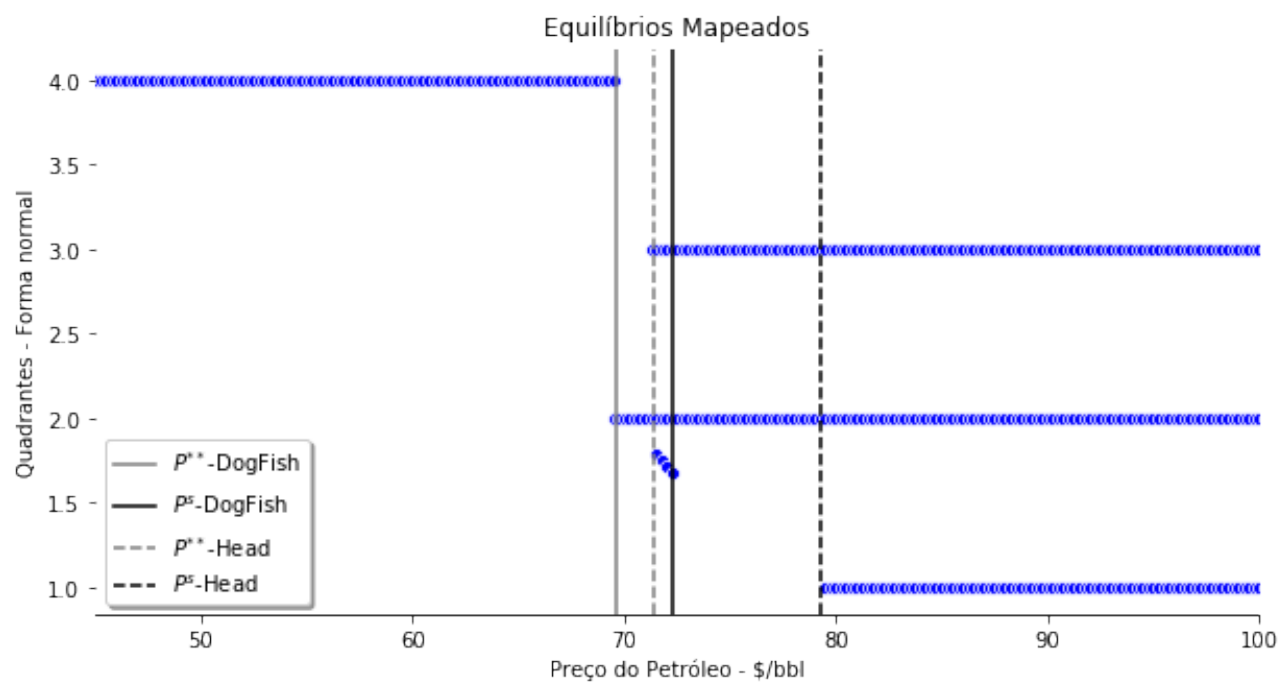

Figura 4.45: Equil. Mapeados - J. Assimétrico - $B_{\text {Head }} 15 \%$ maior

Porém, essa guerra de atrito não é factível se o jogo começar com um preço baixo do barril de petróleo. Note que vindo de um preço baixo e ultrapassando o gatilho exploratório do jogador $1\left(P^{* *}(D)\right)$, a melhor escolha desse jogador é investir e o jogador 2 esperar por informações (quadrante 2 da figura 4.45). Portanto, a EEE continua a mesma do exemplo anterior $\left\{t_{L}, t_{F}\right\}$, que também é um ENPS e EPM , sendo uma situação sem disputa por informações.

Ná hipótese da reserva estimada da oportunidade Head seja $37 \%$ acima do valor a priori, com o novo $B_{\text {Head }}=1310$ milhões de barris, há uma sobreposição dos gatilhos exploratórios das duas oportunidades (figura 4.46). Com a mudança do volume recuperável esperado, também altera o preço do gatilho simultâneo $P^{s}(H)$, ainda sendo mais elevado que o gatilho simultâneo do prospecto DogFish. Essa sobreposição dos gatilhos de explorar acontece quando se altera o volume recuperável da oportunidade Head em que a razão entre o valor e o investimento da oportunidade DogFish é igual ao da oportunidade Head com esse novo volume. Em termos de formulação, isso é igual a $\frac{V^{D}}{I^{D}}=\frac{V^{H}\left(B^{*}\right)}{I^{H}\left(B^{*}\right)}$, onde o subscrito $D$ e $H$ correspondem às oportunidades DogFish e Head, $B^{*}$ é o volume recuperável ótimo da oportunidade Head para que essa igualdade seja respeitada, além de $V^{i}=C F_{i} q_{i} B_{i} P$ e $I^{i}=C F_{i} I_{d i}+I_{w i}$, em que $i$ é a oportunidade $D$ ou $H$ indicada. 


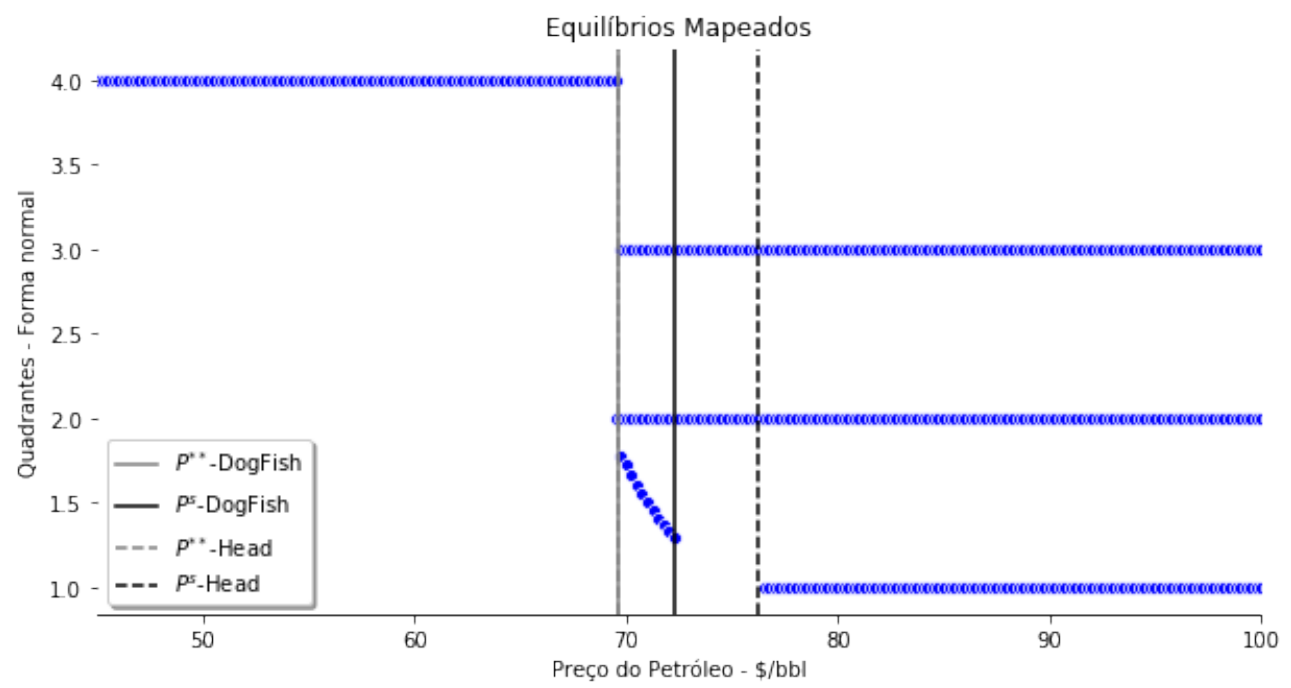

Figura 4.46: Equil. Mapeados - J. Assimétrico - $B_{\text {Head }} 37 \%$ maior

Note que esse cenário coloca o ativo Head com a valoração acima do ativo DogFish, efeito que pode ser percebido comparando a figura (4.47) com a figura (4.41).

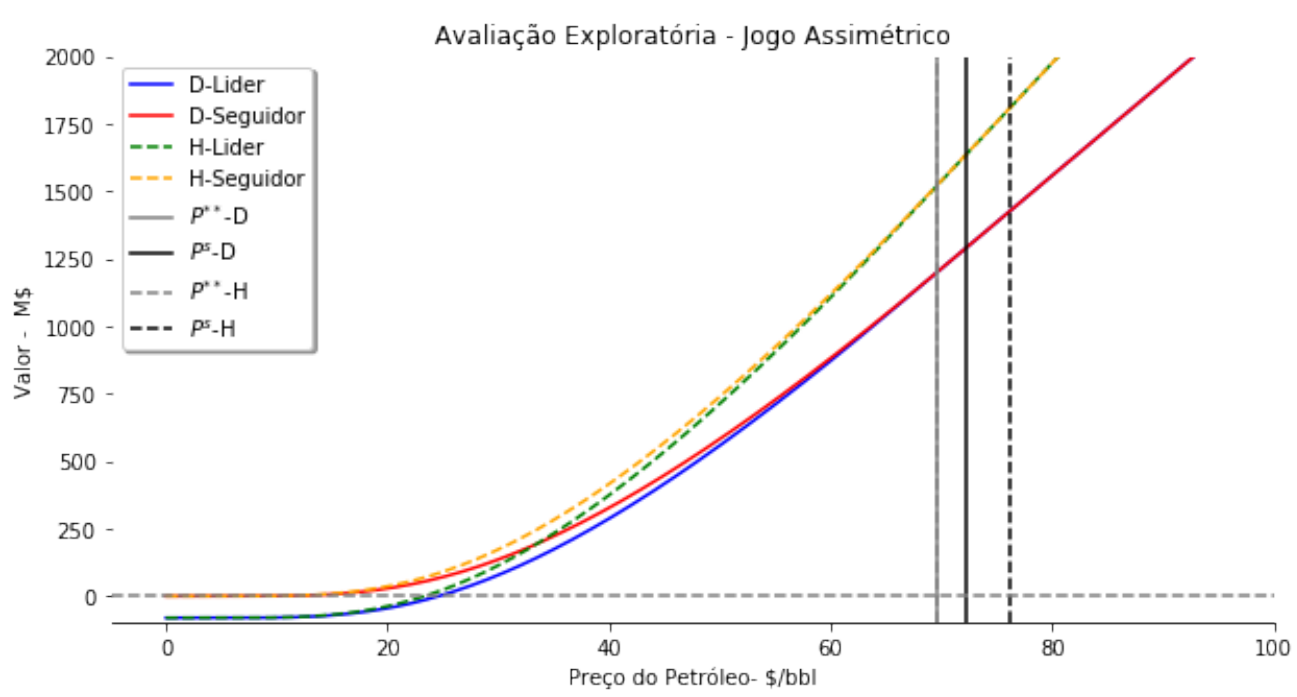

Figura 4.47: Preço x Valor - DogFish e Head - $B_{\text {Head }} 37 \%$ maior

Inclusive, essa mudança altera o benefício de espera do ativo Head, pois fica mais atraente perfurá-lo a preços mais baixos. A figura (4.48) mostra a aproximação em valor do benefício da espera ao ativo DogFish quando comparado ao caso base da figura (4.42). Mesmo assim, em preços mais altos, o benefício da espera da oportunidade Head ainda é superior em relação à oportunidade DogFish. 


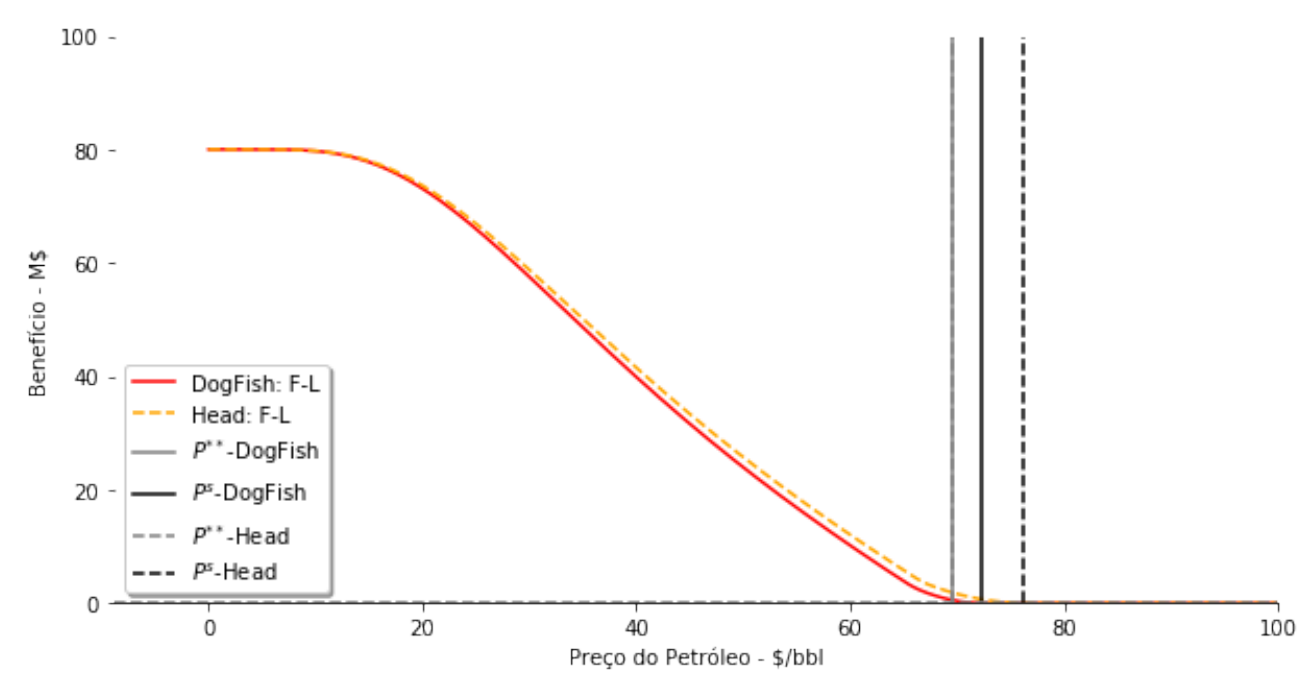

Figura 4.48: Benefício da Espera -D. e H. - $B_{\text {Head }} 37 \%$ maior

Com o preço a $\$ 70$ dólares o barril do petróleo (tabela 4.21 ), existem três equilíbrios de Nash, sendo dois puros (\{investe, espera $\}$, \{espera, investe $\}) \mathrm{e}$ um em estratégias mistas, com as probabilidades de $69.89 \%$ em investir no ativo DogFish e de $88.08 \%$ em investir na oportunidade Head, obtidas pelas equações (3-40) e (3-41). Além disso, a utilidade no equilíbrio em estratégias mistas para o jogador 1 é de $\$ 1212.64$ milhões e para o jogador 2 é de $\$ 1537.10$ milhões, sendo a solução dos payoffs pela equação (3-39) e com informações da tabela (4.21). É possível reparar que as utilidades no ENPS não são simétricas e dado um pequeno distúrbio deste equilíbrio pode deslocar das probabilidades nas ações acima demonstradas de cada jogador. Isso pode levar para ações degeneradas dos agentes, ou seja, pequenas perturbações podem conduzir ao exercício da opção de investir para um dos operadores. Dessa maneira, a guerra de atrito pode existir, mas aqui o equilíbrio em estratégias mistas em jogo assimétrico não é estável em termos de jogos evolucionários.

$$
\begin{array}{lccc} 
& & \multicolumn{2}{c}{\text { J2- Head }} \\
& & \text { Investe } & \text { Espera } \\
\text { J1 - DogFish } & \text { Investe } & 1212.64 ; 1537.10 & \underline{1212.64} ; \underline{1538.75} \\
\cline { 2 - 4 } & \text { Espera } & \underline{1213.05} ; \underline{1537.10} & 1209.61 ; 1533.27
\end{array}
$$

Tabela 4.21: F. normal: J. Assim. - $P=\$ 70, \tau=3$ e $B_{\text {Head }}=37 \%$ maior

A instabilidade pode ser notada no plano de fase da figura (4.49). Se partir de uma fração da população de $q=1$ e $p^{*}=0.6989$, justo em cima da linha horizontal, os vetores não direcionam para o ponto de equilíbrio do jogo assimétrico de $\$ 70$ o barril da tabela (4.21). Isso faz crer que o equilíbrio 
$\left\{p^{*}, q^{*}\right\}=\{0.6989,0.8808\}$ não é estável em termos de jogos evolucionários por não ser um máximo global.

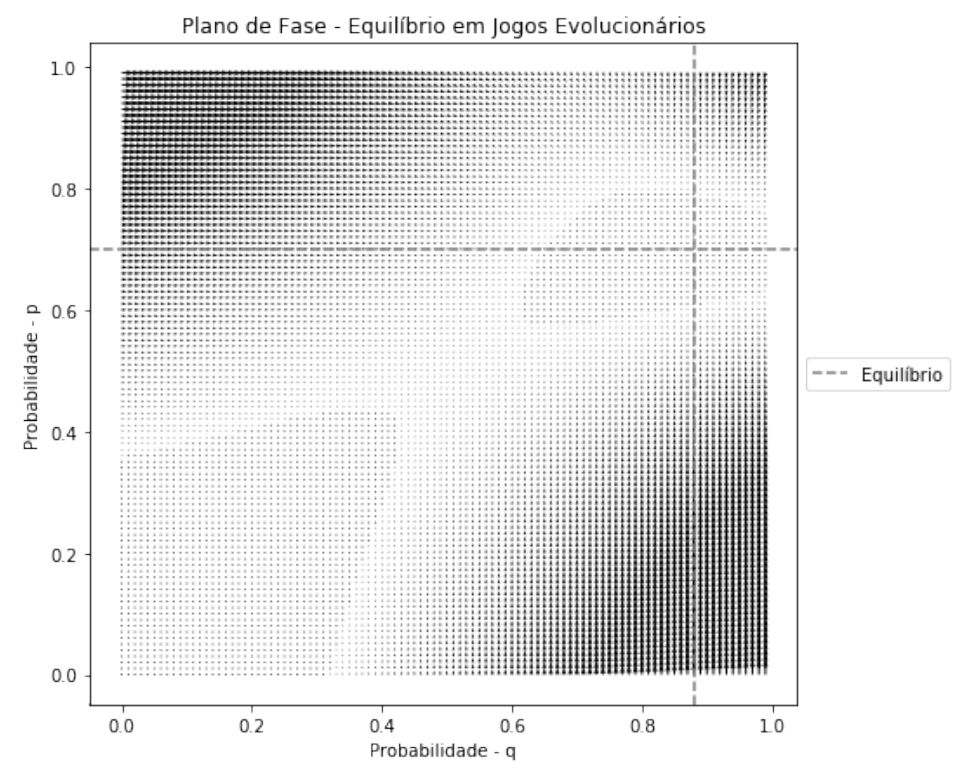

Figura 4.49: J. Evol. - P. de Fase - Assimétrico -\$70/bbl

Contudo, na prática, pode acontecer dos jogadores ficarem "presos" nesse impasse. Com essa possibilidade, pode-se configurar uma guerra por informação e os operadores poderiam estar melhores em um ambiente de negociação. Então, para a barganha ser analisada, é necessária uma avaliação conjunta entre DogFish e Head, como feita na seção (4.2.1). A análise naquela seção indica que a ordem de perfuração é relevante em termos de valor em intervalos de preços entre 34 e 37 dólares o barril e próximo do final do contrato, sendo sempre preferível revelar primeiro a informação da oportunidade DogFish. Porém, para os outros preços e momentos do contrato, a vantagem para o valor do portfólio é marginal no caso em que a primeira perfuração seja o ativo DogFish. Portanto, na negociação da fusão dos blocos exploratórios, o acordo de uma ordem de perfuração entre as operadoras não é tão relevante nesta situação, pois não altera tanto o valor do portfólio.

Em ativos simétricos, como no caso da seção (4.2.2.1), intuitivamente a divisão do portfólio é de $50 \%$ na barganha para cada jogador. Na solução de Nash para a barganha cooperativa, o peso da divisão do prêmio é dado pela diferença no ponto de discordância de cada jogador, normalizado pelo dobro do prêmio a ser repartido, adicionado $50 \%$ a essa razão (equações 3-52 e 3-53). No caso da simetria dos prospectos, como cada jogador tem o mesmo ponto de discordância, pois os ativos são iguais, resta na solução da equação somente o termo de $50 \%$ para cada jogador. 


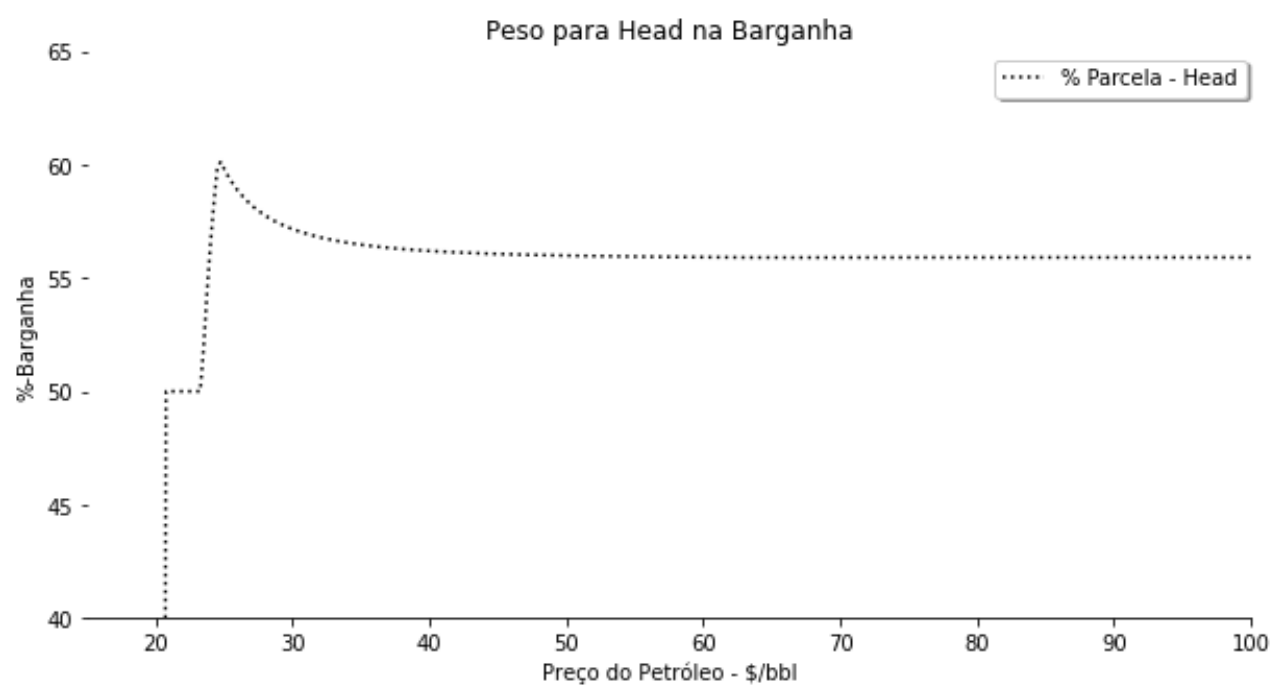

Figura 4.50: Peso na Barganha: DogFish x Head - 37\% maior

No caso de jogo assimétrico, os pontos de discordância são diferentes entre si. Esses pontos são as utilidades em ENPS da guerra de atrito, visto que representam o melhor payoff se os agentes não jogarem a barganha (DIAS; TEIXEIRA, 2009). A figura (4.50) apresenta o peso da barganha do portfólio no tempo $t=0$ para a operadora $B$ e a figura (4.51) representa os payoffs com as utilidades da barganha repartida entre os operadores. Abaixo de 25 dólares o barril, o peso para os dois jogadores é nulo, dado que não há unidade de valor para compartilhar. Para o detentor do ativo Head, em condições do preço do barril acima de 25 dólares, define-se um pequeno patamar na quantidade de $50 \%$ do total e com os preços ainda mais altos possui um pico de $60.11 \%$, estabilizando-se em preços maiores na porcentagem de $55.90 \%$ do total da unitização. 


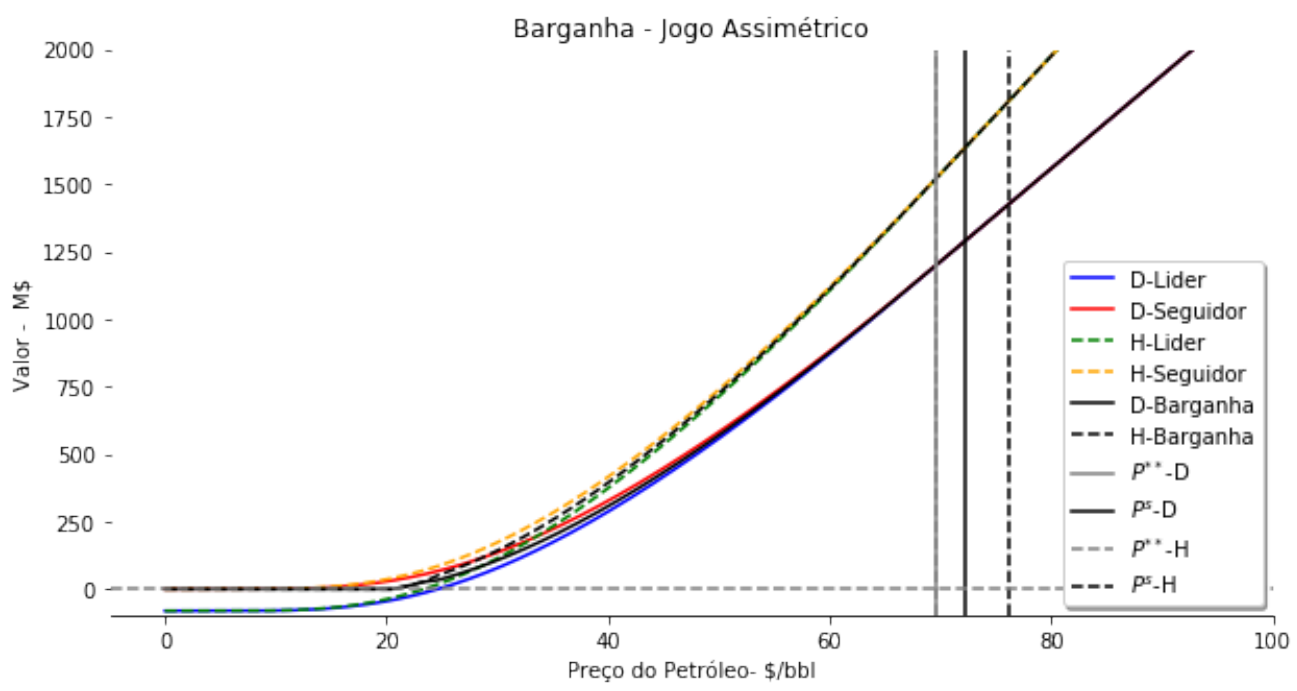

Figura 4.51: Barganha Cooperativa: DogFish x Head - 37\% maior

A figura (4.52) mostra em detalhes o intervalo dos gatilhos exploratórios e de perfuração simultânea, sendo que o valor da barganha é igual a da posição de líder e abaixo da posição de seguidor.

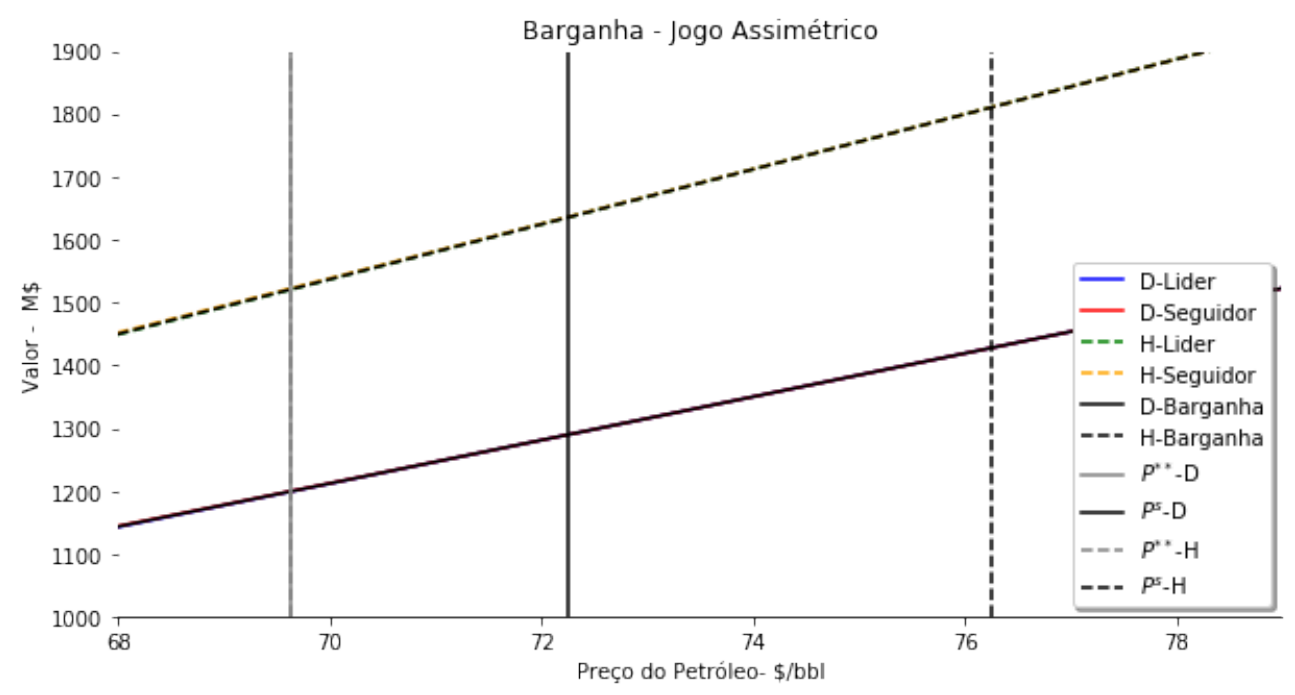

Figura 4.52: Detalhe - Barganha: DogFish x Head - 37\% maior

Em um ambiente de negociação, a troca de informações tende a ser maior que o informe obrigatório feito a mercado em caso de descoberta de hidrocarboneto. Inclusive, a própria negociação aproxima os conhecimentos de equipes diferentes, refletindo sobre os projetos anteriormente desenhados, podendo haver uma readequação da estrutura de desenvolvimento de produção ou até mesmo uma sinergia entre projetos. Dessa forma, o conhecimento privado se torna público entre os participantes e conduz a um maior poder de 
revelação da informação. A medida de revelação do conhecimento é representada pela correlação entre os ativos e a subida do $\rho$ indica que a informação privada revela mais que a informação pública (DIAS; TEIXEIRA, 2009). Para simular esse cenário, elevou-se o parâmetro para $\rho=95 \%$ e com o barril a $\$$ 70 no tempo presente, a barganha eleva de $\$ 1537.10$ milhões para $\$ 1538.94$ milhões para o operador $B$, sendo mais alto que sua posição de seguidor ( $\$$ 1538.75 milhões) e evidentemente em relação a posição de líder (\$1537.10 milhões). No caso do detentor do ativo DogFish, a barganha vale $\$ 1212.64$ milhões sem efeitos da interação do negócio, já em condições de maior troca de informações, a cooperação eleva para $\$ 1214.45$ milhões. Esse valor é maior que sua posição de seguidor (\$1213.05 milhões) e de líder (\$1212.64 milhões) (vide jogo da tabela 4.21). Com esses parâmetros, a barganha é vantajosa para o detentor da oportunidade Head a partir de $\$ 69.25$ o barril e para o detentor da oportunidade DogFish, a partir de $\$ 65$ dólares o barril. Como o intervalo da possível guerra de atrito por informações é entre $\$ 69.62$ e $\$ 72.25$ o barril, a mudança de jogo para a barganha cooperativa é factível.

O estudo do jogo assimétrico apresenta importantes condições para a guerra de atrito. Quando os gatilhos de explorar os prospectos forem distintos, não há conflito por informação, por isso, a empresa com o gatilho mais baixo vai perfurar e passar a informação para a empresa de gatilho exploratório mais alto. Porém, quando os gatilhos de explorar são sobrepostos, o conflito é instável em termos de jogos evolucionários e é limitado superiormente pelo menor gatilho de perfuração simultânea dentre as empresas. Sobre a barganha, as condições para a migração do conflito para um jogo cooperativo são as mesmas que no jogo simétrico, mas a divisão do portfólio é distinta, visto que as porcentagens da unitização para cada empresa se alteram em função do preço do petróleo e do momento no contrato. 


\subsection{3}

\section{Jogo com três prospectos: Carteira com 2 e um prospecto vizinho}

A chance da empresa com o prospecto de maior valor entrar num quadro de guerra de atrito é mais improvável, visto que o seu gatilho deve ser mais baixo e ocorrerá o exercício do investimento antes da concorrente (tabela 4.6). Ademais, como discutido, devido à assimetria inerente entre os ativos e evidentemente entre os portfólios das empresas, o equilíbrio estável por jogos evolucionários tende a ser degenerado nas ações, indicando que haverá a perfuração por uma empresa e a informação gratuita para a outra. Sabese também, que as empresas podem falhar nessa percepção de equilíbrio de longo prazo e ficarem "presas" na guerra de atrito. Também, para ocorrer a guerra por informações, as empresas precisam estar indiferentes em relação às ações, com as probabilidades de esperar e perfurar, ou seja, deve haver um equilíbrio em estratégias mistas para configurar a situação de impasse e de não cooperação. Aqui isso ocorre somente quando os gatilhos dos dois portfólios são próximos um ao outro.

A figura (4.53) apresenta a situação final a ser estudada. A empresa $A$ detém o portfólio composto pelos prospectos DogFish e Feather e a empresa $B$ possui o ativo Head.

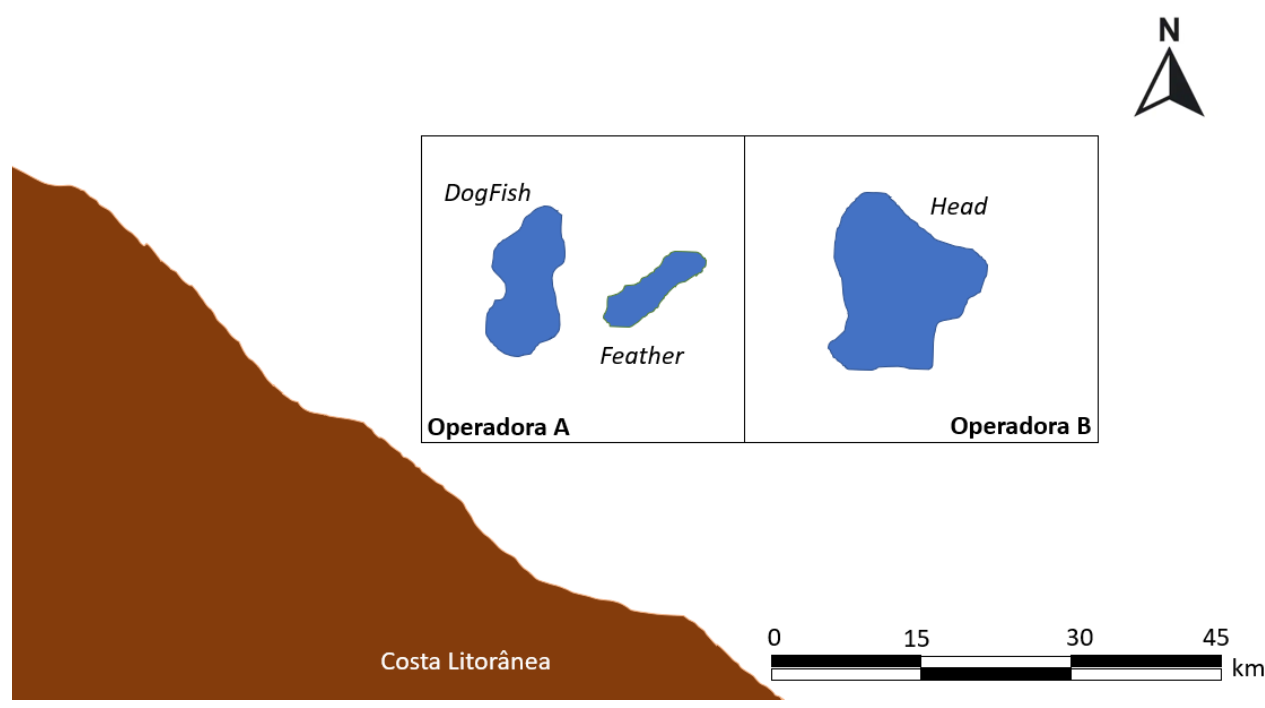

Figura 4.53: Modelo - 2 Blocos - A - DogFish e Feather - B Head

O jogo em portfólio é um pouco distinto do jogo com um só ativo no bloco. A forma normal da tabela (4.22) apresenta o modelo, sendo somente o jogador 1 com um portfólio de dois ativos. 


\begin{tabular}{|c|c|c|c|}
\hline \multirow{4}{*}{ Jogador 1} & & \multicolumn{2}{|c|}{ Jogador 2} \\
\hline & & Investe & Espera \\
\hline & Investe & $V M E_{\pi_{1}} ; V M E_{2}$ & $V M E_{\pi_{1}} ; E_{2 \mid 1}$ \\
\hline & Espera & $\Pi_{1 \mid 2} ; V M E_{2}$ & $\Pi_{1}-c_{1} ; E_{2}-c_{2}$ \\
\hline
\end{tabular}

Tabela 4.22: Forma normal: Payoffs no caso de Portfólio

A empresa que possui um portfólio exploratório pode avaliar todos os ativos separadamente pelo valor monetário esperado, que insere a opção de investir em desenvolvimento no seu cálculo $(V M E(P, t))$ ou pelo valor da opção exploratória $E(P, t)$. Contudo, sabe-se que há efeitos complementares na carteira pelo VOI, sendo a soma dos ativos stand-alone menor que os ativos em portfólio exploratório com aprendizado. Para a espera em portfólio $\Pi(P, t)$, foi utilizada a equação diferencial (3-57) e para o valor monetário esperado em portfólio $V M E_{\pi}(P, t)$, foi utilizada a equação diferencial (3-62). Essa última medida considera a escolha de uma sequência ótima de perfuração do portfólio, mas assume o risco do primeiro poço como a métrica do VME, portanto, pode possuir valores negativos, diferentemente do portfólio exploratório $\Pi(P, t)$. Igualmente ao caso de um ativo, a posição do agente seguidor tem a vantagem informacional da concorrente, dessa maneira, o portfólio com informações vizinhas $\left(\Pi_{i \mid j}(P, t)\right)$ é representado por uma outra equação diferencial (3-61).

Além das diferentes métricas citadas, o jogo de atrito em portfólio possui um outro custo de espera. Primeiramente, o custo é acionado pelo gatilho do portfólio, não sendo de um ativo em particular e quando este é acionado, o custo de espera não é em função de todo o portfólio, mas justamente do ativo não perfurado da sequência ótima. Dessa forma, com o preço do barril do petróleo $P$ acima do gatilho do portfólio da operadora $A$, essa empresa tem a preferência de perfurar o prospecto DogFish (figura 4.18), como discutido na seção (4.2.1). Como dito, o custo da espera será em relação ao $V M E(P, t)$ da oportunidade não perfurada DogFish, não do valor do portfólio que este ativo faz parte. Pela mesma razão, a informação esperada pela operadora $B$ está relacionada com o prospecto DogFish, já que é a primeira oportunidade no cronograma de perfuração da operadora $A$.

As curvas das opções de espera com informações gratuitas e as curvas do valor monetário esperado no início do contrato são apresentadas na figura (4.54). É possível notar que o prêmio do portfólio é mais elevado que o prêmio do ativo Head da empresa $B$ em qualquer preço, tanto na posição de líder como na posição de seguidora. Porém, o gatilho de investir em exploração é similar $P^{* *}(D+F) \sim P^{* *}(H)$ (para o ativo Head, tabela 4.6 e a carteira $D+F$, figura 4.18). Apesar disso, para a empresa detentora do portfólio, o gatilho em que a empresa é indiferente entre aguardar informações ou perfurar $\left(P^{s}(D+F)\right)$ 
é menor que o da empresa $B$ detentora do ativo Head $\left(P^{s}(H)\right)$. Nesse caso, a empresa a sair de uma possível guerra de atrito e investir se o preço do petróleo estiver maior que o preço de $P^{s}(D+F)$ é a detentora do portfólio.

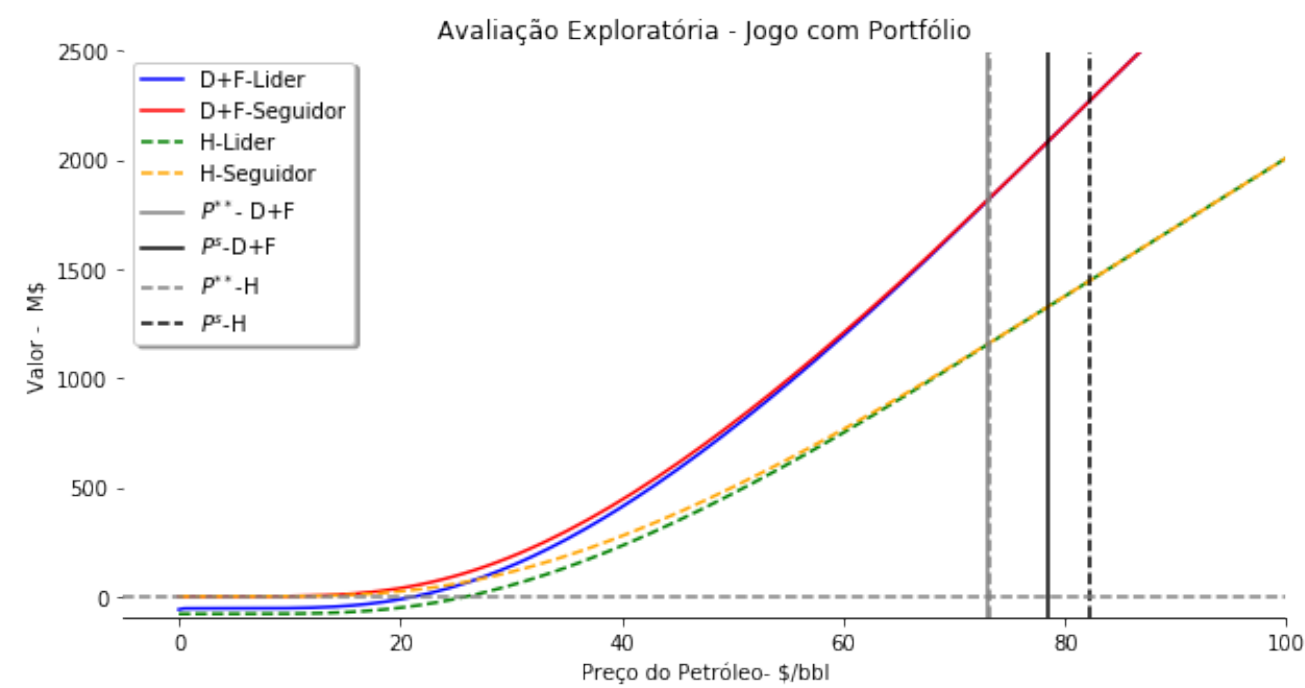

Figura 4.54: Jogo Portfólio: Preço x Valor $-\Pi(D+F)$ e Head

Curiosamente, para os preços menores e até os preços próximos do gatilho de explorar, o benefício da espera do portfólio DogFish + Feather é maior que o da oportunidade Head (figura 4.55). Contudo, o benefício da espera nessa região é devido à espera do próprio portfólio, não por vantagem da informação pela perfuração do vizinho. Para os preços maiores, há o início da possível guerra de atrito e o benefício se inverte, sendo maior para a oportunidade Head. Por fim, o benefício líquido da espera desse portfólio se iguala a zero em $P^{s}(D+F)$ e sendo ainda positivo para o ativo Head de propriedade da operadora $B$, tornando-se nulo em $P^{s}(H)$. 


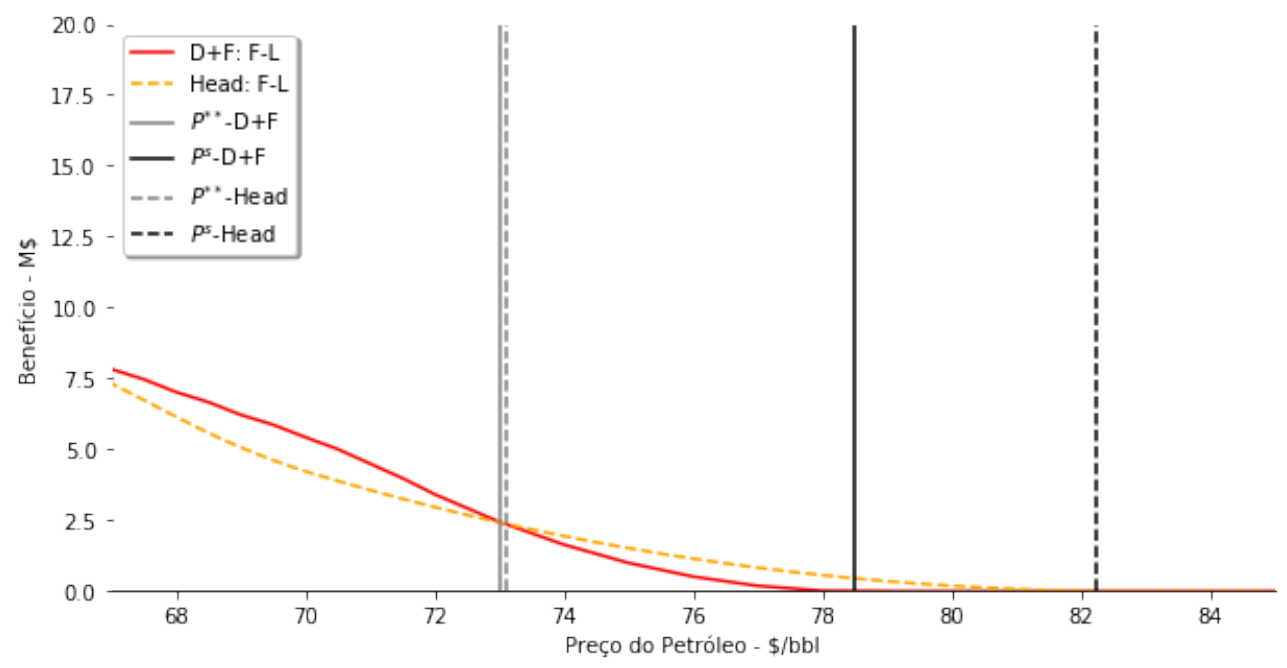

Figura 4.55: Benefício da Espera: $\Pi(D+F)$ e Head

Similar ao caso assimétrico, existem intervalos importantes para analisar o jogo no início do contrato $(\tau=3)$. Na sequência são apresentados os casos em que os preços estão abaixo dos gatilhos exploratórios, entre o gatilho exploratório e o gatilho simultâneo do portfólio, além do intervalo entre os gatilhos simultâneos e acima do gatilho simultâneo da oportunidade Head:

$$
\begin{aligned}
& -\left[0 ; \sim 73.0\left[-\left[0 ; P^{* *}(D+F) \text { e } P^{* *}(H)[\right.\right.\right. \\
& -\left[\sim 73.0 ; 78.5\left[-\left[P^{* *}(D+F) \text { e } P^{* *}(H) ; P^{s}(D+F)[\right.\right.\right. \\
& -\left[78.5 ; 82.25\left[-\left[P^{s}(D+F) ; P^{s}(H)[\right.\right.\right. \\
& -\left[82.25 ; \infty\left[-\left[P^{s}(H) ; \infty[\right.\right.\right.
\end{aligned}
$$

Como esperado, quando o preço do petróleo está abaixo da curva do gatilho exploratório do portfólio e do ativo Head, o ENPS ocorre na estratégia pura $\{$ espera, espera $\}$.

$$
\begin{array}{llcc} 
& & \multicolumn{2}{c}{\text { J2- Head }} \\
& & \text { Investe } & \text { Espera } \\
\mathrm{J} 1-\Pi(D+F) & \text { Investe } & 770.83 ; 471.13 & 770.83 ; \underline{500.48} \\
\text { Espera } & \underline{793.57} ; 471.13 & \underline{786.91} ; \underline{\underline{497.72}}
\end{array}
$$

Tabela 4.23: Forma normal: $\Pi(D+F)$ e Head $-P=\$ 50, \tau=3$

Com o petróleo a $\$ 75$ dólares o barril, existem três equilíbrios de Nash: dois puros ( $\{$ investe, espera $\}$, \{espera, investe $\}$ ) e um em estratégias mistas. Este último se dá com a probabilidade para o detentor do portfólio em perfurar de $66.66 \%$ e em esperar de $33.33 \%$, já o proprietário da oportunidade Head com $58.15 \%$ para perfuração (uso das equações 3-40 e 3-41) . Essas probabilidades 
colocam os payoffs esperados do equilíbrio em estratégias mistas com valores de (1912.80; 1217.55) (uso da equação 3-39). Como já examinado nos jogos assimétricos, quando os payoffs são diferentes em estratégias mistas, podem gerar incentivos a desvios dos jogadores, conduzindo ao longo prazo para valores de payoffs melhores. Isso indica que esse equilíbrio em estratégias mistas não é estável em termos de jogos evolucionários.

$$
\begin{array}{llcc} 
& & \multicolumn{2}{c}{\text { J2- Head }} \\
& & \text { Investe } & \text { Espera } \\
\mathrm{J} 1-\Pi(D+F) & \text { Investe } & \underline{1912.80} ; 1217.55 & \underline{1912.80} ; \underline{1219.07} \\
\cline { 2 - 4 } & \text { Espera } & \underline{1913.80} ; \underline{1217.55} & 1911.41 ; 1214.51
\end{array}
$$

Tabela 4.24: Forma normal: $\Pi(D+F)$ e Head $-P=\$ 75, \tau=3$

A situação curiosa com dois equilíbrios puros, mas sem equilíbrio em estratégias mistas da seção (4.2.2.1) também acontece quando o preço do petróleo está em 80 dólares o barril no jogo de atrito com portfólio (tabela 4.25). A ação investe para o detentor do portfólio domina fracamente a ação espera. Com isso, a estratégia pura \{espera, investe\} não é o equilíbrio mais provável. Nesse preço, o detentor do portfólio vai perfurar o ativo DogFish e o detentor da oportunidade Head vai obter a informação gratuita do sucesso ou fracasso do vizinho, sendo o equilíbrio provável a estratégia \{investe, espera\}.

$$
\begin{array}{llcc} 
& \multicolumn{3}{c}{\mathrm{J} 2-\text { Head }} \\
\text { Investe } & \text { Espera } \\
\mathrm{J} 1-\Pi(D+F) & \text { Investe } & \underline{2160.61 ; 1376.04} & \underline{2160.61 ; 1376.23} \\
\text { Espera } & \underline{2160.61 ; 1376.04} & 2159.22 ; 1372.60
\end{array}
$$

Tabela 4.25: Forma normal: $\Pi(D+F)$ e Head $-P=\$ 80, \tau=3$

A tabela (4.26) apresenta um instante do jogo acima do gatilho simultâneo da oportunidade Head a $\$ 85$ o barril do petróleo. O jogo apresenta três equilíbrios de Nash: \{investe, investe $\},\{$ investe, espera $\}$ e $\{$ espera, investe $\}$. Essa situação é similar às questões discutidas nas seções (4.2.2.1 e 4.2.2.2), em que o equilíbrio mais provável é o \{investe, investe\}, visto que para os jogadores 1 e 2, a ação investe domina fracamente em relação à ação espera.

$$
\begin{array}{cccc} 
& \multicolumn{3}{c}{\text { J2- Head }} \\
\text { J1 } 1-\Pi(D+F) & \text { Investe } & \underline{2408.42} ; \underline{1534.52} & \underline{2408.42} ; \underline{1534.52} \\
& \text { Espera } & \underline{2408.42} ; \underline{1534.52} & 2407.02 ; 1530.69
\end{array}
$$

Tabela 4.26: Forma normal: $\Pi(D+F)$ e Head $-P=\$ 85, \tau=3$ 
A consolidação também é apresentada em um gráfico de preço versus estratégia, sendo as simbologias dos pares de estratégias seguindo a tabela (4.14), em que os números não inteiros representam o equilíbrio em estratégias mistas (figura 4.56).

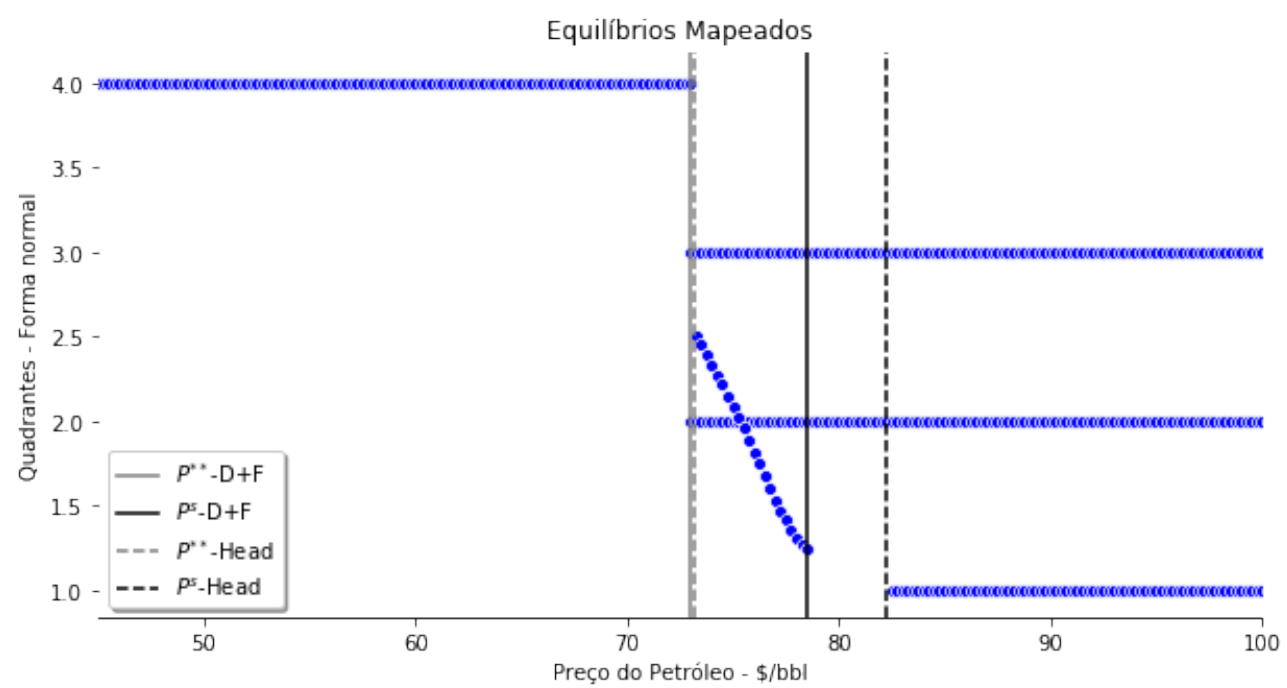

Figura 4.56: Equilíbrios Mapeados - Jogo $\Pi(D+F)$ e Head

No intervalo de preços em que há o equilíbrio de Nash em estratégias mistas existe a possibilidade do jogador em aguardar por informações, o que pode se configurar uma guerra de atrito. O estudo do plano de fase com preço em 75 dólares o barril (tabela 4.24) apresenta os máximos das utilidades resistentes aos distúrbios (figura 4.57).

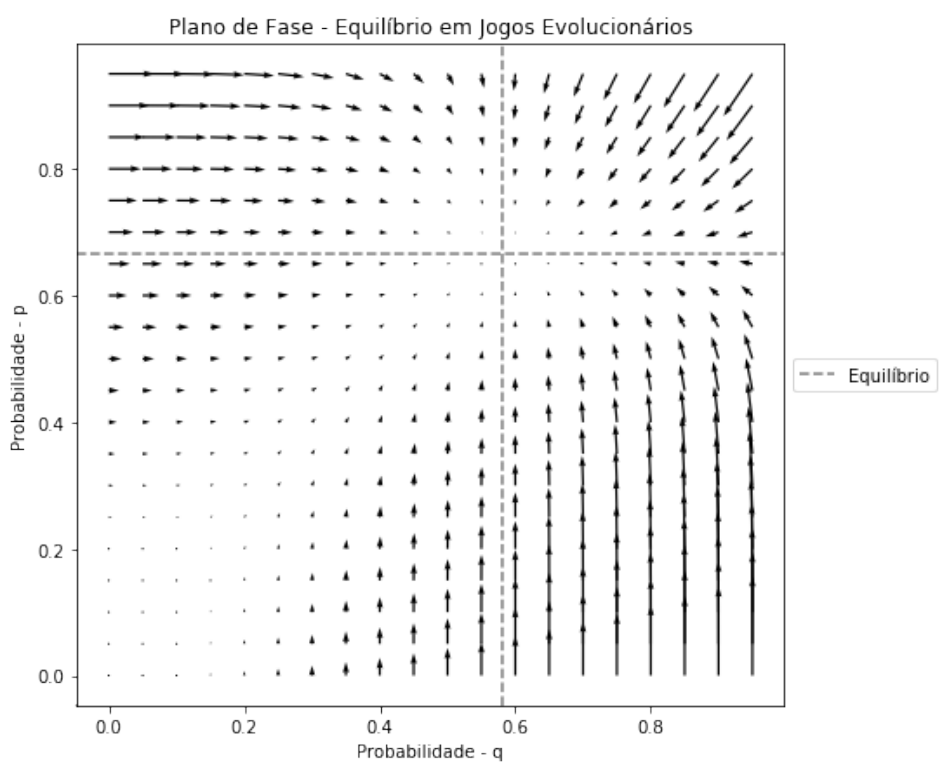

Figura 4.57: J. Evol. - P. de Fase - Portfólio - $\$ 75 /$ bbl 
É possível notar que os vetores no plano de fase possuem direção e magnitude para o equilíbrio $\left\{p^{*}, q^{*}\right\}=\{0 . \dot{6}, 0.5815\}$. Porém, observando em uma malha mais densa (figura 4.58), nota-se os detalhes do jogo.

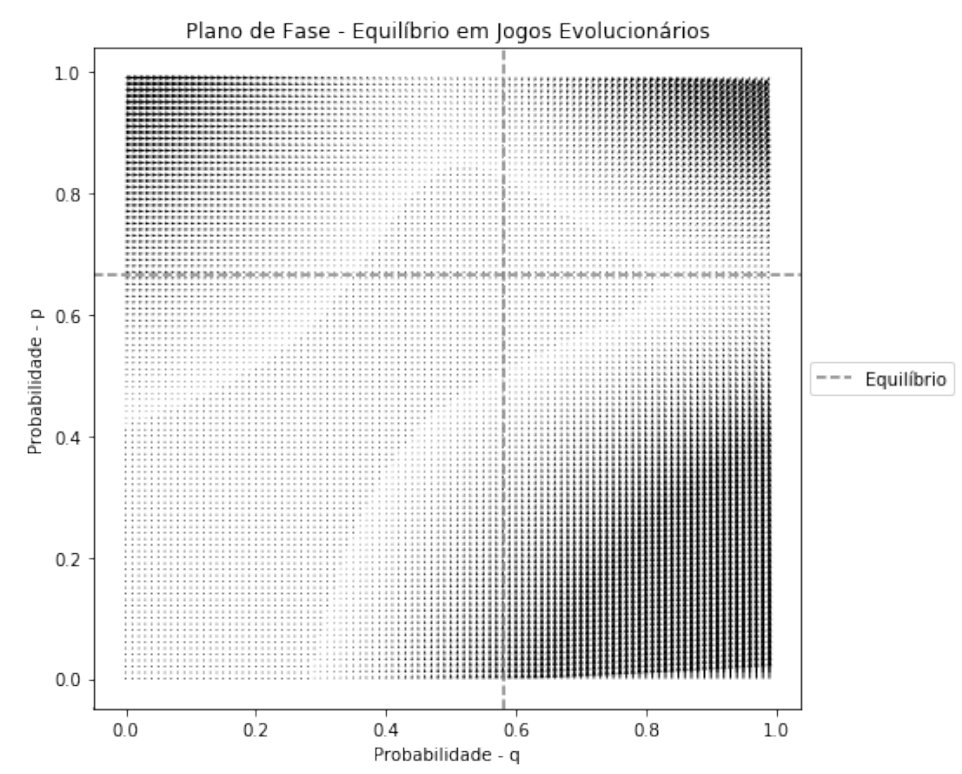

Figura 4.58: J. Evol. - P. de Fase Denso - Portfólio - $\$ 75 / \mathrm{bbl}$

Na hipótese de uma população inicial partindo de $\{p, q\}=\{1,0\}$, o caminho evolutivo seria para o equilíbrio $\left\{p^{*}, q^{*}\right\}$. Também, partindo da relação inicial $\{p, q\}=\{0,1\}$, os vetores indicam para o equilíbrio estável em $\left\{p^{*}, q^{*}\right\}$. Porém, se partir de uma população, por exemplo, $\{p, q\}=\{0.2,0.2\}$, o fluxo não seguirá necessariamente para o equilíbrio $\left\{p^{*}, q^{*}\right\}$. Assim, o equilíbrio $\left\{p^{*}, q^{*}\right\}$ não é estável em termos de jogos evolucionários, pois não é um máximo global.

Contudo, as empresas podem ficar "presas" nesse impasse caso o preço da commodity continuar no intervalo de $\$ 73$ até $\$ 78.50$ o barril. Então, é proposto uma mudança para o jogo da barganha cooperativa, em que funciona como uma unitização dos ativos caso a posição seja melhor para os agentes que o equilíbrio de Nash perfeito em subjogos da guerra de atrito. Essa consolidação dos prospectos é feita pela análise ótima de uma sequência informacional dos ativos exploratórios, também considerando o valor da espera e a repartição proporcional dos benefícios para cada empresa.

A formulação da carteira é obtida pelo cálculo do $V M E_{\pi D+F+H}$ com a equação (3-62). A carteira composta pelos ativos DogFish, Feather e Head começa a ter valor a partir de 19.25 dólares o barril e com a unitização, nota-se que a sequência exploratória ótima se altera. Antes, o operador $A$ perfuraria primeiro o prospecto DogFish, agora com a unitização, os dois operadores preferem perfurar o prospecto Feather. Como discutido no final 
da seção (4.2.1), esse ativo tem uma importância na carteira conjunta, pois é de maior valor informacional para os ativos DogFish e Head. Sobre a separação da barganha, no intervalo dos preços críticos da possível guerra de atrito, a empresa $B$, a qual detinha o ativo Head, tem $38.8 \%$ de participação do todo (figura 4.59).

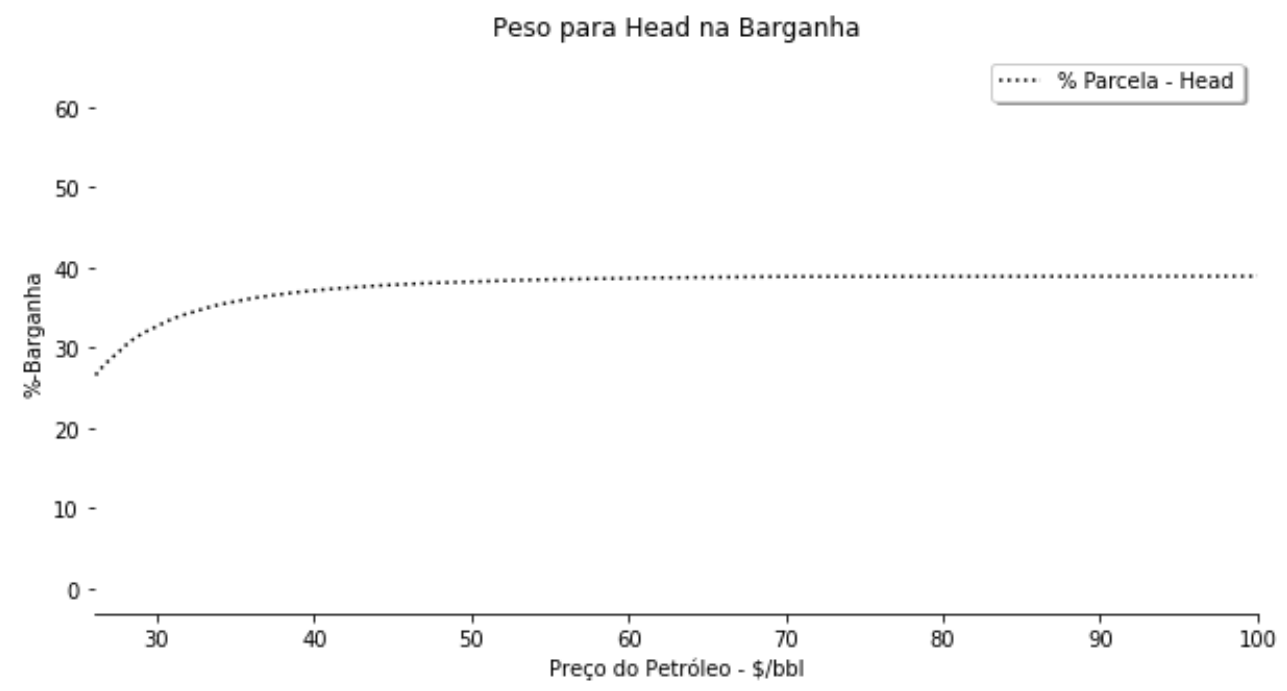

Figura 4.59: Peso na Barganha: DogFish -Feather- Head

A figura (4.60) apresenta no início do contrato ( $\tau=3$ anos) os prêmios em cada ação para todos os preços. Acrescenta-se nesse gráfico o prêmio dividido na barganha cooperativa.

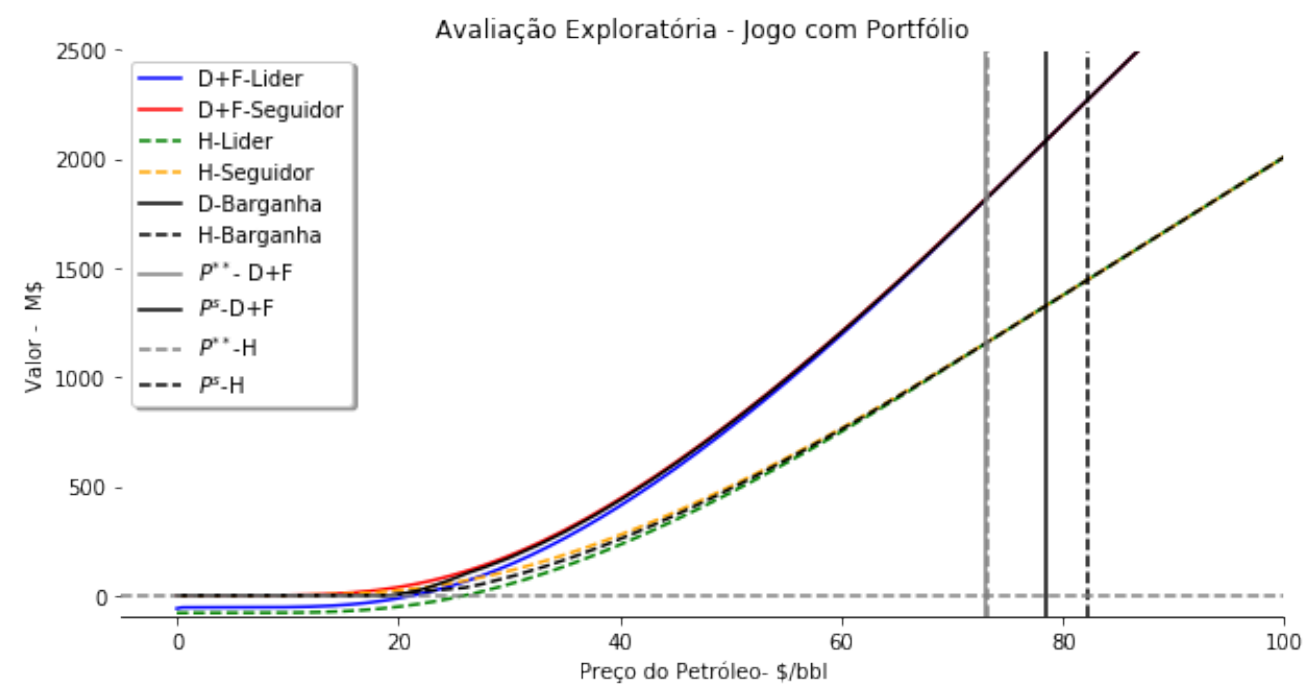

Figura 4.60: Barganha Coop.: $\Pi(D+F)$, Head e $\Pi(D+F+H)$

No intervalo de guerra por informações (figura 4.61), os valores da barganha são inferiores aos valores de serem seguidores, além de serem iguais 
aos valores de serem líderes por ambas as operadoras. Dessa maneira, a mudança do jogo não é vantajosa para as empresas.

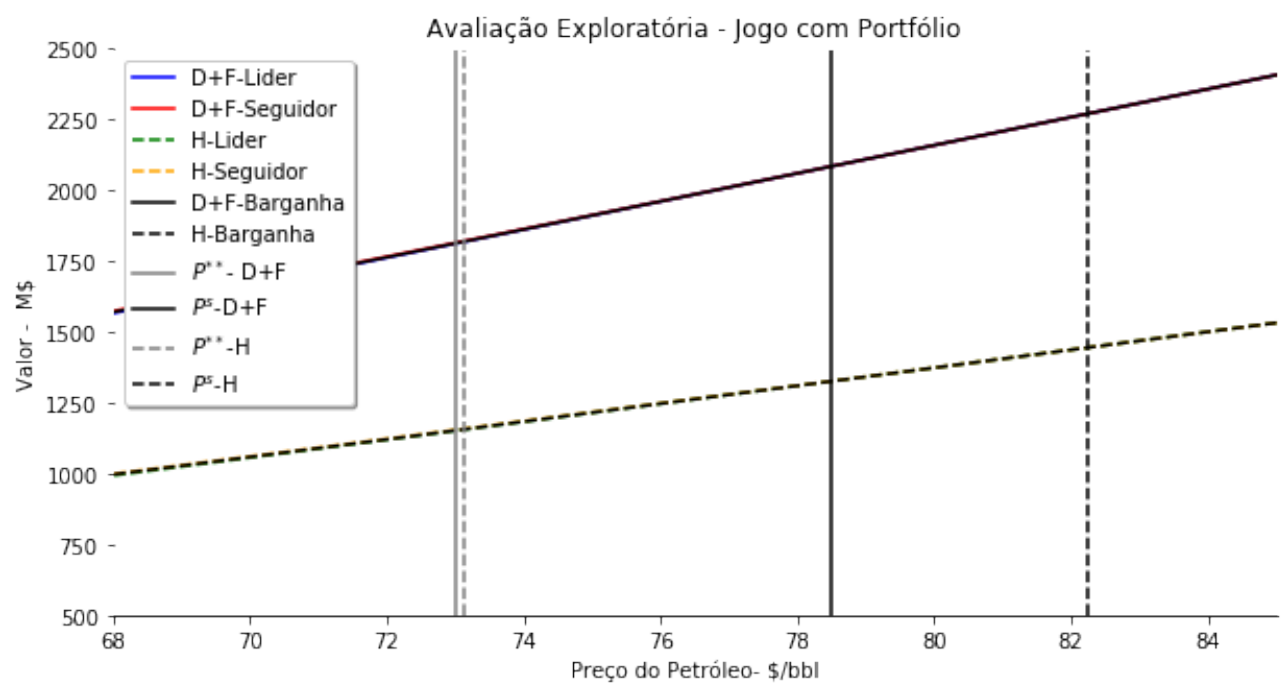

Figura 4.61: Detalhe - B. Coop.: $\Pi(D+F)$, Head e $\Pi(D+F+H)$

Porém, quando há um espaço de negociação, as empresas revelam informações privadas e obtém um conjunto de informação igual ou maior que as informações públicas na guerra de atrito (DIAS; TEIXEIRA, 2009). Nos projetos, além da informação mais valiosa, ainda se poderia considerar os benefícios adicionais de sinergias, reduções de custos e importação de expertises de outros projetos. Dado que a medida de aprendizado é representada pela correlação ( $\rho$ ) (tabela 4.4), propõe-se que a informação privada aumenta em $10 \%$ o valor desta medida em cada oportunidade, como pode ser visto na tabela (4.27).

\begin{tabular}{|c|c|c|c|}
\hline$\rho$ & DogFish & Feather & Head \\
\hline DogFish & 1 & - & - \\
\hline Feather & 0.7 & 1 & - \\
\hline Head & 0.6 & 0.7 & 1 \\
\hline \hline
\end{tabular}

Tabela 4.27: Correlação dos prospectos - Informação Privada

Com a interação entre as empresas, a barganha cooperativa é maior que o valor de qualquer payoff de qualquer jogador no intervalo do impasse (figura 4.62). Dado esse resultado, os operadores serão tentados a migrar da guerra de atrito para a barganha cooperativa. Observa-se também como pequenas variações na correlação afetam a utilidade da carteira, sendo, por essa razão, uma medida importante de ser estimada na avaliação de portfólio. 


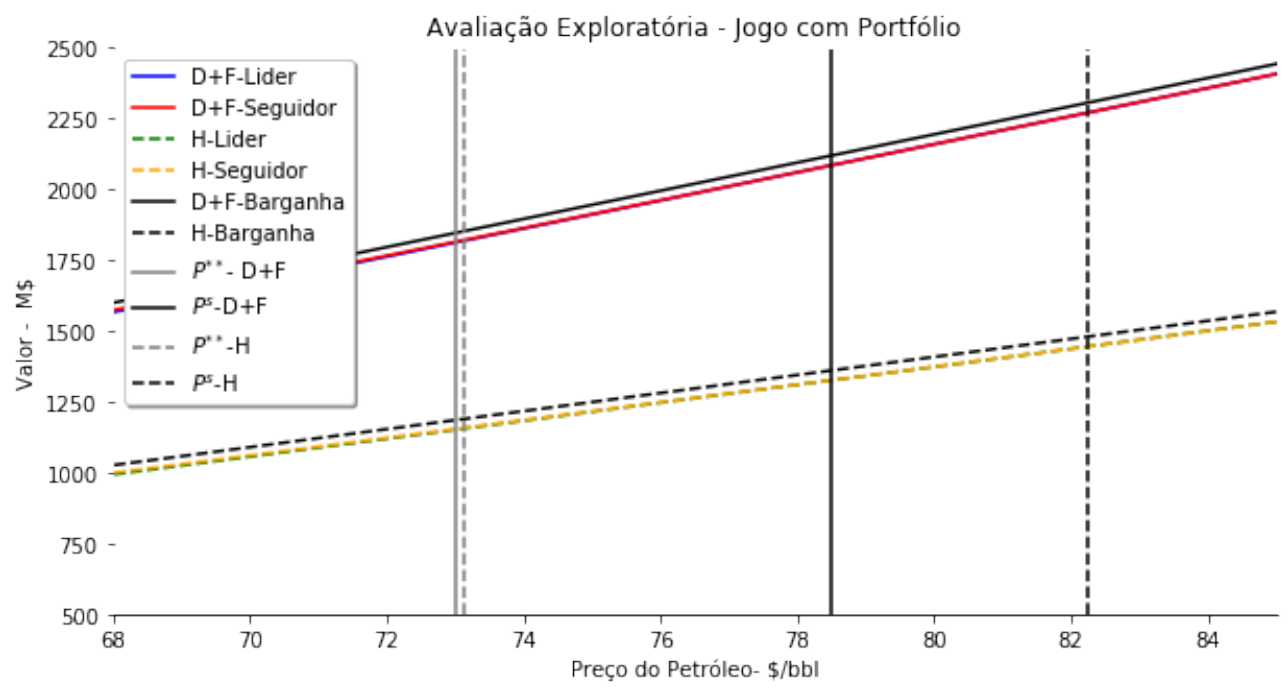

Figura 4.62: Detalhe - B. Coop.: maior $\rho-\Pi(D+F)$, Head e $\Pi(D+F+H)$

No caso de portfólio, as condições para o conflito por informação são similares a guerra de atrito com assimetria (seção 4.2.2.2). A diferença ocorre nos cálculos dos payoffs, visto que são equações diferenciais que consideram o efeito da opção de espera com o aprendizado. Além disso, o custo da espera é acionado pelo gatilho do portfólio, mas é em função do prospecto não investido. Sobre a migração para a barganha cooperativa, como há mais ativos na unitização, maior é o número de permutações entre os prospectos e dessa forma, maior é o excedente de valor pela informação na junção monetária na negociação. Assim, a medida de aprendizado $\rho$ se torna muito relevante e com uma mudança marginal dos parâmetros, pode-se facilmente deslocar da situação de conflito por informação. 


\section{5}

\section{Conclusão}

Os contratos em exploração de petróleo têm embutidos obrigações e opções de investimento, cada qual com suas condições contratuais. Normalmente, os blocos exploratórios têm mais de um prospecto e são leiloados juntos e vizinhos a outros blocos, os quais também possuem outras oportunidades exploratórias. Não é raro que operadoras distintas arrematem áreas em que seus prospectos são correlacionados com os prospectos vizinhos. Nesse contexto, se torna importante o estudo em portfólio dadas as incertezas de preços e técnica, assim como feito nesta dissertação com dois e três prospectos, incluindo a interferência de outra empresa na decisão de investimento. Essa interferência acontece, pois, as empresas buscam informações gratuitas de ocorrência de hidrocarboneto e devido à correlação com os ativos vizinhos, podem postergar o momento de investir em exploração. O último estudo de caso desta dissertação é de uma disputa por informação sobre a existência de petróleo entre a operadora $A$, detentora dos ativos DogFish e Feather e a operadora $B$, detentora da oportunidade Head. Dessa forma, a análise envolveu as TOR, VOI e TJ+OR para as soluções dos casos.

Sobre a incerteza de preços, o modelo de escolha é relevante para o resultado e análise final. O Movimento Geométrico Browniano foi adotado para os preços por ser estatisticamente aceitável e por ser um processo de difusão mais simples. A partir deste modelo de preços, foi demonstrada a equação diferencial parcial para a opção real, que foi resolvida por diferenças finitas explícitas em todos os casos deste trabalho. Contudo, a aplicação do teste econométrico, o qual não rejeitou o MGB, tem baixo poder estatístico. Dessa maneira, o MGB é um excelente modelo como uma primeira etapa de pesquisa, para analisar e compreender a dinâmica dos ativos, com ou sem aprendizado em portfólio e com e sem interação com outros agentes. Em trabalhos futuros pode-se aplicar outro modelo de preços com maior significância estatística. Para esse avanço e refinamento dos resultados, deve ser considerado o trade-off entre a simplificação e a complexidade de implementação.

Os três prospectos estudados têm VMEs positivos, mas de acordo com a teoria das opções reais não estão maduros economicamente para investir, dadas as variáveis de estado no momento inicial do contrato. Na análise estática do 
portfólio com a soma simples (stand-alone) e com o efeito do aprendizado, esta última se mostra superior, pois se administra melhor a ordem dos ativos devido ao valor adicionado que a sequência de perfurações gera para a carteira. Contudo, a análise estática do aprendizado em portfólio é inferior ao estudo combinado das incertezas de preços com a técnica-geológica pelo aprendizado, visto que considera somente um preço médio, sendo que existe a probabilidade de ocorrência de outros preços da commodity. Considerando a estocasticidade dos preços com a gestão da ordem de perfuração, alteram-se as decisões de investimento em exploração e por consequência, os valores dos ativos e da carteira.

Quando é considerado o portfólio exploratório sequencial com a espera, adiciona-se mais valor à carteira que a simples soma stand-alone das opções de explorar, em que se dimensiona somente o valor da espera tradicional. Isso é devido aos efeitos combinados entre a espera e o VOI. No caso da comparação com a análise estática, a abordagem proposta ordena melhor a carteira, como acontece no portfólio exploratório DogFish +Feather comparado ao DogFish+Head. Considerando a carteira DogFish+Feather+Head, há uma grande zona de primeira perfuração da oportunidade Feather, sendo esta de menor VME e de menor valor da opção tradicional de espera. Isso ocorre porque ela traz mais informações que as outras, além de ser mais barata a aquisição da informação. Ademais, a depender dos preços, pode-se inverter a ordem ótima de perfuração, como ocorre com essa mesma carteira em preço mais elevados, além de aparecer novas zonas de espera. Dentre as vantagens desse tipo de análise, se destaca a existência de uma curva de gatilho unificada, útil como ferramenta para o decisor organizar e planejar o investimento no bloco exploratório.

É comum que as empresas tenham blocos com os ativos exploratórios correlacionados com os ativos vizinhos. Por vezes, se configura um conflito por informação gratuita de ocorrência de hidrocarboneto, esse jogo conhecido como guerra de atrito em TJ. Nesse jogo, as empresas sofrem perdas, pois postergam o investimento além do seu ótimo, apostando na possibilidade de ser um agente free-rider. Dado esse conflito, há a possibilidade de nenhuma empresa investir, mesmo que os ativos estejam avaliados acima do ótimo por todas as métricas.

Este trabalho estudou os casos de um jogo simétrico, assimétrico e com um portfólio de dois prospectos.

A apresentação do jogo simétrico, mesmo que considerado o exemplo menos realista, é importante para delimitar melhor as condições de guerra por informação exploratória. Nele, percebe-se que para os preços menores que o gatilho exploratório, não há guerra de atrito, pois as empresas não têm 
interesse econômico para perfurar. A partir do preço do gatilho, a tensão se inicia entre as duas empresas, pois como a situação vizinha é um espelho do seu ativo, o gatilho de perfuração ocorre ao mesmo preço nos dois blocos e, portanto, o interesse por informação gratuita começa no mesmo momento para os dois agentes. Pelo modelo estocástico dos preços, foi estimado por simulação de Monte Carlo o tempo de início desse impasse. O início, assim como o término do conflito são indeterminados, pois a variável preço é estocástica. O término do conflito não depende somente do estado dos preços, mas também da correlação entre os ativos, sendo mais improvável o término do conflito quanto maior a correlação. Isso acontece até o preço denominado de gatilho simultâneo $P^{s}$, comum aos dois nesse caso simétrico. Com os preços maiores que este, as empresas ignoram a presença da outra operadora, pois a perfuração imediata é ótima para os agentes, mesmo se recebessem uma informação desfavorável do vizinho.

Nesse modelo simétrico é apresentada a mudança de jogo. No intervalo de preços em que há um conflito entre os jogadores, a mudança do jogo só ocorre caso exista um prêmio melhor que o ENPS para cada jogador. O jogo apresentado é a simples barganha cooperativa, ou seja, juntar os ativos e dividir os valores. Contudo, a simples unitização e divisão não eleva o valor das partes acima do ENPS da guerra de atrito. Então, nessa situação de negociação, aqui é considerado como condição que a informação pública seja mais restrita que a informação privada. E de fato, em negociações, pode haver informações mais detalhadas e valiosas do que as informações públicas. Assim, uma melhora na correlação dos ativos pode ser suficiente para sair da guerra de atrito e os operadores migrarem para o jogo da barganha cooperativa.

Em modelos assimétricos, é relevante a relação do prêmio da espera com o valor intrínseco do ativo, que no caso é o valor monetário esperado, comparado com esses mesmos parâmetros do vizinho. A outra face da mesma moeda é o gatilho exploratório, sendo o parâmetro mais prático e direto que o prêmio de espera da opção de investir em exploração. Quando os gatilhos dos prospectos das empresas são díspares, a probabilidade de atrito é baixa. Isso quer dizer que a empresa que tem o preço do gatilho baixo não vai aguardar a empresa de gatilho alto perfurar, posto que tem o interesse econômico imediato no seu projeto e em equilíbrio seria inútil esperar, pois não obterá informação alguma. Dessa forma, a empresa detentora desse ativo de gatilho mais baixo perfura e gera a informação pública para a outra empresa. Também, outra forma útil de analisar esse desequilíbrio é pelo benefício da espera no intervalo de interesse, sendo que a empresa com o maior gatilho exploratório será a seguidora, ou seja, o agente free-rider. 
Em caso de valores assimétricos, mas com os gatilhos iguais ou próximos, ocorre o equilíbrio perfeito em subjogos em estratégias mistas no intervalo entre o gatilho de exploração e o preço mais baixo do gatilho simultâneo. Contudo, esse equilíbrio não é estável em jogos evolucionários. O plano de fase ajuda a elucidar essa questão, pois não há um máximo global e, portanto, tendo incentivos ao desvio pelos jogadores. Esse efeito também pode ser notado nas diferenças entre as utilidades esperadas no equilíbrio em estratégias mistas, provocando incentivos ao desvio para as probabilidades degeneradas. Dado o efeito prático dos negócios, pode acontecer dos jogadores ficaram "presos" nessa guerra de atrito e se confundindo no ótimo para seus projetos.

Nessa situação, a barganha cooperativa é a solução para esse possível impasse. Com os valores assimétricos, a divisão pela solução de Nash na barganha não é igual entre os agentes como em ativos simétricos e também é em função do preço e do momento de negociação. Isso porque o ponto de discordância também é em função das mesmas variáveis $P$ e $t$, assim como os ativos a serem unitizados e repartidos. No caso de dois ativos, uma pequena mudança na correlação é condição suficiente para alterar o jogo e migrar para a barganha cooperativa.

Em jogos com portfólio, os cálculos dos payoffs são diferentes, pois os ativos se correlacionam dentro do próprio bloco exploratório. Porém, o custo da espera considera somente o primeiro ativo a perfurar da sequência ótima, não o prêmio total do portfólio. Da mesma forma, a empresa vizinha considera como revelação da informação somente o primeiro prospecto do cronograma de sondas da concorrente. Como no caso assimétrico, quando os gatilhos exploratórios são similares, há a possibilidade de guerra por informação exploratória até o mais baixo gatilho simultâneo das empresas. A primeira perfuração pode acontecer com a empresa de maior ou de menor portfólio, dependendo do benefício da espera ou da combinação entre os gatilhos exploratório e simultâneo.

Em caso de persistência do conflito, a barganha cooperativa é um valioso jogo para substituir a guerra de atrito. Com o portfólio unitizado, a sequência de perfuração pode alterar, como foi o caso na mudança de preferência para a oportunidade Feather. Essa oportunidade é a de gatilho exploratório mais alto, mas quando em carteira com os prospectos DogFish e Head, o ativo Feather possui maior poder informativo para o portfólio. Isso é devido à mais alta correlação com estes dois prospectos e se torna a primeira opção de perfuração. Além do mais, na barganha cooperativa, um pequeno aumento nas correlações dos prospectos pode adicionar um relevante valor na unitização dos blocos. Esse efeito coloca a estimativa da medida de aprendizado (correlação entre 
ativos) com uma grande importância na avaliação de portfólios. O efeito ocorre, pois com mais ativos, maior é o número de opções de aprendizagem, visto que se eleva fatorialmente o número de sequências possíveis, havendo mais possibilidades para o ótimo exploratório e para o gestor ordenar as preferências de perfuração.

O trabalho pode ser estendido por diversas linhas de pesquisa. A começar pelo modelo de preços, considerando movimentos com reversão à média de longo prazo e saltos. Essa mudança tem consequência para a solução matemática do problema, também sendo uma nova fonte de extensão de trabalhos. Em portfólios, poderia ser considerado um poço para dois prospectos sobrepostos, visto que essa mudança pode afetar a sequência ótima com aprendizado combinando com uma redução de custo exploratório. Além disso, os modelos com sinergias de projetos de desenvolvimento dos campos consideram uma redução de custo devido à economia de escala na produção de petróleo, dada a similaridade entre os ativos e a proximidade entre eles. De tal sorte que esses tipos de modelos cabem na extensão desta pesquisa, visto que as oportunidades exploratórias estão no mesmo play geológico e com uma proximidade física entre elas. Ademais, os futuros estudos podem considerar o aprofundamento das diferenças entre a informação pública, exigida pela ANP após a perfuração de um poço pioneiro e a informação privada, por meio da negociação entre as empresas, assim como as possíveis metodologias para estimar as correlações entre os prospectos. 


\section{Referências}

ADKINS, Roger; PAXSON, Dean. The Tourinho model: neglected nugget or a receding relic? The European Journal of Finance, Taylor \& Francis, v. 19, n. 7-8, p. 604-624, 2013.

AIUBE, Fernando Antonio Lucena. Modelos quantitativos em finanças com enfoque em commodities. [S.l.]: Bookman Editora, 2013.

AIUBE, Fernando Antonio Lucena; BAIDYA, Tara Keshar Nanda; TITO, Edison Americo Huarsaya. Analysis of commodity prices with the particle filter. Energy Economics, Elsevier, v. 30, n. 2, p. 597-605, 2008.

AIUBE, Fernando Antonio Lucena; SAMANEZ, Carlos Patricio. On the comparison of Schwartz and Smith's two-and three-factor models on commodity prices. Applied Economics, Taylor \& Francis, v. 46, n. 30, p. 3736-3749, 2014.

AMIC, Etienne; GEMAN, Hélyette. The Oil Market as a World Market. [S.l.]: John Wiley \& Sons, 2005. cap. 10, p. 201-224.

ARORA, Ashish; GAMBARDELLA, Alfonso. Complementarity and External Linkages: The Strategies of the Large Firms in Biotechnology. The Journal of Industrial Economics, Wiley, v. 38, n. 4, p. 361-379, 1990.

BAKER, Malcolm P; MAYFIELD, E Scott; PARSONS, John E. Alternative models of uncertain commodity prices for use with modern asset pricing methods. The Energy Journal, International Association for Energy Economics, v. 19, n. 1, 1998.

BENARD, J et al. Oil Prices: Heavy Tails, Mean Reversion and the Convenience Yield. Cahiers de recherche, v. 0801, 01=30, 2008.

BHAR, Ramaprasad; LEE, Damien. Time-varying market price of risk in the crude oil futures market. Journal of Futures Markets, Wiley Online Library, v. 31, n. 8, p. 779-807, 2011.

BICKEL, J Eric; SMITH, James E. Optimal sequential exploration: A binary learning model. Decision Analysis, INFORMS, v. 3, n. 1, p. 16-32, 2006.

BICKEL, J Eric; SMITH, James E; MEYER, Jennifer L. Modeling dependence among geologic risks in sequential exploration decisions. SPE 
Reservoir Evaluation \& Engineering, Society of Petroleum Engineers, v. 11, n. 02, p. 352-361, 2008.

BISHOP, DT; CANNINGS, Chris. A generalized war of attrition. Journal of Theoretical Biology, Elsevier, v. 70, n. 1, p. 85-124, 1978.

BJERKSUND, Petter; EKERN, Steinar. Managing Investment Opportunities under Price Uncertainty: From "Last Chance"to "Wait and See"Strategies.

Financial Management, Financial Management Association International, Wiley, v. 19, n. 3, p. 65-83, 1990.

BLACK, Fischer; SCHOLES, Myron. The pricing of options and corporate liabilities. Journal of Political Economy, The University of Chicago Press, v. 81, n. 3, p. 637-654, 1973.

BONATTI, Alessandro. Game Theory for Strategic Advantage 15.025 - Lecture 9: War of Attrition. [S.l.]: MIT Course Ware, 2015. Disponível em: <https://ocw.mit.edu/courses/>.

BRANDÃO, Luiz E; DYER, James S; HAHN, Warren J. Using binomial decision trees to solve real-option valuation problems. Decision Analysis, INFORMS, v. 2, n. 2, p. 69-88, 2005.

BRANDÃO, Luiz E.; FERNANDES, Gláucia; DYER, James S. Valuing multistage investment projects in the pharmaceutical industry. European Journal of Operational Research, v. 271, n. 2, p. 720-732, 2018. DOI: https://doi.org/10.1016/j.ejor.2018.05.044.

BRANDENBURGER, Adam M; NALEBUFF, Barry J. Co-opetition. [S.l.]: Currency Doubleday, 1996.

BRATVOLD, Reidar B; BICKEL, J Eric; LOHNE, Hans Petter. Value of information in the oil and gas industry: past, present, and future. SPE Reservoir Evaluation \& Engineering, Society of Petroleum Engineers, v. 12, n. 04, p. 630-638, 2009.

BRATVOLD, Reidar Brumer; BEGG, Steve. Making good decisions. [S.1.]: Society of Petroleum Engineers Richardson, Texas, 2010. v. 207.

BRENNAN, Michael; SCHWARTZ, Eduardo. Evaluating natural resource investments. Journal of business, JSTOR, p. 135-157, 1985. 
Finite difference methods and jump processes arising in the pricing of contingent claims: A synthesis. Journal of Financial and Quantitative Analysis, JSTOR, p. 461-474, 1978.

BROSCH, Rainer. Portfolio-aspects in real options management. [S.l.], 2001.

CALVETTE, Luigi de Magalhães Detomi; PACHECO, Marco Aurélio C. Genetic Algorithms and Real Options on WildCat drilling optimal choice. Citeseer, 2014.

CHEVALIER-ROIGNANT, Benoit et al. Strategic investment under uncertainty: A synthesis. European Journal of Operational Research, Elsevier, v. 215, n. 3, p. 639-650, 2011.

COPELAND, Tom; ANTIKAROV, Vladimir. Real options. [S.l.]: Texere New York, 2001.

CORTAZAR, Gonzalo; CASASSUS, Jaime. Optimal timing of a mine expansion: Implementing a real options model. The Quarterly Review of Economics and Finance, Elsevier, v. 38, n. 3, p. 755-769, 1998. DOI: https ://doi .org/10.1016/S1062-9769(99)80100-8.

CORTAZAR, Gonzalo; NARANJO, Lorenzo. An N-factor Gaussian model of oil futures prices. Journal of Futures Markets: Futures, Options, and Other Derivative Products, Wiley Online Library, v. 26, n. 3, p. 243-268, 2006.

CORTAZAR, Gonzalo; SCHWARTZ, Eduardo. Implementing a real option model for valuing an undeveloped oil field. International Transactions in Operational Research, Wiley Online Library, v. 4, n. 2, p. 125-137, 1997. Implementing a stochastic model for oil futures prices. Energy Economics, Elsevier, v. 25, n. 3, p. 215-238, 2003.

CORTAZAR, Gonzalo; SCHWARTZ, Eduardo; CASASSUS, Jaime. Optimal exploration investments under price and geological - technical uncertainty: a real options model. In: REAL R \& D Options. [S.l.]: Elsevier, 2003. p. 149-165.

COX, John C; ROSS, Stephen A; RUBINSTEIN, Mark. Option pricing: A simplified approach. Journal of Financial Economics, Elsevier, v. 7, n. 3, p. 229-263, 1979. 
DIAS, Marco Antonio Guimarães. Análise de Investimentos com

Opções Reais: Teoria e Prática com Aplicações em Petróleo e em outros Setores (Vol. 1: Conceitos Básicos e Opções Reais em Tempo Discreto). [S.l.]: Rio de Janeiro: Interciência, 2015.

Análise de Investimentos com Opções Reais: Teoria e Prática com Aplicações em Petróleo e em outros Setores (Vol. 2: Processos Estocásticos e Opções Reais em Tempo Contınuo). [S.l.]: Rio de Janeiro: Interciência, 2015. . Calculating Real Option Values. Wiley Encyclopedia of

Operations Research and Management Science, Wiley Online Library, 2010 . Investment in information in petroleum, real options and revelation. In: PROCEEDING at 6th Annual International Conference on Real Options. Real Options Group at Cyprus, Cyprus. [S.l.: s.n.], 2002.

Opções Reais Rıbridas com Aplicações em Petróleo. 490 f. 2005. Tese (Doutorado) - Departamento de Engenharia Industrial, PUC-RJ. . Real options theory for real asset portfolios: The oil exploration case. In: PROCEEDING 10th Annual International Conference on Real Options, June 14-17. [S.l.: s.n.], 2006.

. Real options, Learning Measures, and Bernoulli Revelation Processes. In: PROCEEDING at 9th Annual International Conference on Real Options, Paris. [S.l.: s.n.], 2005.

. The Timing of Investment in E\&P: Uncertainty, Irreversibility, Learning, and Strategic Consideration. In: SPE. SPE Hydrocarbon Economics and Evaluation Symposium. [S.l.: s.n.], 1997. . Valuation of Exploration and Production Assets: An Overview of Real Options Models. Journal of Petroleum Science and Engineering, Elsevier, v. 44, n. 1-2, p. 93-114, 2004.

DIAS, Marco Antonio Guimarães; CALVETTE, Luigi de Magalhães Detomi. Portfolio of Oil Exploration Assets: Learning Options, Sequential Drilling Options and Defer Options. In: PROCEEDINGS of the 21th Annual International Conference on Real Options. Real Options Group at Boston. [S.l.: s.n.], 2017. 
DIAS, Marco Antonio Guimarães; TEIXEIRA, José. Continuous-time Option Games: Review of models and Extensions. Multinational Finance Journal, v. 14, n. 3/4, p. 219-254, 2010. . Continuous-time Option Games: War of Attrition and Bargaining Under uncertainty in oil exploration. OPEC, Oil Prices and LNG (Energy Policies, Politics and Prices). Hauppauge, NY: Nova Science Publishers, p. 73-105, 2009.

DIXIT, Avinash K; PINDYCK, Robert S. Investment Under Uncertainty. [S.1.]: Princeton University Press, 1994.

EIA. Cushing, OK WTI Spot Price FOB (Dollars per Barrel). [S.l.: s.n.], nov. 2020. https://www.eia.gov/dnav/pet/hist/RWTCD.htmUS Energy Information Administration.

FAIZ, Soussan. Real Options Application: From Successes in Asset Valuation to Challenges for an Enterprise-Wide Approach. In: All Days. (SPE Annual Technical Conference and Exhibition). SPE-62964-MS.

FAÚNDEZ, Patricio Ignacio et al. Valuation and Prioritization of Early-Stage Exploration Projects: a Case Study of $\mathrm{Cu}-\mathrm{Ag}$ and Au-Mineralized Systems in the Tiltil Mining District, Chile. Natural Resources Research, Springer, v. 29, n. 5, p. 2989-3014, 2020.

FRED. 20-Year Treasury Constant Maturity Rate. [S.l.: s.n.], nov. 2020. https://fred.stlouisfed.org/series/DGS20.

GEMAN, Hélyette. Commodities and commodity derivatives: modeling and pricing for agriculturals, metals and energy. [S.l.]: John Wiley \& Sons, 2005.

GHEMAWAT, Pankaj. Games businesses play: cases and models. [S.l.]: MIT Press, 1997.

GHEMAWAT, Pankaj; NALEBUFF, Barry. Exit. The RAND Journal of Economics, JSTOR, p. 184-194, 1985.

GIBBONS, Robert S. Game theory for applied economists. [S.l.]:

Princeton University Press, 1992.

GIBSON, Rajna; SCHWARTZ, Eduardo. Stochastic convenience yield and the pricing of oil contingent claims. The Journal of Finance, Wiley Online Library, v. 45, n. 3, p. 959-976, 1990. 
GRENADIER, Steven R. Option exercise games: the intersection of real options and game theory. Journal of Applied Corporate Finance, Wiley Online Library, v. 13, n. 2, p. 99-107, 2000.

. The strategic exercise of options: Development cascades and overbuilding in real estate markets. The Journal of Finance, Wiley Online Library, v. 51, n. 5, p. 1653-1679, 1996.

GUEDES, José; SANTOS, Pedro. Valuing an offshore oil exploration and production project through real options analysis. Energy Economics, Elsevier, v. 60, p. 377-386, 2016.

HAMMERSTEIN, Peter; PARKER, Geoffrey A. The asymmetric war of attrition. Journal of Theoretical Biology, Elsevier, v. 96, n. 4, p. 647-682, 1982.

HAMMERSTEIN, Peter; SELTEN, Reinhard. Game theory and evolutionary biology. Handbook of game theory with economic applications, Elsevier, v. 2, p. 929-993, 1994.

HARVEY, Andrew C. Forecasting, structural time series models and the Kalman filter. [S.l.]: Cambridge University Press, 1990.

HAUG, Espen Gaarder. Option pricing formulas. [S.l.]: McGraw-Hill, New York, 2007.

HENDRICKS, Ken; WEISS, Andrew; WILSON, Charles. The war of attrition in continuous time with complete information. International Economic Review, JSTOR, p. 663-680, 1988.

HUISMAN, Kuno JM; KORT, Peter M. Effects of strategic interactions on the option value of waiting. CentER Discussion Paper; Vol. 1999-92. Microeconomics, Tilburg University Netherlands, 1999.

JAFARIZADEH, Babak; BRATVOLD, Reidar Brumer. Oil and gas exploration valuation and the value of waiting. The Engineering Economist, Taylor \& Francis, v. 60, n. 4, p. 245-262, 2015.

JOE, Harry. Multivariate models and multivariate dependence concepts. [S.1.]: CRC Press, 1997.

KAPUR, Sandeep. Markov perfect equilibria in an N-player war of attrition. Economics Letters, Elsevier, v. 47, n. 2, p. 149-154, 1995. 
KLOEDEN, Peter E; PLATEN, Eckhard. Numerical solution of stochastic differential equations. [S.l.]: Springer Science \& Business Media, 1992. v. 23.

KRISHNA, Vijay; MORGAN, John. An analysis of the war of attrition and the all-pay auction. Journal of Economic Theory, New York: Academic Press., v. 72, n. 2, p. 343-362, 1997.

LANDER, Diane M; PINCHES, George E. Challenges to the practical implementation of modeling and valuing real options. The Quarterly Review of Economics and Finance, Elsevier, v. 38, n. 3, p. 537-567, 1998. LAWRENCE, David B. The economic value of information. New York: SpringerVerlag. [S.l.]: Inc, 1999.

LEAHY, John V. Investment in competitive equilibrium: The optimality of myopic behavior. The Quarterly Journal of Economics, MIT Press, v. 108, n. 4, p. 1105-1133, 1993.

LONGSTAFF, Francis A; SCHWARTZ, Eduardo. Valuing American options by simulation: a simple least-squares approach. The Review of Financial Studies, Oxford University Press, v. 14, n. 1, p. 113-147, 2001.

MARKOWITZ, H. Portfolio Selection: Efficient Diversification of Investments. Cowles Foundation for Research in Economics at Yale University. Wiley, 1959.

MASKIN, Eric; TIROLE, Jean. A theory of dynamic oligopoly, I: Overview and quantity competition with large fixed costs. Econometrica: Journal of the Econometric Society, JSTOR, p. 549-569, 1988.

MERTON, Robert C. Theory of rational option pricing. The Bell Journal of Economics and Management Science, JSTOR, p. 141-183, 1973.

DOI: $10.2307 / 3003143$.

MURTHA, J.A. Estimating reserves and success for a prospect with geologically dependent layers. In: SOCIETY OF PETROLEUM ENGINEERS. SPE Hydrocarbon Economics and Evaluation Symposium. [S.l.: s.n.], 1995.

MYERSON, Roger B. Learning from Schelling's strategy of conflict. Journal of Economic Literature, v. 47, n. 4, p. 1109-25, 2009. 
NASH, John. Non-Cooperative Games. Annals of Mathematics, Annals of Mathematics, v. 54, n. 2, p. 286-295, 1951.

Two-Person Cooperative Games. Econometrica, [Wiley,

Econometric Society], v. 21, n. 1, p. 128-140, 1953.

OLIVEIRA, Carlos Alberto Pereira. Avaliação e gerência de jazidas de petróleo: uma abordagem pela teoria das opções. 1990. (Dissertação (Mestrado) - Departamento de Engenharia Industrial, PUC-RJ.

PADDOCK, James L; SIEGEL, Daniel R; SMITH, James. Option valuation of claims on real assets: The case of offshore petroleum leases. The Quarterly Journal of Economics, MIT Press, v. 103, n. 3, p. 479-508, 1988.

PETERAF, Margaret A; BARNEY, Jay B. Unraveling the resource-based tangle. Managerial and Decision Economics, Wiley Online Library, v. 24, n. 4, p. 309-323, 2003.

PINDYCK, Robert S. The dynamics of commodity spot and futures markets: a primer. The Energy Journal, International Association for Energy Economics, v. 22, n. 3, 2001. DOI:

https : //doi .org/10.5547/ISSN0195-6574-EJ-Vol22-No3-1.

The Long-Run Evolution of Energy Prices. sl: MIT Center for Energy and Environmental Policy Research, 1999. DOI: https ://doi .org/10.5547/ISSN0195-6574-EJ-Vol20-No2-1.

QUANDL-CME. Crude Oil Futures-Wiki Continuous Futures. [S.l.: s.n.], nov. 2020. https://www. quandl . com/data/CHRIS/.

QUANDL-FRED. 3-Month Treasury Constant Maturity Rate. [S.l.: s.n.], nov. 2020. https ://www . quandl . com/data/FRED/DGS3MO-3Month-Treasury-Constant-Maturity-Rate.

ROSE, Peter R. Risk analysis and management of petroleum exploration ventures. [S.l.]: American Association of Petroleum Geologists Tulsa, OK, 2001. v. 12. . Taking the risk out of petroleum exploration; the adoption of systematic risk analysis by international corporations during the 1990s. The Leading Edge, n. 18, p. 192-199, 1999. 
SAITO, R et al. Value assessment for reservoir recovery optimization.

Journal of Petroleum Science and Engineering, Elsevier, v. 32, n. 2-4, p. $151-158,2001$.

SCHWARTZ, Eduardo. The real options approach to valuation: Challenges and opportunities. Latin American Journal of Economics, v. 50, n. 2, p. 163-177, 2013.

. The stochastic behavior of commodity prices: Implications for valuation and hedging. The Journal of Finance, Wiley Online Library, v. 52, n. 3, p. 923-973, 1997.

. Valuing long-term commodity assets. Journal of Energy

Finance \& Development, Elsevier, v. 3, n. 2, p. 85-99, 1998. DOI: https://doi.org/10.1016/S1085-7443(99)80070-2.

SCHWARTZ, Eduardo; SMITH, James. Short-term variations and long-term dynamics in commodity prices. Management Science, Informs, v. 46, n. 7, p. 893-911, 2000.

SEPPI, Duane J; RONN, E. Risk-neutral stochastic processes for commodity derivative pricing: An introduction and survey. Real Options and Energy Management Using Options Methodology to Enhance Capital Budgeting Decisions, Risk Publications London, p. 3-60, 2002.

SHUMWAY, Robert H; STOFFER, David S. Time series analysis and its applications: with R examples. [S.l.]: Springer Science, 2017.

SLADE, Margaret E. Valuing managerial flexibility: An application of real-option theory to mining investments. Journal of Environmental Economics and Management, Academic Press, v. 41, n. 2, p. 193-233, 2001.

SMIT, Han TJ; TRIGEORGIS, Lenos. Real options and games:

Competition, alliances and other applications of valuation and strategy.

Review of Financial Economics, Elsevier, v. 15, n. 2, p. 95-112, 2006.

SMITH, J Maynard; PRICE, George R. The logic of animal conflict.

Nature, Nature Publishing Group, v. 246, n. 5427, p. 15-18, 1973.

SMITH, James E; MCCARDLE, Kevin F. Valuing oil properties: integrating option pricing and decision analysis approaches. Operations Research, INFORMS, v. 46, n. 2, p. 198-217, 1998. 
SMITH, John Maynard. Evolution and the Theory of Games. [S.l.]: Cambridge university press, 1982.

. Evolution and the Theory of Games: In situations characterized by conflict of interest, the best strategy to adopt depends on what others are doing. American Scientist, Sigma Xi, The Scientific Research Society, v. 64, n. 1, p. 41-45, 1976.

The theory of games and the evolution of animal conflicts. Journal of Theoretical Biology, Academic Press, v. 47, n. 1, p. 209-221, 1974.

SMITH; THOMPSON, Rex. Managing a portfolio of real options: Sequential exploration of dependent prospects. The Energy Journal, JSTOR, p. 43-61, 2008.

STABELL, Charles B et al. Alternative approaches to modeling risks in prospects with dependent layers. In: SOCIETY OF PETROLEUM ENGINEERS. SPE Annual Technical Conference and Exhibition. [S.l.: s.n.], 2000 .

TAVELLA, Domingo. Quantitative methods in derivatives pricing: an introduction to computational finance. [S.l.]: John Wiley \& Sons, 2003. v. 158.

TEECE, David J; PISANO, Gary; SHUEN, Amy. Dynamic capabilities and strategic management. Strategic Management Journal, Wiley Online Library, v. 18, n. 7, p. 509-533, 1997.

TITMAN, Sheridan. Urban land prices under uncertainty. The American Economic Review, JSTOR, v. 75, n. 3, p. 505-514, 1985.

TOURINHO, Octavio Augusto Fontes. Revisiting the Tourinho real options model: outstanding issues 30 years later. The European Journal of Finance, Taylor \& Francis, v. 19, n. 7-8, p. 591-603, 2013.

. The valuation of reserves of natural resources: an option pricing approach. 1979. 1979. Tese (Doutorado) - University of California, Berkeley (CA).

TRIGEORGIS, Lenos. Real options: a primer. In: THE new investment theory of real options and its implication for telecommunications economics. [S.1.]: Springer, 1999. p. 3-33. 
TRIGEORGIS, Lenos. Real options: Managerial flexibility and strategy in resource allocation. [S.l.]: MIT press, 1996.

The nature of option interactions and the valuation of investments with multiple real options. Journal of Financial and Quantitative Analysis, Cambridge University Press, v. 28, n. 1, p. 1-20, 1993.

VASSOLO, Roberto S; ANAND, Jaideep; FOLTA, Timothy B.

Non-additivity in portfolios of exploration activities: A real options-based analysis of equity alliances in biotechnology. Strategic Management Journal, Wiley Online Library, v. 25, n. 11, p. 1045-1061, 2004.

WILMOTT, Paul. Paul Wilmott on quantitative finance. 2nd. [S.l.]: John Wiley \& Sons, 2006.

ZAN, Kun; BICKEL, J Eric. Components of portfolio value of information. Decision Analysis, INFORMS, v. 10, n. 2, p. 171-185, 2013. 
A

\section{Portfólio Sem Risco}

O ativo base segue um MGB segundo a equação diferencial estocástica abaixo:

$$
d P=\mu P d t+\sigma P d z
$$

Para o derivativo, que será o valor do projeto $V(P, t)$, utiliza-se a fórmula de Itô-Doeblin para encontrar sua dinâmica:

$$
d V=V_{t} d t+V_{P} d P+\frac{1}{2} V_{P P} d[P, P](t)
$$

Sendo $V_{P}$ e $V_{P P}$ a primeira e segunda derivada de $V$ em relação a $P, V_{t}$ a derivada de $V$ em relação ao tempo e $d[P, P](t)$ a covariação quadrática de $P$. Esse último termo é de ordem $d t$, sendo no MGB igual a $\sigma^{2} P^{2} d t$.

Monta-se um portfólio em que não há risco, sendo que sua variação rende a taxa livre de risco. Assim, o portfólio pode ser desenhado como comprado no derivativo $V$ e vendido em $\Delta$ no ativo base $P$ :

$$
\phi=V-\Delta P
$$

E a variação desse portfólio num intervalo $d t$ é igual a:

$$
d \phi=(d V+\pi(P, t) d t)-\Delta(d P+\delta P d t)=r \phi d t
$$

Caso o derivativo já tenha um fluxo de caixa, ele vai gerar $\pi(P, t)$ em $d t$. $\mathrm{O}$ ativo base $P$ paga um dividendo $\delta P$ em $d t$. Substituindo $d V$ :

$$
d \phi=\left(V_{t} d t+V_{P} d P+\frac{1}{2} V_{P P} \sigma^{2} P^{2} d t+\pi(P, t) d t\right)-\Delta(d P+\delta P d t)
$$

Substituindo $d P$ :

$d \phi=V_{t} d t+V_{P} \mu P d t+V_{P} \sigma P d z+\frac{1}{2} V_{P P} \sigma^{2} P^{2} d t+\pi(P, t) d t-\Delta \mu P d t-\Delta \sigma P d z-\Delta \delta P d t$

Agrupando $d t$ e $d z$ :

$d \phi=\left(V_{t}+V_{P} \mu P-\Delta \mu P+\frac{1}{2} V_{P P} \sigma^{2} P^{2}+\pi(P, t)-\Delta \delta P\right) d t+\left(V_{P}-\Delta\right) \sigma P d z$

Se o portfólio não tem risco, os termos estocásticos $d z$ devem ser iguais 
a zero, ou seja:

$$
\left(V_{P}-\Delta\right) \sigma P d z=0 \Leftrightarrow \Delta=V_{P}
$$

Assim, a equação $d \phi$ acima fica, cortando também $V_{P} \mu P d t$ :

$$
d \phi=V_{t}+\frac{1}{2} \sigma^{2} P^{2} V_{P P} d t+\pi(P, t) d t-\delta P V_{P} d t
$$

Como foi visto, a variação de portfólio é igual ao rendimento livre de risco $(d \phi=r \phi d t)$, assim:

$$
V_{t}+\frac{1}{2} \sigma^{2} P^{2} V_{P P}+\pi(P, t)-\delta P V_{P}=r \phi
$$

O portfólio $\phi$ foi montado na equação (A-3), contudo agora sabe-se o delta hedge $\left(\Delta=V_{P}\right)$, portanto:

$$
V_{t}+\frac{1}{2} \sigma^{2} P^{2} V_{P P}+\pi(P, t)-\delta P V_{P}=r\left(V-P V_{P}\right)
$$

Chegamos na equação diferencial do valor do projeto, como pode ser visto abaixo:

$$
V_{t}+\frac{1}{2} \sigma^{2} P^{2} V_{P P}+\pi(P, t)-\delta P V_{P}-r V+r P V_{P}=0
$$

Arrumando os termos:

$$
V_{t}+\frac{1}{2} \sigma^{2} P^{2} V_{P P}(P)+(r-\delta) P V_{P}(P)-r V(P, t)+\pi(P, t)=0
$$

Caso considere que o derivativo não gera fluxo de caixa, como é a situação de projetos exploratórios, $\pi(P, t)$ é zero, convertendo em uma equação diferencial parcial igual aos trabalhos de Black e Scholes (1973) e Merton (1973). 


\section{B \\ Diferenças Finitas}

Os métodos de diferenças finitas podem ser classificados em :

- Diferenças Finitas Explícitas

- Diferenças Finitas Implícitas

- Método de Crank-Nicolson

A equação diferencial do derivativo $f$ é apresentada abaixo, similar a formulação demonstrada em Black e Scholes (1973) e Merton (1973), mas com o ativo base $S_{t}$ que segue um MGB e paga dividendos $(\delta)$ :

$$
\frac{\partial f}{\partial t}+(r-\delta) \frac{\partial f}{\partial S} S+\frac{1}{2} \frac{\partial^{2} f}{\partial S^{2}} \sigma^{2} S^{2}=r f
$$

\section{Diferenças Finitas Explícitas}

Diferenciação forward. O tempo só move para frente, sendo $j$ igual ao tempo e $i$ ao valor:

$$
\frac{\partial f}{\partial t} \approx \frac{f_{j+1, i}-f_{j, i}}{\Delta t}
$$

Para o delta e gama, utiliza-se a aproximação da diferenciação central, já que o valor pode mover para qualquer direção:

$$
\begin{gathered}
\frac{\partial f}{\partial S} \approx \frac{f_{j+1, i+1}-f_{j+1, i-1}}{2 \Delta S} \\
\frac{\partial^{2} f}{\partial S^{2}} \approx \frac{f_{j+1, i+1}-2 f_{j+1, i}+f_{j+1, i-1}}{\Delta S^{2}}
\end{gathered}
$$

Aplicando as aproximações (B-2,B-3 e B-4) na equação (B-1), temos: 


$$
\begin{aligned}
\frac{f_{j+1, i+1}-f_{j+1, i-1}}{2 \Delta S}+(r-\delta) & \frac{f_{j+1, i+1}-2 f_{j+1, i}+f_{j+1, i-1}}{\Delta S^{2}} S \\
+ & \frac{1}{2} \frac{f_{j+1, i+1}-2 f_{j+1, i}+f_{j+1, i-1}}{\Delta S^{2}} \sigma^{2} S^{2}=r f_{i, j}
\end{aligned}
$$

Essa equação pode ser reescrita como:

$$
f_{i, j}=\frac{1}{1+r \Delta t}\left(p_{u} f_{j+1, i+1} p_{m} f_{j+1, i}+p_{d} f_{j+1, i-1}\right)
$$

Onde,

$$
\begin{gathered}
p_{u}=\frac{1}{2}\left[\sigma^{2} i^{2}+i(r-\delta)\right] \Delta t \\
p_{m}=1-\sigma^{2} i^{2} \Delta t
\end{gathered}
$$

$$
p_{d}=\frac{1}{2}\left[\sigma^{2} i^{2}-i(r-\delta)\right] \Delta t
$$

Na implementação do algoritmo, é necessário ter um valor máximo para o ativo base $S$. Wilmott (2006, Cap.77, p.1202) recorda da equação de BlackScholes, em que se integra de zero a infinito dos possíveis valores no vencimento, porém, na prática, ressalta que não precisa ser um valor tão alto. Primeiro, ainda que a soma seja até infinito, a probabilidade de ocorrência é baixa para valores de $S$ muito altos. Segundo, quanto maior a malha, maior é o consumo de tempo de máquina, assim, recomenda valores no máximo de 3 ou 4 vezes o $S$ inicial. Dias (2015b, Cap.26, p. 408) sugere o uso de uma porcentagem acima do gatilho da opção perpétua, dado que a opção perpétua tem o gatilho sempre acima da opção com vencimento. Também atenta a questão da estabilidade, vinculando a discretização $S$ com o tempo, assim como Haug (2007, Chap.7, p.337) e Tavella (2003, Cap.7, p.225). 


\section{B.0.0.0}

\section{Solução Numérica (Algoritmo)}

Result: Op. Americana de Compra e Gatilho - DF Explícita

Definição do $S_{\max }$;

Definição dos passos $\Delta S(\mathrm{M})$ e $\Delta t(\mathrm{~N})$;

Localização do $\mathrm{S}$ de entrada no vetor $S_{\text {Grid }}$;

Cálculo da taxa de desconto;

for $j$ em $M$ - cálculo no vencimento do

Cálculo do vetor $\mathrm{S}$;

$F_{N, j}=\max \left[0 ; S_{j}-\mathrm{I}\right]$;

\section{end}

Gatilho no vencimento = I;

for $i$ em $N-1$ - backward do

for $j \mathrm{em} M$ do

$F_{i, j}=$ ponderação da opção no tempo posterior em diferentes

$F_{i+1}\left(F_{i+1, j-1}, F_{i+1, j}\right.$ e $\left.F_{i+1, j+1}\right)$ por $p_{u}, p_{m}$ e $p_{d}$, descontado pela taxa livre de risco;

if $\left(F_{i, j}\right.$ for maior que $\left.S_{j}-I\right)$ e $\left(F_{i, j-1}\right.$ for menor $\left.S_{j-1}-I\right)$ then Gatilho $=$ Média de $S_{j}$ e $S_{j-1}$

end

$F_{i, j}=\max \left[F_{i, j} ; S_{j}-\mathrm{I}\right]$

end

end

Vetor Gatilho;

Opção Hoje $=F_{0, S_{\text {Grid }}}$.

Algorithm 1: DF Explícita - Opção de Compra e Gatilho 


\section{C \\ Dados e Programas}

- Este documento foi escrito em $\mathrm{AT}_{\mathrm{E} X} \mathrm{X}$ com o editor overleaf.

- Todos os programas estão carregados em:

- github.com/lucasmesz/Portfolio_Exploratorio.

- Toda a programação fez uso da linguagem Python e escrita no Project Notebook.

- Os aplicativos suportes para os loops das soluções numéricas foram o pandas, para a organização da informação e numpy, para as diversas operações matemáticas.

- A organização dos portfólios foi feita por um programa de sequenciamento de permutações e combinatória das correlações chamado itertools.

- As imagens foram geradas pelo matplotlib.pyplot com aplicação e o estilo do seaborn, além do uso dos seus histogramas, heatmaps e regressão linear.

- A simulação de Monte Carlo teve uso das funções estatísticas do scipy.stats, como a amostragem aleatória da distribuição normal.

- Os equilíbrios dos jogos foram mapeados pelo aplicativo nashpy.

- A integração do replicador dinâmico foi feita pela função scipy.integrate.

- As estimações por aproximações dos contratos futuros foram feitas por mínimos quadrados ordinários com o uso do aplicativo statsmodels.formula.api.ols e o teste ADF pelo statsmodels.tsa.stattools.adfuller.

- Os hiperparâmetros do filtro de Kalman foram estimados em R-Project com o uso do pacote astsa. 